\begin{tabular}{ll|l} 
Universidad & Campus \\
de Excelencia \\
Internacional
\end{tabular}

\title{
RESISTENCIA A DIAMIDAS, SPINOSAD E INDOXACARB EN Tuta absoluta (MEYRICK) (LEPIDOPTERA: GELECHIIDAE)
}

Autora:

Lidia García Vidal

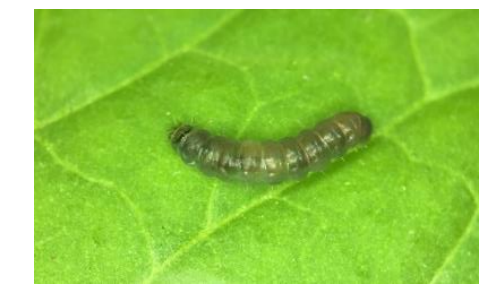

TESIS DOCTORAL

Director

Pablo Bielza Lino

Programa de Doctorado en Técnicas Avanzadas en Investigación y Desarrollo Agrario y Alimentario

Cartagena, 2018 
A mis Incondicionales, Nemo, Nora y Agui. 


\section{AGRADECIMIENTOS}

A Pablo Bielza, mi director de tesis. Por todo su apoyo, confianza, paciencia y atención. Gracias por haberme dado la oportunidad de embarcarme en el proyecto de realizar esta tesis doctoral, sin duda una de las experiencias más felices y enriquecedoras que tendré en mi vida.

A todos mis compañeros y compañeras de laboratorio. El trabajo ha sido mucho más ameno y grato a vuestro lado.

A las profesoras del Grupo de Investigación de Protección de Cultivos, Dina y Josefina. Un placer haber trabajado con vosotras.

A mi familia. Mamá, Papá, Mari y Víctor. Muchísimas gracias por todo vuestro apoyo a lo largo de esta aventura. Siempre estáis ahí.

La realización de esta tesis doctoral ha sido llevada a cabo gracias a la financiación de la beca FPU (13/01528), concedida en septiembre del año 2014 por el Ministerio de Educación, Cultura y Deporte. 


\section{RESUMEN}

Tuta absoluta (Meyrick) es una plaga originaria de Sudamérica. Desde mediados del siglo XX hasta la actualidad, se ha ido expandiendo rápidamente hacia las principales áreas del cultivo de tomate en todo el mundo, convirtiéndose en una de las principales plagas de este cultivo. $T$. absoluta causa graves daños en el tomate, llegando incluso a provocar la pérdida total de las plantaciones.

El uso de fitosanitarios es uno de los principales métodos de control de $T$. absoluta. Sin embargo, en los últimos años han aparecido casos de resistencia en $T$. absoluta a muchos insecticidas, debido a su uso excesivo e incorrecto. Este escenario da lugar a la necesidad de conocer el estado actual de la resistencia en $T$. absoluta a los insecticidas empleados para su control, así como conocer los mecanismos implicados en esta resistencia y las posibles resistencias cruzadas. Con toda esta información se podrán desarrollar estrategias antiresistencia que nos permitan un control más eficaz y sostenible en campo de $T$. absoluta.

En este trabajo se ha estudiado la evolución de la resistencia de diferentes poblaciones de campo europeas de T. absoluta a los insecticidas diamidas clorantraniliprol, flubendiamida y ciantraniliprol, y a spinosad e indoxacarb. Los resultados de este trabajo mostraron una alta susceptibilidad de las poblaciones a los insecticidas clorantraniliprol, ciantraniliprol, flubendiamida, spinosad e indoxacarb. Por otro lado, han aparecido en los últimos años poblaciones europeas con una ligera a moderada resistencia a clorantraniliprol, ciantraniliprol y flubendiamida. Este hecho refleja que se ha realizado un uso excesivo de estos insecticidas en algunas zonas, lo cual puede desencadenar en un problema de resistencia a insecticidas en un futuro. Esto se debe tener en cuenta para desarrollar una estrategia de control en las zonas con riesgo de resistencia a estos insecticidas.

También se ha estudiado cómo afecta el estado de desarrollo larvario, en larvas en estadio 2 (L2) o 4 (L4), en la susceptibilidad de poblaciones de T. absoluta, a los insecticidas estudiados en este trabajo. Se ha podido comprobar que no hay ningún efecto significativo en la susceptibilidad de $T$. absoluta cuando se bioensayaron las poblaciones en estadio L2 o L4, para clorantraniliprol, ciantraniliprol, spinosad e indoxacarb. Sin embargo, sí se ha detectado cierta influencia en la susceptibilidad a flubendiamida, siendo las poblaciones menos susceptibles a este insecticida en estadio L4. Este hallazgo puede resultar interesante para futuras aplicaciones de este insecticida en campo.

Con respecto a las resistencias cruzadas, en este trabajo se ha visto que existe una fuerte resistencia cruzada entre las diamidas (clorantraniliprol, ciantraniliprol y flubendiamida), coincidiendo estos resultados con otros ya publicados. Por otro lado, no se ha detectado ninguna resistencia cruzada entre clorantraniliprol y los insecticidas spinosad, indoxacarb y emamectina benzoato, ni entre ciantraniliprol y spinosad, indoxacarb y emamectina benzoato. Además, en el estudio de los mecanismos implicados en la resistencia a clorantraniliprol y ciantraniliprol en $T$. absoluta, los resultados muestran que, aunque las enzimas P450 monooxigenasas parecen estar involucradas en la resistencia a clorantraniliprol en $T$. absoluta, la resistencia en $T$. absoluta a los insecticidas diamidas (clorantraniliprol, ciantraniliprol y 
flubendiamida) se debe sobre todo a un mecanismo de resistencia en el punto de acción. Este hecho concuerda con la fuerte resistencia cruzada entre estos tres insecticidas mostrada en este trabajo.

En el caso de spinosad, no se han encontrado resistencias cruzadas entre spinosad ni los insecticidas clorantraniliprol, ciantraniliprol, flubendiamida, indoxacarb y emamectina benzoato. Por otra parte, los resultados muestran que el mecanismo metabólico no está implicado en la resistencia a spinosad en $T$. absoluta, sugiriendo que esta resistencia pueda deberse a un mecanismo de resistencia en el punto de acción, coincidiendo así con otros trabajos ya publicados. Además, la población de $T$. absoluta resistente a spinosad utilizada en este trabajo, experimentó una fuerte disminución en su resistencia cuando se dejó de ejercer presión insecticida. Esto puede deberse a un coste adaptativo de la población resistente, ligado a la resistencia a spinosad.

En vista de los resultados obtenidos, una vez conocida la existencia de la resistencia cruzada entre los insecticidas diamidas, y los mecanismos de resistencia implicados en la resistencia a estos insecticidas y a spinosad, es necesario desarrollar estrategias de manejo de la resistencia en $T$. absoluta, integrándolas dentro de un programa de gestión integrado, con el fin de realizar un uso sostenible de los fitosanitarios. 


\section{ABSTRACT}

Tuta absoluta (Meyrick) is native to South America. From the mid-20th century, it has been rapidly spreading to the main tomato areas in the world, becoming one of the main pests of this crop. T. absoluta causes serious damage to tomato, even causing the total loss of the crop.

The use of phytosanitary products is one of the main control methods of $T$. absoluta. However, cases of resistance development in $T$. absoluta to many insecticides have appeared recently, due to the excessive and incorrect use of these insecticides. Therefore, it is necessary to know the current state of $T$. absoluta resistance to insecticides used for its control, as well as the mechanisms involved and the possible cross-resistances. With all this information, antiresistance strategies can be developed to control more effectively and sustainably $T$. absoluta.

The evolution of resistance of different European field populations of $T$. absoluta to the diamide insecticides chlorantraniliprole, flubendiamide and cyantraniliprole, and to spinosad and indoxacarb was studied in this work. The results showed a high susceptibility of the populations to chlorantraniliprole, cyantraniliprole, flubendiamide, spinosad and indoxacarb. On the other hand, European populations with a slight to moderate resistance to chlorantraniliprole, cyantraniliprole and flubendiamide have been observed in recent years. This fact reflects an excessive use of these insecticides in some areas, which may trigger an insecticide resistance problem in the future. This must be taken into account to develop a resistance management strategy in zones with a high resistance risk.

In addition, the effect of the stage of larval development (L2 or L4) in the susceptibility of $T$. absoluta to these insecticides has been studied. The results showed that there is no a significant effect on the susceptibility of $T$. absoluta when the populations were bioassayed in stage L2 or L4 to chlorantraniliprole, cyantraniliprole, spinosad and indoxacarb. However, some influence in the susceptibility to flubendiamide has been detected, being the populations less susceptible to this insecticide in stage L4. This may be interesting for future applications of this insecticide in the field.

A strong cross-resistance between the diamides (chlorantraniliprole, cyantraniliprole and flubendiamide) has been found in this work, in agreement with other results already published. On the other hand, no cross-resistance between chlorantraniliprole and spinosad, indoxacarb and emamectin benzoate was detected, nor between cyantraniliprole and spinosad, indoxacarb and emamectin benzoate. Besides, in the study of the mechanisms involved in resistance to chlorantraniliprole and cyantraniliprole in $T$. absoluta, the results show that, although the P450 monooxygenase enzymes seem to be involved in the resistance to chlorantraniliprole in $T$. absoluta, the resistance to the diamide insecticides (chlorantraniliprole, cyantraniliprole and flubendiamide) is due mainly to a target-site mechanism. This fact agrees with the strong cross-resistance between these three insecticides shown in this work. 
On the other hand, no cross-resistance between spinosad and the insecticides chlorantraniliprole, cyantraniliprole, flubendiamide, indoxacarb and emamectin benzoate has been found. The results show that a metabolic mechanism is not involved in the resistance to spinosad in T. absoluta, suggesting that this resistance may be due to a target-site mechanism, in agreement with other works already published. In addition, the $T$. absoluta population resistant to spinosad used in this work, experienced a strong decrease in its resistance when the insecticidal pressure was interrupted. This may be due to a fitness cost of the resistant population, linked to resistance to spinosad.

Finally, once known the existence of cross-resistance between the diamide insecticides and the resistance mechanisms involved in the resistance to these insecticides and spinosad, it is necessary to develop resistance management strategies in $T$. absoluta, integrating them within an integrated management program to make a sustainable use of phytosanitary products. 


\section{ÍNDICE GENERAL}

\section{INTRODUCCIÓN}

1.1. Tuta absoluta (Meyrick 1917) ................................................. 1

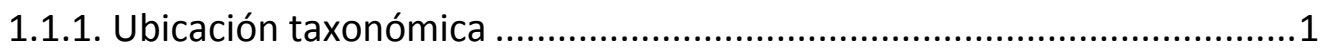

1.1.2. Origen y distribución ....................................................................2



1.1.4. Descripción morfológica ................................................................ 5



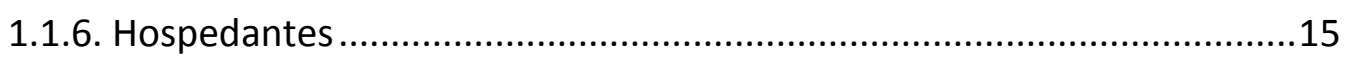

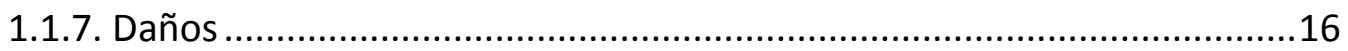

1.2. Estrategias de control de T. absoluta......................................... 18



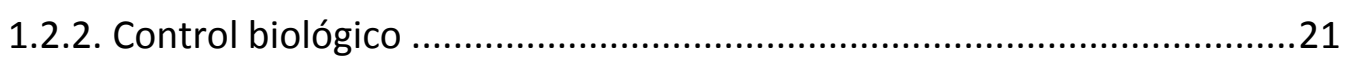

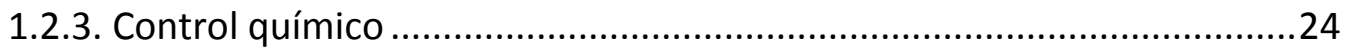

1.3. Resistencia a insecticidas..................................................... 34

1.3.1. Definición y tipos de resistencia ..........................................................34

1.3.2. Factores que influyen en la resistencia ...............................................35

1.3.3. Mecanismos implicados en la resistencia ...........................................36

1.4. Resistencia de T. absoluta a insecticidas ..................................... 40

1.5. Referencias bibliográficas...................................................... 42 
2. JUSTIFICACIÓN Y OBJETIVOS

2.1. Justificación

2.2. Objetivos

3. MATERIAL Y MÉTODOS GENERALES

3.1. Cría de Tuta absoluta (Meyrick). 61

3.1.1. Jaulas de cría. 61

3.1.2. Material vegetal.

3.1.3. Mantenimiento de las poblaciones de $T$. absoluta 63

3.2. Poblaciones de campo de T. absoluta 64

3.3. Insecticidas 66

3.4. Bioensayos

3.4.1. Bioensayos de susceptibilidad 68

3.4.2. Bioensayos de selección de resistencias . .71

3.4.3. Bioensayos con sinergistas .73

3.5. Referencias bibliográficas 74

4. CAPÍTULO 1. SUSCEPTIBILIDAD DE POBLACIONES EUROPEAS DE Tuta absoluta (MEYRICK) (LEPIDOPTERA: GELECHIIDAE) A LOS INSECTICIDAS DIAMIDAS

4.1. Introducción 77

4.2. Material y Métodos 77 


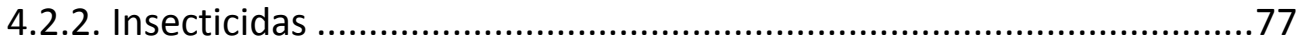

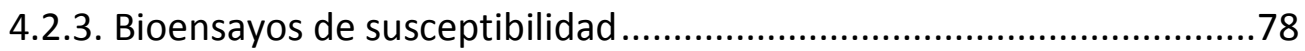

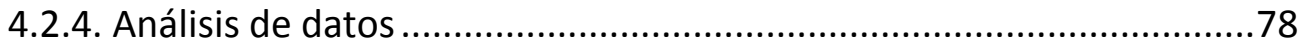

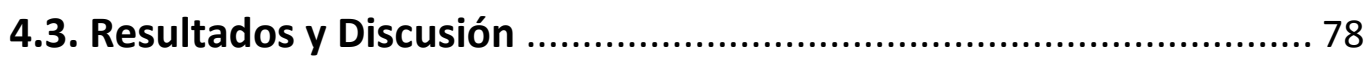



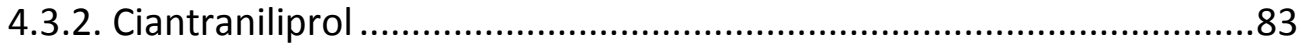

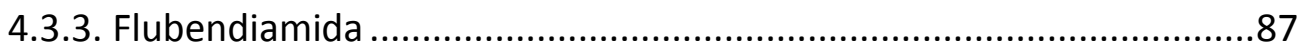

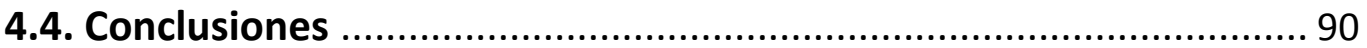

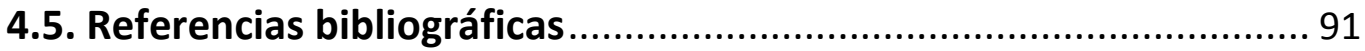

5. CAPÍTULO 2. SUSCEPTIBILIDAD DE POBLACIONES EUROPEAS DE Tuta absoluta (MEYRICK) (LEPIDOPTERA: GELECHIIDAE) A LOS INSECTICIDAS SPINOSAD E INDOXACARB

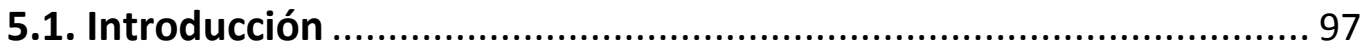

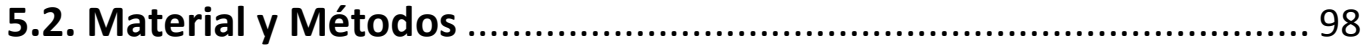

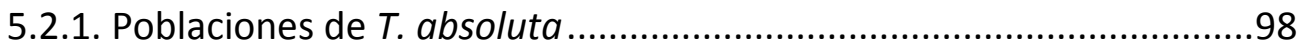

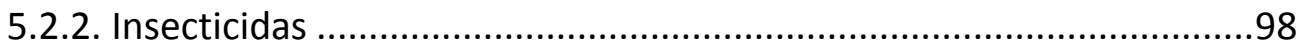

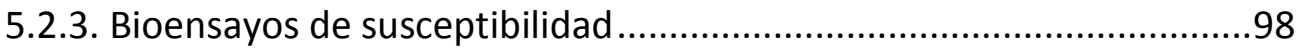

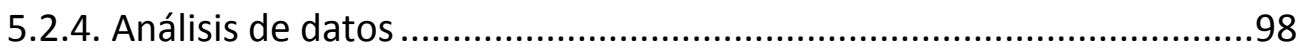





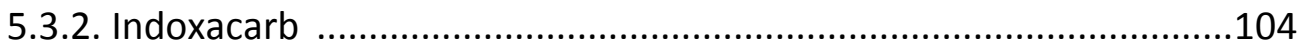


6. CAPÍTULO 3. MECANISMOS DE RESISTENCIA A DIAMIDAS $Y$ RESISTENCIAS CRUZADAS EN Tuta absoluta (MEYRICK) (LEPIDOPTERA: GELECHIIDAE)

6.1. Introducción

6.2.2. Insecticidas

6.2.3. Bioensayos de susceptibilidad

6.2.4. Bioensayos de selección de resistencias

6.2.5. Bioensayos con sinergistas

6.2.6. Análisis de datos

6.3. Resultados y Discusión

6.3.1. Selección a clorantraniliprol, resistencias cruzadas y mecanismos de resistencia

6.3.2. Selección a ciantraniliprol, resistencias cruzadas y mecanismos de resistencia

6.4. Conclusiones 
7. CAPÍTULO 4. MECANISMOS DE RESISTENCIA A SPINOSAD $Y$ RESISTENCIAS CRUZADAS EN Tuta absoluta (MEYRICK) (LEPIDOPTERA: GELECHIIDAE)

7.1. Introducción 131

7.2. Material y Métodos .............................................................. 132

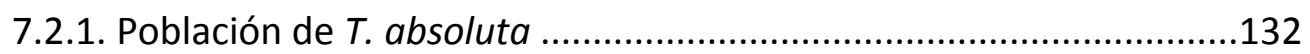

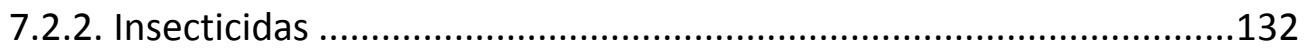

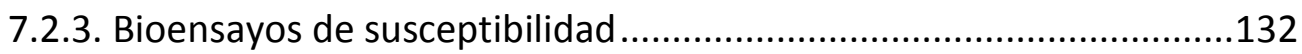

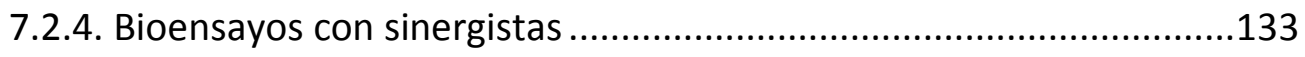

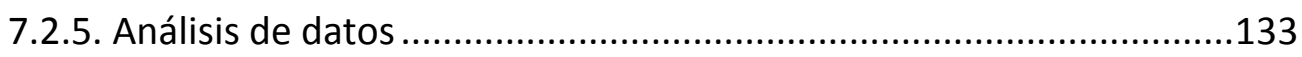

7.3. Resultados y Discusión ............................................................... 133

7.3.1. Resistencias cruzadas y mecanismos de resistencia a spinosad

7.4. Conclusiones 137

7.5. Referencias bibliográficas.

8. CONCLUSIONES GENERALES

8.1. Conclusiones. 




\subsection{Tuta absoluta (Meyrick 1917)}

Tuta absoluta es conocida con los siguientes nombres: polilla del tomate, gusano minador del tomate, polilla perforadora, palomilla del tomate, cogollero del tomate, y minador de hojas y tallos de la papa. En inglés, se le denomina comúnmente como "tomato leaf miner", "tomato borer", "South American tomato moth" y "South American tomato pinworm"; en Portugal se le conoce con el nombre de "traça-do-tomateiro"; en Francia como "mineuse de la tomate" (NAPPO, 2013); en Italia como "tignola del pomodoro"; y en Suecia como "tomatmal" (Ramos, 2015).

\subsubsection{Ubicación taxonómica}

La ubicación taxonómica de T. absoluta es:

Reino: Animalia

Phylum: Artropoda

Subphylum: Hexapoda

División: Exopterygota

Clase: Insecta

Orden: Lepidoptera

Suborden: Glossata

Superfamilia: Gelechioidea

Familia: Gelechiidae

Subfamilia: Gelechiinae

Tribu: Gnorimoschemini

Género: Tuta

Especie: Tuta absoluta (Meyrick 1917) 


\subsubsection{Origen y distribución}

T. absoluta es un microlepidóptero descrito originariamente por el entomólogo E. Meyrick como Phthorimaea absoluta. Meyrick lo describió a partir de un individuo macho recolectado en Huancayo, Perú (López, 2003). Más tarde, en 1962 esta especie fue denominada como Gnorimoschema absoluta (Clarke), en 1964 como Scrobipalpula absoluta (Povolny), en 1987 como Scrobipalpuloides absoluta (Povolny), y finalmente fue descrita bajo el género Tuta en 1994 también por Povolny (Barrientos et al., 1998).

Esta especie es una plaga originaria de Sudamérica, donde se ha ido expandiendo desde mediados del siglo XX hacia las principales áreas del cultivo de tomate en el continente sudamericano (Chile, Argentina y el sur de Brasil), representando una de las principales plagas en este cultivo (Garcia-Marí et al., 2010). A finales de 2006, T. absoluta fue introducida en Europa desde Sudamérica a través de España, detectándose su presencia por vez primera en invernaderos de tomate en Castellón (Urbaneja et al., 2012). En 2007, fue observada en todas las principales áreas del cultivo de tomate de España, y entre 2008 y 2009, fue detectada en Italia, sur de Francia, Grecia, Portugal, Marruecos, Argelia y Túnez (Potting, 2009; Desneux et al., 2010). No se conoce con seguridad cómo ha llegado esta plaga a Europa, aunque las posibilidades de propagación se incrementan con los intercambios de mercancías, contenedores y personas, los cuales son cada vez más frecuentes entre continentes (Monserrat, 2009).

La invasión de $T$. absoluta en España ha seguido la siguiente cronología: desde la primera detección de la plaga en invernaderos de tomate en Castellón en 2006, se localizó su presencia al año siguiente, en 2007, en las Comunidades Autónomas de Cataluña, Murcia y Andalucía (presente en Almería). En 2008 se propaga por Aragón, Navarra, Castilla-La Mancha, Madrid, Extremadura, Castilla y León y País Vasco; y en 2009 se expande por La Rioja, Galicia, Cantabria y Asturias, alcanzando las Islas Canarias (Garcia-Marí et al., 2010).

Desde España se ha propagado a diferentes países de Europa y África a un ritmo asombroso. En 2008 se detectan los primeros focos en invernaderos de tomate en la región de Mostaganem (Argelia), en cultivo de tomate al aire libre en la región de Nador (Marruecos) y en invernadero de tomate en Calabria (Italia). También en 2008 se detecta su presencia en invernaderos y en cultivos de tomate al aire libre en Cerdeña, Sicilia y Campania (Italia), en la isla de Córcega y la región de Provence-Alpes-Côte d'Azur (Francia). Por esas fechas se detecta también en tomate al aire libre en la región de Akkouda (Túnez). En 2009 se observa su presencia en Holanda, Reino Unido, Malta, Suiza, Alemania, Chipre, Bulgaria y Rusia (GarciaMarí et al., 2010) (Figura 1.1). 


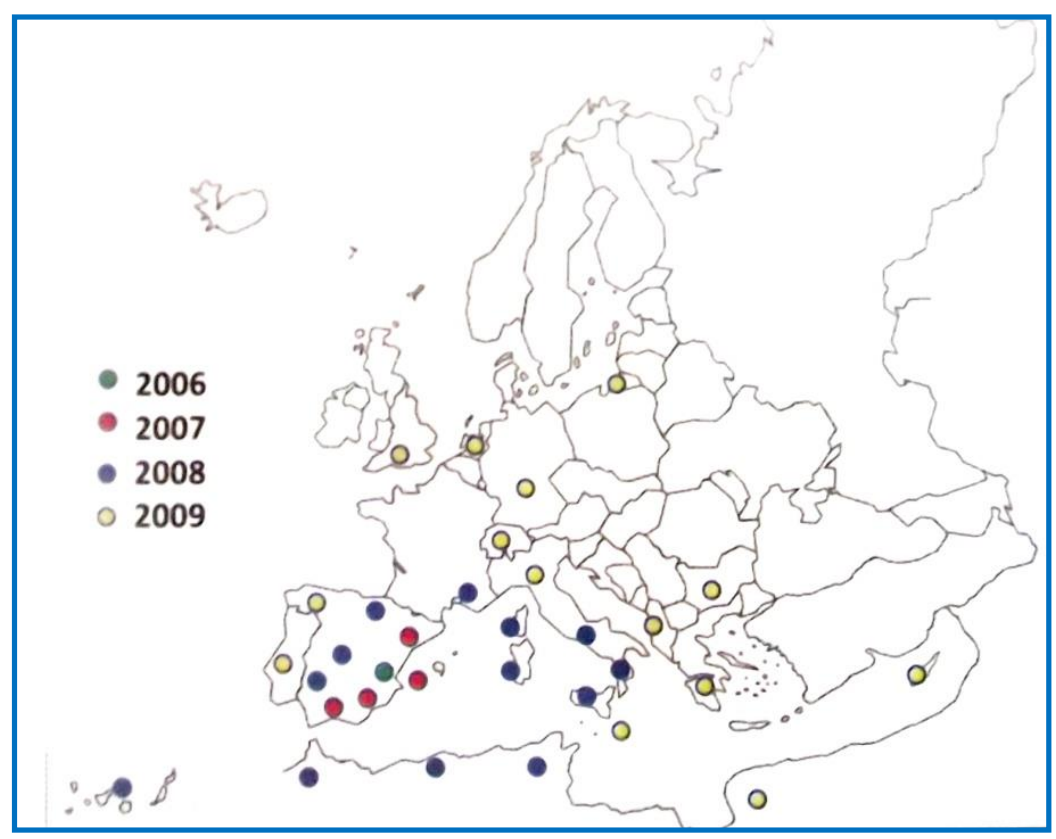

Figura 1.1: Expansión de T. absoluta por Europa y el norte de África entre 2006 y 2009 (Garcia-Marí et al., 2010).

En 2011, Cifuentes et al. (2011) estudiaron la variabilidad genética de diferentes poblaciones de $T$. absoluta procedentes de Sudamérica y de varios países del área Mediterránea. Estos autores encontraron una elevada homogeneidad genética entre todas las poblaciones estudiadas, sugiriendo que la población invasora de T. absoluta que llegó al área Mediterránea provenía de una única población procedente de Sudamérica. Recientemente, Guillemaud et al. (2015) corroboraron el estudio de los autores anteriormente citados. Con el empleo de marcadores microsatélites que permiten estimar el grado de parentesco entre poblaciones, demostraron que el origen de la población de T. absoluta que invadió Europa proviene de la zona Central de Chile, siendo una única población invasora la que llegó a las principales zonas de cultivo de tomate en el área Mediterránea. Además, concluyeron que la población de $T$. absoluta nativa en Sudamérica no es genéticamente homogénea, presentando diferencias genéticas significativas entre las poblaciones de las regiones norte y sur, y que existe una elevada homogeneidad genética entre las poblaciones de las áreas invadidas a lo largo del tiempo, desde el sur de España hasta Israel y desde Israel hasta Marruecos.

Según datos de la EPPO (2017), son numerosos los países donde T. absoluta se encuentra establecida y varias las zonas donde se ha informado de su presencia recientemente: Albania, Arabia Saudí, Argelia, Argentina, Bangladesh, Bélgica, Bolivia, Bosnia y Herzegovina, Brasil, Bulgaria, Chile, Chipre, Colombia, Costa Rica, Croacia, Ecuador, Egipto, Eslovenia, España, Etiopía, Francia, Grecia, Hungría, India, Irak, Irán, Israel, Italia, Kenia, Libia, Lituania, Malta, Marruecos, Montenegro, Mozambique, Namibia, Nepal, Nigeria, Países Bajos, Panamá, Paraguay, Perú, Portugal, Qatar, Rumania, Rusia, Senegal, Serbia, Siria, Sudáfrica, Sudán, Suiza, Tanzania, Túnez, Turquía, Uganda, Uruguay, Venezuela, Yemen, Zambia y Zimbabue. 


\subsubsection{Importancia económica}

En la actualidad, T. absoluta está considerada una de las plagas más importantes del cultivo de tomate debido a su rápida expansión y distribución geográfica (Desneux et al., 2011; Haddi et al., 2012). Esta plaga afecta tanto a la producción de tomate en invernadero como al aire libre (Desneux et al., 2010), y también ataca a los cultivos de tomate destinados para la industria alimentaria y a los destinados para el mercado en fresco (López, 1991; Apablaza, 1992). Además, provoca serios daños debido a la presencia de elevados niveles poblacionales tanto en invierno como en verano.

A partir de su introducción en España en 2006, su evolución ha sido bastante rápida, dando lugar a la pérdida total de plantaciones de tomate entre los años 2007 y 2008, convirtiéndose en esos años en la plaga más devastadora del cultivo. Actualmente, en la Región de Murcia esta plaga está bastante controlada, generando problemas graves de control de forma puntual, debiéndose sobre todo a la acción de productores que realizan un manejo fitosanitario inadecuado del cultivo, o porque las plantaciones se encuentran en zonas de especial riesgo de desarrollo de la plaga o coinciden con momentos de mayor riesgo de desarrollo de la plaga (Monserrat, 2016).

Si no se toman medidas de control adecuadas, T. absoluta puede causar hasta el $100 \%$ de pérdida de la plantación de tomate en áreas de reciente invasión (Desneux et al., 2010). No obstante, aun tomando medidas para su control, el daño de $T$. absoluta en las plantaciones todavía podría ser de entre el 1 y el 5\% (TaRI, 2017). Además, en las áreas donde aparece $T$. absoluta por primera vez, la plaga es especialmente problemática durante el primer año de infestación. Sin embargo, tras dos o tres años de control, se ha podido observar una menor incidencia de $T$. absoluta en ciertas áreas, debido entre otras causas, a un mayor conocimiento del comportamiento y la biología de la plaga por parte de los agricultores y productores, y a una correcta aplicación de un programa de Gestión Integrada de Plagas (GIP) (Urbaneja et al., 2012).

El impacto económico de $T$. absoluta se refleja en el aumento de los costes de producción del cultivo, debido al incremento en los costes para el manejo y control de la plaga, a la disminución del producto comercializable, y también a la posible pérdida de socios comerciales a causa de las restricciones en la exportación del producto a países en donde no se ha detectado aún la plaga. Además, se ha observado que en algunos países está resultando muy difícil controlar y limitar su propagación (Keller et al., 2011; Garnas et al., 2016). 


\subsubsection{Descripción morfológica}

El huevo es de forma ovalada, con un color blanco-cremoso recién puesto y tornándose a un color anaranjado cuando se aproxima a la eclosión. Su tamaño oscila alrededor de 0,4 mm de largo y 0,2 mm de diámetro (Vargas, 1970) (Figuras 1.2 y 1.3 ).

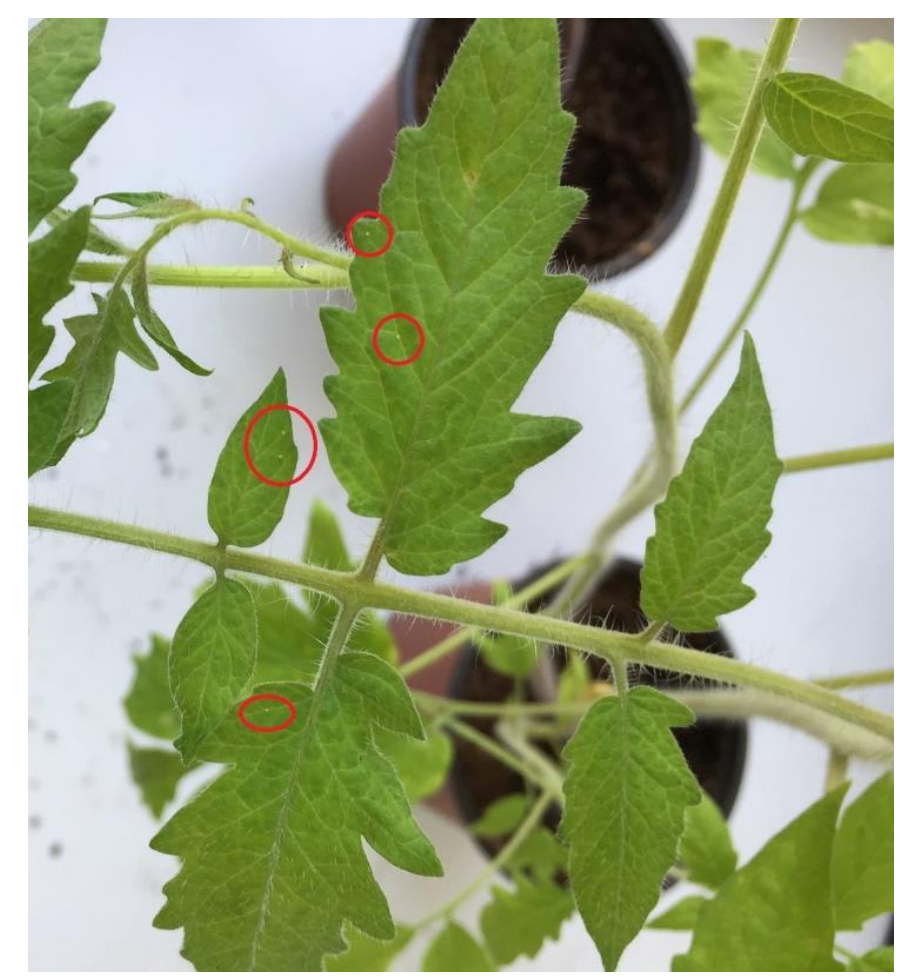

Figura 1.2: Huevos de T. absoluta en planta de tomate (Fuertes, 2017).

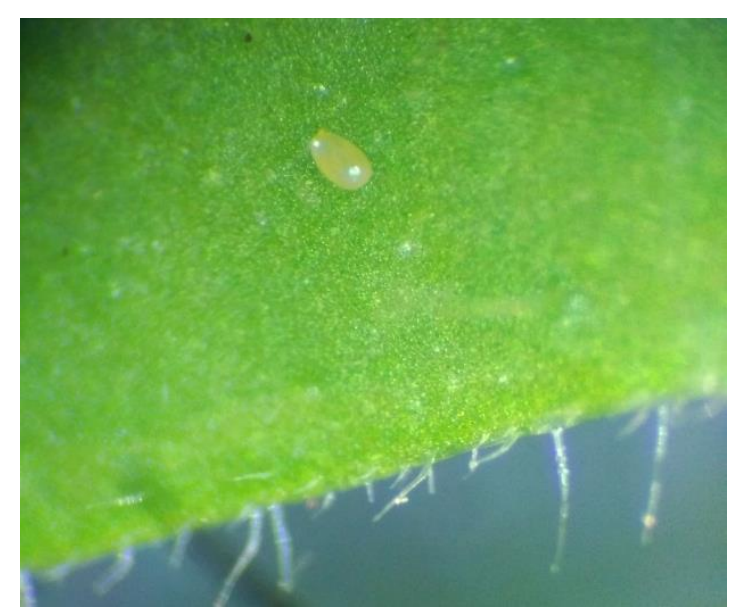

Figura 1.3: Huevo de T. absoluta (Fuente propia). 
Las larvas de T. absoluta pasan por 4 estadios larvarios, a veces 5 (Monserrat, 2009). Son de tipo eruciforme, con tres pares de patas y cinco pares de propatas (López, 2010; Santos et al., 2010). Presentan una cabeza oscura con una mancha lateral que se extiende desde los ocelos hasta el margen posterior. Además, carecen de placa dorsal en el protórax y en su lugar presentan una banda oscura oblicua que no llega a cubrir la línea media dorsal. Poseen setas anteriores al espiráculo protorácico separadas en un grupo de dos, mientras que la tercera está aislada junto al margen anterior del espiráculo y carece de placa basal (Ramos et al., 2011).

La larva de primer estadio (L1) es la que emerge del huevo. Presenta una forma cilíndrica ligeramente aplastada dorsalmente. Su cabeza es prognata, aplastada en forma visible y de color oscuro. Su color es amarillo claro cuando sale del huevo y va adquiriendo un tono verde claro a medida que se alimenta y desarrolla. Sin embargo, regresa a su tonalidad amarillo claro cuando va a mudar, debido a que deja de alimentarse y vacía sus intestinos (López, 2003). El tamaño en este estadio es alrededor de 0,9 mm (Notz, 1992) (Figura 1.4).



Figura 1.4: Larva L1 de T. absoluta saliendo del huevo (Nayana et al., 2015).

La larva de segundo estadio (L2) mide aproximadamente 2,8 mm (Mollá et al., 2011a). Es de color gris blanquecino al principio y se torna verde claro a medida que vuelve a alimentarse. Próxima a mudar adquiere de nuevo una tonalidad amarillo claro (López, 2003) (Figura 1.5). 


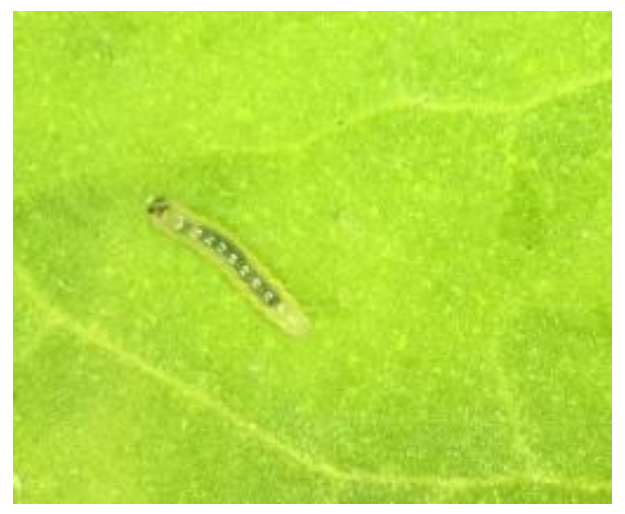

Figura 1.5: Larva L2 de T. absoluta (Fuente propia).

La larva de tercer estadio (L3) es similar a la larva L2. Al principio su color es gris blanquecino y se vuelve verde claro durante el desarrollo de la larva, intensificándose este color verde de forma gradual. Al final del periodo adquiere una tonalidad blanquecina (López, 2003). El tamaño de este estadio larvario es de aproximadamente 4,7 mm (Mollá et al., 2011a) (Figura 1.6).

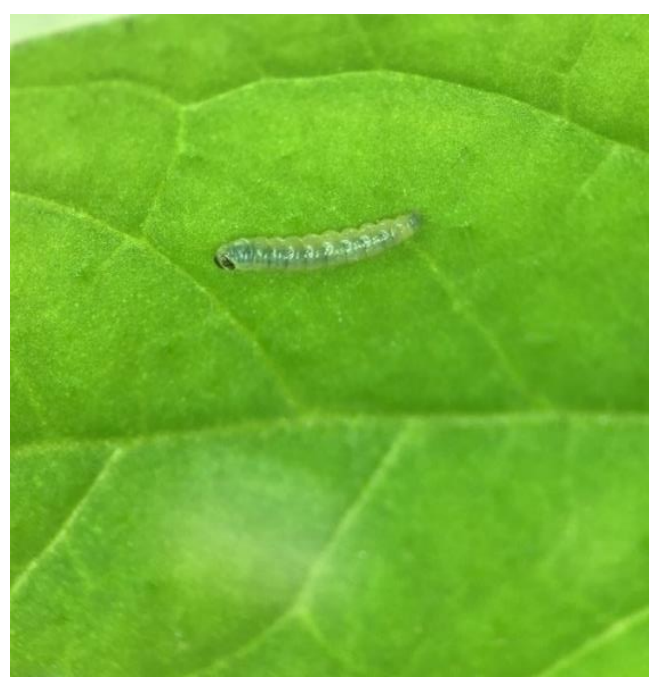

Figura 1.6: Larva L3 de T. absoluta (Fuente propia).

Por último, tenemos el cuarto estadio larvario (L4). La forma de la larva es prácticamente igual al resto de los estadios larvarios, y el color verde claro adquiere una tonalidad ligeramente rosada en la región dorsal al finalizar el periodo de larva activa. La cabeza es de color café, con una sutura epicraneal bien marcada. El escudo protorácico es visible, con una línea semicircular oscura en la parte posterior (López, 2003). Es este estadio, la larva puede llegar a 
medir 7,5 mm de longitud (Notz, 1992). Según otros autores, la larva L4 puede llegar a medir hasta $10 \mathrm{~mm}$ de longitud en su máximo desarrollo (JA, 2010) (Figuras 1.7 y 1.8).
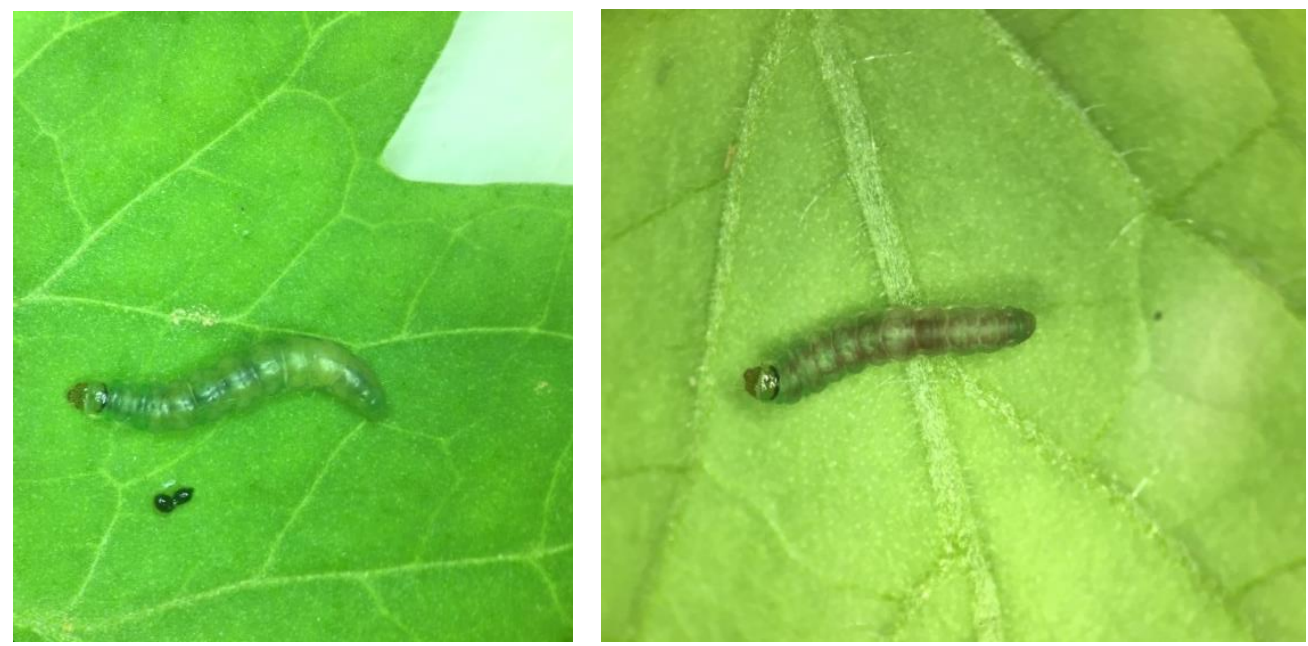

Figuras 1.7 y 1.8: Larva L4 de T. absoluta (Fuente propia).

En el periodo de pre-crisálida o pre-pupa, la larva deja de alimentarse, se acorta y se prepara para crisalidar (Larraín, 2011) (Figura 1.9).



Figura 1.9: Larva L4 de T. absoluta preparándose para crisalidar, protegida por un capullo sedoso (Fuente propia). 
La crisálida o pupa es de tipo obtecta, de color verde olivo al inicio y de color marrón antes de que emerja el adulto (López, 2010; Santos et al., 2010). Es de forma cilíndrica, de 4,3 mm de largo y $1,1 \mathrm{~mm}$ de diámetro (Vargas, 1970). Sin embargo, otros autores indican que la pupa puede llegar a medir hasta $5 \mathrm{~mm}$ de largo, y que presenta dimorfismo sexual en función de la ubicación de los poros genitales (Quiroz, 1976). La pupa hembra es de mayor tamaño que la pupa macho, midiendo 4,67 y $4,27 \mathrm{~mm}$ de largo y 1,37 y $1,23 \mathrm{~mm}$ de ancho respectivamente (JA, 2010) (Figuras 1.10 y 1.11).
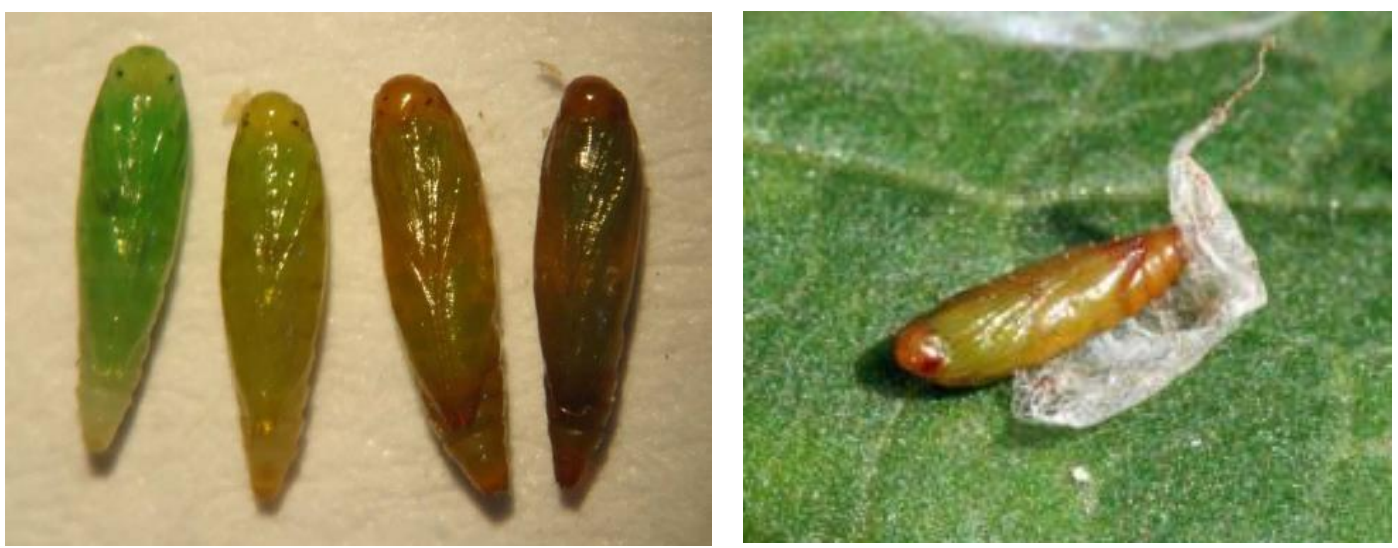

Figuras 1.10 y 1.11: Crisálidas de T. absoluta (1.10: García-Vidal, 2011; 1.11: Ramos et al., 2011).

De la pupa emerge el adulto de $T$. absoluta, que puede alcanzar una longitud de entre 5 a 7 $\mathrm{mm}$, de 10 a $11 \mathrm{~mm}$ de envergadura (Estay et al., 2002), y $1 \mathrm{~mm}$ de anchura en reposo (Monserrat, 2009). Otros autores mencionan que el adulto puede alcanzar los $10 \mathrm{~mm}$ de longitud (López, 2010; Santos et al., 2010). Los adultos para ambos sexos, presentan las alas anteriores con matices que varían de oscuro a gris, las alas posteriores son de color negruzco brillante con las cilias oscuras, y la cabeza, tórax y palpos son de color gris cenizo con tintes oscuros. Las alas anteriores presentan una longitud de 4,5 a 4,7 mm (Notz, 1992). Las alas posteriores presentan una banda de pelos o fleco fino en el borde posterior (López, 2010; Santos et al., 2010). Las antenas del adulto son filiformes, en forma de collar y largas con anillos de colores, alternando color café claro y oscuro, palpos maxilares vestigiales y palpos labiales gruesos, aguzados, largos y vueltos hacia arriba. El palpo labial presenta en el tercer segmento un anillo de gran tamaño de color negro en el primer tercio distal y otro en el ápice del segmento. El abdomen es de color café cremoso, y es más grueso en las hembras que en los machos (Brambila et al., 2010). Además, las antenas del adulto son más largas en los machos que en las hembras (Coelho et al., 1987) (Figuras 1.12, 1.13 y 1.14). 

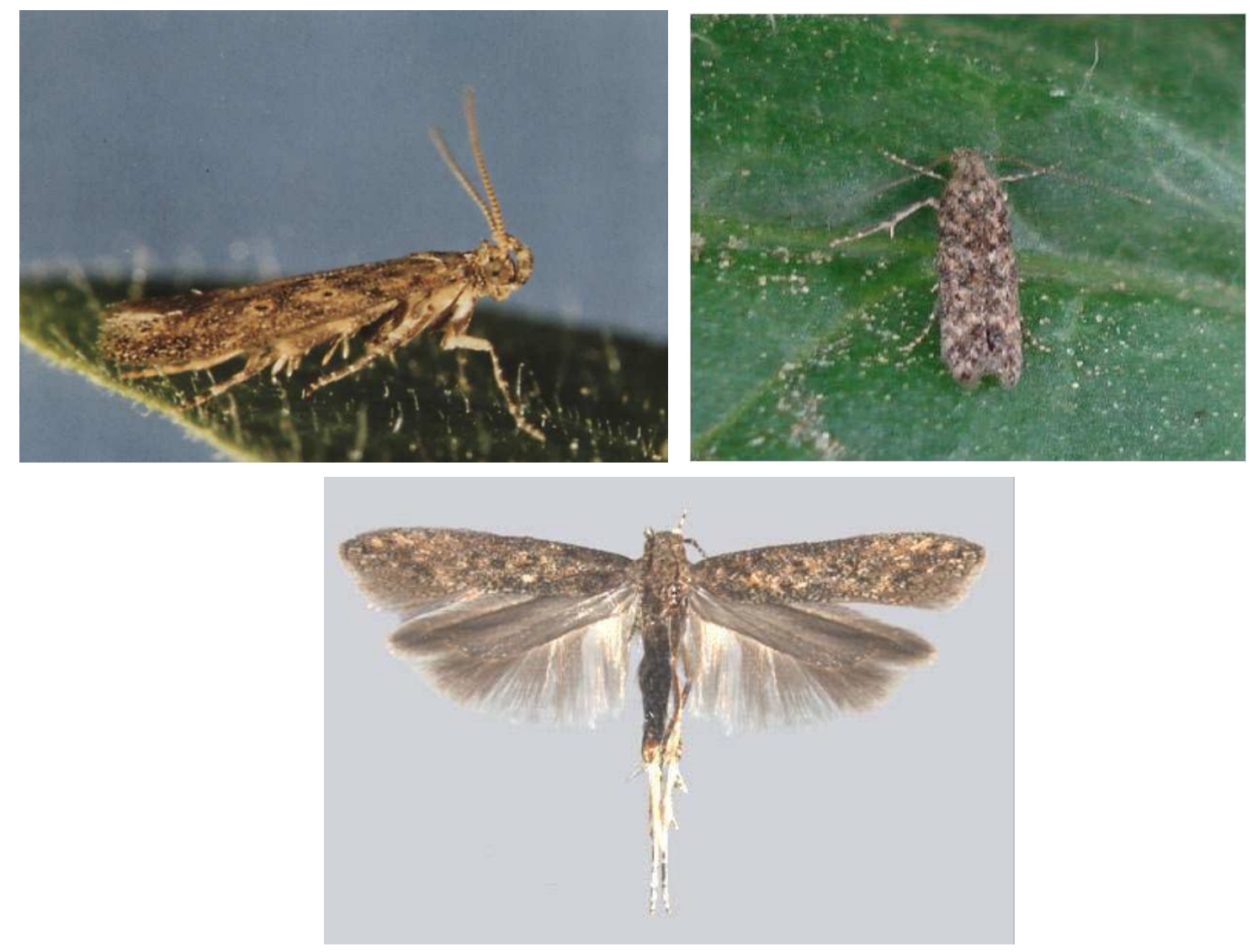

Figuras 1.12, 1.13 y 1.14: Adulto de T. absoluta (1.12: Senasica, 2013; 1.13: Monserrat, 2009; 1.14: Ramos et al., 2011).

Existen diferencias entre machos y hembras en la morfología de la genitalia del adulto de $T$. absoluta. Así, la genitalia del adulto macho se caracteriza por presentar un uncus en forma de campana y ancho hacia el ápice (a), también presenta una valva digitada y setosa apicalmente, con un margen interno convexo medialmente (b), un tegumen ensanchado basalmente (c), gnathos ancho con ápice redondeado (d), un vinculum ancho y bien desarrollado con un saccus ancho y alargado (e), y un aedeagus con un ciego prominente (f). Mientras que la genitalia de la hembra adulta de $T$. absoluta se caracteriza por presentar el conducto seminal en pleno, un cuerpo bursal cónico como un embudo y casi dos tercios tan largo como la bolsa copulatriz (Ramos et al., 2011) (Figura 1.15). 


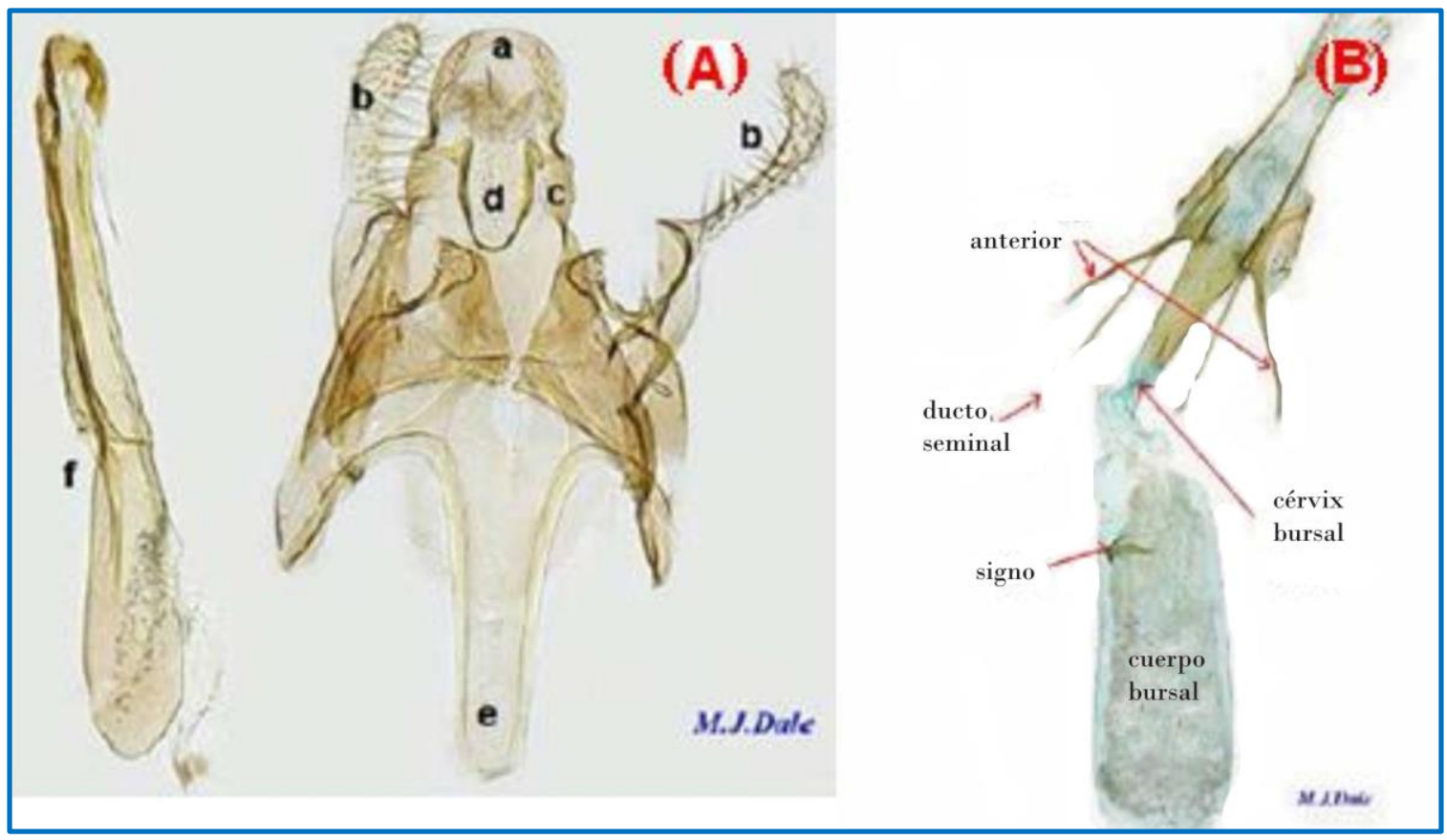

Figura 1.15: Genitalia del adulto de T. absoluta. (A) Macho, (B) hembra (Ramos et al., 2011).

\subsubsection{Biología}

El ciclo biológico de T. absoluta pasa por cuatro etapas de desarrollo diferentes: huevo, cuatro estadios larvarios (larva), crisálida y adulto, y dura entre 29 y 38 días en zonas con climatología suave (Monserrat, 2009) (Figura 1.16).

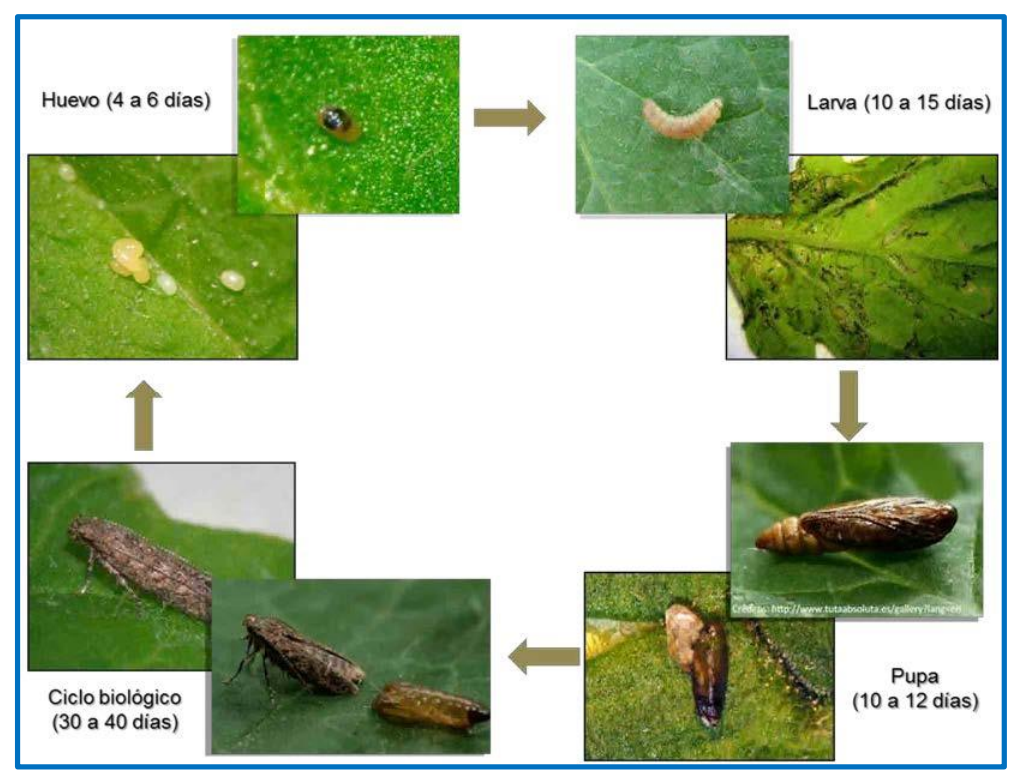

Figura 1.16: Esquema del ciclo biológico de T. absoluta (Senasica, 2013). 
T. absoluta es una especie multivoltina, es decir, que completa varias generaciones en un año (Pereyra, 2002), llegando a completar hasta 12 generaciones en ambientes cálidos. Por otro lado, Biurrun (2008) indica que en el norte de España, puede completar más de 10 generaciones en un año. $T$. absoluta es capaz de desarrollarse en un rango bastante amplio de temperaturas, adaptando la duración de su ciclo de vida a la climatología de la zona, pudiendo completar su ciclo biológico en menos de un mes si las condiciones ambientales son favorables. Se desarrolla sin problema entre $12^{\circ} \mathrm{C}$ y $30^{\circ} \mathrm{C}$, tardando casi 240 días en completar su ciclo a $12{ }^{\circ} \mathrm{C}$ y solamente 20 días a temperaturas de 30ㄷ (Vercher et al., 2010). Betancourt et al. (1996) indican que a temperatura constante de 35ㄷ las larvas de $T$. absoluta no pueden completar su desarrollo, sin embargo, a temperaturas variables de entre 25 y $35^{\circ} \mathrm{C}$ sí son capaces de desarrollarse. Por otro lado, Quiroz (1976) logró mantener durante 45 días larvas a $60 \mathrm{C}$ de temperatura, mientras que Vercher et al. (2010) mantuvieron durante varias semanas larvas a temperaturas de 4 ㅇ․ Vargas (1970) señala que en el laboratorio, a temperatura contante de $25 \circ \mathrm{C}$ y humedad relativa de $75 \%, T$. absoluta es capaz de completar una generación en 28,7 días.

Según distintos autores (Betancourt et al., 1996; Barrientos et al., 1998; Estay et al., 2002), 8C es el promedio de temperatura umbral para un ciclo completo de T. absoluta. A pesar de que las temperaturas bajas son un factor limitante para su supervivencia, T. absoluta puede pasar el invierno en estado de huevo, pupa o adulto en función de las condiciones ambientales (NAPPO, 2013). Además, las larvas no entran en estado latente cuando tienen disponibilidad de alimento (Desneux et al., 2010). Por otro lado, puede haber una elevada mortandad de huevos cuando las temperaturas son muy elevadas y la humedad relativa es baja (Monserrat, 2016).

T. absoluta presenta un alto potencial reproductor. La cópula se inicia inmediatamente después de la emergencia de los adultos, y la mayoría de los huevos son puestos durante los 10 primeros días del inicio de la oviposición (Larraín, 2011). Sin embargo, otros autores (Vercher et al., 2010) indican que las hembras fecundadas de $T$. absoluta ponen la mayoría de los huevos entre los 3 y 5 días después de la cópula, y preferentemente al atardecer y al amanecer, que es cuando los adultos presentan más actividad. Según estudios llevados a cabo por Hickel et al. (1991), las hembras realizan su llamamiento para la cópula nada más amanecer y dura unas dos horas, teniendo los machos su máximo de actividad una hora después de que las hembras realicen su Ilamamiento. Por otro lado, Vercher et al. (2010) señalan que las hembras, cuando emergen de la pupa, tienen un periodo de pre-cópula promedio de 21,5 \pm 1 horas, copulan una media de 5 horas y son capaces de copular varias veces en el transcurso de su vida. Estos autores también indican que el periodo de preoviposición de la hembra es de 1,2 días, por lo que pasan entre 2 y 3 días desde que la hembra emerge de la pupa hasta que realiza la puesta. 
Las hembras fecundadas llegan a poner entre 180 y 260 huevos a lo largo de varios días (Monserrat, 2009), aunque algunos autores reducen este número entre 40 y 50 huevos (Apablaza, 1992) o entre 40 y 150 huevos (Estay et al., 2002). Las hembras suelen poner los huevos de forma individual o en grupos de no más de 2-3 huevos (Monserrat, 2009), y según Fernández et al. (1990) los huevos eclosionan de 5 a 10 días después de la oviposición. Segovia (1997) indica que la mayoría de los huevos se localizan en las plantas situadas en los bordes de los invernaderos y en la parte superior de la planta, mientras que Vercher et al. (2009), señalan que un $73 \%$ de los huevos son depositados en el envés de la hoja, mientras que un $6 \%$ en frutos verdes, sobre todo en los sépalos. Monserrat (2009) indica que los frutos próximos a su maduración o los desprovistos de cáliz, no son receptivos a la oviposición, pero cuando hay muchos adultos de T. absoluta y no hay plantas disponibles para que la hembra realice la puesta, como en los almacenes donde se guarda el tomate recolectado, esta se realiza en frutos sin peciolo. Por otro lado, Torres et al. (2001) observaron que en plantas prereproductivas, las hembras realizan la puesta preferentemente en la zona apical de la planta, sobre todo en el envés, mientras que en plantas post-reproductivas la puesta la realizan tanto en la zona media como en la zona apical, y en el envés y en la cara de los foliolos.

Según Monserrat (2009), a 30C se acorta el ciclo biológico de $T$. absoluta, cuando comparó el desarrollo de esta plaga a 15ㅇ $\mathrm{C}$ y a $30 \circ \mathrm{C}$ (Tabla 1.1).

Tabla 1.1: Duración promedio del ciclo de desarrollo de T. absoluta a 15ㄷ y 30 으 (Monserrat, 2009).

\begin{tabular}{c|ccccc}
\hline \multirow{2}{*}{ TEMPERATURA } & HUEVO & LARVAS & PUPA & ADULTO \\
\cline { 2 - 5 } & \multicolumn{5}{|c}{ Días } \\
\hline $15^{\circ} \mathrm{C}$ & 10 & 36 & 20 & 23 \\
$30^{\circ} \mathrm{C}$ & 4 & 11 & 5 & 9 \\
\hline
\end{tabular}

Otro estudio informó sobre las temperaturas base inferiores para cada una de las etapas del ciclo biológico de T. absoluta, bajo las cuales no es posible el desarrollo del insecto (Estay, 2000) (Tabla 1.2).

Tabla 1.2: Temperatura base estimada para cada uno de los estados de desarrollo de $T$. absoluta (Estay, 2000). 
Con respecto a la relación intraespecífica de T. absoluta, Bultman et al. (1986) señalaron que los dos primeros estadios larvarios son bastante sedentarios, mientras que las larvas L3 y L4 poseen la capacidad de poder desplazarse lo suficiente para iniciar nuevas galerías en la misma hoja de tomate o en otra diferente. También vieron que una elevada densidad larval dentro de una misma hoja puede tener un efecto crítico en los primeros estadios de desarrollo, disminuyendo la supervivencia de las larvas y la fecundidad de los adultos. Por otro lado, Pereyra (2002) indicó que el tamaño de la hoja de tomate no parece afectar mucho al desarrollo de T. absoluta.

La larva, desde el primer estadio hasta el final del cuarto, se desarrolla en un periodo de 13 a 23 días en función de las condiciones ambientales (Cáceres, 2007; Monserrat, 2009). Por otro lado, la distribución de las larvas en la planta es más uniforme, ya que suelen preferir siempre el estrato medio (Leite et al., 1995; Haji, 1997; Torres et al., 2001).

La mayoría de las larvas, una vez que han completado su fase larvaria, se dejan caer al suelo con la ayuda de un hilo de seda para crisalidar, mientras que algunas otras crisalidan directamente sobre distintas partes de la planta, sobre todo en el envés de las hojas y junto al cáliz del fruto, protegiéndose con un pequeño capullo (Monserrat, 2009).

La vida media de los adultos de T. absoluta es de 10 a 15 días en las hembras, y de 6 a 7 días en los machos (Estay et al., 2002). Los adultos de T. absoluta presentan una sorprendente capacidad para localizar sus objetivos, como las plantas huéspedes, y desplazarse hacia ellos a distancias muy considerables para un insecto de su tamaño y características (Monserrat, 2016). Tienen hábitos nocturnos y suelen permanecer escondidos durante el día, manifestando una mayor actividad diurna y crepuscular. Pueden dispersarse volando a varios kilómetros de distancia o empujados por el viento (Desneux et al., 2010).

Existen estudios sobre la preferencia de puesta por parte de las hembras de T. absoluta y preferencia de alimentación de las larvas en diferentes variedades de tomate (Vercher et al., 2010). Estos autores no encontraron diferencias con respecto a la puesta, pero sí en la alimentación de las larvas, viendo que mostraban preferencia por los tomates de la variedad Raff en comparación con los de la variedad kumato o tipo cherry.

El estado de pupa dura de 7 a 21 días en función de la temperatura (Cáceres, 2007). Monserrat (2009) indica que las pupas de T. absoluta pueden permanecer enterradas en el suelo, por lo que las parcelas quedan "contaminadas" durante varias semanas hasta la emergencia de los adultos. El tiempo de supervivencia de T. absoluta en un terreno puede variar de 4 a 6 semanas, alargándose este periodo a temperaturas bajas. 


\subsubsection{Hospedantes}

T. absoluta tiene como hospedante principal al tomate (Solanum lycopersicum L.) (Figuras 1.17 y 1.18), pero también puede alimentarse, reproducirse y completar su ciclo biológico en otras solanáceas cultivadas: Solanum melongena L., Solanum tuberosum L., Solanum muricatum L., Nicotiana tabacum L. (Vargas, 1970; Campos, 1976) y Capsicum annuum L. (Akiyoshi et al., 2004) (Figuras 1.19 y 1.20).
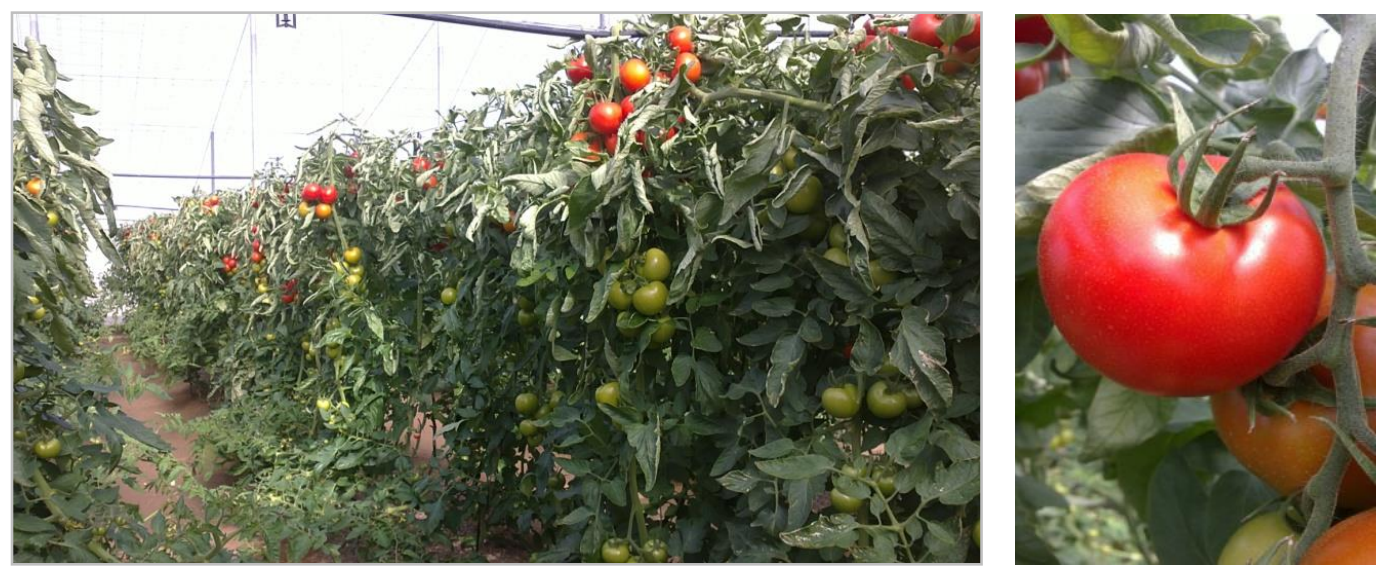

Figuras 1.17 y 1.18: Cultivo de tomate en invernadero y fruto de tomate (Solanum lycopersicum) (Fuente propia).


Figuras 1.19 y 1.20: Daño de T. absoluta en berenjena (Solanum melongena) y en patata (Solanum tuberosum) (USDA, 2011).

Además, T. absoluta ataca a otras plantas solanáceas silvestres, tales como: Lycopersicon puberulum Phil., Solanum bonariense L., Solanum sisymbriifolium Lam., Solanum saponaceum Hook. (García et al., 1982), Lycopersicon hirsutum Humb. \& Bonpl., Solanum lyratum Thunb., Solanum nigrum L., Solanum eleagnifolium Cav., Solanum puberulum Nutt. ex Seem., Datura stramonium L., Datura ferox L., Lycium chilense Miers ex Bertero (EPPO, 2005, 2009), y Physalis peruviana L. (Tropea Garzia, 2009). 
También se ha detectado en Phaseolus vulgaris L., Nicotiana glauca Graham y Chenopodium murale L., en zonas con elevadas poblaciones de T. absoluta procedentes de tomate (Van der Blom et al., 2011).

La capacidad de $T$. absoluta para alimentarse de un amplio rango de plantas silvestres supone un grave problema, debido a que estos hospedantes secundarios facilitan la introducción y establecimiento de la plaga en nuevas zonas cultivadas, a la vez que pueden actuar como reservorio de poblaciones en ausencia de cultivo (Cifuentes et al., 2011).

\subsubsection{Daños}

Los daños son producidos por las larvas de $T$. absoluta, y están directamente relacionados con la densidad poblacional de la plaga en el cultivo (Monserrat, 2016).

Las plantas de tomate pueden ser atacadas por las larvas de $T$. absoluta en cualquier momento de la etapa de desarrollo fenológico de la planta, ya sea en plantas en producción como en plantas de semillero (TaRI, 2017).

Al emerger la larva del huevo, esta camina sobre la superficie de la hoja buscando un punto de penetración y rompiendo la epidermis de la hoja. Una vez que se encuentra en el interior de la hoja, se alimenta del mesófilo formando galerías transparentes entre la epidermis superior e inferior de la hoja (Quiroz, 1976). Estas galerías, además de limitar la capacidad fotosintética de la planta y debilitarla, son también puntos de infecciones fúngicas y bacterianas debido a los excrementos que las larvas depositan en su interior. Frecuentemente, las larvas de $T$. absoluta salen de las galerías al exterior de la hoja para iniciar otras galerías o trasladarse a otras hojas o frutos. Asimismo, sobre ramilletes pueden provocar la pérdida de frutos pequeños (Monserrat, 2016) (Figuras 1.21 y 1.22).
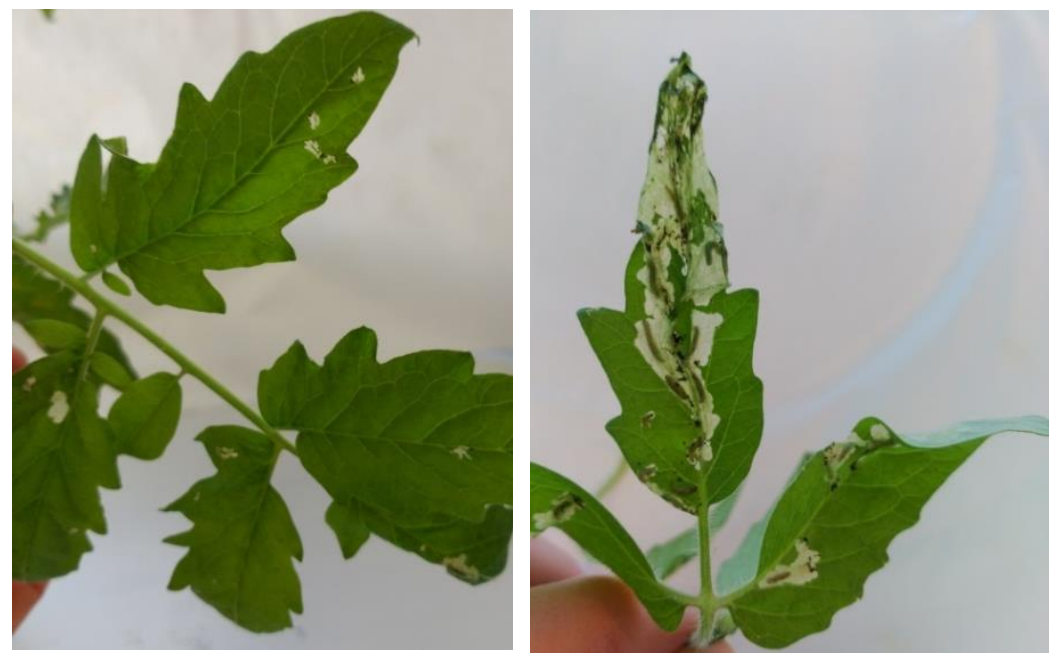

Figuras 1.21 y 1.22: Daño de T. absoluta en hojas de tomate (Fuente propia). 
Las larvas también pueden atacar brotes, flores y frutos, pero prefieren alimentarse de las hojas en formación y los racimos florales (López, 1991). En las flores, se alimentan de los ovarios, causando que las flores se sequen y cuelguen sin llegar a caerse (Flores et al., 2003), mientras que las larvas prefieren los brotes de la parte apical de la planta (Apablaza, 1992).

Las penetraciones de las larvas de $T$. absoluta en los tallos pueden provocar su debilitación y desecación, dando lugar a daños severos al inicio de la plantación (Monserrat, 2016) (Figuras 1.23 y 1.24$)$.
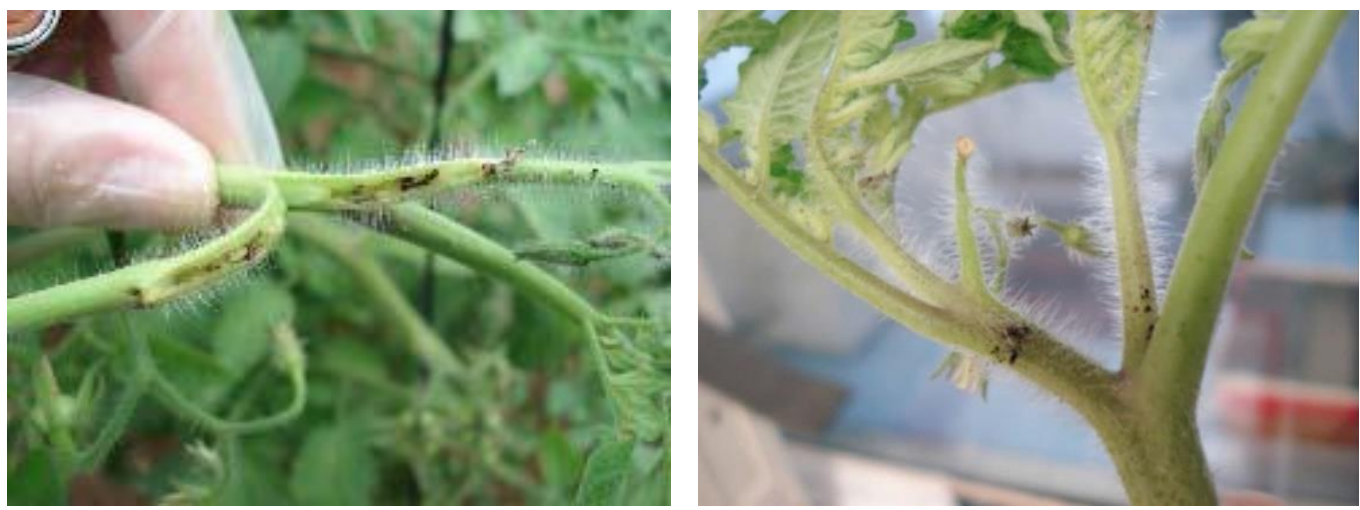

Figuras 1.23 y 1.24: Daño de T. absoluta en tallo de tomate (Senasica, 2013).

Las larvas de $T$. absoluta pueden dañar los frutos de tomate desde el mismo momento en que el fruto está recién cuajado. Suelen penetrar en el fruto por la zona protegida del cáliz, o por partes de los frutos que están protegidos por hojas u otros frutos. Además, las galerías que realizan las larvas en el interior del fruto son un foco de entrada de patógenos, tanto hongos como bacterias (Biurrun, 2008) (Figuras 1.25 y 1.26).
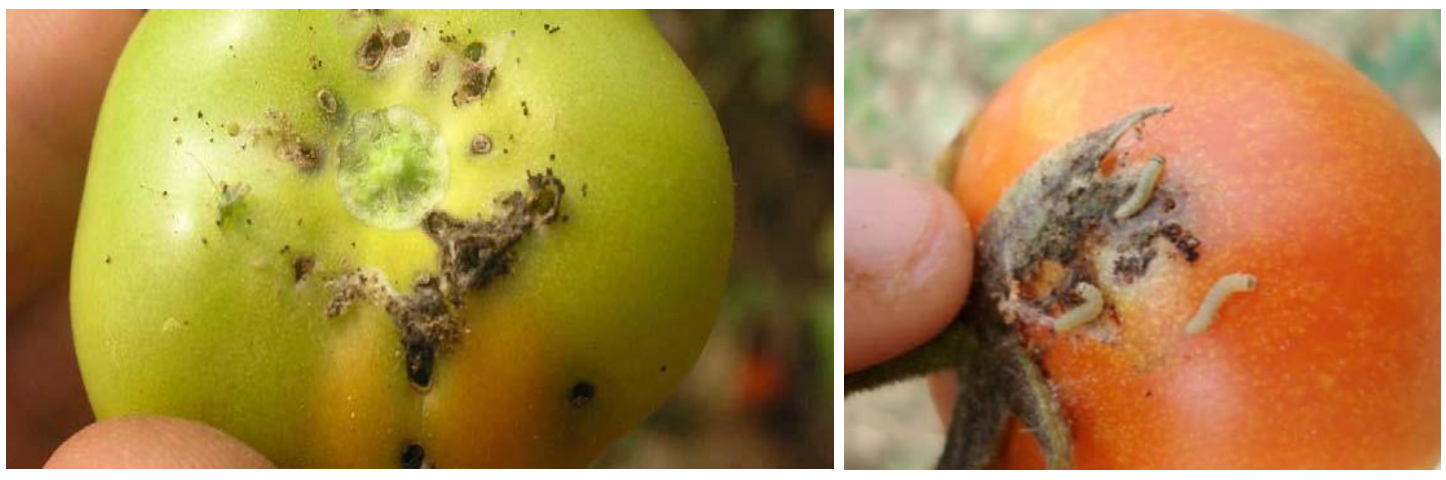

Figuras 1.25 y 1.26: Daño de T. absoluta en fruto de tomate (1.25: USDA, 2011; 1.26: Senasica, 2013). 
Cuando la densidad de población de T. absoluta en las plantaciones es baja, solamente suelen apreciarse galerías en las hojas. Sin embargo, si las densidades poblacionales son elevadas se observan daños en hojas, tallos y frutos jóvenes. Los frutos más maduros son afectados posteriormente por larvas de tercer y cuarto estadio. Las larvas desarrolladas que proceden de otras zonas de la planta, pueden penetrar por toda la superficie del fruto y en cualquier estado de madurez del mismo (Monserrat, 2009). Por otro lado, las larvas de T. absoluta que proceden de huevos depositados directamente sobre el cáliz del fruto, penetran en los frutos y no salen al exterior durante los primeros estadios larvarios, dificultando su control (Vercher et al., 2010). Ocasionalmente, la larva de $T$. absoluta puede salir de un fruto para penetrar en otro dentro de un mismo racimo (López, 1991).

La consecuencia de todos estos daños es la pérdida de rendimiento y calidad del fruto debido a la alimentación de las larvas (Flores et al., 2003). Además, si no se realiza una detección inicial de la plaga en el cultivo y no se aplican debidamente las diferentes medidas de control, los daños que puede causar $T$. absoluta pueden llegar a ser muy importantes, dando lugar en algunos casos a la retirada total de la plantación.

\subsection{Estrategias de control de $T$. absoluta}

Actualmente, son necesarias estrategias de control que combinen la implementación de medidas culturales, el uso de enemigos naturales, trampas y feromonas, así como insecticidas para poder controlar de manera eficaz a T. absoluta de forma sostenible, y limitar su impacto en las diferentes áreas invadidas. Al mismo tiempo, es importante adecuar todas estas medidas a las características propias de cada explotación, a la evolución de la plaga en el cultivo y al ciclo de cultivo, con el fin de mejorar la eficacia de esta estrategia de control integrado sobre la plaga.

\subsubsection{Medidas culturales}

Existen diversas medidas culturales que se pueden llevar a cabo para el control de T. absoluta. Entre ellas se encuentran una adecuada preparación del terreno antes de la plantación, rotación de los cultivos (evitando otras solanáceas), buenas barreras físicas, la destrucción apropiada de restos vegetales al finalizar la cosecha y la realización de un seguimiento para conocer la evolución de la población en campo. 


\section{Medidas de higiene de las parcelas}

En primer lugar, es importante retirar todos los restos de plantaciones anteriores que pudieran servir de reservorios de la plaga, y mantener las parcelas limpias con el fin de garantizar la ausencia de cualquier foco de contaminación en el momento previo al trasplante. Se puede realizar una solarización o mantener la parcela libre de restos de cultivo durante 6 u 8 semanas. Si en invernaderos se consiguen temperaturas próximas a $60^{\circ} \mathrm{C}$, este periodo podría reducirse a 4 semanas en época estival (Monserrat, 2016).

Una vez iniciado el cultivo, es importante realizar una revisión de las plantas y eliminar de forma manual las hojas que presenten galerías mientras el nivel de plaga en el cultivo sea bajo, retrasando así la instalación de la plaga (Monserrat, 2010). Además, durante todo el ciclo de cultivo es necesario eliminar los frutos con presencia de $T$. absoluta, debido a que estos pueden ser un foco de contaminación constante en la parcela (Monserrat, 2009), así como las hojas senescentes de la parte basal de la planta, ya que estas suelen presentar un elevado grado de infestación de larvas de T. absoluta (Larraín, 1992).

\section{Material vegetal}

La planta del semillero empleada para el trasplante debe llegar exenta de plaga, por lo tanto es necesario evitar almacenamientos en zonas no protegidas donde podrían llegar a ser alcanzadas por hembras de $T$. absoluta que realizarían la puesta sobre la planta. Si se detectara la presencia de la plaga, las plantas podrán ser tratadas con algún insecticida específico contra T. absoluta, pudiendo evitar las colonizaciones de estas plantas por parte de la plaga en los días posteriores al trasplante (Monserrat, 2016).

\section{Barreras físicas}

En cultivos que estén protegidos bajo invernadero, se deben revisar los cerramientos unos días previos al trasplante. Con esta medida se pretende eliminar todos los huecos o rotos por donde pudiera entrar la plaga al invernadero. Con el fin de reducir la posibilidad de colonización del cultivo, es imprescindible instalar una doble puerta con una cámara entre ambas, para que no permanezcan abiertas de forma simultánea, y colocar trampas adhesivas en ella. Durante el ciclo de cultivo es importante seguir revisando todos los cerramientos del invernadero, debido a que los adultos de $T$. absoluta tienen una gran capacidad de búsqueda, atraídos por las sustancias volátiles que emite el tomate, pudiendo localizar sin mucha dificultad pequeños agujeros que puedan quedar en la estructura del invernadero (Monserrat, 2010). La densidad mínima de las mallas empleadas en los invernaderos que impiden la entrada de los adultos de T. absoluta es de $9 \times 6$ hilos por $\mathrm{cm}^{2}$ (Monserrat, 2016) (Figura 1.27). 


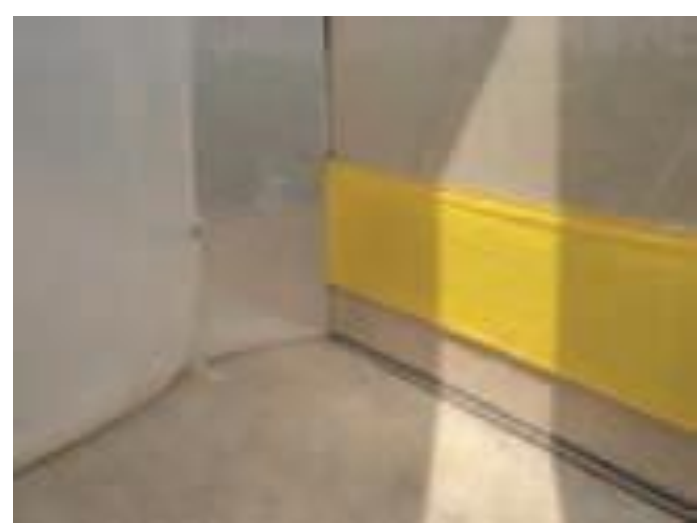

Figura 1.27: Trampa adhesiva entre doble puerta de un invernadero (Monserrat, 2009).

\section{Captura masiva y confusión sexual}

El uso de trampas cebadas con atrayentes o feromonas es una buena herramienta que permite estudiar la biología de la plaga, su distribución y su nivel poblacional (Urbaneja et al., 2007).

La colocación de trampas adhesivas, como complemento a las medidas de higiene de la parcela y la instalación de barreras físicas, puede contribuir a la eliminación de los adultos que pudiesen haber permanecido refugiados en la parcela o emerger durante los días previos o posteriores al trasplante. Por tanto, es importante que las trampas se instalen varios días antes de plantar, distribuyéndolas de manera uniforme por toda la parcela y reforzando los bordes y las inmediaciones de las puertas. Además, la altura de colocación debe ser próxima al suelo. Otra alternativa sería el uso de trampas de agua cebadas con feromonas, las cuales se emplean para la captura masiva de machos. Estas trampas son más eficaces en parcelas que presentan buenos cerramientos, y cuando los niveles poblacionales de la plaga son bajos y no hay hembras fecundadas en la parcela (Monserrat, 2016) (Figuras $1.28,1.29$ y 1.30).


Figuras 1.28, 1.29 y 1.30: Trampa adhesiva azul, trampa adhesiva amarilla y trampa de agua con feromonas (1.28 y 1.29: Monserrat, 2009; 1.30: USDA, 2011). 
La captura masiva mediante el uso de trampas con la feromona sexual de la hembra de $T$. absoluta será más o menos eficaz en función de las condiciones en las que se utilice, pero en ningún caso su uso resultará contraproducente, debido a que no atraen a las hembras a la parcela cultivada. Sin embargo, la utilización de algunos tipos de trampas luminosas, sobre todo en parcelas que no estén totalmente impermeabilizadas a la entrada de T. absoluta y otros lepidópteros, puede resultar un riesgo, ya que estas trampas ejercen una gran atracción de hembras y machos, los cuales no siempre serán capturados por las trampas (Monserrat, 2010) (Figuras 1.31 y 1.32).
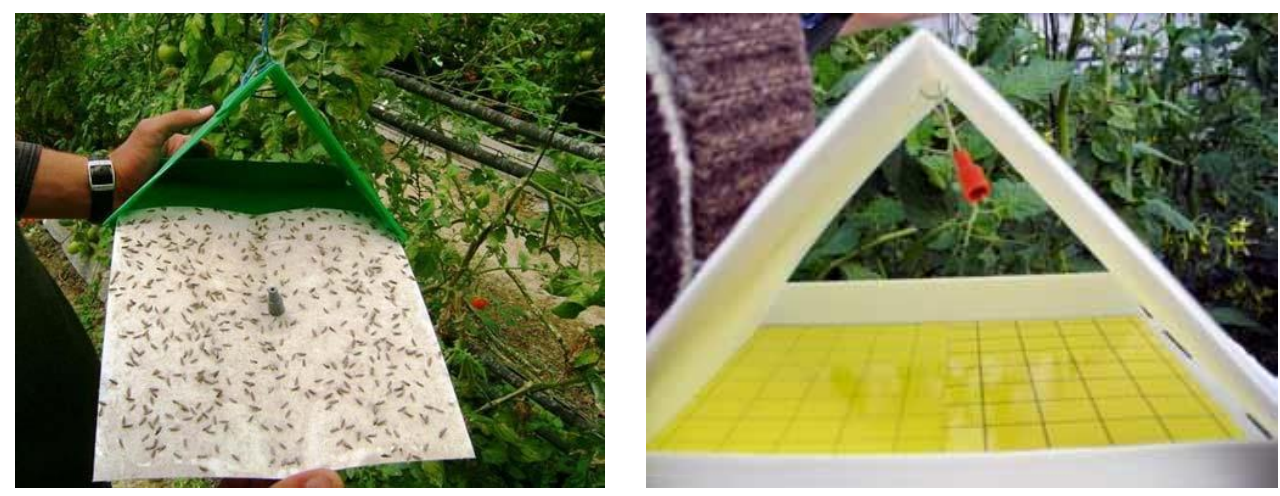

Figuras 1.31 y 1.32: Trampas tipo delta con feromona sexual de $T$. absoluta (1.31: USDA, 2011; 1.32: Van der Blom et al., 2011).

\subsubsection{Control biológico}

Para lograr un control más eficaz de $T$. absoluta, se recomienda emplear distintos métodos de control, los cuales deben estar incluidos en un programa de Gestión Integrada de Plagas (GIP). Entre estos métodos se encuentra el uso de enemigos naturales, que llevan a cabo una labor muy importante en el control de plagas como $T$. absoluta, con las que el riesgo de recolonización de las plantaciones cultivadas es continuo (Monserrat, 2016). En relación al empleo de esta herramienta de control, es necesario, por un lado, evaluar la naturaleza y potencial de los enemigos naturales endémicos asociados con T. absoluta en las diferentes regiones de cultivo de tomate, y por otro lado, definir los umbrales económicos y niveles de intervención para el uso del control biológico en T. absoluta (Desneux et al., 2010).

En la actualidad, existen varios enemigos naturales, parasitoides y depredadores, que controlan de forma natural a $T$. absoluta en plantaciones de tomate de Europa y el norte de África. Además, se han descrito más de 70 especies de enemigos naturales generalistas para $T$. absoluta en la región Paleártica occidental (Zappalà et al., 2013). 
En el cultivo del tomate, la utilización de míridos depredadores como Nesidiocoris tenuis Reuter (Hemiptera: Miridae) y Macrolophus pygmaeus (Rambur) (Hemiptera: Miridae), está resultando muy eficaz para controlar diferentes plagas, como Bemisia tabaci (Gennadius) (Hemiptera: Aleyrodidae) y T. absoluta (Gerling et al., 2001; Gabarra et al., 2008; Arnó et al., 2010; Calvo et al., 2012a; Urbaneja et al., 2012). Adultos y ninfas de estas dos especies de míridos se alimentan de los huevos de T. absoluta. Además, se ha observado que adultos de estas especies pueden consumir más de 100 huevos al día en condiciones de laboratorio, y son capaces de alimentarse de estadios larvarios primarios de T. absoluta (Arnó et al., 2009; Urbaneja et al., 2009). Se recomienda la introducción de míridos desde las primeras semanas de cultivo, realizando una suelta directa controlada o mediante la introducción de plantas refugio, como Dittrichia viscosa (L.) Greuter permanentemente inoculadas (JA, 2010) (Figuras 1.33 y 1.34$)$.
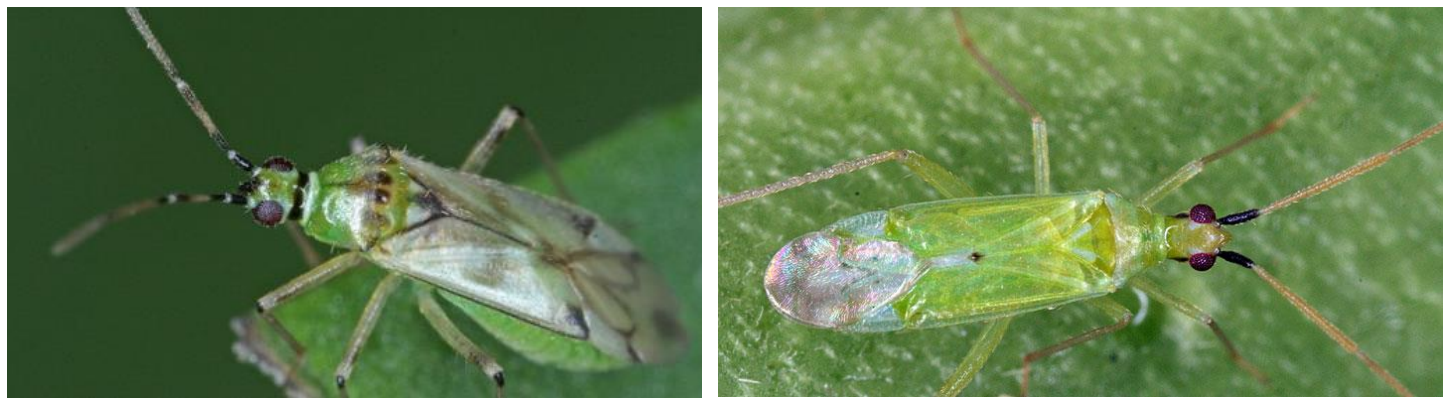

Figuras 1.33 y 1.34: Adulto de Nesidiocoris tenuis y Macrolophus pygmaeus (http://bioplanet.eu/es/nes/).

En la actualidad, $N$. tenuis es ampliamente empleado en programas de control biológico en cultivos de tomate en el sur de Europa (Vacante et al., 1994; Mollá et al., 2011b; Zappalà et al., 2013; Sanchez et al., 2014), y además, es el depredador más empleado para el control biológico en $T$. absoluta. Sin embargo, $N$. tenuis es también un insecto fitófago, pudiéndose convertir en un problema muy importante para las plantaciones cuando sus poblaciones crecen en exceso y no hay suficiente densidad de plaga de la que puedan alimentarse. En plantas muy jóvenes de tomate pueden llegar a provocar daños en los brotes, en los ramilletes en formación y en frutos jóvenes, así como inducir abortos florales y causar pequeñas picaduras en los frutos de tomate (Monserrat, 2009).

Otro mírido depredador muy extendido y que puede resultar eficaz en el control biológico de T. absoluta es Dicyphus errans (Wolff) (Hemiptera: Miridae) (Ingegno et al., 2017), debido a su capacidad para sobrevivir en diferentes ambientes, tanto en plantas cultivadas como no cultivadas. 
El uso de parasitoides es una herramienta muy importante dentro del control biológico de $T$. absoluta, y hasta hace unos años han sido el agente biológico más común en el control de esta plaga (Ghoneim, 2014). El parasitoide de huevos más empleado en el cultivo de tomate para $T$. absoluta ha sido Trichogramma achaeae Nagaraja \& Nagarkatti (Hymenoptera: Trichogrammatidae) (Cabello et al., 2012; Calvo et al., 2012b). No obstante, este parasitoide no ha conseguido altos porcentajes de parasitismo en campo, ya que le afectan negativamente las temperaturas elevadas y la humedad baja (Monserrat, 2016) (Figura 1.35).

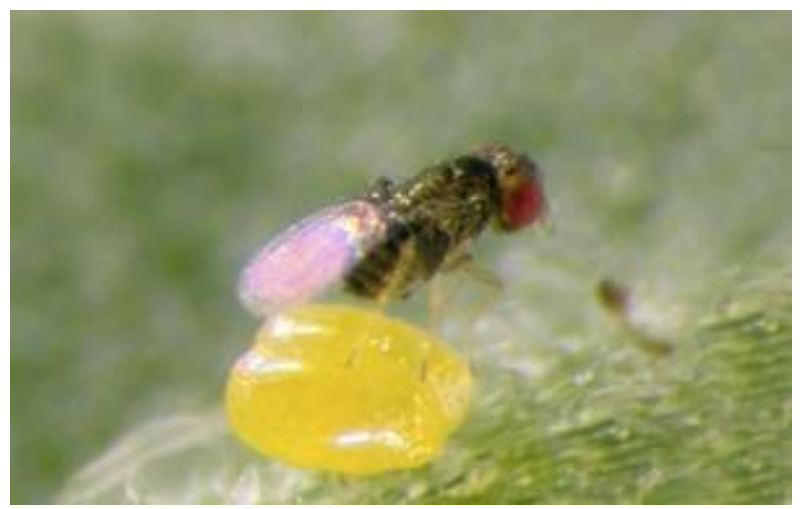

Figura 1.35: Adulto de Trichogramma achaeae parasitando huevo de T. absoluta (GarcíaVidal, 2011).

Los parasitoides de larvas Necremnus artynes (Walker) (Hymenoptera: Eulophidae) y Necremnus tutae Ribes \& Bernardo (Hymenoptera: Eulophidae), son especies muy abundantes que se encuentran parasitando de forma natural a las larvas de T. absoluta (Calvo et al., 2013). Sin embargo, estos enemigos naturales por si solos no son capaces de controlar elevados niveles de plaga, pero realizando un uso conjunto de varios de ellos se puede llegar a alcanzar un adecuado control (Figura 1.36).

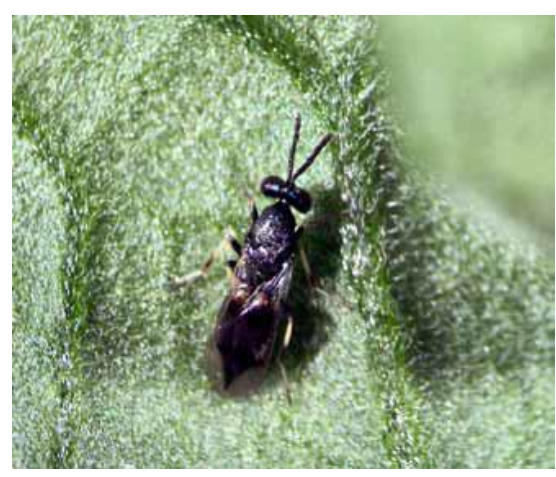

Figura 1.36: Hembra adulta de Necremnus artynes (Van der Blom et al., 2011). 
Para obtener un buen control biológico es muy importante que los enemigos naturales que se empleen estén bien establecidos y permanezcan en el cultivo una vez se haya realizado la liberación de los mismos (Santos et al., 2010).

Entre los entomopatógenos empleados en el cultivo de tomate, la bacteria Bacillus thuringiensis (Berliner) (Firmicutes: Bacillaceae) y el hongo ascomiceto Beauveria bassiana (Balsamo) Vuillemin (Hypocreales: Clavicipitaceae) son las opciones más eficientes en el control de T. absoluta, y además son compatibles con sus enemigos naturales (Biondi et al., 2012; Biondi et al., 2013; Klieber et al., 2016). B. thuringiensis ha demostrado ser bastante efectivo en el control de T. absoluta, siendo tóxico frente a las larvas de T. absoluta, y obteniendo mayor efectividad sobre larvas de primer estadio (González-Cabrera et al., 2011).

Por otro lado, el hongo Metarhizium anisopliae (Metsch) Sorokin (Hypocreales: Clavicipitaceae) ha demostrado ser efectivo en el control de T. absoluta. Este hongo entomopatógeno se aplica en el agua de riego y es tóxico frente a las crisálidas de $T$. absoluta (Contreras et al., 2014).

Con respecto a los nematodos entomopatógenos, se han llevado a cabo ensayos con tres especies, Steinernema carpocapsae Weiser (Nematoda: Steinernematidae), Steinernema feltiae Filipjev (Nematoda: Steinernematidae) y Heterorhabditis bacteriophora Poinar (Nematoda: Heterorhabditidae), obteniendo una elevada eficacia frente a larvas de $T$. absoluta (Batalla-Carrera et al., 2010; Garcia-del-Pino et al., 2011). Un reciente estudio demostró que el nematodo Meloidogyne incognita (Kofoid \& White) Chitwood (Tylenchida: Meloidogynidae) afecta al comportamiento de la oviposición de las hembras de T. absoluta y al desarrollo de su descendencia, afectando al proceso de pupación (Arce et al., 2017).

\subsubsection{Control químico}

El control químico se basa en el empleo de productos fitosanitarios. Los tratamientos insecticidas han sido y siguen siendo uno de los principales métodos de control de $T$. absoluta. Es esencial que estos tratamientos sean compatibles con el empleo de enemigos naturales y otros métodos de control, con el fin de integrarse en un programa de GIP.

Para llevar a cabo un uso adecuado y sostenible de los productos insecticidas, es importante establecer el momento óptimo y las condiciones adecuadas para su aplicación. Además, es necesario desarrollar estrategias anti-resistencia, seleccionando y alternando adecuadamente los productos en función de sus mecanismos de acción (Monserrat, 2010). Por otro lado, es importante el uso de coadyuvantes que ayuden a facilitar la penetrabilidad del insecticida en el cultivo (Santos et al., 2010). 
Los principales grupos de insecticidas registrados para el control químico de $T$. absoluta son:

\section{Carbamatos.}

Los insecticidas carbamatos son ésteres del ácido carbámico. Dentro de este grupo se encuentra el insecticida metomilo, con actividad por contacto e ingestión y gran efecto de choque. Es un insecticida sistémico, con buena absorción foliar y poco persistente. Sin embargo, es muy tóxico para polinizadores y enemigos naturales. En la actualidad, está registrado en España para el control de T. absoluta.

Según la clasificación que realiza el Comité de Acción contra la Resistencia a Insecticidas (IRAC, por sus siglas en inglés, Insecticide Resistance Action Committee) (IRAC, 2016), el insecticida metomilo pertenece al grupo $1 \mathrm{~A}$ Inhibidores de la acetilcolinesterasa (AChE). Actúa sobre el sistema nervioso del insecto, inhibiendo la acetilcolinesterasa, enzima encargada de finalizar la acción de excitación neurotransmisora de la acetilcolina en la sinapsis nerviosa. Causan la hiperexcitación del sistema nervioso del insecto. En los carbamatos, a diferencia de los organofosforados con quien comparten el mismo modo de acción, la inhibición enzimática es parcialmente reversible.

\section{Organofosforados.}

Entre los productos organofosforados utilizados para el control de $T$. absoluta están los insecticidas clorpirifos y metamidofos. Según la clasificación que realiza IRAC (2016) estos insecticidas pertenecen al grupo $1 \mathrm{~B}$ Inhibidores de la acetilcolinesterasa. El modo de acción de los organofosforados es idéntico al de los carbamatos, inhiben la actividad de la acetilcolinesterasa bloqueando la transmisión de los impulsos nerviosos, provocando excitación, hiperactividad, descoordinación, temblores y muerte rápida de los insectos.

Clorpirifos es un insecticida no sistémico que actúa por contacto, ingestión e inhalación y se caracteriza por tener un gran efecto de choque. Además, está registrado en España para su uso en $T$. absoluta. Por otro lado, metamidofos posee acción sistémica y actúa por contacto e ingestión. Tiene una buena acción residual y también se caracteriza por su buena absorción radical y foliar. Es un insecticida prohibido en muchos países por ser considerado nocivo para el medio ambiente y la salud humana. En España no está registrado. Estos dos insecticidas son considerados altamente tóxicos para la fauna auxiliar y las abejas (USDA, 2011).

\section{Piretroides.}

Los piretroides son compuestos químicos derivados de las piretrinas, las cuales se han empleado durante siglos por su actividad insecticida. Además, los piretroides son casi insolubles en agua, lo que favorece su rápida acción de choque ya que penetran rápidamente en el insecto, y prácticamente no poseen acción sistémica ni translaminar. 
Entre los piretroides empleados para el control de $T$. absoluta se encuentran los siguientes insecticidas: alfa-cipermetrín, betaciflutrín, cipermetrín, deltametrín, esfenvalerato, etofenprox, lambda-cihalotrín, tau-fluvalinato, zeta-cipermetrín, bifentrín, ciflutrín, gammacihalotrín, beta-cipermetrín, fenpropatrín y permetrina. Según la clasificación que hace IRAC (2016) estos insecticidas pertenecen al grupo 3A Moduladores del canal de sodio. Mantienen abiertos los canales de sodio, causando hiperexcitación, y en algunos casos, bloqueo nervioso. Los canales de sodio están implicados en la propagación de potenciales de acción a lo largo de los axones nerviosos.

Los piretroides sintéticos registrados en España para su uso frente a $T$. absoluta son: cipermetrín, deltametrín, alfa-cipermetrín, betaciflutrín, esfenvalerato, etofenprox, lambdacihalotrín, tau-fluvalinato y zeta-cipermetrín. Cipermetrín posee una acción repelente en adultos y antialimentaria en larvas. Actúa por contacto e ingestión. Asimismo, deltametrín presenta propiedades similares a cipermetrín, destacando su gran actividad insecticida. Alfacipermetrín es un insecticida no sistémico, posee una gran acción de choque y poca persistencia. Es repelente y antialimentario, con actividad por contacto e ingestión. Por otro lado, betaciflutrín actúa principalmente por contacto, y también algo por ingestión. Presenta un rápido efecto inicial y una prolongada acción residual, reforzada por su efecto repelente. Esfenvalerato posee actividad insecticida por contacto e ingestión, un potente efecto de choque y acción repelente. Etofenprox actúa también por contacto e ingestión, posee rápido efecto de choque y presenta buena actividad sobre todos los estadios larvarios de $T$. absoluta. Además, es compatible con abejorros y fauna auxiliar. Lambda-cihalotrín es un insecticida no sistémico, actúa por contacto e ingestión, posee un buen efecto de choque y buena persistencia, mientras que el insecticida tau-fluvalinato tiene actividad por contacto y en menor medida por ingestión, posee un fuerte efecto de choque y elevada persistencia repelente. Finalmente, zeta-cipermetrín es un insecticida no sistémico, actúa por contacto e ingestión, presenta rápida acción y buena persistencia.

\section{Spinosines.}

En el grupo de los spinosines se encuentran los insecticidas spinosad y spinetoram, que proceden de la fermentación del actinomiceto Saccharopolyspora spinosa Mertz \& Yao (Actinomycetales: Pseudonocardiaceae). Estos dos insecticidas pertenecen a una nueva clase de productos Ilamada NATURALYTE, y su uso está permitido en agricultura ecológica. Según la clasificación que hace IRAC (2016) pertenecen al grupo 5 Moduladores alostéricos del receptor nicotínico de la acetilcolina. Activan alostéricamente los receptores, provocando la hiperexcitación del sistema nervioso, la parálisis del insecto y por último su muerte. La acetilcolina es el principal neurotransmisor excitador en el sistema nervioso central del insecto. 
Spinosad está formado por la combinación de dos moléculas, spinosyn A y spinosyn D, procedentes de la fermentación de S. spinosa, en una proporción de $85 \%$ de la molécula A y $15 \%$ de D. Su actividad por ingestión es 10 veces mayor a su actividad por contacto, y presenta un perfil medioambiental y toxicológico muy favorable, que lo hace compatible con los enemigos naturales y adecuado para programas GIP (Torné et al., 2010). Está registrado en España para el control de T. absoluta (Figura 1.37).

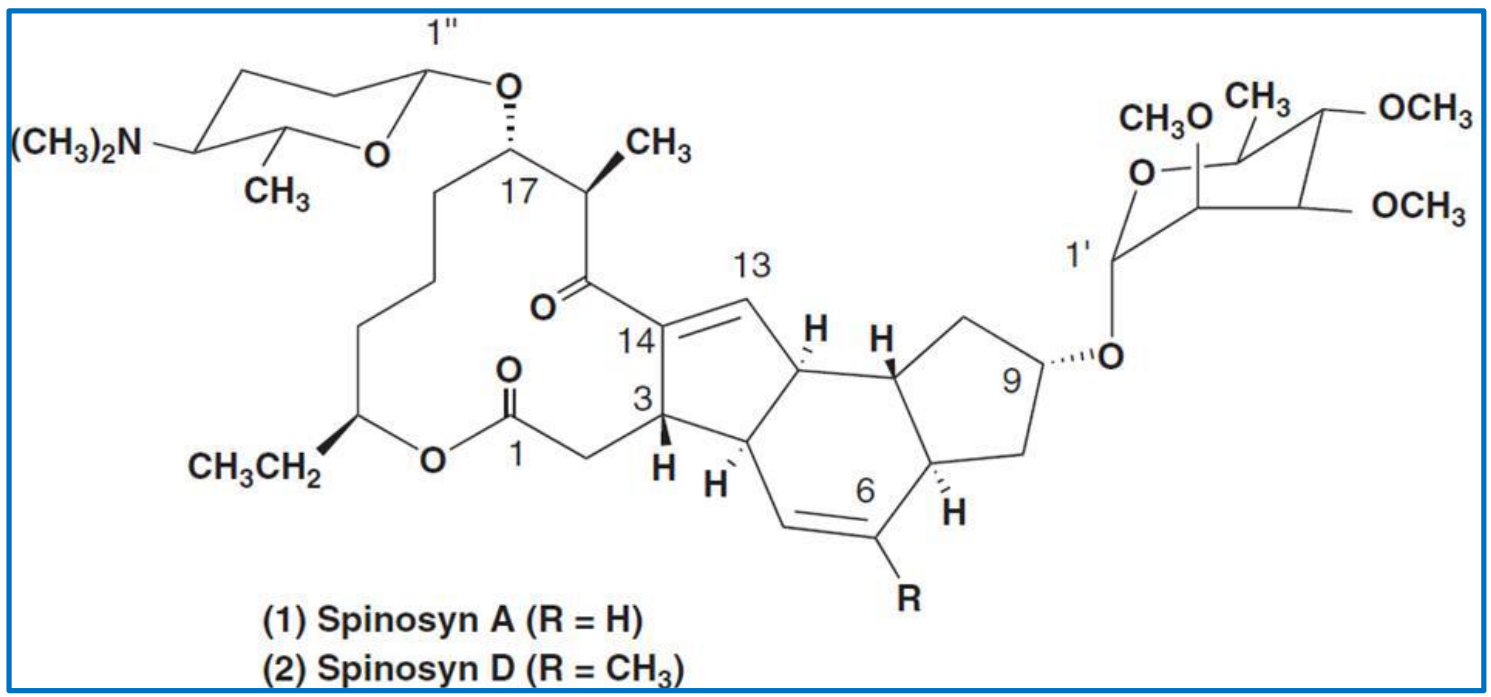

Figura 1.37: Estructura química de los metabolitos spinosyn $A$ y spinosyn $D$ (Aboul-Enein et al., 2012).

Spinetoram es una spinosina de segunda generación y está formado por la combinación de las moléculas, spinosyn J y spinosyn L. Actúa por ingestión y por contacto, aunque su modo de acción principal es el primero. Además, presenta una buena acción translaminar. Al igual que spinosad, posee un perfil medioambiental y toxicológico muy favorable, compatible con enemigos naturales y polinizadores. Este insecticida no está registrado en España para el control de T. absoluta.

\section{Avermectinas.}

Las avermectinas provienen de la bacteria del suelo Streptomyces avermitilis Kim \& Goodfellow (Actinomycetales: Streptomycetaceae), que se encuentra de forma natural en el suelo. Bloquean la transmisión eléctrica de las células nerviosas y musculares, causando la parálisis y muerte del insecto. Entre las avermectinas se encuentran los insecticidas abamectina y emamectina benzoato, que proceden de la fermentación natural de $S$. avermitilis. Ambos insecticidas pertenecen al grupo 6 Moduladores alostéricos del canal de cloro dependiente de glutamato, según la clasificación que hace IRAC (2016). Activan alostéricamente el glutamato en canales de cloro, causando parálisis del insecto. El glutamato es un importante neurotransmisor inhibidor en insectos. 
Abamectina tiene una buena acción translaminar, penetrando rápidamente en el interior de las hojas y teniendo un prolongado efecto residual. Actúa por ingestión y ligeramente por contacto (Salvo et al., 2007). Sin embargo, abamectina es muy tóxica frente a polinizadores.

Emamectina benzoato es una avermectina de segunda generación, sintetizada en 5 pasos a partir de la abamectina y con una potencia insecticida sobre lepidópteros, a dosis muy bajas, mayor que abamectina. Actúa básicamente por ingestión y en menor medida por contacto. Su actividad por ingestión le permite controlar todos los estadios larvarios del insecto (efecto larvicida), aunque también posee efecto ovo-larvicida, ya que también es eficaz contra las larvas neonatas presentes en el interior de los huevos. Es rápidamente translocada, con un prolongado efecto residual, y la parte que queda en la superficie de la planta se degrada rápidamente limitando la actividad por contacto sobre artrópodos beneficiosos y polinizadores. En el caso de emamectina benzoato, esta posee dos modos de acción fisiológicos. Por un lado se une a los receptores GABA (Ácido Amino Butírico) en la sinapsis inhibida y por otro lado, se une a los receptores $\mathrm{H}$ del glutamato en la superficie del músculo. Este último modo de acción es el que utiliza IRAC para clasificar a emamectina benzoato en el grupo 6 (López et al., 2010). Ambos insecticidas, abamectina y emamectina benzoato, están registrados para su uso en España frente a T. absoluta.

\section{Pirroles.}

En este grupo se encuentra el insecticida clorfenapir, un pro-insecticida que se convierte en un metabolito tóxico en el interior del insecto (Yu, 2008). Actúa sobre todo por ingestión pero también tiene cierta acción por contacto, y tiene una buena actividad translaminar en las plantas. Según la clasificación que hace IRAC (2016), pertenece al grupo 13 Desacopladores de la fosforilación oxidativa mediante la interrupción del gradiente de protones. Cuando clorfenapir entra en contacto con las células del insecto, este inhibe la generación de energía por la liberación y extracción de protones $\mathrm{H}^{+}$antes de llegar al ATP, produciendo la muerte celular y por consiguiente la muerte del insecto. Es tóxico para las abejas y los enemigos naturales, y no está permitido su uso en España.

\section{Análagos de la nereistoxina.}

A este grupo pertenece cartap. Es un insecticida tiocarbamato, sistémico, de amplio espectro y actúa por contacto e ingestión. Además, es de acción rápida y duradera. Según la clasificación que hace IRAC (2016) pertenece al grupo 14 Bloqueadores del canal de iones del receptor nicotínico de la acetilcolina. Este insecticida bloquea el canal de iones del receptor nicotínico de la acetilcolina, dando lugar a un bloqueo del sistema nervioso y la parálisis el insecto. Se recomienda no usar en presencia de abejas y no está registrado en España. 


\section{Benzoilureas.}

Dentro de este grupo se encuentran los insecticidas diflubenzurón, lufenurón, triflumurón, flufenoxurón, novalurón, noviflumurón y teflubenzurón. Actúan como reguladores del crecimiento de los insectos, y según la clasificación que hace IRAC (2016) pertenecen al grupo 15 Inhibidores de la biosíntesis de quitina, tipo 0. La quitina es el componente básico del exoesqueleto de los insectos. Inhiben la síntesis de quitina en el cuerpo del insecto, evitando la incorporación de las unidades de $\mathrm{N}$-acetilglucosamina, en el polímero de la quitina, y tienen una acción citostática sobre las células epidérmicas que producen quitina (Beeman, 1982). Además, este tipo de compuestos también pueden tener efectos secundarios en el metabolismo de los ácidos nucleicos y en el de la hormona de la muda (Mauchamp et al., 1987).

Las benzoilureas registradas en España para su uso en el control de $T$. absoluta son: diflubenzurón, lufenurón y triflumurón. El diflubenzurón actúa por ingestión y tiene cierta acción por contacto en algún caso. El lufenurón posee cierta acción translaminar y un prolongado efecto residual. También actúa por ingestión y algo por contacto. Y por último, el triflumurón es un insecticida no sistémico que actúa por ingestión y ligeramente por contacto, y tiene un prolongado efecto residual.

Diacilhidracinas.

En el grupo de la familia química de las diacilhidracinas se hallan los insecticidas metoxifenocida, tebufenocida y cromafenocida, que actúan como reguladores del crecimiento del insecto. Imitan la hormona de la muda, la ecdisona, induciendo una muda precoz. Son capaces de unirse a los receptores de la ecdisona y provocar una respuesta celular, acelerando la muda de los insectos, induciendo una parada rápida de la alimentación y provocando una muda prematura. La ecdisona es la hormona que provoca las mudas larvarias y la ecdisis en los insectos. Según la clasificación que hace IRAC (2016) pertenecen al grupo 18 Agonistas del receptor de ecdisona. Estos insecticidas actúan por ingestión y ligeramente por contacto, poseen cierta acción ovicida y reducen la fecundidad de las hembras. Tienen un perfil ecotoxicológico favorable, ya que son respetuosos con el medio ambiente, los enemigos naturales y los polinizadores. Metoxifenocida y tebufenocida están registrados en España para el control de T. absoluta, mientras que cromafenocida no está registrado en España para $T$. absoluta.

\section{Oxadiacinas.}

Dentro del grupo químico de las oxadiacinas se encuentra el insecticida indoxacarb. Actúa por ingestión y por contacto, y es un insecticida no sistémico. Si se adiciona un adyuvante oleoso junto a indoxacarb, se favorece la penetración del insecticida en el mesófilo de las hojas, incrementando su eficacia. Posee una marcada acción larvicida, y en algunas especies, presenta también una excelente actividad ovicida y ovo-larvicida. El empleo de indoxacarb es adecuado en programas de GIP, debido a que tiene un reducido impacto sobre la mayoría de polinizadores y la fauna auxiliar (Figura 1.38). 


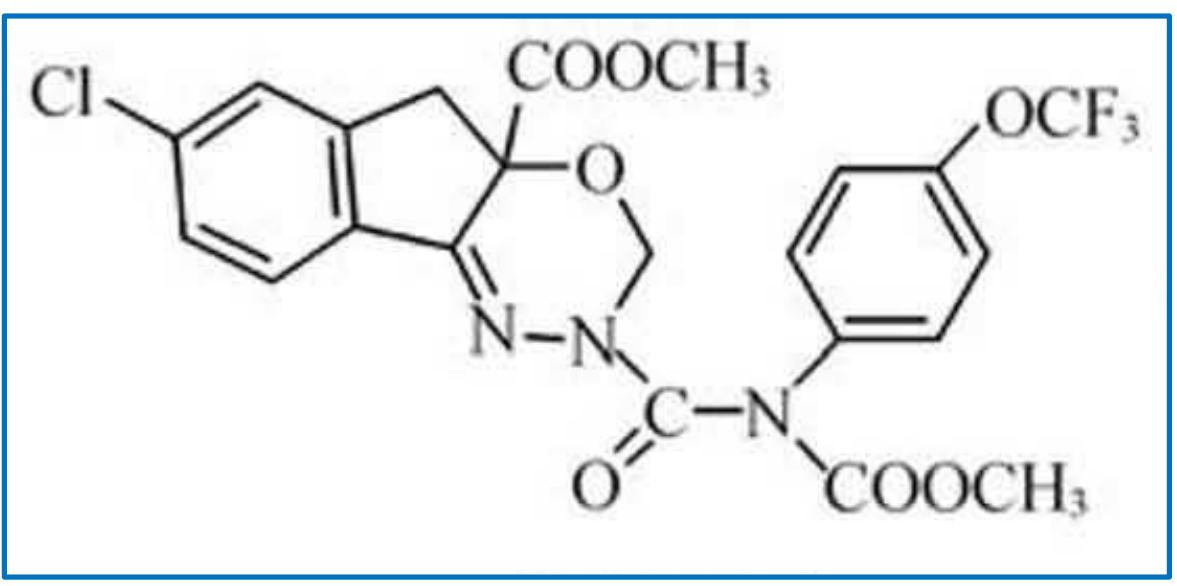

Figura 1.38: Estructura química de indoxacarb (Fu-Gen et al., 2014).

Indoxacarb pertenece al grupo 22A Bloqueadores del canal de sodio dependiente del voltaje, según la clasificación que hace IRAC (2016). Bloquean los canales de sodio causando el colapso del sistema nervioso del insecto y su parálisis, seguido del cese de la alimentación y muerte del insecto. Los canales de sodio están implicados en la propagación de potenciales de acción a lo largo de los axones nerviosos. La molécula de indoxacarb no es la responsable directa de la actividad insecticida, sino que tras sufrir una reacción metabólica en el tracto digestivo del insecto, se produce un proceso de $\mathrm{N}$-decarbometoxilación que lo transforma en un metabolito activo, siendo este el que ejerce la acción insecticida. Este proceso de transformación se llama bioactivación, y solo se produce de forma eficiente en orugas de lepidópteros, por lo que es un insecticida altamente específico frente a estas especies plaga. Indoxacarb está registrado en España para el control de T. absoluta.

\section{Semicarbazonas.}

El insecticida metaflumizona pertenece a la familia química de las semicarbazonas. Según la clasificación que hace IRAC (2016) pertenece al grupo 22B Bloqueadores del canal de sodio dependiente del voltaje. Bloquea el flujo de iones de sodio a través de los canales específicos del sistema nervioso central de los insectos, causando el colapso del sistema nervioso y la parálisis del insecto. Esta parálisis impide la alimentación del insecto a las pocas horas de su aplicación, provocando su muerte en las siguientes 24-72 horas (Araújo Gonçalves, 2010).

Metaflumizona es un insecticida no sistémico, con limitado movimiento translaminar y actúa por ingestión con una limitada actividad de contacto sobre los lepidópteros, siendo este el caso de $T$. absoluta. Es respetuoso con la fauna auxiliar, los polinizadores y el medio ambiente. Está registrado su uso en España para el control de T. absoluta. 
Diamidas.

Las diamidas son una nueva clase de insecticidas que presentan una alta eficacia frente a lepidópteros. El grupo de las diamidas lo componen los siguientes insecticidas: flubendiamida, una diamida del ácido ftálico, y clorantraniliprol y ciantraniliprol, diamidas del ácido antranílico.

Flubendiamida es un insecticida específico para el control de lepidópteros. Tiene una elevada persistencia en el cultivo, es compatible con los enemigos naturales y polinizadores, y actúa por ingestión (Figura 1.39).

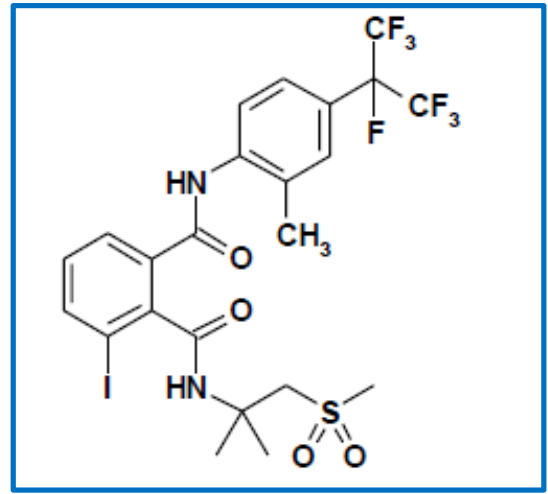

Figura 1.39: Estructura química de flubendiamida (Lahm et al., 2005).

Clorantraniliprol actúa fundamentalmente por ingestión y ligeramente por contacto. Tiene actividad foliar y sistémica, y también es compatible con polinizadores y enemigos naturales. Una diferencia entre clorantraniliprol y flubendiamida es que la actividad de flubendiamida está limitada a las larvas de lepidópteros, mientras que clorantraniliprol es efectivo frente a larvas y huevos (Lahm et al., 2009) (Figura 1.40).

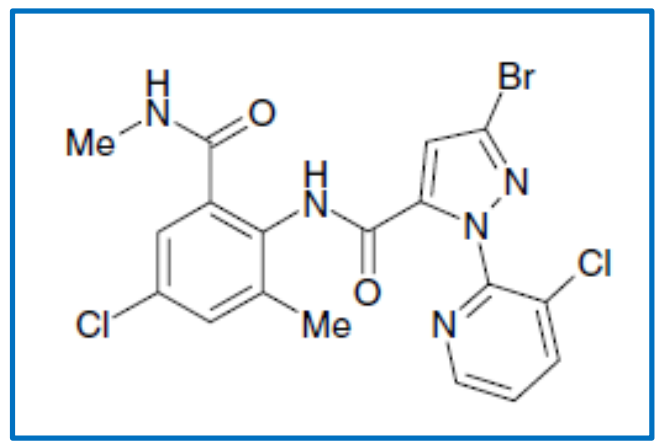

Figura 1.40: Estructura química de clorantraniliprol (Me: $\mathrm{CH}_{3}$ ) (Lahm et al., 2007). 
Por último, ciantraniliprol es una diamida antranílica de segunda generación, con un espectro de acción más amplio que clorantraniliprol. Actúa sobre todo por ingestión pero también algo por contacto, y tiene actividad larvicida, ovicida y adulticida. Presenta actividad foliar y sistémica, y es moderadamente tóxico frente a las abejas y enemigos naturales (Figura 1.41).

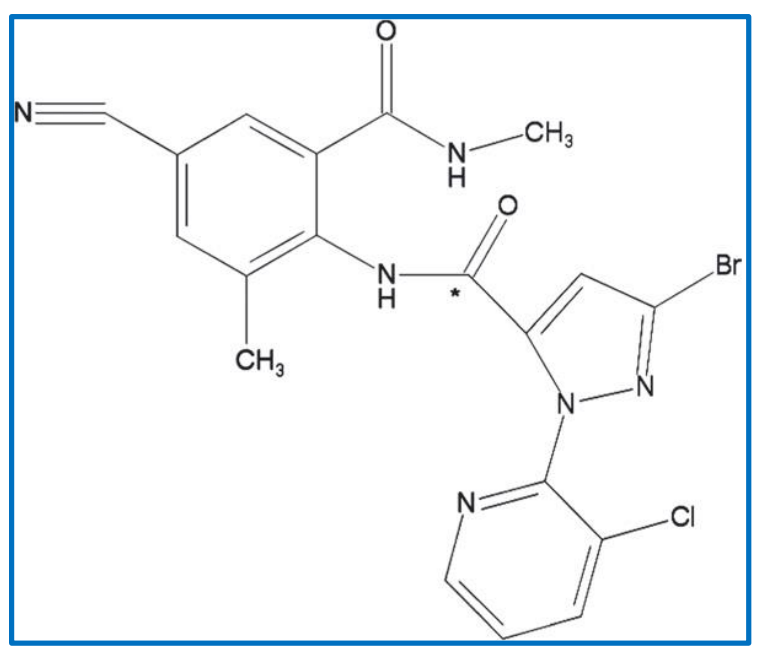

Figura 1.41: Estructura química de ciantraniliprol (Barry et al., 2015).

Según la clasificación que hace IRAC (2016), las diamidas pertenecen al grupo 28 Moduladores del receptor de la rianodina. Activan los receptores musculares de la rianodina, lo que provoca contracción y parálisis. Los receptores de la rianodina intervienen en la liberación de calcio en el citoplasma desde las reservas intracelulares, teniendo un papel crítico en la función muscular. La contracción de las células del músculo requiere una descarga regulada del calcio desde los depósitos internos en el citoplasma de la célula. Estos insecticidas se unen a los receptores de la rianodina, causando una liberación incontrolada de calcio y por tanto, el agotamiento de las reservas de las células musculares, impidiendo la contracción muscular. Los insectos cesan rápidamente de alimentarse, muestran letargo, regurgitación y parálisis muscular, produciéndose por último su muerte (Figura 1.42). 


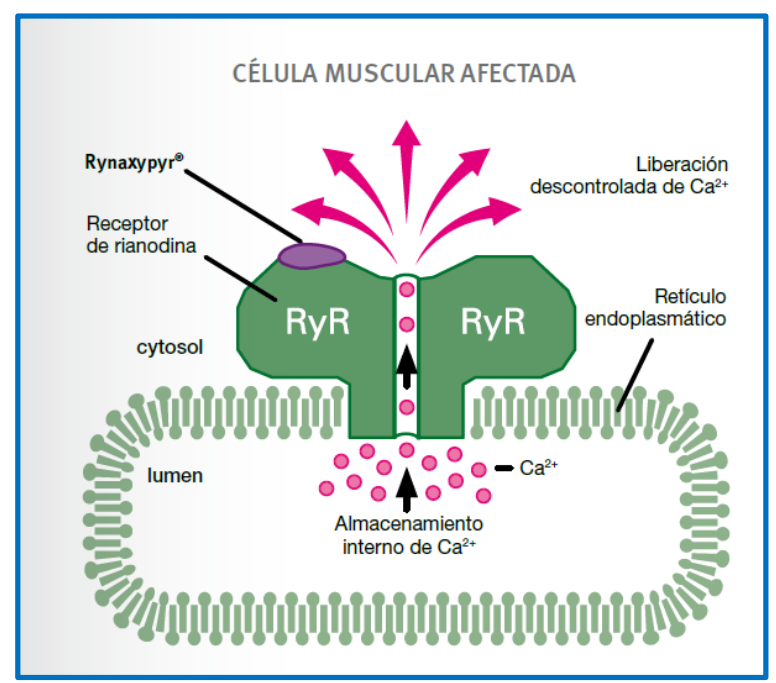

Figura 1.42: Modo de acción de las diamidas (DuPont, 2017).

En la actualidad, el insecticida clorantraniliprol está registrado en España para el control de $T$. absoluta, mientras que flubendiamida y ciantraniliprol no están registrados para su uso en España frente a $T$. absoluta. Flubendiamida fue retirado del mercado europeo para su uso en T. absoluta a principios del año 2017. Ciantraniliprol está registrado en algunos países de América, Asia y Oceanía. En Europa está pendiente de registro, pero obtuvo una extensión de autorización para uso menor de 120 días en el Reino Unido contra Plutella xylostella Linnaeus (Lepidoptera: Plutellidae). En España, ciantraniliprol ha obtenido una autorización de uso excepcional en la campaña 2017 para su utilización en los cultivos de ajo y cebolla en CastillaLa Mancha, Comunidad Valenciana, Cataluña y Navarra contra Delia antiqua Meigen (Diptera: Anthomyiidae), y también ha obtenido una autorización de uso excepcional para el control de la mosca de la col, Delia radicum Linnaeus (Diptera: Anthomyiidae), en los cultivos de brócoli, coliflor, col y coles de Bruselas, en las Comunidades Autónomas de Navarra, La Rioja, Cataluña, Extremadura (periodo de validez del 15 de julio al 15 de octubre de 2017) y Región de Murcia (del 1 de septiembre al 29 de diciembre de 2017).

\section{Azadiractín.}

Azadiractín es un insecticida biorracional que se extrae del árbol de Nim Azadirachta indica A. Juss (Sapindales: Meliaceae) y se puede emplear en agricultura ecológica (Tomé et al., 2013). Actúa por contacto e ingestión, y también presenta una buena acción sistémica. Esta clase de insecticida se cree que inhibe la formación de la ecdisona, que es la principal hormona responsable de la muda de los insectos, interfiriendo en el proceso de cambio de estado de desarrollo del insecto, poseyendo además un efecto antialimentario, de repelencia, de confusión sexual e inhibitorio de la oviposición de las hembras. IRAC (2016) clasifica a este insecticida dentro del grupo UN Compuestos de modo de acción desconocido o incierto. Es compatible con la fauna auxiliar, presenta baja toxicidad frente a polinizadores y está registrado en España para el control de T. absoluta. 


\subsection{Resistencia a insecticidas}

\subsubsection{Definición y tipos de resistencia}

IRAC (2014) define la resistencia a insecticidas como "un cambio heredable en la sensibilidad de una población de una plaga que se refleja en repetidos fallos de un producto para alcanzar los niveles de control esperados al ser usado de acuerdo con las recomendaciones de la etiqueta para esa plaga". IRAC considera que esta definición de la resistencia es la más precisa y práctica de cara a los agricultores y productores. Además, añade a su definición que una situación de resistencia se puede alcanzar debido a un "uso abusivo" o "mal uso" de un insecticida o acaricida en el control de una plaga, dando lugar a la selección de individuos resistentes y la resultante evolución de esas poblaciones resistentes.

Existen otras definiciones de resistencia, como la que hace la FAO (2013) que define la resistencia como un cambio genético en un organismo como respuesta a la selección por sustancias tóxicas. También habla del término "resistencia práctica" como un cambio heredable en la sensibilidad de la población de una plaga, el cual se manifiesta por el fallo repetido de un plaguicida con el fin de alcanzar el nivel de control deseado, cuando el producto se usa de acuerdo a las recomendaciones de la etiqueta para esa plaga y donde los problemas de almacenamiento del producto, aplicación y condiciones inusuales climáticas y ambientales pueden ser excluidos de las causas del fallo.

Por otro lado, la OMS (Brown et al., 1971) define la resistencia como el desarrollo de la habilidad en una raza de insectos para tolerar dosis de tóxicos que han demostrado ser letales para la mayoría de los individuos en una población normal de la misma especie.

Existen diferentes tipos de resistencia:

Resistencia simple: aquella en la que una población de una plaga puede tener un único mecanismo de resistencia.

Resistencia cruzada: puede ser positiva o negativa. La resistencia cruzada positiva ocurre cuando una plaga que desarrolla resistencia a un plaguicida adquiere un mecanismo de resistencia determinado, y este le puede conferir resistencia a otros plaguicidas, que puede que no se hayan aplicado nunca contra esa plaga. Monge (1986) define resistencia cruzada positiva como "la resistencia que se genera en los insectos a un determinado plaguicida y a otros que no se han aplicado, pero que tienen forma de acción o de detoxificación similares".

A veces, algunos mecanismos de resistencia pueden afectar a compuestos que pertenezcan a diferentes grupos químicos. Por ejemplo, tanto el DDT y los piretroides son afectados por el gen $\mathrm{kdr}$, que interfiere con el canal de sodio en las células nerviosas. Un uso intensivo de piretroides en una población, que ha tenido un problema anterior de resistencia con DDT, puede resultar en el desarrollo de la resistencia de la población a los piretroides (FAO, 2013). Otro ejemplo es la resistencia cruzada que existe entre carbamatos y organofosforados por la selección de la "acetilcolinesterasa insensible" (Bisset et al., 1990). 
Por otro lado, la resistencia cruzada negativa ocurre cuando al emplear un plaguicida y aumentar la resistencia a este en una determinada plaga, al mismo tiempo le confiere una mayor susceptibilidad a otro plaguicida.

Resistencia múltiple: este tipo de resistencia se da cuando dos o más mecanismos de resistencia están operando en el mismo insecto. Cuando dos mecanismos de resistencia actúan sobre un mismo insecticida, el nivel de resistencia es frecuentemente mucho mayor que la adición simple de los niveles de resistencia conferidos por ambos mecanismos de forma independiente. El término de resistencia múltiple no necesariamente implica el término de resistencia cruzada, debido a que un insecto puede ser resistente a dos o más insecticidas, y cada resistencia puede ser atribuida a diferentes mecanismos (Bisset, 2002). Un ejemplo sería el de Myzus persicae Sulzer (Hemiptera: Aphididae), que ha desarrollado resistencia a diferentes clases de insecticidas en los últimos 60 años (Bass et al., 2014), por medio de al menos siete mecanismos de resistencia diferentes.

\subsubsection{Factores que influyen en la resistencia}

Según la FAO (2013) son tres los grupos de factores que afectan el desarrollo de la resistencia a los insecticidas en una plaga: la composición genética de esta, su biología y los factores operacionales. Estos últimos incluyen las prácticas agrícolas y las características del insecticida y su aplicación. A continuación se detallan los factores que influyen dentro de cada grupo:

\section{Factores genéticos.}

- Aparición de genes de resistencia

- Número de mecanismos de resistencia

- Frecuencia de los genes de resistencia

- Predominio de los genes de resistencia

- Capacidad de adaptación de los individuos resistentes

- Protección aportada por los genes de resistencia

- Resistencia cruzada

- Selección pasada

- Genes reguladores 


\section{Factores biológicos.}

- Tamaño de la población

- Potencial reproductivo

- Tasa de generación

- Tipo de reproducción

- Dispersión

- Metabolismo de los insecticidas

- Número de sitios de acción del insecticida

- Rango de hospedantes de la plaga

\section{Factores operacionales.}

- Actividad del espectro del insecticida

- Dosis de aplicación del insecticida

- Cobertura de aplicación

- Regularidad

- Frecuencia del tratamiento

- Presencia de plagas secundarias

- Estadios de vida tratados con los insecticidas indicados

- Proporción de la población tratada

- Persistencia

- Número de cultivos tratados

- Secuencia de cultivos

- Tácticas de control de plagas

- Ningún efecto sobre el objeto de control (efecto o no sobre los enemigos naturales)

\subsubsection{Mecanismos implicados en la resistencia}

En la actualidad se conocen cuatro tipos diferentes de mecanismos que las plagas pueden desarrollar para llegar a ser resistentes a los insecticidas:

Resistencia por comportamiento: esta resistencia se da cuando los insectos evitan el contacto con el insecticida, ya sea por repulsión de las zonas tratadas o por abandono de estas zonas hacia zonas sin tratar. Este mecanismo no es muy importante, pero influye en la disminución de la efectividad del insecticida. Además, no confiere al insecto una resistencia real, ya que los individuos no llegan a estar en contacto con el insecticida, y tampoco genera unos niveles elevados de resistencia. 
Resistencia por penetración reducida: cuando los insectos son capaces de desarrollar una cutícula que impide o retarda la penetración del insecticida por contacto. Es un mecanismo que protege frente a varios insecticidas, pero no confiere elevados niveles de resistencia en los individuos.

Resistencia metabólica: es el mecanismo de resistencia más común entre los insectos y el causante de la mayoría de los casos de resistencia en las plagas agrícolas. Los insectos, así como otros animales, plantas y hongos, poseen enzimas de detoxificación que degradan cualquier tóxico al que puedan estar expuestos. Estas enzimas son capaces de metabolizar los insecticidas a productos no tóxicos y fácilmente excretables, con el fin de rebajar la dosis de insecticida a niveles subletales. Esta degradación por parte de las enzimas depende de la naturaleza química del insecticida, es decir, que afecta de igual manera a insecticidas con estructuras químicas similares, y por tanto, confiere resistencia a insecticidas con distinto modo de acción.

Existen estudios de detoxificación en insectos que demuestran que la versatilidad en la adaptación de los insectos a su medio se debe al fenómeno de inducción, proceso en el cual un estímulo químico impulsa la actividad del sistema de detoxificación mediante la producción de enzimas adicionales (Bisset, 2002).

Según Sotolongo et al. (1988), en el interior del organismo del insecto, el insecticida sufre una serie de reacciones mediante las cuales logra grupos funcionales que le permiten en una segunda fase, conjugarse con sustancias endógenas y originar compuestos más polares de menor solubilidad en lípidos y más fácilmente excretables. No siempre es necesario que el insecticida se transforme mediante reacciones de la primera fase, ya que en su estructura puede tener grupos funcionales que le permitan experimentar directamente las reacciones de la segunda fase.

Existen tres clases de enzimas de detoxificación: las P450 monooxigenasas (que metabolizan la materia activa del insecticida mediante oxidaciones), las esterasas (mediante hidrólisis) y las glutatión S-transferasas (mediante conjugaciones).

- P450 monooxigenasas. El complejo enzimático citocromo P450 monooxigenasa es el principal responsable del metabolismo oxidativo de los xenobióticos. Muestra una gran versatilidad funcional, debido a que es capaz de catalizar una gran variedad de procesos y metabolizar un elevado número de sustratos. Interviene en reacciones de oxidación, hidrólisis, hidratación y reducción (Conney, 1986; Okey, 1990). Este grupo de enzimas se caracteriza por tener su máxima absorción de luz a los $450 \mathrm{~nm}$, y por utilizar el NADPH para reducir el oxígeno molecular hasta agua, a la vez que incorpora un átomo de oxígeno al sustrato (Omura et al., 1964). Asimismo, estas enzimas están implicadas en muchos casos de resistencia metabólica, ya que detoxifican insecticidas organofosforados, piretroides y DDT entre otros (Casida, 1970). 
- Esterasas. Estas enzimas se encargan de romper los enlaces éster en alcoholes y ácidos por medio de una reacción de hidrólisis. Muchas de las enzimas esterasas pertenecen a la familia de las carboxilesterasas, las cuales son capaces de hidrolizar una gran variedad de sustratos con diferentes características químicas (Punta et al., 2012). Un amplio rango de insecticidas contienen enlaces éster, por lo que pueden ser hidrolizados por la actividad de las enzimas esterasas (Sogorb et al., 2002). Estas enzimas están implicadas en la degradación de carbamatos, organofosforados y piretroides (Terriere, 1984; Bisset, 2002). Mediante la acción de estas enzimas, el insecticida es degradado a productos más hidrosolubles y fáciles de excretar por el insecto.

- Glutatión S-transferasas. Son una familia de enzimas que catalizan la conjugación del glutatión endógeno a una variedad de compuestos electrofílicos, protegiendo las macromoléculas biológicas, como las proteínas y ácidos nucleicos, de las consecuencias tóxicas de una reacción covalente con el insecticida. Además, han sido implicadas en la detoxificación y biotransformación de muchos xenobióticos, incluidos varios carcinógenos y medicamentos. La conjugación incrementa la solubilidad del compuesto insecticida facilitando su excreción (Board et al., 1994). Estas enzimas se clasifican según la reacción que catalizan como alquil, aril y epoxitransferasas (Terriere, 1984). Las transferasas del glutation son importantes en la detoxificación de organofosforados y proporcionan la forma más importante de resistencia metabólica al DDT a través de la dehidroclorinación al DDE en insectos (Brattsten et al., 1986; Lalah et al., 1995).

Resistencia en el punto de acción: este mecanismo de resistencia es, después del metabólico, el más común en los insectos, y se produce cuando los insectos resistentes tienen alterado el sitio donde actúa el insecticida. De esta forma, se elimina o se reduce la acción del insecticida, dando lugar a niveles de resistencia muy elevados y resistencias cruzadas para otros insecticidas que actúen en el mismo punto de acción.

Cada insecticida tiene un sitio en el insecto donde actúa provocando su efecto plaguicida. Un insecto resistente tiene ese punto de acción alterado por una mutación genética, la cual impide el acoplamiento del insecticida y por tanto su efecto en el insecto. Cuando se da este tipo de mecanismo de resistencia en el insecto, se recomienda alternar insecticidas que tengan diferentes modos de acción (Bielza, 2010). 
Hay cuatro sitios de acción principales donde el insecticida actúa en el interior del insecto:

- Acetilcolinesterasa (AChE). La AChE modificada es menos eficiente al hidrolizar su sustrato que una enzima normal, por lo que la alteración en los sitios activos provoca una disminución en la reactividad con el inhibidor. Los estudios de inhibición indican que el acceso a los centros catalíticos de la enzima modificada es restringido por un cambio en su conformación (Voss et al., 1965; Smissaert et al., 1970). Cambios en este sitio de acción producen un amplio espectro de resistencia a la mayoría de los organofosforados y carbamatos (Bisset, 2002). Por ejemplo, es el mecanismo de resistencia de pirimicarb en Phorodon humuli (Schrank) (Hemiptera: Aphididae) y en M. persicae, y es responsable de la resistencia en Tetranychus urticae Koch (Prostigmata: Tetranychidae) (FAO, 2013).

- Canal de sodio en las células nerviosas. Los canales de sodio dependientes de potencial son proteínas transmembranales que permiten el paso de iones sodio a través de la membrana celular, y están implicados en la propagación de potenciales de acción a lo largo de los axones nerviosos. Una alteración en los canales de sodio de las células nerviosas de los insectos da lugar a una reducida sensibilidad en el sistema nervioso de estos. Este tipo de resistencia se le conoce como resistencia de choque o knockdown (Bisset, 2002). Este es un mecanismo común en la resistencia al DDT y a los piretroides, y se ha detectado en múltiples plagas de insectos, como en $M$. persicae, y también en Anopheles gambiae (Giles) (Diptera: Culicidae) y Blattella germanica Linnaeus (Blattodea: Blattellidae) (FAO, 2013).

- Receptores GABA (Ácido Amino Butírico). El GABA es el principal neurotransmisor inhibitorio en el sistema nervioso de insectos, y actúa a través de un receptor formando un complejo macromolecular con sitios de unión al GABA y a otras sustancias. Este complejo forma un canal en la membrana celular, en donde al unirse el GABA al receptor, fluye una corriente de iones cloro modificando el potencial eléctrico de las células. Estos receptores son también el punto de unión de algunos insecticidas derivados del ciclodieno, los cuales impiden el funcionamiento normal del GABA (French-Constant et al., 1993).

- Receptor nicotínico de la acetilcolina (nAChR). Los receptores nicotínicos de acetilcolina son proteínas receptoras que responden al neurotransmisor acetilcolina. Se localizan en el sistema nervioso central y periférico, el músculo y otros tejidos de muchos organismos, incluidos los humanos. En la unión neuromuscular, son el receptor primario en el músculo para la comunicación motora-nerviosa que controla la contracción muscular. En el sistema nervioso periférico, transmiten señales salientes desde el presináptico a las células postsinápticas dentro del sistema nervioso simpático y parasimpático, y son los receptores del músculo esquelético que reciben la liberación de acetilcolina para señalar la contracción muscular (Lu et al., 2014). En insectos, el sistema colinérgico se limita al sistema nervioso central (Yamamoto, 1999). 
Se han descrito mutaciones en este receptor que confieren resistencia a neonicotinoides en $M$. persicae (Bass et al., 2014) y a spinosad en Frankliniella occidentalis (Pergande) (Thysanoptera: Thripidae) (Bielza, 2008).

\subsection{Resistencia de T. absoluta a insecticidas}

Debido al elevado potencial reproductivo de T. absoluta, y su capacidad para completar un ciclo generacional en apenas un mes si las condiciones ambientales son favorables, le convierte en una plaga muy proclive a desarrollar resistencia a los insecticidas empleados para su control. Además, este riesgo de desarrollo de resistencia se incrementa cuando el manejo se realiza mediante control químico casi exclusivamente y empleando un número limitado de insecticidas, aumentando por tanto la presión de selección sobre la plaga.

En los últimos 20 años, diferentes autores han estudiado la resistencia a piretroides, organofosforados, abamectina, cartap e insecticidas reguladores del crecimiento en poblaciones sudamericanas y europeas de T. absoluta (Salazar et al., 1997; Siqueira et al., 2000a, 2000b; Salazar et al., 2001; Siqueira et al., 2001; Lietti et al., 2005; Silva et al., 2011; Haddi et al., 2012; Campos et al., 2014; Silva et al., 2015; Haddi et al., 2017).

En el año 2016, se encontraron los primeros casos de poblaciones de $T$. absoluta que presentaban una moderada resistencia a emamectina benzoato (Roditakis et al., 2017b). En este trabajo se bioensayaron poblaciones griegas e italianas 16 y 35 veces, respectivamente, más resistentes que sus poblaciones susceptibles de referencia.

Por otro lado, se han encontrado poblaciones europeas de $T$. absoluta con valores moderados de resistencia a metaflumizona (Roditakis et al., 2013a; Karaağaç, 2015). Asimismo, Yalçin et al. (2015) encontraron poblaciones de campo procedentes de Turquía muy resistentes a metaflumizona, y en 2017, Roditakis et al. (2017a) mostraron resultados de una población de campo griega que presentaba una elevada resistencia a metaflumizona, siendo 17 veces más resistente que su población susceptible.

Con respecto a la resistencia de T. absoluta a indoxacarb, en 2011 aparecieron los primeros casos de poblaciones brasileñas de $T$. absoluta con moderados niveles de resistencia a indoxacarb, siendo 28 veces más resistentes que su población susceptible de referencia (Silva et al., 2011). En 2013 se encontraron poblaciones griegas ligeramente resistentes a indoxacarb, con una variabilidad de 10,1 (Roditakis et al., 2013a), y poblaciones italianas moderadamente resistentes, con una variabilidad de 11,6 (Roditakis et al., 2013b). A partir del año 2015, comenzaron a aparecer poblaciones de $T$. absoluta que presentaban una elevada resistencia a indoxacarb. Por ejemplo, Yalçin et al. (2015) encontraron poblaciones de campo de $T$. absoluta procedentes de Turquía con elevada resistencia a indoxacarb, y una variabilidad de 8 veces entre la población más resistente y la más susceptible. Por otro lado, en 2017 se publicaron resultados de poblaciones griegas ligeramente resistentes a indoxacarb, con una variabilidad de 23 veces entre poblaciones (Roditakis et al., 2017a). 
Existen varios trabajos sobre la resistencia a spinosad en T. absoluta. Silva et al. (2011) publicaron los primeros datos sobre poblaciones brasileñas ligeramente resistentes a spinosad, con una variabilidad de casi 5 veces entre la población más susceptible y la más resistente. También en 2012, se publicaron datos sobre poblaciones turcas que presentaban cierta resistencia a spinosad, con una variabilidad de 5 entre poblaciones (Dağli et al., 2012). Sin embargo, en el año 2016 aparecen poblaciones de T. absoluta bastantes resistentes a spinosad. Silva et al. (2016b) encontraron poblaciones brasileñas resistentes a spinosad, que presentaban una variabilidad de 294 veces entre la población más susceptible y la más resistente. Mientras que Berger et al. (2016) encontraron poblaciones de campo procedentes de distintos países (España, Italia, Brasil y Portugal) ligeramente resistentes a spinosad y con una variabilidad entre poblaciones de 8 veces.

En los últimos años han aparecido poblaciones de $T$. absoluta con elevada resistencia a los insecticidas diamidas clorantraniliprol y flubendiamida. Roditakis et al. (2015) encontraron poblaciones griegas ligeramente resistentes a clorantraniliprol y flubendiamida, y poblaciones italianas que presentaban una elevada resistencia a clorantraniliprol (hasta una variabilidad de más de 2000 con respecto a su población susceptible) y a flubendiamida (con una variabilidad de 1700 veces). Igualmente en 2015, se publicaron resultados sobre poblaciones turcas de $T$. absoluta con cierta resistencia a clorantraniliprol (Karaağaç, 2015; Yalçin et al., 2015).

En 2016, Silva et al. (2016a) hallaron poblaciones brasileñas con elevados niveles de resistencia a clorantraniliprol (con una variabilidad de 315500 veces con respecto a su población susceptible), y a flubendiamida (con una variabilidad de casi 80000 veces). En 2017, Roditakis et al. (2017a) mostraron resultados de una población de $T$. absoluta procedente de Grecia resistente a clorantraniliprol, con una variabilidad de 519 veces con respecto a su población susceptible de referencia.

Con respecto a la diamida ciantraniliprol, hasta la fecha se ha detectado resistencia en poblaciones brasileñas de $T$. absoluta, que presentaban una variabilidad de 18700 veces con respecto a su población sensible (Silva et al., 2016a). 


\subsection{Referencias bibliográficas}

Aboul-Enein, A.M., Aboul-Soud, M.A.M., Said, H.K., Ali, H.F.M., Ali, Z.Y., Mahdi, A.M., Giesy, J.P. (2012). Hepatoprotective effects of antioxidants against non-target toxicity of the bioinsecticide spinosad in rats. Afr J of Pharm Pharmaco 6 (8): 550-559.

Akiyoshi, F., Wagner, V., Picanço, M., Foster, J. (2004). Genetic divergence among tomato leaf miner populations based on AFLP analysis. Pesq Agropec Bras 39: 645-651.

Apablaza, J. (1992). La polilla del tomate y su manejo. Tattersal 79: 12-13.

Araújo Gonçalves, A. (2010). Alverde ${ }^{\circledR}$ : la solución BASF para el control de Tuta absoluta. PHYTOMA España 217: 21-22.

Arce, C.C.M., Machado, R.A.R., Ribas, N.S., Cristaldo, P.F., Ataíde, L.M.S., Pallini, A., Carmo, F.M., Freitas, L.G., Lima, E. (2017). Nematode Root Herbivory in Tomato Increases Leaf Defenses and Reduces Leaf Miner Oviposition and Performance. J Chem Ecol 43: 120-128.

Arnó, J., Castañé, C., Riudavets, J., Gabarra, R. (2010). Risk of damage to tomato crops by the generalist zoophytophagous predator Nesidiocoris tenuis (Reuter) (Hemiptera: Miridae). $B$ Entomol Res 100: 105-115.

Arnó, J., Sorribas, R., Prat, M., Matas, M., Pozo, C., Rodríguez, D., Garreta, A., Gómez, A., Gabarra, R. (2009). Tuta absoluta, a new pest in IPM tomatoes in the northeast of Spain. IOBC/WPRS Bull 49: 203-208.

Barrientos, Z.R., Apablaza, H.J., Norero, S.A., Estay, P.P. (1998). Temperatura base y constante térmica de desarrollo de la polilla del tomate, Tuta absoluta (Lepidoptera: Gelechiidae). Ciencia e Investigación Agraria 25 (3): 133-137.

Barry, J.D., Portillo, H.E., Annan, I.B., Cameron, R.A., Clagg, D.G., Dietrich, R.F., Watson, L.J., Leighty, R.M., Ryan, D.L., McMillan, J.A., Swain, R.S., Kaczmarczyk, R.A. (2015). Movement of cyantraniliprole in plants after foliar applications and its impact on the control of sucking and chewing insects. Pest Manag Sci 71: 395-403.

Bass, C., Puinean, A.M., Zimmer, C.T., Denholm, I., Field, L.M., Foster, S.P., Gutbrod, O., Nauen, R., Slater, R., Williamson, M.S. (2014). The evolution of insecticide resistance in the peach potato aphid, Myzus persicae. Insect Biochem Molec 51: 41-51.

Batalla-Carrera, L., Morton, A., García-del-Pino, F. (2010). Efficacy of entomopathogenic nematodes against the tomato leafminer Tuta absoluta in laboratory and greenhouse conditions. BioControl 55: 523-530.

Beeman, R.W. (1982). Recent advances in mode of action of insecticides. Annu Rev Entomol 27: $253-281$. 
Berger, M., Puinean, A.M., Randall, E., Zimmer, C., Silva, W.M., Bielza, P., Field, L.M., Hughes, D., Mellor, I., Hassani-Pak, K., Siqueira, H.A.A., Williamson, M.S., Bass, C. (2016). Insecticide resistance mediated by an exon skipping event. Mol Ecol 25: 5692-5704.

Betancourt, C., Scatoni, I., Rodríguez, J. (1996). Influencia de la temperatura sobre la reproducción y el desarrollo de Scrobipalpula absoluta (Meyrick) (Lepidoptera: Gelechiidae). Rev Brasil Biol 56 (4): 661-670.

Bielza, P. (2008). Perspective Insecticide resistance management strategies against the western flower thrips, Frankliniella occidentalis. Pest Manag Sci 64: 1131-1138.

Bielza, P. (2010). La resistencia a insecticidas en Tuta absoluta (Meyrick). PHYTOMA España 217: 103-106.

Biondi, A., Desneux, N., Siscaro, G., Zappalà, L. (2012). Using organic-certified rather than synthetic pesticides may not be safer for biological control agents: selectivity and side effects of 14 pesticides on the predator Orius laevigatus. Chemosphere 87: 803-812.

Biondi, A., Zappalà, L., Stark, J.D., Desneux, N. (2013). Do biopesticides affect the demographic traits of a parasitoid wasp and its biocontrol services through sublethal effects? PLOS ONE 8: e76548.

Bisset, J. (2002). Uso correcto de insecticidas: control de la resistencia. Rev Cubana Med Trop 54 (3): 202-219.

Bisset, J.A., Rodríguez, M.M., Díaz, C., Ortiz, E., Marquetti, M.C., Hemingway, J. (1990). The mechanisms of organophosphate and carbamate resistance in Culex quinquefasciatus (Diptera: Culicidae) from Cuba. B Entomol Res 80: 245-50.

Biurrun, R. (2008). Tuta absoluta. La polilla del tomate. Navarra Agraria. En línea: http://www.itga.com/docs/publicaciones/plagas/tuta.pdf.

Board, P., Russell, R.J., Marano, R.J., Oakeshott, J.G. (1994). Purification, molecular cloning and heterologous expression of a glutathione s-transferase from Australian sheep blowfly (Lucilia cuprina). Biochem J 299: 425-30.

Brambila, J., Lee, S., Passoa, S., Straten, M. (2010). Tuta absoluta. The Tomato Leafminer, Field Screeniing AID, Cooperative Agricultural Pest Survey Program (CAPS). En línea: http://caps.ceris.purdue.edu/screening/tuta_absoluta.

Brattsten, L.B., Holyoke, C.V., Leeper, J.R., Raffa, K.F. (1986). Insecticide resistance: challenge to pest management and Basic Research. Science 2: 1255-1260.

Brown, A.W.A., Pal, K. (1971). Insecticide resistance in arthropods. En: World Health Organization Monograph, Series № 38. Geneva, World Health Organization, pp. 491.

Bultman, T. L., Faeth, S. H. (1986). Effect of Mithin Meaf Mensity and Leaf Size on Pupal Weight of a Leaf Miner, Cameraria (Lepidoptera: Gracillariidae). Southwest Nat 31: 201-206. 
Cabello, T., Gallego, J.R., Fernandez, F.J., Gamez, M., Vila, E., Del Pino, M., Hernandez, E. (2012). Biological control strategies for the South American tomato moth (Lepidoptera: Gelechiidae) in greenhouse tomatoes. J Econ Entomol 105: 2085-2096.

Cáceres, S. (2007). Manejo de la polilla del tomate en Corrientes. Instituto Nacional de Tecnología Agropecuaria (INTA). Secretaría de Agricultura, Ganadería, Pesca y Alimentación. Estación Experimental Agropecuaria Bella Vista. Hoja de divulgación № 32. En línea: http://www.inta.gov.ar/bellavista/info/documentos/hortalizas/HD32-

Polilla\%20del\%20tomate.pdf.

Calvo, F.J., Bolckmans, K., Belda, J.E. (2012a). Release rate for a pre-plant application of Nesidiocoris tenuis for Bemisia tabaci control in tomato. BioControl 57: 809-817.

Calvo, F.J., Lorente, M.J., Stansly, P.A., Belda, J.E. (2012b). Preplant release of Nesidiocoris tenuis and supplementary tactics for control of Tuta absoluta and Bemisa tabaci in greenhouse tomato. Entomol Exp App/ 143: 111-119.

Calvo, F.J., Soriano, J.D., Bolckmans, K., Belda, J.E. (2013). Host instar suitability and life-history parameters under different temperature regimes of Necremnus artynes on Tuta absoluta. Biocontrol Sci Techn 23 (7): 803-815.

Campos, M.R., Rodrigues, A.R.S., Silva, W.M., Silva, T.B.M., Silva, V.R.F., Guedes, R.N.C., Siqueira, H.A.A. (2014). Spinosad and the Tomato Borer Tuta absoluta: A Bioinsecticide, an Invasive Pest Threat, and High Insecticide Resistance. PLoS One 9: e103235.

Campos, R.G. (1976). Control químico del "minador de hojas y tallos de la papa" (Scrobipalpula absoluta Meyrick) en el valle del Cañete. Rev Per Entomol 19: 102-106.

Casida, J.E. (1970). Mixed-function oxidase involvement in the biochemistry of insecticide sinergists. J Agric Food Chem 18 (5): 753-772.

Cifuentes, D., Chynoweth, R., Bielza, P. (2011). Genetic study of Mediterranean and South American populations of tomato leafminer Tuta absoluta (Povolny, 1994) (Lepidoptera: Gelechiidae) using ribosomal and mitochondrial markers. Pest Manag Sci 67: 1155-1162.

Coelho, M.C.F., França, F.H. (1987). Biologia, quetotaxia de larva e descriçao da pupa e adulto da traça-do-tomateiro. Pesquisa Agropecuária Brasileira 22 (2): 129-135.

Conney, A.H. (1986). Induction of microsomal cytochrome P-450 enzymes. Life Sci 39: 24932518.

Contreras, J., Mendoza, J.E., Martínez-Aguirre, M.R., García-Vidal, L., Izquierdo, J.I., Bielza, P. (2014). Efficacy of Enthomopathogenic Fungus Metarhizium anisopliae Against Tuta absoluta (Lepidoptera: Gelechiidae). J Econ Entomol 107 (1): 121-124.

Dağli, F., Ikten, C., Sert, E., Bölücek, E. (2012). Susceptibility of tomato borer, Tuta absoluta (Meyrick) (Lepidoptera: Gelechiidae) populations from Turkey to 7 different insecticides in laboratory bioassay. Bulletin OEPP/EPPO Bulletin 42 (2): 305-311. 
Desneux, N., Luna, M.G., Guillemaud, T., Urbaneja, A. (2011). The invasive South American tomato pinworm, Tuta absoluta, continues to spread in Afro-Eurasia and beyond: the new threat to tomato world production. J Pest Sci 84: 403-408.

Desneux, N., Wajnberg, E., Wyckhuys, K.A.G., Burgio, G., Arpaia, S., Narváez-Vasquez, C.A., González-Cabrera, J., Catalán Ruescas, D., Tabone, E., Frandon, J., Pizzol, J., Poncet, C., Cabello, T., Urbaneja, A. (2010). Biological invasion of European tomato crops by Tuta absoluta: ecology, geographic expansion and prospects for biological control. J Pest Sci 83: 197-215.

DuPont. (2017). DuPont ${ }^{\mathrm{TM}}$ Coragen $^{\circledR}$ control de insectos. Boletín Técnico. Ed. DuPont Ibérica, S.L. Protección de Cultivos, pp. 7.

EPPO. (2005). European and Mediterranean Plant Protection Organization. Tuta absoluta. Data sheets on quarantine pests. EPPO Bull 35: 434-435.

EPPO. (2009). European and Mediterranean Plant Protection Organization. EPPO Reporting Service № 8. En línea: http://archives.eppo.org.

EPPO. (2017). European and Mediterranean Plant Protection Organization. EPPO Global Database. En línea: https://gd.eppo.int (consultado: 27 de julio de 2017).

Estay, P. (2000). Polilla del tomate Tuta absoluta (Meyrick). Informativo La Platina 9: 1-4.

Estay, P., Bruna, A. (2002). Insectos y ácaros asociados al tomate en Chile. En: Estay, P., Bruna, A. (Eds.). Centro regional de Investigación INIA La Platina. Santiago, Chile, pp. 173.

FAO. (2013). Directrices sobre la Prevención y Manejo de la Resistencia a los Plaguicidas. En línea:

http://www.fao.org/fileadmin/templates/agphome/documents/Pests_Pesticides/Code/FAO_R MG_SP.pdf (consultado: 23 de septiembre de 2017).

Fernández, S., Montagne, A. (1990). Biología del minador del tomate Scrobipalpula absoluta (Meyrick) (Lepidoptera: Gelechiidae). Bol Entomol 5: 89-99.

Flores, L.V., Gilardón, E., Gardenal, C.N. (2003). Genetic structure of populations of Tuta absoluta Meyrick (Lepidoptera: Gelechiidae). J Basic Appl Genet 15: 29-32.

French-Constant, R.H., Rocheleau, J.C., Steichen, T.A., Chalmers, A.E. (1993). A point mutation in a Drosophila GABA receptor confers insecticide resistance. Nature 363: 449-451.

Fuertes, E. (2017). Herencia de resistencia a ciantraniliprol en Tuta absoluta (Lepidoptera: Gelechiidae). Trabajo Fin de Grado, Universidad Politécnica de Cartagena, pp. 10.

Fu-Gen, L., Guo-Min, A., Dong-Yun, Z., Ying, J., Bao-Gen, G., Xi-Wu, G. (2014). Characterization of Activation Metabolism Activity of Indoxacarb in Insects by Liquid Chromatography-Triple Quadrupole Mass Spectrometry. Chin J Anal Chem 42 (4): 463-468. 
Gabarra, R., Arnó, J., Riudavets, J. (2008). Tomate. En: Jacas, J.A., Urbaneja, A. (Eds.). Control biológico de plagas agrícolas. Ed. Phytoma-España, Valencia, España, pp. 496.

García, M.F., Espul, J.C. (1982). Bioecología de la polilla del tomate (Scrobipalpula absoluta) en Mendoza, República Argentina. Revista de Investigaciones Agropecuarias 17: 135-146.

Garcia-del-Pino, F., Alabern, X., Morton, A. (2011). Efficacy of entomopathogenic nematodes against the larvae and adults of the tomato leafminer Tuta absoluta in soil treatments and their compatibility with the insecticides used against this insect. IOBC/WPRS Bull 66: 267-270.

Garcia-Marí, F., Vercher, R. (2010). Descripción, origen y expansión de Tuta absoluta (Lepidoptera: Gelechiidae). PHYTOMA España 217: 16-20.

García-Vidal, L. (2011). Susceptibilidad base de poblaciones europeas de Tuta absoluta (Lepidoptera: Gelechiidae) a spinosad e indoxacarb. Trabajo Fin de Máster, Universidad Politécnica de Cartagena, pp. 60.

Garnas, J.R., Auger-Rozenberg, M.A., Roques, A., Bertelsmeier, C., Wingfield, M.J., Saccaggi, D.L., Roy, H.E., Slippers, B. (2016). Complex patterns of global spread in invasive insects: ecoevolutionary and management consequences. Biol Invasions 18: 935-952.

Gerling, D., Alomar, O., Arnó, J. (2001). Biological control of Bemisia tabaci using predators and parasitoids. Crop Prot 20: 779-799.

Ghoneim, K. (2014). Parasitic insects and mites as potential biocontrol agents for a devastive pest of tomato, Tuta absoluta Meyrick (Lepidoptera: Gelechiidae) in the world: a review. Int J Res Rev Appl Sci 19 (1): 36-68.

González-Cabrera, J., Mollá, O., Montón, H., Urbaneja, A. (2011). Efficacy of Bacillus thuringiensis (Berliner) for controlling the tomato borer, Tuta absoluta (Meyrick) (Lepidoptera: Gelechiidae). Biocontrol 56: 71-80.

Guillemaud, T., Blin, A., Le Goff, I., Desneux, N., Reyes, M., Tabone, E., Tsagkarakou, A., Niño, L., Lombaert, E. (2015). The tomato borer, Tuta absoluta, invading the Mediterranean Basin, originates from a single introduction from Central Chile. Sci Rep 5: 8371.

Haddi, K., Berger, M., Bielza, P., Cifuentes, D., Field, L.M., Gorman, K., Rapisarda, C., Williamson, M.S., Bass, C. (2012). Identification of mutations associated with pyrethroid resistance in the voltage-gated sodium channel of the tomato leaf miner (Tuta absoluta). Insect Biochem Molec 42: 506-513.

Haddi, K., Berger, M., Bielza, P., Rapisarda, C., Williamson, M.S., Moores, G., Bass, C. (2017). Mutation in the ace-1 gene of the tomato leaf miner (Tuta absoluta) associated with organophosphates resistance. J Appl Entomol 141 (8): 612-619.

Haji, F.N.P. (1997). Controle biológico da traca do tomateiro com Trichogramma no Nordeste do Brasil. En: Postali, J.R., Zucchi, R.A. (Eds.). Trichogramma e o controle biológico aplicado FEALQ, Piracicaba, Brasil, pp. 319-324. 
Hickel, E.R., Vilela, E.F. (1991). Comportamento de chamamento e aspectos do comportamento de acasalamento de Scrobipalpula absoluta (Lep., Gelechiidae), sob condicoes de campo. Ann Soc Entomol Bras 20: 173-182.

Ingegno, B.L., Candian, V., Psomadelis, I., Bodino, N., Tavella, L. (2017). The potential of host plants for biological control of Tuta absoluta by the predator Dicyphus errans. B Entomol Res 107: 340-348.

IRAC. (2014). Clasificación del modo de acción de insecticidas y acaricidas (Versión 7.3) (2014). En línea: http://www.irac-online.org.

IRAC. (2016). Mode of Action Classification Scheme (Version 8.1) (2016). En línea: http://www.irac-online.org.

JA. (2010). Polilla del Tomate (Tuta absoluta). Junta de Andalucía. Consejería de Agricultura y Pesca. Dirección General de la Producción Agrícola y Ganadera. Red de Alerta e Información Fitosanitaria. En línea:

http://www.juntadeandalucia.es/agriculturaypesca/raif/Ayudas/Tomate/TutaAbsoluta.pdf.

Karaağaç, S.U. (2015). Enzyme Activities and Analysis of Susceptibility Levels in Turkish Tuta absoluta Populations to Chlorantraniliprole and Metaflumizone Insecticides. Phytoparasitica 43: 693-700.

Keller, R.P., Geist, J., Jeschke, J.M., Kühn, I. (2011). Invasive species in Europe: ecology, status, and policy. Environ Sci Eur 23: 23.

Klieber, J., Reineke, A. (2016). The entomopathogen Beauveria bassiana has epiphytic and endophytic activity against the tomato leaf miner Tuta absoluta. J Appl Entomol 140: 580-589.

Lahm, G.P., Cordova, D., Barry, J.D. (2009). New and selective ryanodine receptor activators for insect control. Bioorgan Med Chem 17: 4127-4133.

Lahm, G.P., Selby, T.P., Freudenberger, J.H., Stevenson, T.M., Myers, B.J., Seburyamo, G., Smith, B.K., Flexner, L., Clark, C.E., Cordova, D. (2005). Insecticidal anthranilic diamides: a new class of potent ryanodine receptor activators. Bioorg Med Chem Lett 15: 4898-4906.

Lahm, G.P., Stevenson, T.M., Selby, T.P., Freudenberger, J.H., Cordova, D., Flexner, L., Bellin, C.A., Dubas, C.M., Smith, B.K., Hughes, K.A., Hollingshaus, J.G., Clark, C.E., Benner, E.A. (2007). Rynaxypyr: a new insecticidal anthranilic diamide that acts as a potent and selective ryanodine receptor activator. Bioorg Med Chem Lett 17: 6274-6279.

Lalah, J.O., Chien, C.I., Motoyama, N., Dauterman, W.C. (1995). Glutathione S-transferases: alpha-naphthyl acetate activity and possible role in insecticide resistance. J Econ Entomol 88: 768-770.

Larraín, P. (1992). Plagas en cultivos bajo plástico. IPA La Platina 73: 41-52. 
Larraín, P. (2011). Descripción, ciclo biológico, hospederos y aspectos etológicos de Tuta absoluta. En: Taller Regional para la vigilancia fitosanitaria de la palomilla del tomate (Tuta absoluta). Centro Nacional de Referencia Fitosanitaria SENASICA-SAGARPA OIRSA México. Mazatlán, Sinaloa, México.

Leite, G.L.D., Picanço, M.C., Silva, D.J.H., Mata, A.C., Jham, G.N. (1995). Distribuição de oviposição de Scrobipalpuloides absoluta no dosel de Lycopersicon esculentum, L. hirsutum e $L$. peruvianum. Horticultura Brasileira 13: 47-51.

Lietti, M.M.M., Botto, E., Alzogaray, R.A. (2005). Insecticide resistance in Argentine populations of Tuta absoluta (Meyrick) (Lepidoptera: Gelechiidae). Neotrop Entomol 34: 113-119.

López, E. (1991). Polilla del tomate: Problema crítico para la rentabilidad del cultivo de verano. Empresa y Avance Agrícola 1: 6-7.

López, J.M., Metín, L., López, A., Correia, R., González, F., Sanz, E., Gallardo, M., Cantus, J.M. (2010). AFFIRM (Emamectina), una nueva arma contra la Tuta absoluta y otras orugas de lepidópteros. PHYTOMA España 217: 90-94.

López, N.S. (2010). Aspectos biológicos de Tuta absoluta (Lepidoptera: Gelechiidae). En: Memorias del Curso Taller Sobre la Palomilla del Tomate (Tuta absoluta). Camayagua, Honduras.

López, P. (2003). Manejo integrado de Tuta absoluta (Meyrick) (Lepidoptera: Gelechiidae) asociado al cultivo de tomate en Chile. Departamento de Agricultura del Desierto, Universidad Arturo Prat, Seminario, Ing. Ejec. Agrícola. Iquique, Chile, p. 77.

Lu, B., Kwan, K., Levine, Y.A., Olofsson, P.S., Yang, H., Li, J., Joshi, S., Wang, H., Andersson, U., Chavan, S.S., Tracey, K.J. (2014). $\alpha 7$ nicotinic acetylcholine receptor signaling inhibits inflammasome activation by preventing mitochondrial DNA release. Mol Med 20: 350-358.

Mauchamp, B., Perrineau, O. (1987). Chitin biosynthesis after treatment with benzoylphenyl ureas. En: Wright, J. E., Retnakaran, A. (Eds.). Chitin and benzoylphenyl ureas. Ed. Dr. Junk. Pub. The Netherlands, pp. 101-109.

Mollá, O., Alonso, M., Beitia, F.J., González-Cabrera, J., Urbaneja, A. (2011a). Enemigos naturales de Tuta absoluta y su utilización en programas de control biológico. Vida Rural № 326. En línea: http://www.agronline.es/hemeroteca-articulos-enemigos-naturales-tutaabsoluta-y-utilizacion-programas-control-biologico/1/1639.html.

Mollá, O., González-Cabrera, J., Urbaneja, A. (2011b). The combined use of Bacillus thuringiensis and Nesidiocoris tenuis against the tomato borer Tuta absoluta. BioControl 56: 883-891.

Monge, L.A. (1986). Manejo Racional de Insecticidas. Resistencia y rotación. Ed. Editorial tecnológica de Costa Rica. Cartago, Costa Rica, pp. 74. 
Monserrat, A. (2009). La palomilla del tomate "Tuta absoluta" en la región de Murcia: bases para su control. Ed. Consejería de Agricultura y Agua, Murcia, España, pp. 112.

Monserrat, A. (2010). Estrategias globales en el manejo de Tuta absoluta en Murcia. PHYTOMA España 217: 81-86.

Monserrat, A. (2016). Estrategias fitosanitarias en tomate. Ed. Comunidad Autónoma de la Región de Murcia, Instituto Murciano de Investigación y Desarrollo Agrario y Alimentario (IMIDA), pp. 253.

NAPPO. (2013). Protocolo de vigilancia para el minador de la hoja del tomate, Tuta absoluta, para los países miembros de la NAPPO. North American Plant Protection Organization (NAPPO). En línea: http://www.nappo.org.

Nayana, B.P., Kalleshwaraswamy, C.M. (2015). Biology and external morphology of invasive tomato leaf miner, Tuta absoluta (Meyrick) (Lepidoptera: Gelechiidae). Pest Management in Horticultural Ecosystems 21 (2): 169-174.

Notz, A. (1992). Minador pequeño de la hoja del tomate; Palomilla pequeña; Minador del tomate Tuta absoluta (Meyrick) 1917. Plagas Agrícolas de Venezuela. Artrópodos y vertebrados. Sociedad Venezolana de Entomología. Fichas técnicas de organismos plaga. En línea: http://www.miza-ucv.org.ve/plagasagricolas/fichas/ficha. php?hospedero=326\&plaga $=225$.

Okey, A.B. (1990). Enzyme induction in the cytochrome P-450 system. Pharm Ther 45: 241-298.

Omura, T., Sato, R. (1964). The carbon monoxide-binding pigment of liver microsomes: II. Solubilization, purification and properties. J Biol Chem 239: 2379-2385.

Pereyra, P. (2002). Evidencia de competencia intraespecífica en estadios larvales tempranos de la polilla del tomate, Tuta absoluta (Lepidoptera: Gelechiidae). Ecología Austral 12 (2): 143148.

Potting, R. (2009). Pest risk analysis, Tuta absoluta, tomato leaf miner moth. Plant protection service of the Netherlands, pp. 24. En línea: www.minlnv.nl.

Punta, M., Coggill, P.C., Eberhardt, R.Y., Mistry, J., Tate, J., Boursnell, C., Pang, N., Forslund, K., Ceric, G., Clements, J., Heger, A., Holm, L., Sonnhammer, E.L.L., Eddy, S.R., Bateman, A., Finn, R.D. (2012). The Pfam protein families databases. Nucleic Acids Res 40: D290-D301.

Quiroz, C. (1976). Nuevos antecedentes sobre la biología de la polilla del tomate, Scrobipalpula absoluta (Meyrick). Programa Hortalizas. Subprograma de Entomología, Estación Experimental la Platina, Instituto de Investigaciones Agropecuarias (INIA). Agricultura Técnica (Chile) 36: 8286. 
Ramos, C. (2015). Manual para la identificación de Tuta absoluta (Meyrick) Lepidóptera: Gelechiidae mediante el procedimiento de extracción y montaje de la genitalia. Organismo Internacional Regional de Sanidad Agropecuaria. En línea: https://www.oirsa.org.

Ramos, C., Juárez, M. (2011): Protocolo de identificación de la polilla del tomate (Tuta absoluta Meyrick) Lepidóptera: Gelechiidae. Programa Fitosanitario Regional de Apoyo a la Cadena de Solanáceas. Ed. Organismo Internacional Regional de Sanidad Agropecuaria (OIRSA), pp. 10.

Roditakis, E., Mavridis, K., Riga, M., Vasakis, E., Morou, E., Rison, J.L., Vontas, J. (2017a). Identification and detection of indoxacarb resistance mutations in the para sodium channel of the tomato leafminer, Tuta absoluta. Pest Manag Sci doi: 10.1002/ps.4513.

Roditakis, E., Skarmoutsou, C., Staurakaki, M. (2013a). Toxicity of insecticides to populations of tomato borer Tuta absoluta (Meyrick) from Greece. Pest Manag Sci 69: 834-840.

Roditakis, E., Skarmoutsou, C., Staurakaki, M., Martínez-Aguirre, M.R., García-Vidal, L., Bielza, P., Haddi, K., Rapisarda, C., Rison, J-L., Bassi, A., Teixeira, L.A. (2013b). Determination of baseline susceptibility of European populations of Tuta absoluta (Meyrick) to indoxacarb and cholorantraniliprole using a novel dip bioassay method. Pest Manag Sci 69: 217-227.

Roditakis, E., Vasakis, E., García-Vidal, L., Martínez-Aguirre, M.R., Rison, J.L., Haxaire-Lutun, M.O., Nauen, R., Tsagkarakou, A., Bielza, P. (2017b). A four-year survey on insecticide resistance and likelihood of chemical control failure for tomato leaf miner Tuta absoluta in the European/Asian región. J Pest Sci doi: 10.1007/s10340-017-0900-x.

Roditakis, E., Vasakis, E., Grispou, M., Stavrakaki, M., Nauen, R., Gravouil, M., Bassi, A. (2015). First report of Tuta absoluta resistance to diamide insecticides. J Pest Sci 88: 9-16.

Salazar, E.R., Araya, J.E. (1997). Detection of insecticide resistance in the tomato moth. Simiente 67: 8-22.

Salazar, E.R., Araya, J.E. (2001). Respuesta de la polilla del tomate, Tuta absoluta (Meyrick), a insecticidas en Arica. Agric Tech 61: 429-435.

Salvo, A., Valladares G.R. (2007). Leafminer parasitoids and pest management. Ciencia $e$ Investigación Agraria 34 (3): 125-142.

Sanchez, J.A., La Spina, M., Lacasa, A. (2014). Numerical response of Nesidiocoris tenuis (Hemiptera: Miridae) preying on Tuta absoluta (Lepidoptera: Gelechiidae) in tomato crops. Eur J Entomol 111 (3): 387-395.

Santos, B., Perera, S. (2010). Medidas de control de la Palomilla del tomate (Tuta absoluta). Cabildo Tenerife. Servicio Técnico y Desarrollo Rural Área de Aguas y Agricultura. En línea: http://www.agrocabildo.com/publica/Publicaciones/toma_266_L_hdtuta.pdf. 
Segovia, M. (1997). Monitoreo de la polilla del tomate Scrobipalpuloides absoluta (Meyrick), en cultivo de tomate (Lycopersicon esculentum Mill) bajo plástico en la zona de Quillota. Taller de Licenciatura Ing. Agr. Quillota, Universidad Católica de Valparaíso, Facultad de Agronomía. Chile, pp. 76.

Senasica. (2013). Palomilla del tomate (Tuta absoluta Meyrick). Dirección General de Sanidad Vegetal. Sistema Nacional de Vigilancia Epidemiológica Fitosanitaria. LANREF-CP. México, D.F. Ficha Técnica № 28, pp. 20.

Silva, G.A., Picanço, M.C., Bacci, L., Crespo, A.L.B., Rosado, J.F., Guedes, R.N.C . (2011). Control failure likelihood and spatial dependence of insecticide resistance in the tomato pinworm, Tuta absoluta. Pest Manag Sci 67: 913-920.

Silva, J.E, Assis, C.P.O., Ribeiro, L.M.S., Siqueira, H.A.A. (2016a). Field-Evolved Resistance and Cross-Resistance of Brazilian Tuta absoluta (Lepidoptera: Gelechiidae) Populations to Diamide Insecticides. J Econ Entomol 109 (5): 2190-2195.

Silva, W.M., Berger, M., Bass, C., Balbino, V.Q., Amaral, M.H.P., Campos, M.R., Siqueira, H.A.A. (2015). Status of pyrethroid resistance and mechanisms in Brazilian populations of Tuta absoluta. Pestic Biochem Phys 122: 8-14.

Silva, W.M., Berger, M., Bass, C., Williamson, M., Moura, D.M.N., Ribeiro, L.M.S., Siqueira, H.A.A. (2016b). Mutation (G275E) of the nicotinic acetylcholine receptor $\alpha 6$ subunit is associated with high levels of resistance to spinosyns in Tuta absoluta (Meyrick) (Lepidoptera: Gelechiidae). Pestic Biochem Phys 131: 1-8.

Siqueira, H.A.A., Guedes, R.N.C., Fragoso, D.B., Magalhães, L.C. (2001). Abamectin resistance and synergism in Brazilian populations of Tuta absoluta (Meyrick) (Lepidoptera: Gelechiidae). Int J Pest Manage 47: 247-251.

Siqueira, H.A.A., Guedes, R.N.C., Picanço, M.C. (2000a). Cartap resistance and synergism in populations of Tuta absoluta (Lep., Gelechiidae). J Appl Entomol 124: 233-238.

Siqueira, H.A.A., Guedes, R.N.C., Picanço, M.C. (2000b). Insecticide resistance in populations of Tuta absoluta (Lepidoptera: Gelechiidae). Agric For Entomol 2: 147-153.

Smissaert, H.R., Voerman, S., Oostenbrugge, L., Renooy, N. (1970). Achetylcolinesterases of Organophosphate-Susceptible and -Resistant Spider Mites. J Agr Food Chem 18 (1): 66-75.

Sogorb, M.A., Vilanova, E. (2002). Enzymes involved in the detoxification of organophosphorous, carbamate and pyrethroid insecticides through hydrolysis. Toxicol Lett 128: $215-228$.

Sotolongo, M.G., Vidal, A.N. (1988). Metabolismo y excreción de los compuestos extraños. En: Elementos de Toxicología. La Habana: Ed. Pueblo y Educación, pp. 11-12. 
TaRI. (2017). Tuta absoluta Red de Información. En línea: www.tutaabsoluta.es (consultado: 16 de agosto de 2017).

Terriere, C.L. (1984). Induction of detoxication enzymes in insects. Ann Rev Entomol 29: 71-8.

Tomé, H.V.V., Martins, J.C., Corrêa, A.S., Galdino, T.V.S., Picanço, M.C., Guedes, R.N.C. (2013). Azadirachtin avoidance by larvae and adult females of the tomato leafminer Tuta absoluta. Crop Prot 46: 63-69.

Torné, M., Martín, A., Fernández, J. (2010). SPINTOR 480SC: eficacia natural. PHYTOMA España 217: 27-31.

Torres, J.B., Faria, C.A., Evangelista, W.S., Pratissoli, D. (2001). Within-plant distribution of the leafminer Tuta Absoluta (Meyrick) immatures in processing tomatoes, with notes on plant phenology. Int J Pest Manage 47 (3): 173-178.

Tropea Garzia, G. (2009). Physalis peruviana L. (Solanaceae), a host plant of Tuta absoluta in Italy. IOBC/WPRS Bull 49: 231-232.

Urbaneja, A., González-Cabrera, J., Arnó, J., Gabarra, R. (2012). Prospects for the biological control of Tuta absoluta in tomatoes of the Mediterranean basin. Pest Manag Sci 68: 12151222.

Urbaneja, A., Montón, H., Mollá, O. (2009). Suitability of the tomato borer Tuta absoluta as prey for Macrolophus caliginosus and Nesidiocoris tenuis. J Appl Entomol 133: 292-296.

Urbaneja, A., Vercher, R., Navarro, V., García Marí, F., Porcuna, J.L. (2007). La polilla del tomate, Tuta absoluta. PHYTOMA España 194: 16-23.

USDA. (2011). New Pest Response Guidelines Tomato Leafminer (Tuta absoluta). United States Department of Agriculture. Animal and Plant Health Inspection Service. Cooperating State Departments of Agriculture, pp. 176.

Vacante, V., Tropea Garzia, G. (1994). Nesidiocoris tenuis: antagonista naturale di aleurodidi. Informatore fitopatologico 4: 23-28.

Van der Blom, J., Robledo, A., Torres, S. (2011). Control de Tuta absoluta mediante medidas culturales. Documentos Técnicos/ 04. Ed. Fundación Cajamar, pp. 42.

Vargas, H.C. (1970). Observaciones sobre la biología y enemigos naturales de la polilla del tomate, Gnorimoschema absoluta (Meyrick) (Lepidoptera: Gelechiidae). Idesia 1: 75-110.

Vercher, R., Calabuig, A., Felipe, C. (2010). Ecología, muestreo y umbrales de Tuta absoluta. PHYTOMA España 217: 23-26. 
Vercher, R., Calabuig, A., Gómez, F. (2009). Ecología de la nueva plaga invasora del tomate Tuta absoluta (Meyrick). En: Miranda, M.A., Alemany, A., Paredes, C. (Eds.). Actas del VI Congreso nacional de Entomología Aplicada. 19-23 Octubre de 2009. XII Jornadas Científicas de la SEEA, España, pp.14.

Voss, G., Matsumura, F. (1965). Biochemical studies on a modified and normal cholinesterase found in the Levercusen strains of the two-spotted spider mite Tetranychus urticae. Can J Biochem, 43 (1): 63-72.

Yalçin, M., Mermer, S., Kozaci, L.D., Turgut, C. (2015). Insecticide resistance in two populations of Tuta absoluta (Meyrick, 1917) (Lepidoptera: Gelechiidae) from Turkey. Türk Entomol Derg 39 (2): 137-145.

Yamamoto, I. (1999). Nicotine to Nicotinoids: 1962 to 1997. En: Yamamoto, I., Casida, J. (Eds.). Nicotinoid Insecticides and the Nicotinic Acetylcholine Receptor. Tokyo. Ed. SpringerVerlag, pp. 3-27.

Yu, S.J. (2008). The toxicology and biochemistry of insecticides. Ed. CRC Press/Taylor \& Francis Group, Boca Raton, Florida, pp. 276.

Zappalà, L., Biondi, A., Alma, A., Al-Jboory, I.J., Arnó, J., Bayram, A., Chailleux, A., El-Amaouty, A., Gerling, D., Guenaoui, Y., Shaltiel-Harpaz, L., Siscaro, G., Stavrinides, M., Tavella, L., Vercher Aznar, R., Urbaneja, A., Desneux, N. (2013). Natural enemies of the South American moth, Tuta absoluta, in Europe, North Africa and Middle East, and their potential use in pest control strategies. J Pest Sci 86: 635-647. 



\section{JUSTIFICACIÓN Y OBJETIVOS}





\subsection{Justificación}

Desde la aparición de Tuta absoluta (Meyrick) en España en el año 2006 y su rápida expansión a otros países de Europa, esta plaga se ha mostrado muy invasiva y voraz, considerándose una de las más importantes y devastadoras del cultivo del tomate. En la actualidad, se sigue la tendencia de combinar varios métodos de control en campo, los cuales puedan integrarse en un programa de Gestión Integrada de Plagas (GIP). El control químico es un método muy eficaz contra $T$. absoluta, por lo tanto es importante comprobar la eficacia de los productos autorizados para su control y desarrollar una buena estrategia anti-resistencias para $T$. absoluta en el cultivo del tomate.

\subsection{Objetivos}

El objetivo general de esta tesis es estudiar las bases de la resistencia a los insecticidas clorantraniliprol, ciantraniliprol, flubendiamida, spinosad e indoxacarb en $T$. absoluta, con el fin de desarrollar una estrategia de manejo de la resistencia a estos insecticidas.

Así, se proponen los siguientes objetivos específicos:

1. Estudiar la línea base de susceptibilidad de poblaciones de campo de T. absoluta a los insecticidas clorantraniliprol, flubendiamida, ciantraniliprol, spinosad e indoxacarb, y su evolución.

2. Evaluar cómo afecta el estado de desarrollo larvario de $T$. absoluta en la susceptibilidad a los insecticidas anteriormente citados.

3. Obtener dos poblaciones de T. absoluta resistentes a los insecticidas diamidas clorantraniliprol y ciantraniliprol, mediante un proceso de selección en el laboratorio.

4. Determinar si existen resistencias cruzadas entre las diamidas clorantraniliprol y ciantraniliprol, y entre estas y otros insecticidas de uso en $T$. absoluta, en dos poblaciones seleccionadas a clorantraniliprol y ciantraniliprol.

5. Conocer qué mecanismo de resistencia está implicado en la resistencia a clorantraniliprol y a ciantraniliprol en T. absoluta.

6. Estudiar las resistencias cruzadas entre spinosad y los insecticidas clorantraniliprol, ciantraniliprol, flubendiamida, indoxacarb y emamectina benzoato, en una población de $T$. absoluta resistente a spinosad.

7. Determinar si la resistencia a spinosad en $T$. absoluta se debe a un mecanismo de resistencia metabólico. 

3. MATERIAL Y MÉTODOS GENERALES 



\subsection{Cría de Tuta absoluta (Meyrick)}

La cría de $T$. absoluta en el laboratorio se realiza en el interior de unas jaulas de cría en donde se introducen plantas de tomate libre de tratamientos con insecticidas, para poder realizar el mantenimiento de las diferentes poblaciones de $T$. absoluta que se encuentran en el laboratorio.

\subsubsection{Jaulas de cría}

Las jaulas de cría que se utilizan para el mantenimiento de las poblaciones de $T$. absoluta se realizan empleando dos bandejas de polipropileno negras, con tamaño de $8,5 \mathrm{~cm}$ de alto, 56,5 $\mathrm{cm}$ de ancho y $41,5 \mathrm{~cm}$ de fondo. A una de estas bandejas se le ancla, mediante el uso de bridas, una estructura de malla de cuadros de plástico blanco, cuyo tamaño de cuadro es de $2,5 \mathrm{~cm}$ de largo y $2,5 \mathrm{~cm}$ de ancho. Las dimensiones de la jaula de cría una vez montada son de $50 \mathrm{~cm}$ de alto, $52 \mathrm{~cm}$ de ancho y $37 \mathrm{~cm}$ de fondo. Sobre la estructura de la jaula se coloca una funda de nytal (malla anti-trips con diámetro de 150 micras) con una cremallera en la parte más ancha de la jaula. Esta funda se realiza a medida, y permite la aireación en el interior de la jaula, y a la vez evita la salida del interior de individuos de la población y entrada del exterior de cualquier insecto. La cremallera de la funda facilita el acceso al interior de la jaula, pudiendo introducir y retirar plantas de tomate e individuos con facilidad. Por último, toda la estructura de la jaula con la funda se coloca sobre una segunda bandeja negra, con el fin de sujetar bien la funda y conseguir que toda la estructura sea lo más hermética posible (Figuras 3.1 y 3.2$)$.

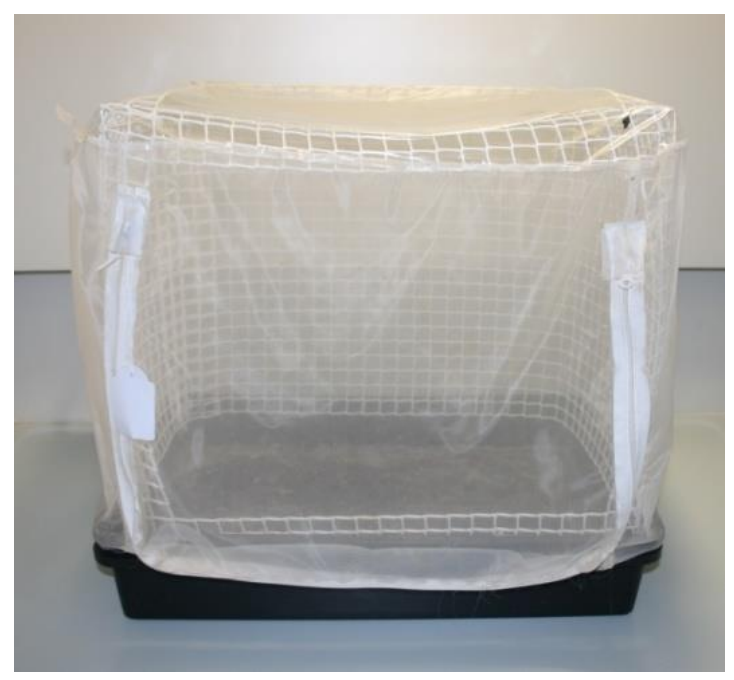

Figura 3.1: Jaula de cría de $T$. absoluta (Fuente propia). 


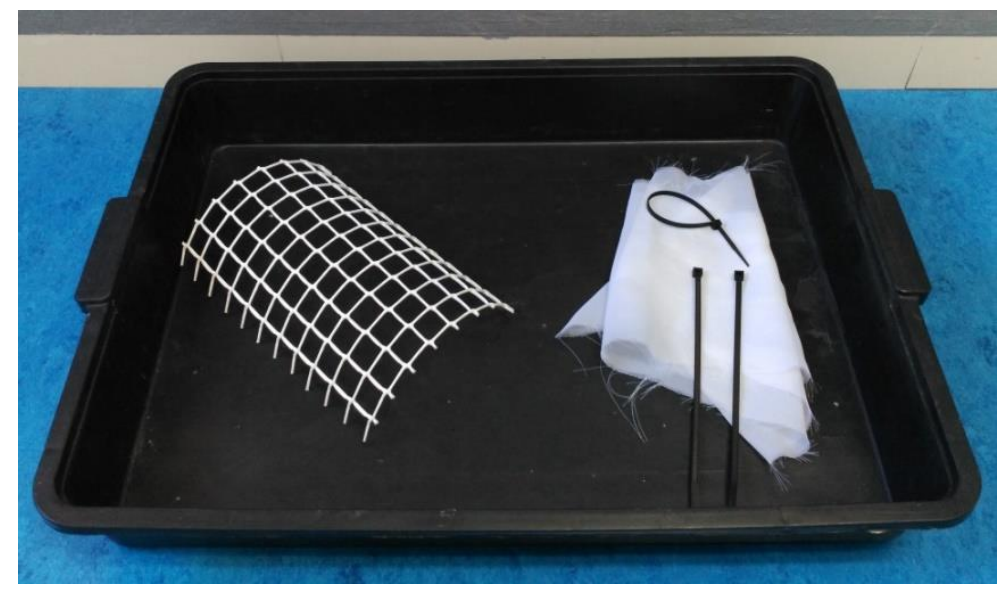

Figura 3.2: Material empleado para las jaulas de cría de $T$. absoluta (Fuente propia).

\subsubsection{Material vegetal}

Las plantas de tomate empleadas para la cría de las poblaciones de T. absoluta proceden de un invernadero situado en la Estación Experimental Agroalimentaria Tomás Ferro, perteneciente a la Universidad Politécnica de Cartagena y dependiente de la Escuela Técnica Superior de Ingeniería Agronómica. Semanalmente, se siembran semillas de tomate (Solanum lycopersicum L. cv. Bobcat) en una cámara de cultivo situada en el laboratorio asignado al grupo de investigación de Protección de Cultivos. Cuando las plantas de tomate tienen una altura aproximada de entre $15-20 \mathrm{~cm}$ de alto, se llevan al invernadero para conseguir un crecimiento más rápido de la planta y fortalecer su tallo. En ningún momento se aplica tratamiento fitosanitario a las plantas de tomate previo a su utilización en el laboratorio (Figura 3.3).

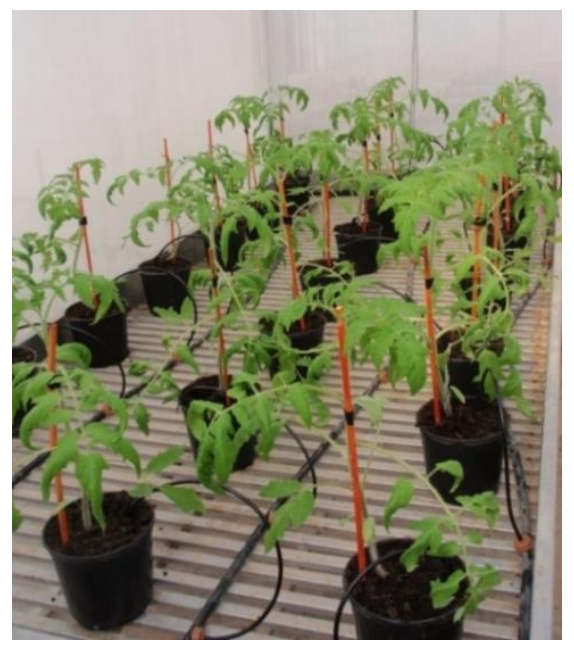

Figura 3.3: Plantas de tomate empleadas para la cría de $T$. absoluta (Fuente propia). 


\subsubsection{Mantenimiento de las poblaciones de T. absoluta}

Todas las semanas se introducen plantas de tomate limpias en cada una de las jaulas de cría de T. absoluta. La cantidad de planta de tomate que se emplea para la cría semanal varía en función de la que necesite cada población para su mantenimiento. Todas las plantas de tomate que se introducen en las jaulas de cría son regadas. Cada jaula puede alojar entre 9-12 plantas de tomate (Figura 3.4). Cuando las larvas se han alimentado de todo el mesófilo de las hojas, y las jaulas de las poblaciones están ocupadas totalmente con planta, se corta la parte aérea que todavía puede contener algunas larvas y crisálidas, se deja en el interior de las jaulas y se sacan todas las macetas vacías, con el fin de introducir nueva planta de tomate para alimentar la población. Esta parte aérea se mantiene en el interior de las jaulas no más de una semana, tiempo suficiente para que de las crisálidas que puedan permanecer en la parte aérea emerjan los adultos, y al mismo tiempo las larvas se pasen a otra planta de tomate limpia. Con esta metodología también se evita que aparezca moho en el interior de las jaulas. La turba de las macetas vacías que se extraen de las jaulas se desecha y las macetas se congelan a $18^{\circ} \mathrm{C}$ bajo cero durante 24 horas, debido a que en los bordes de las macetas pueden encontrarse crisálidas de $T$. absoluta, y posteriormente puede emerger el adulto y contaminar planta limpia de tomate.

Cada jaula de cría está identificada con el nombre de la población de $T$. absoluta que le corresponda, y cada una de las poblaciones tendrá tanto adultos, como larvas y crisálidas en su interior (Figura 3.5).

Las mismas jaulas deben ser usadas para las mismas poblaciones, con el fin de no mezclar individuos de poblaciones distintas. Por ello, cuando una jaula se vacíe totalmente de planta e individuos, debe desinfectarse con alcohol y dejarla en cuarentena, hasta su nuevo uso.

Todas las jaulas de cría se sitúan en unas estanterías en el laboratorio, bajo una pantalla de luz con dos tubos fluorescentes, uno de luz de crecimiento y el otro de luz normal, con fotoperiodo de $16 / 8$ (luz/oscuridad). La temperatura en el laboratorio para la cría es de $25 \pm 2{ }^{\circ} \mathrm{C}$ y la humedad relativa es de $60 \pm 5 \%$ (Figura 3.6).

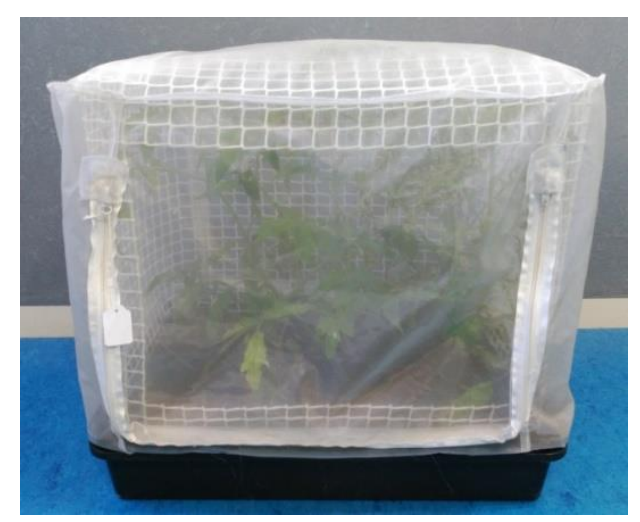

Figura 3.4: Jaula de cría de una población de T. absoluta (Fuente propia). 


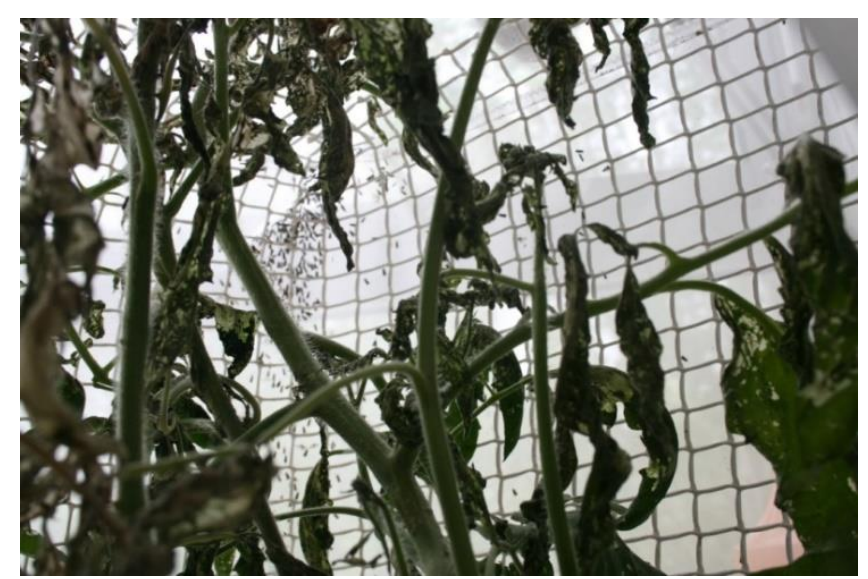

Figura 3.5: Detalle del interior de una jaula de cría de $T$. absoluta (Fuente propia).

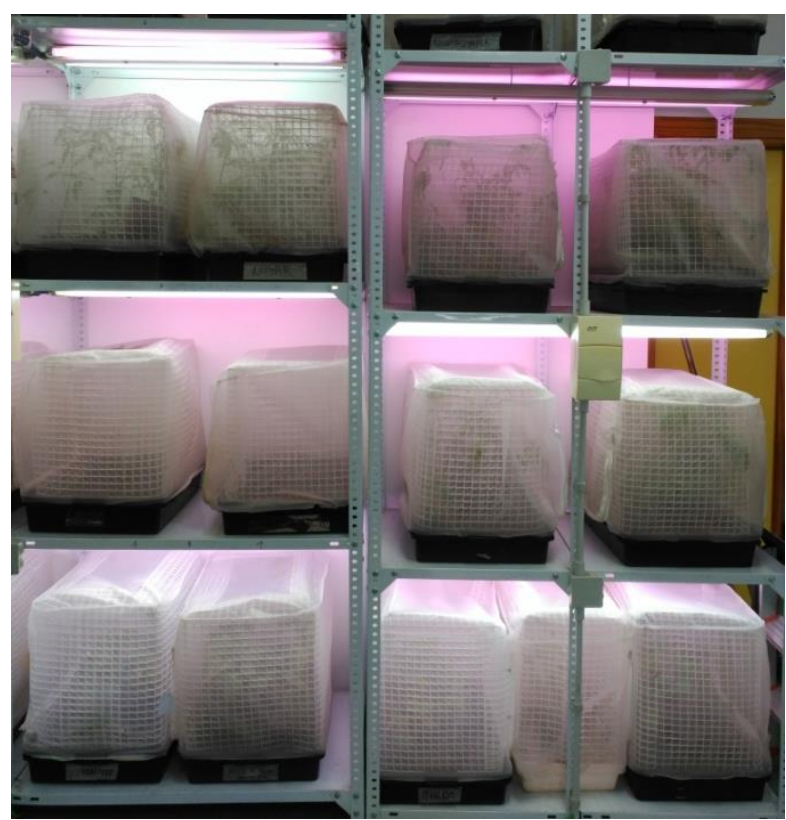

Figura 3.6: Disposición de las jaulas de cría de $T$. absoluta en el laboratorio (Fuente propia).

\subsection{Poblaciones de campo de T. absoluta}

Las poblaciones de $T$. absoluta empleadas en este trabajo fueron recolectadas en diferentes países mediterráneos (Tabla 3.1). Todas las poblaciones fueron recolectadas en invernaderos de tomate, y en todos los casos se recogieron hojas de tomate con larvas de $T$. absoluta en su interior. Para algunas poblaciones también se recogieron frutos de tomate que presentaban daños por T. absoluta. En el momento de su llegada al laboratorio, todo el material vegetal infectado se coloca en una jaula de cría con planta de tomate limpia. Seguidamente, se identifica la jaula con el nombre de la población y se ubica en una de las estanterías del laboratorio bajo las pantallas de luz. Para la población Mixta, se introdujeron adultos de 
diferentes poblaciones que estaban entonces en el laboratorio (Águilas, Canarias, Tudela, Gallego1, Foggia, Níjar y Charneca), en una jaula de cría con planta de tomate limpia. Esto se realizó con el fin de mezclar adultos de diferentes poblaciones de T. absoluta entre ellos y fundar una población mezcla.

Tabla 3.1: Origen de las distintas poblaciones de $T$. absoluta recolectadas.

\begin{tabular}{|c|c|c|c|}
\hline Población & Origen & Fecha de recolección & Cultivo \\
\hline Abarán & Murcia (España) & Marzo 2010 & Tomate \\
\hline Almería & Almería (España) & Mayo 2010 & Tomate \\
\hline Canarias & Las Palmas de Gran Canarias (España) & Mayo 2010 & Tomate \\
\hline Níjar & Almería (España) & Mayo 2010 & Tomate \\
\hline Gallego1 & Murcia (España) & Mayo 2010 & Tomate \\
\hline Biancavilla & Sicilia (Italia) & Julio 2010 & Tomate \\
\hline Tudela & Navarra (España) & Septiembre 2010 & Tomate \\
\hline Boavista & Oporto (Portugal) & Septiembre 2010 & Tomate \\
\hline Charneca & Lisboa (Portugal) & Septiembre 2010 & Tomate \\
\hline Águilas & Murcia (España) & Enero 2011 & Tomate \\
\hline Foggia & Foggia (Italia) & Marzo 2011 & Tomate \\
\hline Mazarrón & Murcia (España) & Julio 2012 & Tomate \\
\hline Fossano & Fossano (Italia) & Julio 2012 & Tomate \\
\hline Francia & Villenueve de la Raho (Francia) & Septiembre 2012 & Tomate \\
\hline Grecia & Heraklion (Grecia) & Noviembre 2012 & Tomate \\
\hline Peloponeso & Peloponeso (Grecia) & Mayo 2013 & Tomate \\
\hline Pomodoro & Milán (Italia) & Junio 2013 & Tomate \\
\hline Mixta & Mezcla & Octubre 2013 & Tomate \\
\hline Gallego2 & Murcia (España) & Septiembre 2014 & Tomate \\
\hline Villaverde & Mérida (España) & Octubre 2014 & Tomate \\
\hline Calnegre & Murcia (España) & Noviembre 2014 & Tomate \\
\hline Mojonera & Almería (España) & Noviembre 2014 & Tomate \\
\hline Sicilia & Sicilia (Italia) & Diciembre 2014 & Tomate \\
\hline Almería15 & Almería (España) & Mayo 2015 & Tomate \\
\hline La Cañada & Almería (España) & Julio 2015 & Tomate \\
\hline La Palma & Murcia (España) & Agosto 2015 & Tomate \\
\hline Sannito & Sicilia (Italia) & Mayo 2016 & Tomate \\
\hline Frasanito & Sicilia (Italia) & Mayo 2016 & Tomate \\
\hline Mazarrón2 & Murcia (España) & Junio 2016 & Tomate \\
\hline Portugal1 & Estremadura (Portugal) & Julio 2016 & Tomate \\
\hline Totana & Murcia (España) & Julio 2016 & Tomate \\
\hline Portugal2 & Estremadura (Portugal) & Octubre 2016 & Tomate \\
\hline
\end{tabular}




\subsection{Insecticidas}

Para la realización de los bioensayos de susceptibilidad y los bioensayos de selección de resistencia, se han empleado 4 insecticidas registrados en España para el control de $T$. absoluta en tomate: clorantraniliprol, spinosad, indoxacarb y emamectina benzoato. También se han usado dos insecticidas actualmente no registrados en España para T. absoluta, flubendiamida y ciantraniliprol (Tabla 3.2 y Figura 3.7).

Tabla 3.2: Insecticidas empleados.

\begin{tabular}{|c|c|c|c|c|c|}
\hline & GRUPO IRAC & $\begin{array}{l}\text { MATERIA } \\
\text { ACTIVA }\end{array}$ & $\begin{array}{l}\text { NOMBRE } \\
\text { COMERCIAL }\end{array}$ & $\begin{array}{c}\text { CASA } \\
\text { COMERCIAL }\end{array}$ & $\begin{array}{c}\text { DOSIS DE } \\
\text { CAMPO }\left(\mathrm{mg} \mathrm{L}^{-1}\right)\end{array}$ \\
\hline $\begin{array}{c}\text { Clorantraniliprol } \\
\text { (Rynaxypyr) }\end{array}$ & 28 Diamidas & $\begin{array}{c}\text { Clorantraniliprol } \\
\text { 35\% WG }\end{array}$ & Altacor & DuPont & 35 \\
\hline $\begin{array}{c}\text { Ciantraniliprol } \\
\text { (Cyazypyr) }\end{array}$ & 28 Diamidas & $\begin{array}{c}\text { Ciantraniliprol } \\
10,26 \% \text { OD }\end{array}$ & Benevia & DuPont & 100 \\
\hline Flubendiamida & 28 Diamidas & $\begin{array}{c}\text { Flubendiamida } \\
24 \% \text { WG }\end{array}$ & Fenos & $\begin{array}{c}\text { Bayer } \\
\text { CropScience }\end{array}$ & 60 \\
\hline Spinosad & 5 Spinosines & Spinosad $48 \%$ SC & Spintor 480 SC & $\begin{array}{c}\text { Dow } \\
\text { AgroScience }\end{array}$ & 120 \\
\hline Indoxacarb & $\begin{array}{c}22 \mathrm{~A} \\
\text { Oxadiacinas }\end{array}$ & $\begin{array}{c}\text { Indoxacarb } 30 \% \\
\text { WG }\end{array}$ & Steward & DuPont & 60 \\
\hline $\begin{array}{l}\text { Emamectina } \\
\text { benzoato }\end{array}$ & $\begin{array}{c}6 \\
\text { Avermectinas }\end{array}$ & $\begin{array}{c}\text { Emamectina } \\
\text { benzoato } \\
0,855 \% \text { SG }\end{array}$ & Affirm & $\begin{array}{l}\text { Syngenta } \\
\text { Agro }\end{array}$ & 15 \\
\hline
\end{tabular}

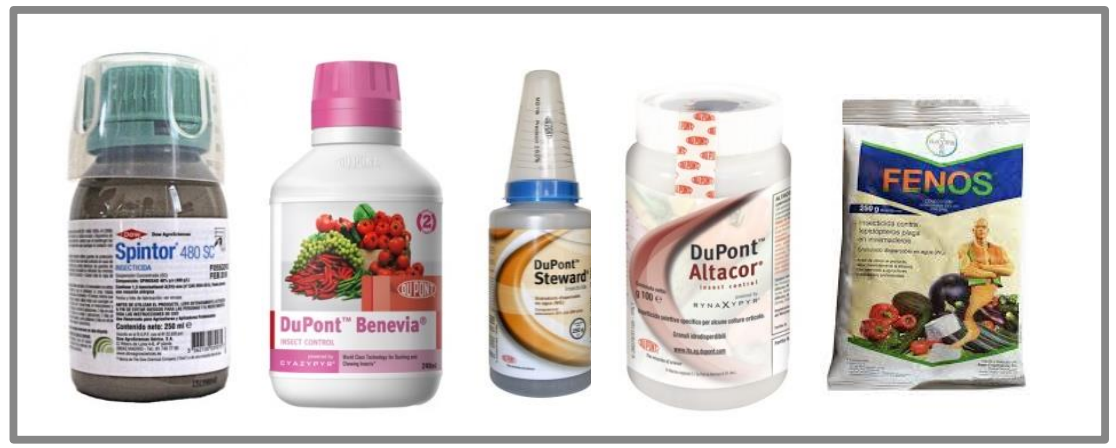

Figura 3.7: Insecticidas empleados (Elaboración propia). 


\subsection{Bioensayos}

En este apartado se describen los diferentes tipos de bioensayos que se llevan a cabo con las distintas poblaciones de $T$. absoluta. Según los resultados que se pretendan obtener se realizará un tipo de bioensayo u otro.

Previo al desarrollo de todos los tipos de bioensayos (bioensayos de susceptibilidad, selección de resistencias y bioensayos con sinergistas) se realiza una etapa de oviposición de los adultos de $T$. absoluta. Una vez elegida la población de $T$. absoluta a bioensayar, se aspiran todos los adultos de la jaula de cría con ayuda de un aspirador entomológico (Figura 3.8), y se colocan en otra jaula de cría con planta de tomate limpia, con el fin de que realicen la oviposición en la planta limpia de tomate. Transcurridas 72 horas, los adultos son aspirados de nuevo y se introducen en su jaula de cría original, teniendo una jaula con planta de tomate y huevos de la población de T. absoluta que se desea bioensayar. Con este paso previo, se pretende conseguir una cantidad de larvas suficientes, y en el mismo estadio larvario, para la realización de los bioensayos. Todos los bioensayos se realizan con larvas en estadio 2 (L2) de T. absoluta, excepto los bioensayos de susceptibilidad con larvas en estadio 4 (L4). Tras 8-11 días, en función de la temperatura, tendremos las larvas en L2 para la realización de los bioensayos (14-17 días para los bioensayos con larvas L4).

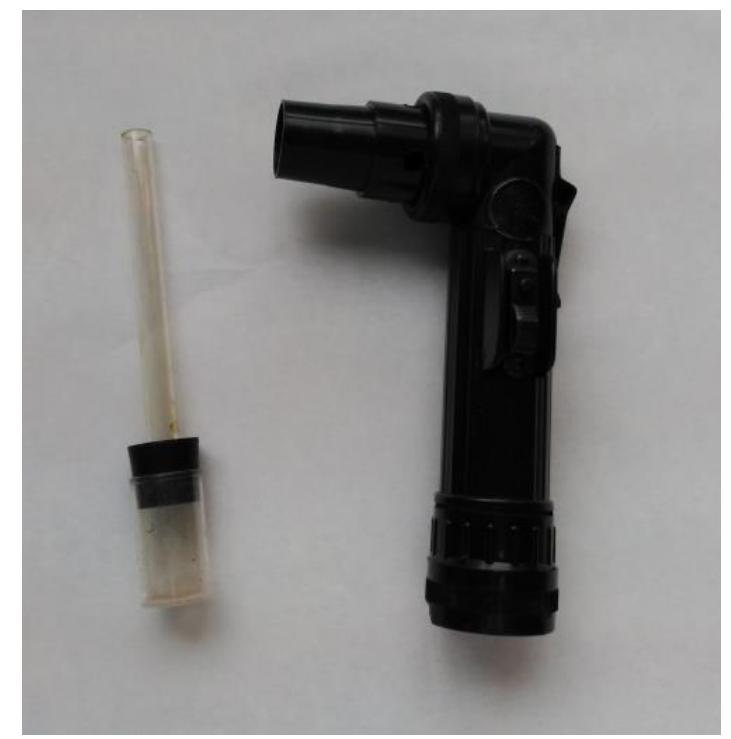

Figura 3.8: Aspirador entomológico (Fuente propia). 


\subsubsection{Bioensayos de susceptibilidad}

Los bioensayos de susceptibilidad se realizan para conocer el nivel de susceptibilidad inicial que tiene una población de T. absoluta a un determinado insecticida, y posteriormente determinar la susceptibilidad basal o línea base de susceptibilidad de $T$. absoluta a los diferentes insecticidas estudiados.

Para la realización de los bioensayos de susceptibilidad se sigue el método número 22 (versión 3) de IRAC (Insecticide Resistance Action Committee) (IRAC, 2012) con pequeñas modificaciones para optimizar el método y así adaptarlo a las condiciones del laboratorio. Este método de bioensayo se desarrolló en nuestro laboratorio en las tareas iniciales del trabajo de esta Tesis (Roditakis et al., 2013).

En primer lugar, se preparan las distintas concentraciones del insecticida en vasos de plástico de un litro de capacidad. Todas las concentraciones se diluyen en agua destilada, y se realiza una concentración control solo con agua destilada. Se preparan entre 3 y 6 concentraciones de insecticida en función de la cantidad de larvas disponibles. A cada concentración y al control se le añade Tween20 $(0,05 \% \mathrm{v} / \mathrm{v})$ como agente humectante no iónico, para mejorar la penetrabilidad del insecticida en la hoja de tomate. Todo este proceso se realiza en una campana de extracción, con un agitador magnético para mezclar bien las concentraciones (Figuras 3.9 y 3.10 ).


Figuras 3.9 y 3.10: Agitador magnético con varias concentraciones del insecticida y envase de Tween20 (Fuente propia). 
A continuación, se cortan 3 foliolos de tomate limpios por concentración más el control. Se sumergen los foliolos en las distintas concentraciones durante 30 segundos, empezando por el control y siguiendo el orden desde la menos concentrada hasta la más concentrada. Una vez mojados los foliolos, se colocan en unas gradillas con viales de plástico con agua, con el peciolo del foliolo en el interior del vial, para evitar que los foliolos se deshidraten mientras absorben el insecticida (Figura 3.11).

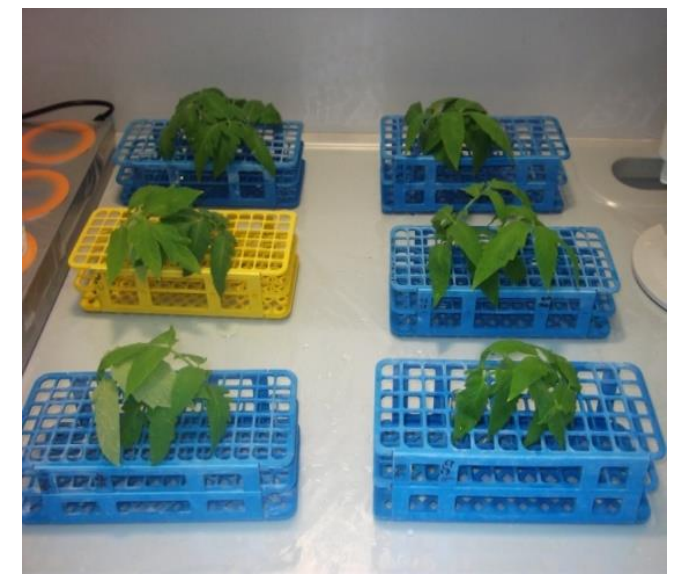

Figura 3.11: Foliolos de tomate tratados con insecticida, secándose en la campana de extracción (Fuente propia).

Una vez secos los foliolos, se van introduciendo uno a uno en una cajita de plástico transparente, de dimensiones $4,5 \mathrm{~cm}$ de alto, $10 \mathrm{~cm}$ de ancho y $7 \mathrm{~cm}$ de fondo, y se les pone un algodón húmedo en el peciolo para que no se deshidraten. Cada cajita de plástico está marcada con su correspondiente número de concentración de insecticida empleada. Se realizan 3 repeticiones por concentración de insecticida y control, utilizando una cajita de plástico por cada repetición (Figura 3.12).

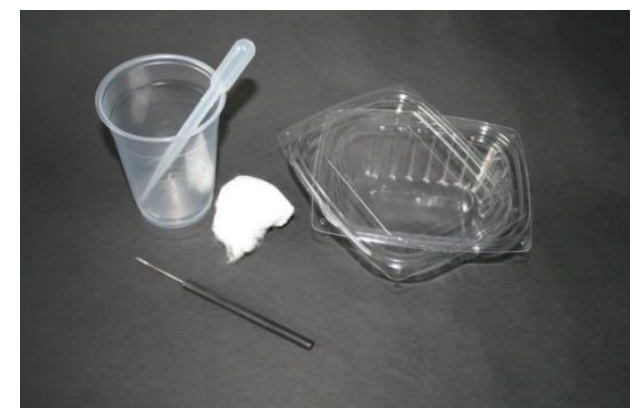

Figura 3.12: Cajita de plástico y material empleado para los bioensayos de T. absoluta (Fuente propia). 
A continuación, se extraen las larvas L2 de las hojas de las plantas limpias de tomate, en las cuales pusimos adultos de $T$. absoluta durante 72 horas para que pusieran huevos. Se emplea pincel, pinza entomológica y bisturí para extraer las larvas de las galerías de las hojas, con el fin de dañar lo menos posible a las larvas. Se introducen 10 larvas en cada cajita de plástico y se les pone su correspondiente tapadera, también transparente, previamente rotulada con la concentración de insecticida, el número de repetición y el nombre de la población de $T$. absoluta bioensayada. Las tapaderas son agujereadas con un punzón para evitar que en la cajita no se condense la humedad. Se colocan 10 larvas por repetición y se realizan 3 repeticiones por concentración, con un total de 30 larvas por concentración de insecticida y control (Figuras 3.13 y 3.14 ).
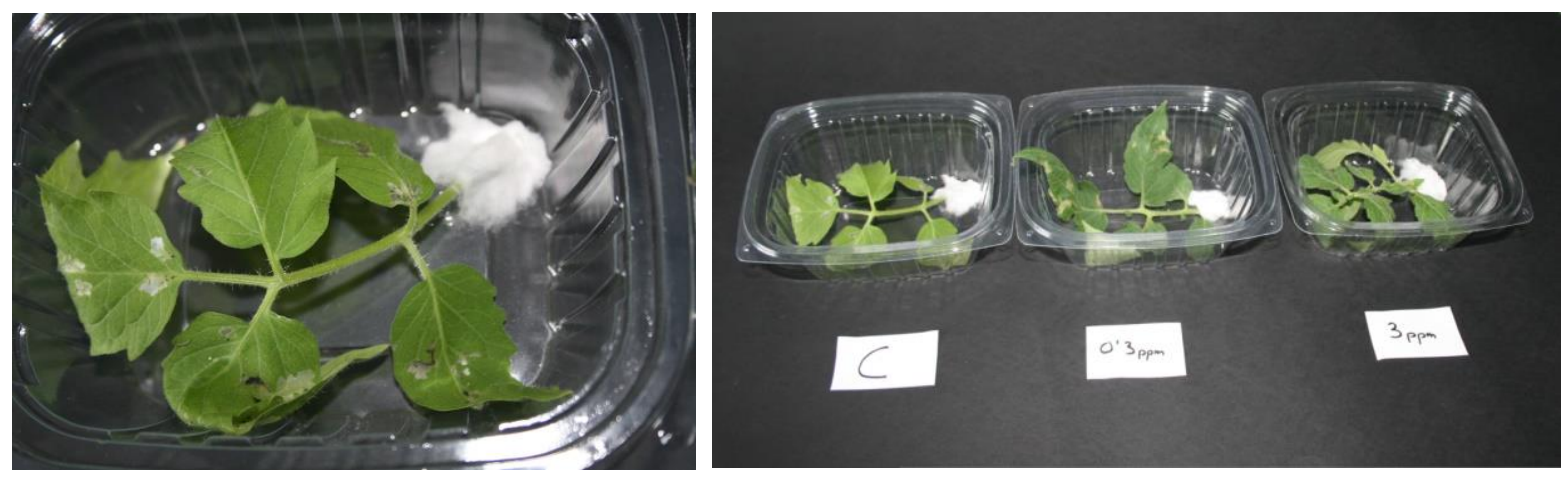

Figuras 3.13 y 3.14: Cajitas de plástico empleadas en los bioensayos, con foliolos de tomate tratados con insecticida y larvas L2 de $T$. absoluta (Fuente propia).

El bioensayo se mantiene en el laboratorio en condiciones controladas de temperatura $\left(25 \pm 2{ }^{\circ} \mathrm{C}\right)$, humedad relativa $(60 \pm 5 \%)$ y fotoperiodo (16/8 luz/oscuridad).

Transcurridas 72 horas, se lee el bioensayo y se diferencian entre larvas vivas, moribundas y muertas. Se consideran larvas vivas aquellas que no se ven afectadas por el insecticida, se mueven de forma coordinada y presentan color normal; larvas moribundas las que presentan un crecimiento y desarrollo anormal, e incluso cambios en el color; y larvas muertas aquellas que no se mueven ni responden a ningún estímulo. Las moribundas se consideran muertas a la hora del tratamiento de los resultados.

Para los bioensayos de susceptibilidad con larvas en estadio 4 (L4) de T. absoluta, en vez de extraer las larvas en $L 2$ de las hojas y colocarlas en las cajitas de bioensayo, se extraen las larvas en L4 y se sigue el mismo desarrollo que para los bioensayos con larvas L2. 


\subsubsection{Bioensayos de selección de resistencias}

Los bioensayos de selección de resistencias se llevan a cabo para seleccionar, en una población determinada de $T$. absoluta, la resistencia a un insecticida en el laboratorio de forma controlada. Previo al desarrollo del bioensayo, se elige la población de $T$. absoluta que se va a seleccionar y el insecticida que se va a emplear para conseguir la resistencia. La población escogida es sometida a tratamientos sucesivos con una concentración de insecticida creciente a la vez que vamos avanzando en la selección. En este caso, se bioensayan alrededor de 1000 larvas L2 en cada selección, y se va aumentando la concentración de insecticida en las sucesivas selecciones, o dentro de una misma selección si fuera necesario, hasta obtener mortalidades de entre $60-80 \%$ de los individuos.

En este tipo de bioensayo también se emplea el mismo método descrito anteriormente en el apartado 3.4.1 de Material y Métodos Generales.

En primer lugar, se prepara la concentración elegida para la selección, con agua destilada y Tween20. En este caso, se cuentan las larvas L2 de la planta de tomate limpia empleada para la oviposición de los adultos, y se cortan los foliolos de tomate con las larvas L2 de T. absoluta en su interior. Los foliolos con las larvas en el interior se sumergen durante 30 segundos en la concentración de insecticida y, posteriormente, se colocan en unas gradillas con viales de plástico con agua para que los foliolos absorban el insecticida sin deshidratarse.

Una vez secos los foliolos, se van introduciendo en unas cajitas de plástico transparente similares a las ya descritas en el apartado anterior, se les pone un algodón húmedo en el peciolo para que no se deshidraten y se les pone su correspondiente tapadera. Las tapaderas se rotulan con la concentración de insecticida empleado y el nombre de la población (Figuras $3.15,3.16$ y 3.17$)$.
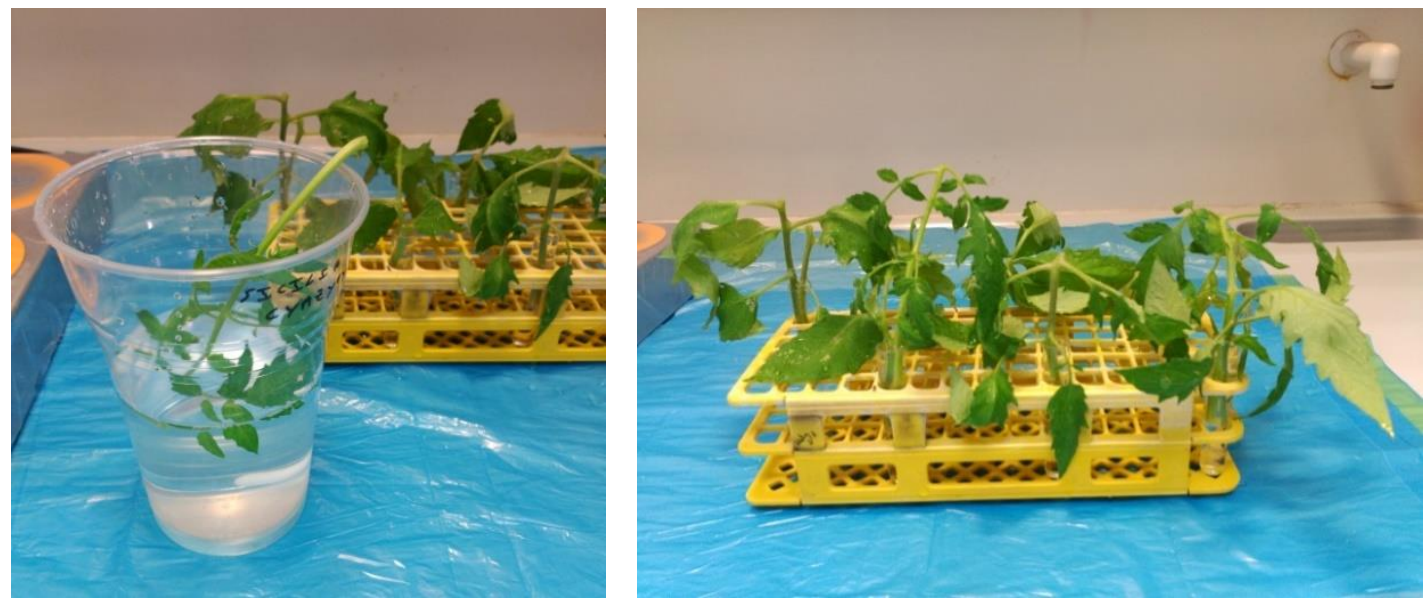

Figuras 3.15 y 3.16: Método de bioensayo de selección de resistencias (Fuente propia). 




Figura 3.17: Cajitas de plástico con foliolos de tomate tratados con insecticida y larvas L2 de T. absoluta en su interior (Fuente propia).

El bioensayo se mantiene en el laboratorio en condiciones controladas de temperatura $(25 \pm 2 \circ \mathrm{C})$, humedad relativa $(60 \pm 5 \%)$ y fotoperiodo (16/8 luz/oscuridad).

Transcurridas 96 horas, se lee el bioensayo, distinguiéndose entre larvas vivas, moribundas y muertas. Las larvas vivas y moribundas se introducen en una jaula de cría con planta de tomate limpia para que se multipliquen y así poder continuar con la selección.

Cuando se estima que se ha alcanzado el nivel de resistencia al insecticida deseado en una población seleccionada, se realiza un bioensayo de susceptibilidad, con un rango de concentraciones del insecticida seleccionado y un control, para comprobar si la población se ha seleccionado correctamente. Cuando ya tenemos la población seleccionada al nivel de resistencia deseado, se mantiene en el laboratorio criándola como el resto de poblaciones del laboratorio, realizándole cada 3 meses un tratamiento de recuerdo para mantener, a lo largo del tiempo, el nivel de resistencia adquirido. Este recuerdo consiste en tratar, a una concentración del insecticida seleccionado que cause una mortalidad aproximada del $70 \%$ de los individuos, planta de tomate limpia hasta punto de goteo con la ayuda de un pulverizador. La planta se deja secar en la campana de extracción y posteriormente se introduce en la jaula de cría de la población resistente al insecticida en cuestión (Figura 3.18). 


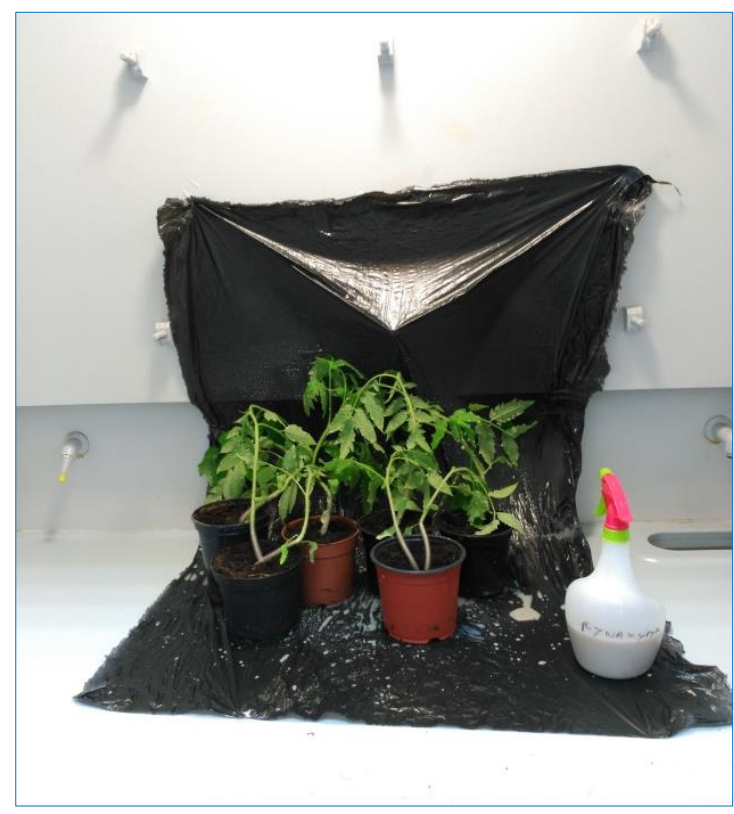

Figura 3.18: Tratamiento de recuerdo para el mantenimiento de la resistencias (Fuente propia).

\subsubsection{Bioensayos con sinergistas}

Los bioensayos con sinergistas se llevan a cabo para determinar si la resistencia al insecticida en una población resistente es debida a una resistencia metabólica por parte del insecto o no. Al añadir el producto sinergista junto al insecticida, el insecticida puede incrementar su actividad insecticida frente al insecto, debido a que el sinergista inhibe las enzimas de detoxificación del insecto.

Son tres los sinergistas empleados en este trabajo: butóxido de piperonilo (PBO), S,S,S tributil fosforotritioato (DEF) y dietil maleato (DEM). El PBO inhibe el citocromo P450 (enzimas P450 monooxigenasas), el DEF inhibe las enzimas esterasas y el DEM inhibe las glutatión Stransferasas.

Para este tipo de bioensayos se sigue el mismo método de desarrollo de los bioensayos de susceptibilidad con larvas en L2 de T. absoluta. La diferencia radica en que una vez extraídas las larvas de las galerías de las hojas de tomate, se añaden $20 \mu \mathrm{L}$ de una dosis subletal del sinergista, $1000 \mathrm{mg} \mathrm{L}^{-1}$ para PBO y $300 \mathrm{mg} \mathrm{L}^{-1}$ para DEF y DEM, a cada una de las larvas. Una vez que las larvas han absorbido tópicamente el sinergista, se introducen en sus respectivas cajitas de bioensayo. Al mismo tiempo, se realiza un control con larvas tratadas con el sinergista para comprobar que este no tenga ningún efecto por sí solo sobre las larvas de T. absoluta. 


\subsection{Referencias bibliográficas}

IRAC. (2012). IRAC Susceptibility Test Method 022, Tuta absoluta (Version 3) (2012). En línea: http://www.irac-online.org.

Roditakis, E., Skarmoutsou, C., Staurakaki, M., Martínez-Aguirre, M.R., García-Vidal, L., Bielza, P., Haddi, K., Rapisarda, C., Rison, J-L., Bassi, A., Teixeira, L.A. (2013). Determination of baseline susceptibility of European populations of Tuta absoluta (Meyrick) to indoxacarb and cholorantraniliprole using a novel dip bioassay method. Pest Manag Sci 69: 217-227. 


\section{CAPítulo 1}

SUSCEPTIBILIDAD DE POBLACIONES EUROPEAS DE

Tuta absoluta (MEYRICK) (LEPIDOPTERA:

GELECHIIDAE) A LOS INSECTICIDAS DIAMIDAS 



\subsection{Introducción}

La polilla del tomate, Tuta absoluta (Meyrick), es en la actualidad una de las plagas más importantes en el cultivo del tomate, causando importantes daños debido a la presencia de elevados niveles poblacionales tanto en invierno como en verano.

El control químico sigue siendo esencial para el control de T. absoluta. Por tanto, es fundamental estudiar la evolución de la resistencia de esta plaga a los insecticidas eficaces para su control, con el fin de desarrollar estrategias anti-resistencia y conocer los mecanismos de resistencia implicados (García-Vidal et al., 2015).

Las diamidas son un grupo nuevo de insecticidas que apareció hace unos años como alternativa química de control de varias plagas agrícolas, entre ellas $T$. absoluta. Hasta la fecha, el grupo de las diamidas lo componen los siguientes insecticidas: clorantraniliprol y ciantraniliprol, diamidas del ácido antranílico, y flubendiamida, una diamida del ácido ftálico (Teixeira et al., 2013). Si se realiza un uso continuado y conjunto de las diamidas, puede aparecer rápidamente resistencia, lo que limitaría su uso para el control de $T$. absoluta (Roditakis et al., 2015).

En este trabajo se ha comparado la evolución de la resistencia de poblaciones de $T$. absoluta, procedentes de diferentes países de Europa (España, Italia, Portugal, Grecia y Francia), a las diamidas: clorantraniliprol, flubendiamida y ciantraniliprol, así como la susceptibilidad en función del estado de desarrollo del insecto.

\subsection{Material y Métodos}

\subsubsection{Poblaciones de T. absoluta}

Las poblaciones de T. absoluta estudiadas en este trabajo se detallan en la tabla 3.1 dentro del apartado 3.2. del capítulo 3 de Material y Métodos Generales. Todas las poblaciones fueron recolectadas (ver apartado 3.2. en el capítulo 3 de Material y Métodos Generales) en invernaderos de tomate de distintos países de Europa, en un intervalo de tiempo de 7 años (2010-2016).

\subsubsection{Insecticidas}

Las formulaciones comerciales de los insecticidas utilizados en los bioensayos fueron: clorantraniliprol 35\% WG (Altacor (rynaxypyr), DuPont), ciantraniliprol 10,26\% OD (Benevia (cyazypyr), DuPont) y flubendiamida 24\% WG (Fenos, Bayer CropScience). 


\subsubsection{Bioensayos de susceptibilidad}

Se realizaron bioensayos de susceptibilidad con larvas en estadio 2 (L2) de T. absoluta para todas las poblaciones estudiadas en este trabajo, así como bioensayos con larvas en estadio 4 (L4) para algunas de las poblaciones.

Ver apartado 3.4.1. Bioensayos de susceptibilidad, en el capítulo 3 de Material y Métodos Generales.

\subsubsection{Análisis de datos}

Los datos de los bioensayos se analizaron usando el programa estadístico POLO-Plus para el análisis probit de los datos (LeOra-Software, 2005). Los parámetros calculados para este estudio fueron: la concentración letal 50 (CL50), que es la concentración que causa una mortalidad del $50 \%$, y sus límites fiduciales al $95 \%$ para cada población e insecticida, expresados en $\mathrm{mg} \mathrm{L}^{-1}$, y los factores de resistencia (FR) de cada población, comparando la CL50 de cada población con la CL50 de la población más susceptible.

\subsection{Resultados y Discusión}

En este apartado se muestran los resultados de los análisis probit de los bioensayos realizados para cada uno de los insecticidas diamidas, comparando la evolución de los niveles de resistencia de las poblaciones bioensayadas a estos insecticidas a lo largo de los últimos 7 años. Asimismo, se muestra la variación de la susceptibilidad, en una misma población, en función del estado de desarrollo del insecto. También se calculó la línea base de susceptibilidad, para cada uno de los insecticidas, en el periodo de tiempo entre 2010 y 2012. La línea base de susceptibilidad representa la respuesta natural de una plaga a un insecticida en ausencia de ningún mecanismo de resistencia implicado. Se obtiene combinando todas las CL50 de las poblaciones bioensayadas en los primeros años del empleo del insecticida y sin tener en cuenta las poblaciones resistentes. Es un dato que se emplea como referencia para estudiar la evolución de la resistencia de una plaga a un insecticida a lo largo del tiempo.

\subsubsection{Clorantraniliprol}

En la tabla 4.1 se muestran los resultados obtenidos de los bioensayos realizados en los años 2010, 2011 y 2012. La población española Gallego1 fue la que presentó un menor valor de $\operatorname{CL50}\left(0,04 \mathrm{~m} \mathrm{~L}^{-1}\right)$, siendo considerada la población más susceptible con respecto al resto de poblaciones. La población portuguesa Charneca fue considerada la menos susceptible, ya que presentó el valor de CL50 más elevado $\left(0,23 \mathrm{mg} \mathrm{L}^{-1}\right)$. Se observó una variabilidad de 5,5 veces entre la población más susceptible y la menos susceptible (FR). 
Se encontraron diferencias significativas entre algunas de las poblaciones, pero estas diferencias se encuentran dentro de la variabilidad natural esperable. La línea base de susceptibilidad calculada fue de 0,13 $\mathrm{mg} \mathrm{L}^{-1}$. Este valor de línea base de susceptibilidad, así como todos los valores de CL50 de las poblaciones bioensayadas, están muy por debajo de la dosis de campo de este insecticida $\left(35 \mathrm{mg} \mathrm{L}^{-1}\right)$. Este hecho pone de manifiesto la elevada susceptibilidad de estas poblaciones a clorantraniliprol, lo que sugiere que entre los años 2010 y 2012 no había indicios de resistencia a este insecticida en poblaciones europeas de $T$. absoluta.

Tabla 4.1: Toxicidad a clorantraniliprol de diferentes poblaciones de $T$. absoluta y línea base de susceptibilidad.

\begin{tabular}{|c|c|c|c|c|c|c|}
\hline País & Año & Población & $\mathrm{CL} 50\left(\mathrm{mg} \mathrm{L}^{-1}\right)$ & $\operatorname{LF}(95 \%)\left(\mathrm{mg} \mathrm{L}^{-1}\right)$ & FR & \\
\hline \multirow{8}{*}{ España } & 2010 & Abarán & 0,21 & $0,09-0,41$ & 5,1 & $*$ \\
\hline & 2010 & Níjar & 0,14 & $0,05-0,26$ & 3,3 & ns \\
\hline & 2010 & Canarias & 0,10 & $0,07-0,13$ & 2,3 & $*$ \\
\hline & 2010 & Gallego1 & 0,04 & $0,02-0,06$ & 1 & - \\
\hline & 2010 & Almería & 0,15 & $0,08-0,28$ & 3,6 & $*$ \\
\hline & 2010 & Tudela & 0,07 & $0,06-0,09$ & 1,7 & ns \\
\hline & 2011 & Águilas & 0,18 & $0,14-0,23$ & 4,5 & $*$ \\
\hline & 2012 & Mazarrón & 0,14 & $0,09-0,26$ & 3,3 & $*$ \\
\hline \multirow{3}{*}{ Italia } & 2010 & Biancavilla & 0,21 & $0,08-0,31$ & 5,0 & $*$ \\
\hline & 2011 & Foggia & 0,06 & $0,04-0,09$ & 1,4 & ns \\
\hline & 2012 & Fossano & 0,10 & $0,05-0,19$ & 2,5 & ns \\
\hline \multirow{2}{*}{ Portugal } & 2010 & Charneca & 0,23 & $0,19-0,27$ & 5,5 & $*$ \\
\hline & 2010 & Boavista & 0,09 & $0,04-0,17$ & 2,1 & ns \\
\hline Francia & 2012 & Francia & 0,09 & $0,06-0,12$ & 2,1 & ns \\
\hline Grecia & 2012 & Grecia & 0,08 & $0,04-0,15$ & 2,0 & ns \\
\hline \multicolumn{3}{|c|}{ Línea Base de Susceptibilidad } & 0,13 & $0,11-0,17$ & - & \\
\hline
\end{tabular}

CL50: Concentración letal 50 en $\mathrm{mg} \mathrm{L}^{-1}$; LF (95\%): Límites fiduciales al 95\% en $\mathrm{mg} \mathrm{L}^{-1}$;

FR: Factor de Resistencia; ns: sin diferencias significativas; *: diferencias significativas

En 2013 se publicaron resultados de poblaciones griegas de $T$. absoluta que presentaban una elevada susceptibilidad a clorantraniliprol (Roditakis et al., 2013a), con CL50 entre 0,12 y 0,53 $\mathrm{mg} \mathrm{L}^{-1}$, y una variabilidad de 4,4 (FR), siendo esta variabilidad similar a la encontrada en este trabajo $(F R=5,5)$. Comparados con nuestros valores de CL50 mostrados en la tabla 4.1, existen diferencias significativas entre la población griega menos susceptible $\left(C L 50=0,53 \mathrm{mg} \mathrm{L}^{-1}\right) \mathrm{y}$ Charneca, nuestra población menos susceptible $\left(C L 50=0,23 \mathrm{mg} \mathrm{L}^{-1}\right)$. Además, en otro trabajo se encontraron bajos niveles de resistencia en poblaciones italianas de T. absoluta (Roditakis 
et al., 2013b), con CL50 que variaban entre 0,23 y 1,34 $\mathrm{mg} \mathrm{L}^{-1}$, encontrándose diferencias significativas entre la población italiana menos susceptible de este trabajo y nuestra población menos susceptible Charneca. Asimismo, la variabilidad encontrada entre las poblaciones italianas fue de 5,8 (FR). Esta variabilidad es también muy parecida a la encontrada en nuestro trabajo ( $F R=5,5$ ). Otros autores (Campos et al., 2014b) publicaron resultados de poblaciones brasileñas de $T$. absoluta muy susceptibles a clorantraniliprol, con valores de CL50 entre 0,003 y $0,030 \mathrm{mg} \mathrm{L}^{-1}$, y una variabilidad de 10 (FR). Las CL50 de las poblaciones brasileñas de $T$. absoluta del trabajo anteriormente citado, están por debajo de la CL50 de nuestra población más susceptible Gallego1 $\left(0,04 \mathrm{mg} \mathrm{L}^{-1}\right)$. Estas pequeñas diferencias en los valores de susceptibilidad en los trabajos mencionados, se pueden achacar a las diferencias en la metodología de los bioensayos y la valoración de la mortalidad.

Una vez obtenida la línea base de susceptibilidad como referencia para estudiar la evolución en el tiempo de la resistencia de $T$. absoluta al insecticida clorantraniliprol, se realizaron bioensayos con poblaciones de T. absoluta entre los años 2013 y 2016. Estos resultados se muestran en la tabla 4.2, y las CL50 se compararon con la línea base de susceptibilidad calculada con los bioensayos realizados entre los años 2010-2012.

Tabla 4.2: Evolución de la toxicidad a clorantraniliprol de diferentes poblaciones de $T$. absoluta entre los años 2013 y 2016.

\begin{tabular}{|c|c|c|c|c|c|c|}
\hline Año & País & Población & CL50 & LF $(95 \%)$ & FR & \\
\hline & & Línea Base & 0,13 & $0,11-0,17$ & 1 & \\
\hline \multirow{3}{*}{2013} & Mezcla & Mixta & 0,12 & $0,10-0,14$ & 0,9 & ns \\
\hline & Italia & Pomodoro & 0,49 & $0,35-0,70$ & 3,8 & $*$ \\
\hline & Grecia & Peloponeso & 0,07 & $0,04-0,13$ & 0,5 & ns \\
\hline \multirow{5}{*}{2014} & \multirow{4}{*}{ España } & Gallego2 & 0,15 & $0,12-0,20$ & 1,2 & ns \\
\hline & & Villaverde & 0,13 & $0,07-0,18$ & 1,0 & ns \\
\hline & & Calnegre & 1,45 & $1,08-2,06$ & 11,2 & $*$ \\
\hline & & Mojonera & 0,44 & $0,29-0,63$ & 3,4 & $*$ \\
\hline & Italia & Sicilia & 47,65 & $24,54-183,09$ & 367 & $*$ \\
\hline \multirow{3}{*}{2015} & \multirow{3}{*}{ España } & Almería15 & 0,17 & $0,11-0,23$ & 1,3 & ns \\
\hline & & La Cañada & 0,14 & $0,07-0,23$ & 1,1 & ns \\
\hline & & La Palma & 0,15 & $0,10-0,21$ & 1,2 & ns \\
\hline \multirow{5}{*}{2016} & \multirow{2}{*}{ España } & Totana & 0,12 & $0,02-0,22$ & 0,9 & ns \\
\hline & & Mazarrón2 & 1,29 & $0,66-6,85$ & 9,9 & $*$ \\
\hline & \multirow{2}{*}{ Italia } & Sannito & 63,19 & $12,49-139,97$ & 486 & $*$ \\
\hline & & Frasanito & 122,63 & $34,82-278,39$ & 943 & $*$ \\
\hline & Portugal & Portugal1 & 0,32 & $0,19-0,49$ & 2,5 & $*$ \\
\hline
\end{tabular}

CL50: Concentración letal 50 en $\mathrm{mg} \mathrm{L}^{-1}$; LF (95\%): Límites fiduciales al $95 \%$ en $\mathrm{mg} \mathrm{L}^{-1}$; FR: Factor de Resistencia; ns: sin diferencias significativas; *: diferencias significativas 
En el año 2013 no se encontraron diferencias significativas con respecto a la línea base de susceptibilidad, excepto para la población italiana Pomodoro, que presentó un FR de 3,8. Este resultado se encuentra dentro de la variabilidad natural esperable, que en los años previos fue de 5,5 (Tabla 4.1).

En 2014, aparecen 2 poblaciones con niveles de resistencia superiores al resto de poblaciones bioensayadas en años anteriores. La población española Calnegre presentó una CL50 de 1,45 $\mathrm{mg} \mathrm{L}^{-1}$, presentando cambios significativos en la susceptibilidad a clorantraniliprol. Igualmente, la población italiana Sicilia obtuvo una CL50 de 47,65 $\mathrm{mg} \mathrm{L}^{-1}$, y un FR con respecto a la línea base de susceptibilidad de 367. Roditakis et al. (2015) mostraron resultados de poblaciones griegas que presentaban cambios significativos en la susceptibilidad a clorantraniliprol, con CL50 que variaban entre 1,34 y $2,45 \mathrm{mg} \mathrm{L}^{-1}$, no habiendo diferencias significativas entre estas poblaciones y nuestra población española Calnegre. Estos autores también observaron los primeros casos de resistencia a clorantraniliprol en poblaciones italianas de $T$. absoluta, con valores de CL50 entre 47,6 y $435 \mathrm{mg} \mathrm{L}^{-1}$, no encontrando diferencias significativas entre estas poblaciones italianas y nuestra población Sicilia. Nuestros resultados también coinciden con los publicados por Karaağaç (2015), que mostró datos sobre poblaciones turcas de $T$. absoluta que presentaban valores de CL50 entre 0,89 y $6,35 \mathrm{mg} \mathrm{L}^{-1}$, y con los de Yalçin et al. (2015), que también mostraron datos sobre poblaciones turcas con CL50 entre 8,36 y 15,35 $\mathrm{mg} \mathrm{L}^{-1}$.

Por otro lado, Campos et al. (2014a) estudiaron la susceptibilidad a clorantraniliprol en una población brasileña de $T$. absoluta, que presentaba una CL50 de $12,18 \mathrm{mg} \mathrm{L}^{-1}$, valor superior a las CL50 halladas en las poblaciones estudiadas en este trabajo, exceptuando las poblaciones italianas bioensayadas en 2014 y 2016 (Tabla 4.2). Asimismo, Silva et al. (2016) publicaron resultados de poblaciones brasileñas con elevados niveles de resistencia a clorantraniliprol, con CL50 entre 0,004 y $1262 \mathrm{mg} \mathrm{L}^{-1}$, y una variabilidad de 315500 (FR). Esta variabilidad es muy superior a la encontrada en este trabajo (Tabla 4.1; Tabla 4.2).

En las poblaciones bioensayadas en 2015 no se encontró variabilidad en la susceptibilidad a clorantraniliprol, sin diferencias significativas con respecto a la línea base de susceptibilidad. Sin embargo, en 2016 apareció una población española, Mazarrón2, que presentó cambios significativos en la susceptibilidad a clorantraniliprol, con una CL50 de 1,29 $\mathrm{mg} \mathrm{L}^{-1}$, y también se bioensayaron dos poblaciones italianas que presentaban elevados niveles de resistencia a clorantraniliprol, Sannito y Frasanito, con CL50 de 63,19 y 122,63 mg L-1 respectivamente. Estos resultados coinciden con los publicados en 2017 por Roditakis et al. (2017a), que mostraron los primeros datos de poblaciones griegas de $T$. absoluta resistentes a clorantraniliprol, con CL50 entre 0,31 y $161 \mathrm{mg} \mathrm{L}^{-1}$, y una variabilidad de 519 (FR). Asimismo, en otro trabajo se mostraron resultados de poblaciones brasileñas muy resistentes a clorantraniliprol, con CL50 de $92 \mathrm{mg} \mathrm{L}^{-1}$ y $650 \mathrm{mg} \mathrm{L}^{-1}$ (Roditakis et al., 2017b). Roditakis et al. (2017c) también encontraron poblaciones italianas, griegas e israelitas con niveles muy elevados de resistencia a clorantraniliprol, con CL50 de $838 \mathrm{mg} \mathrm{L}^{-1}$, más de $1000 \mathrm{mg} \mathrm{L}^{-1} \mathrm{y}$ de casi $7000 \mathrm{mg} \mathrm{L}^{-1}$ respectivamente. Todos estos valores son muy superiores comparados con los evaluados en este trabajo. 
Las poblaciones bioensayadas en 2014 y 2015, Calnegre y Mazarrón2, aunque mostraron cambios significativos en la susceptibilidad a clorantraniliprol, no se espera que presenten problemas de fallos de control en campo, debido a que sus valores de CL50 son aún muy inferiores a la dosis de campo de este insecticida $\left(35 \mathrm{mg} \mathrm{L}^{-1}\right)$. Sin embargo, los elevados valores de CL50 de las poblaciones italianas Sicilia, Sannito y Frasanito, superiores a la dosis de campo, sugieren que ya existen problemas de control en campo de poblaciones de $T$. absoluta en algunas zonas de Sicilia, siendo este hecho bastante significativo y a tener en cuenta para realizar un seguimiento de la resistencia a clorantraniliprol en $T$. absoluta en la región de Sicilia.

En cuanto a otros lepidópteros, se han observado en otros estudios rangos de variabilidad parecidos a los encontrados en este trabajo para T. absoluta. En 2015 se encontraron poblaciones australianas de Helicoverpa armigera (Hübner) (Lepidoptera: Noctuidae) muy susceptibles a clorantraniliprol (Bird, 2015), con valores de CL50 entre 0,014 y 0,048 mg L ${ }^{-1}, \mathrm{y}$ una variabilidad de 3,4 (FR).

Por otro lado, Su et al. (2012), observaron una elevada susceptibilidad a clorantraniliprol en poblaciones chinas de Spodoptera litura (Fabricius) (Lepidoptera: Noctuidae), con CL50 entre 0,004 y 0,102 $\mathrm{mg} \mathrm{L}^{-1}$, y una variabilidad de 25,5 (FR). Más recientemente, en 2016 se encontraron poblaciones chinas de $S$. litura con CL50 entre 0,11 y $1,71 \mathrm{mg} \mathrm{L}^{-1}$ y una variabilidad de 15,4 (FR) (Sang et al., 2016). Estos rangos de variabilidad son superiores a los encontrados en los primeros años de monitoreo de T. absoluta (Tabla 4.1).

En 2011, un trabajo mostró resultados sobre poblaciones de campo de Spodoptera exigua (Hübner) (Lepidoptera: Noctuidae) procedentes de China muy susceptibles a clorantraniliprol, con CL50 entre 0,039 y 0,240 $\mathrm{mg} \mathrm{L}^{-1}$, y una variabilidad de 6,15 (FR) (Lai et al., 2011). Esta variabilidad es ligeramente superior a la encontrada en los primeros años de monitoreo de $T$. absoluta (Tabla 4.1). Por otro lado, Che et al. (2013) encontraron poblaciones chinas con baja susceptibilidad a clorantraniliprol, con valores máximos de CL50 de $16,48 \mathrm{mg} \mathrm{L}^{-1}$ y una variabilidad de 26 (FR), siendo esta última superior a la variabilidad observada en $T$. absoluta entre los años 2010 y 2012 (Tabla 4.1).

También se ha estudiado la susceptibilidad de Plutella xylostella Linnaeus (Lepidoptera: Plutellidae) a clorantraniliprol. Liu et al. (2015) observaron una menor susceptibilidad a clorantraniliprol en poblaciones chinas de $P$. xylostella con CL50 entre 0,058 y 1,63 $\mathrm{mg} \mathrm{L}^{-1}$, y una variabilidad de 28 (FR). Asimismo, Zhang et al. (2016) encontraron poblaciones chinas de P. xylostella con CL50 a clorantraniliprol entre 0,27 y $3,28 \mathrm{mg} \mathrm{L}^{-1}$, y una variabilidad de 12,1 (FR). Estos valores de variabilidad son superiores a los observados en $T$. absoluta entre los años 2010 y 2012 (Tabla 4.1). Sin embargo, al igual que ha ocurrido en T. absoluta en los últimos años, han aparecido casos de resistencia a clorantraniliprol en algunas poblaciones de $P$. xylostella. Troczka et al. (2012) encontraron una población de $P$. xylostella procedente de Filipinas resistente a clorantraniliprol, con un valor de CL50 superior a $200 \mathrm{mg} \mathrm{L}^{-1}$, y Wang et al. (2012) bioensayaron una población china de $P$. xylostella resistente a clorantraniliprol, con una CL50 también superior a $200 \mathrm{mg} \mathrm{L}^{-1}$. 
En 2013, Wang et al. (2013) publicaron resultados sobre una población china bastante resistente a clorantraniliprol (CL50 de $150 \mathrm{mg} \mathrm{L}^{-1}$ ), y en 2014, Gong et al. (2014) también encontraron una población china de $P$. xylostella con una elevada resistencia a clorantraniliprol (CL50 superior a $1000 \mathrm{mg} \mathrm{L}^{-1}$ ). Por otro lado, también en 2014 se encontraron poblaciones brasileñas de $P$. xylostella bastante resistentes a clorantraniliprol, con valores máximos de CL50 de 204,3 $\mathrm{mg} \mathrm{L}^{-1}$ (Ribeiro et al., 2014), y en 2015, un estudio mostró resultados de una población de $P$. xylostella procedente de Filipinas muy resistente a clorantraniliprol, con un valor de CL50 superior a $1000 \mathrm{mg} \mathrm{L}^{-1}$ (Steinbach et al., 2015).

La tabla 4.3 muestra los resultados de los bioensayos realizados con larvas en diferentes estados de desarrollo, L2 y L4, de dos poblaciones de T. absoluta. Para la población Mixta, no hubo diferencias significativas entre los estados de desarrollo, con CL50 de 0,12 y $0,26 \mathrm{mg} \mathrm{L}^{-1}$ para los bioensayos con L2 y L4 respectivamente. Tampoco se observaron diferencias significativas para la población Calnegre, con CL50 de 1,45 y $1,18 \mathrm{mg} \mathrm{L}^{-1}$ para los bioensayos con L2 y L4 respectivamente. Estos datos sugieren que no existen diferencias en la susceptibilidad a clorantraniliprol en función del estado de desarrollo larvario de $T$. absoluta, por lo que los tratamientos con clorantraniliprol tienen el mismo efecto en distintos estadios larvarios de T. absoluta, a diferencia de otros insecticidas como Bacillus thuringiensis (Berliner) (Firmicutes: Bacillaceae) que son más eficaces en los primeros estados de desarrollo larvario (González-Cabrera et al., 2011).

Tabla 4.3: Toxicidad a clorantraniliprol de dos poblaciones de $T$. absoluta en estado larvario L2 y L4.

\begin{tabular}{c|cccc}
\hline \multicolumn{2}{c}{ Población } & CL50 & LF (95\%) & FR \\
\hline Mixta (L2) & 0,12 & $0,10-0,14$ & 1 & \\
\hline Mixta (L4) & 0,26 & $0,14-1,94$ & 2,1 & ns \\
\hline Calnegre (L2) & 1,45 & $1,08-2,06$ & 1 & \\
Calnegre (L4) & 1,18 & $0,59-2,01$ & 0,8 & ns \\
\hline
\end{tabular}

CL50: Concentración letal 50 en $\mathrm{mg} \mathrm{L}^{-1}$; LF (95\%): Límites fiduciales al 95\% en $\mathrm{mg} \mathrm{L}^{-1}$; FR: Factor de Resistencia; ns: sin diferencias significativas

\subsubsection{Ciantraniliprol}

Los resultados obtenidos de los bioensayos realizados en los años 2010, 2011 y 2012 para el insecticida ciantraniliprol se muestran en la tabla 4.4. La población que presentó un menor valor de CL50 fue la española Tudela $\left(0,05 \mathrm{mg} \mathrm{L}^{-1}\right)$. Esta población se consideró como la población susceptible de referencia en comparación con el resto de poblaciones bioensayadas. Por otro lado, las poblaciones de Almería y Mazarrón fueron las que presentaron mayores valores de CL50 (0,15 $\left.\mathrm{mg} \mathrm{L}^{-1}\right)$. La variabilidad entre la población más susceptible y la menos susceptible fue de 3,2 (FR). Aunque hubo diferencias significativas entre algunas de las 
poblaciones, estas se encuentran dentro de la variabilidad natural esperable. Además, el rango de valores de los factores de resistencia para ciantraniliprol reveló menos variabilidad entre las poblaciones que para el insecticida clorantraniliprol. La línea base de susceptibilidad calculada a partir de las CL50 obtenidas con las poblaciones bioensayadas en los años 2010, 2011 y 2012 fue de $0,09 \mathrm{mg} \mathrm{L}^{-1}$, siendo muy similar a la línea base de susceptibilidad de clorantraniliprol $\left(0,13 \mathrm{mg} \mathrm{L}^{-1}\right)$. Los valores de CL50 de las poblaciones bioensayadas a ciantraniliprol y su línea base de susceptibilidad están muy por debajo de la dosis de campo recomendada para este insecticida (100 $\mathrm{mg} \mathrm{L}^{-1}$ ), por lo que las poblaciones se muestran muy susceptibles a este insecticida. Sin embargo, es necesario vigilar que no se ejerza una elevada presión de selección al tratar a la dosis de campo recomendada, debido a que esta es muy superior a los valores de CL50 mostrados por las poblaciones bioensayadas.

Tabla 4.4: Toxicidad a ciantraniliprol de diferentes poblaciones de $T$. absoluta y línea base de susceptibilidad.

\begin{tabular}{|c|c|c|c|c|c|c|}
\hline País & Año & Población & CL50 & LF (95\%) & FR & \\
\hline \multirow{8}{*}{ España } & 2010 & Abarán & 0,09 & $0,07-0,11$ & 2,0 & ns \\
\hline & 2010 & Níjar & 0,09 & $0,05-0,17$ & 2,0 & ns \\
\hline & 2010 & Canarias & 0,07 & $0,06-0,10$ & 1,6 & ns \\
\hline & 2010 & Gallego1 & 0,09 & $0,04-0,15$ & 1,9 & ns \\
\hline & 2010 & Almería & 0,15 & $0,07-0,21$ & 3,2 & ns \\
\hline & 2010 & Tudela & 0,05 & $0,03-0,07$ & 1 & - \\
\hline & 2011 & Águilas & 0,09 & $0,07-0,12$ & 2,0 & ns \\
\hline & 2012 & Mazarrón & 0,15 & $0,11-0,19$ & 3,2 & $*$ \\
\hline \multirow{3}{*}{ Italia } & 2010 & Biancavilla & 0,09 & $0,05-0,14$ & 1,9 & ns \\
\hline & 2011 & Foggia & 0,08 & $0,05-0,13$ & 1,8 & ns \\
\hline & 2012 & Fossano & 0,14 & $0,07-0,29$ & 3,1 & ns \\
\hline \multirow{2}{*}{ Portugal } & 2010 & Charneca & 0,13 & $0,08-0,18$ & 2,8 & $*$ \\
\hline & 2010 & Boavista & 0,12 & $0,07-0,22$ & 2,7 & ns \\
\hline Francia & 2012 & Francia & 0,07 & $0,02-0,15$ & 1,4 & ns \\
\hline \multicolumn{3}{|c|}{ Línea Base de Susceptibilidad } & 0,09 & $0,08-0,11$ & - & \\
\hline
\end{tabular}

CL50: Concentración letal 50 en $\mathrm{mg} \mathrm{L}^{-1}$; LF (95\%): Límites fiduciales al 95\% en $\mathrm{mg} \mathrm{L}^{-1}$; FR: Factor de Resistencia; ns: sin diferencias significativas; *: diferencias significativas

En 2014 se encontraron poblaciones brasileñas de T. absoluta muy susceptibles a ciantraniliprol (Campos et al., 2014b), con CL50 entre 0,008-0,02 $\mathrm{mg} \mathrm{L}^{-1}$ y una variabilidad de 2,5 (FR). Estos valores son muy similares a los mostrados en la tabla 4.4 de las poblaciones bioensayadas en este trabajo. 
En la tabla 4.5 se presentan los resultados de la evolución de la resistencia de $T$. absoluta a ciantraniliprol entre los años 2013 y 2015, comparando las CL50 obtenidas de los bioensayos realizados en ese periodo de tiempo con la línea base de susceptibilidad calculada entre los años 2010-2012.

Tabla 4.5: Evolución de la toxicidad a ciantraniliprol de diferentes poblaciones de $T$. absoluta entre los años 2013 y 2015.

\begin{tabular}{|c|c|c|c|c|c|c|}
\hline Año & País & Población & CL50 & LF (95\%) & FR & \\
\hline & & Línea Base & 0,09 & $0,08-0,11$ & 1 & \\
\hline \multirow{2}{*}{2013} & Mezcla & Mixta & 0,09 & $0,07-0,10$ & 1,0 & ns \\
\hline & Italia & Pomodoro & 0,15 & $0,11-0,22$ & 1,7 & ns \\
\hline \multirow{5}{*}{2014} & \multirow{4}{*}{ España } & Gallego2 & 0,13 & $0,10-0,16$ & 1,4 & ns \\
\hline & & Villaverde & 0,06 & $0,04-0,08$ & 0,7 & ns \\
\hline & & Calnegre & 0,54 & $0,13-1,26$ & 6,0 & $*$ \\
\hline & & Mojonera & 0,28 & $0,19-0,42$ & 3,1 & $*$ \\
\hline & Italia & Sicilia & 6,94 & $2,34-13,59$ & 77,1 & $*$ \\
\hline \multirow{2}{*}{2015} & \multirow{2}{*}{ España } & Almería15 & 0,11 & $0,07-0,15$ & 1,2 & ns \\
\hline & & La Palma & 0,31 & $0,19-0,58$ & 3,4 & $*$ \\
\hline
\end{tabular}

CL50: Concentración letal 50 en $\mathrm{mg} \mathrm{L}^{-1}$; LF (95\%): Límites fiduciales al 95\% en $\mathrm{mg} \mathrm{L}^{-1}$;

FR: Factor de Resistencia; ns: sin diferencias significativas; *: diferencias significativas

En 2013 no se encontraron diferencias significativas para las dos poblaciones bioensayadas, Mixta y Pomodoro, con respecto a la línea base de susceptibilidad. Sin embargo, en el año 2014 dos poblaciones españolas, Calnegre y Mojonera, presentaron una menor susceptibilidad a ciantraniliprol en comparación con el resto de poblaciones bioensayadas y también con respecto a la línea base de susceptibilidad de este insecticida, mostrando unos valores de CL50 de $0,54 \mathrm{mg} \mathrm{L}^{-1}$ y $0,28 \mathrm{mg} \mathrm{L}^{-1}$ respectivamente. En este mismo año, la población italiana Sicilia presentó una CL50 de 6,94 $\mathrm{mg} \mathrm{L}^{-1}$ y un FR con respecto a la línea base de susceptibilidad de 77, siendo esta población mucho menos susceptible a ciantraniliprol que el resto de poblaciones de T. absoluta bioensayadas a este insecticida. En 2016 se encontraron poblaciones brasileñas con valores de CL50 que variaban entre 0,015 y 281,3 $\mathrm{mg} \mathrm{L}^{-1}$ (Silva et al., 2016), siendo este último valor muy superior a cualquiera de los mostrados en la tabla 4.5.

Las poblaciones Calnegre y Sicilia, al igual que ocurre para el insecticida clorantraniliprol, fueron las que presentaron una menor susceptibilidad a ciantraniliprol, aunque sus valores de CL50 están aún muy por debajo de la dosis de campo recomendada para este insecticida (100 $\mathrm{mg} \mathrm{L}^{-1}$ ). La similitud que existe entre los insecticidas ciantraniliprol y clorantraniliprol en dos poblaciones procedentes de diferentes países, sugiere una posible resistencia cruzada entre 
ellos. Esta resistencia cruzada puede deberse al desarrollo de un mecanismo de resistencia en el punto de acción en las poblaciones de $T$. absoluta que presentan menor susceptibilidad a estas dos diamidas.

Por otro lado, en las poblaciones bioensayadas en 2015 no se encontraron diferencias significativas con respecto a la línea base de susceptibilidad, excepto para la población La Palma, que presentó un FR de 3,4. Sin embargo, este resultado se encuentra dentro de la variabilidad natural esperable calculada en los años anteriores, que fue de 3,2 (Tabla 4.4).

En la actualidad, no existen muchos estudios sobre la susceptibilidad de T. absoluta al insecticida ciantraniliprol, seguramente debido a que en algunos países aún no está registrado su uso para esta plaga. Sin embargo, sí se han encontrado trabajos sobre la susceptibilidad a ciantraniliprol en otros lepidópteros como $P$. xylostella. Liu et al. (2015) presentaron resultados sobre la susceptibilidad de poblaciones chinas de $P$. xylostella, con valores de CL50 entre 0,015 y $0,16 \mathrm{mg} \mathrm{L}^{-1}$. Estos resultados son muy similares a los encontrados para $T$. absoluta entre los años 2010 y 2012. En 2016, Zhang et al. (2016) también mostraron datos sobre poblaciones chinas de $P$. xylostella susceptibles a ciantraniliprol, con CL50 entre 0,08 y 0,43 $\mathrm{mg} \mathrm{L}^{-1}$ y una variabilidad de 5,4 (FR). Esta variabilidad es ligeramente superior a la encontrada en $T$. absoluta (Tabla 4.4). Por otro lado, Steinbach et al. (2015) mostraron resultados de una población de $P$. xylostella procedente de Filipinas con un valor de CL50 de $18 \mathrm{mg} \mathrm{L}^{-1}$ a ciantraniliprol, valor muy superior a los encontrados en este trabajo para T. absoluta.

En el año 2016, Sang et al. (2016) encontraron poblaciones chinas de $S$. litura susceptibles a ciantraniliprol, con CL50 que variaban entre 0,083 y 1,336 $\mathrm{mg} \mathrm{L}^{-1}$ y una variabilidad de 16,1 (FR), que comparada con la observada en T. absoluta entre 2010 y 2012 (Tabla 4.4), es superior.

Ciantraniliprol presenta un espectro de acción más amplio que clorantraniliprol y flubendiamida, siendo eficaz para otras plagas agrícolas. Foster et al. (2012) estudiaron la susceptibilidad a ciantraniliprol en poblaciones de Myzus persicae Sulzer (Homoptera: Aphididae) y Aphis gossypii Glover (Hemiptera: Aphididae), obteniendo valores máximos de CL50 de $0,79 \mathrm{mg} \mathrm{L}^{-1}$ y $2,47 \mathrm{mg} \mathrm{L}^{-1}$ respectivamente.

También hay estudios de la susceptibilidad a ciantraniliprol en Frankliniella occidentalis (Pergande) (Thysanoptera: Thripidae). Herron et al. (2014) presentaron un estudio donde encontraron poblaciones australianas de $F$. occidentalis con CL50 que variaban entre 1,8 y 23 $\mathrm{mg} \mathrm{L}^{-1}$. En 2015, Bielza et al. (2015) mostraron los resultados de la susceptibilidad en adultos y larvas de poblaciones de $F$. occidentalis a ciantraniliprol, obteniendo valores máximos de CL50 de $2415 \mathrm{mg} \mathrm{L}^{-1}$ para adultos y 109,2 $\mathrm{mg} \mathrm{L}^{-1}$ para larvas.

En el año 2013, se publicó un estudio sobre la susceptibilidad de poblaciones americanas de Bemisia tabaci (Gennadius) (Homoptera: Aleyrodidae) biotipo B a ciantraniliprol (Caballero et al., 2013). Este trabajo mostró resultados de poblaciones muy susceptibles a ciantraniliprol, tanto en estado de huevo como en estado adulto, con valores máximos de CL50 de 0,034 y 0,059 $\mathrm{mg} \mathrm{L}^{-1}$ respectivamente. Otro trabajo en 2014 (Grávalos et al., 2014) muestra los 
resultados de la susceptibilidad de poblaciones de $B$. tabaci biotipo $Q$ al insecticida ciantraniliprol, con valores de CL50 que variaban entre 0,011 y $0,116 \mathrm{mg} \mathrm{L}^{-1}$ en estado de ninfa.

La tabla 4.6 muestra los resultados de los bioensayos realizados con larvas L2 y L4, de dos poblaciones de T. absoluta. Para la población Mixta, no hubo diferencias significativas entre los estados de desarrollo, con CL50 de 0,09 y $0,15 \mathrm{mg} \mathrm{L}^{-1}$ para los bioensayos con L2 y L4 respectivamente. De igual manera, no se observaron diferencias significativas para la población Calnegre, con CL50 de 0,54 y 0,69 $\mathrm{mg} \mathrm{L}^{-1}$ para los bioensayos con L2 y L4 respectivamente. Al igual que para el insecticida clorantraniliprol, no existen diferencias en la susceptibilidad a ciantraniliprol al aplicar el insecticida sobre larvas en estadio L2 o L4, es decir, su efectividad sobre las poblaciones de $T$. absoluta no depende del estado larvario en la que se encuentren.

Tabla 4.6: Toxicidad a ciantraniliprol de dos poblaciones de $T$. absoluta en estado larvario L2 y L4.

\begin{tabular}{|c|c|c|c|c|}
\hline Población & CL50 & LF (95\%) & FR & \\
\hline Mixta (L2) & 0,09 & $0,07-0,10$ & 1 & \\
\hline Mixta (L4) & 0,15 & $0,09-0,23$ & 1,6 & ns \\
\hline Calnegre (L2) & 0,54 & $0,13-1,26$ & 1 & \\
\hline Calnegre (L4) & 0,69 & $0,19-1,51$ & 1,3 & ns \\
\hline
\end{tabular}

CL50: Concentración letal 50 en $\mathrm{mg} \mathrm{L}^{-1}$; LF (95\%): Límites fiduciales al 95\% en $\mathrm{mg} \mathrm{L}^{-1}$; FR: Factor de Resistencia; ns: sin diferencias significativas

\subsubsection{Flubendiamida}

La tabla 4.7 representa los resultados obtenidos de los bioensayos realizados en los años 2010 y 2011 en poblaciones de T. absoluta para el insecticida flubendiamida. La población española Abarán fue la que mostró un menor valor de $\operatorname{CL50}\left(0,08 \mathrm{mg} \mathrm{L}^{-1}\right)$, siendo considerada la población más susceptible con respecto al resto de poblaciones. La población italiana Foggia fue la menos susceptible, ya que presentó el mayor valor de $\operatorname{CL50}\left(0,20 \mathrm{mg} \mathrm{L}^{-1}\right)$. La población Foggia fue 2,5 veces menos susceptible a flubendiamida que la población Abarán (FR). No se encontraron diferencias significativas entre las poblaciones bioensayadas a flubendiamida, por lo que hubo bastante homogeneidad entre las poblaciones bioensayadas en comparación con las otras dos diamidas, clorantraniliprol (Tabla 4.1) y ciantraniliprol (Tabla 4.4). La línea base de susceptibilidad, teniendo en cuenta todas las poblaciones, fue de $0,12 \mathrm{mg} \mathrm{L}^{-1}, 500$ veces menor que la dosis de campo recomendada para flubendiamida $\left(60 \mathrm{mg} \mathrm{L}^{-1}\right)$. Por otro lado, esta línea base de susceptibilidad es muy similar a las líneas base de susceptibilidad de clorantraniliprol y ciantraniliprol (0,13 y $0,09 \mathrm{mg} \mathrm{L}^{-1}$ respectivamente). 
Tabla 4.7: Toxicidad a flubendiamida de diferentes poblaciones de $T$. absoluta y línea base de susceptibilidad.

\begin{tabular}{|c|c|c|c|c|c|c|}
\hline País & Año & Población & CL50 & LF (95\%) & FR & \\
\hline \multirow{7}{*}{ España } & 2010 & Abarán & 0,08 & $0,02-0,14$ & 1 & - \\
\hline & 2010 & Níjar & 0,19 & $0,12-0,27$ & 2,4 & ns \\
\hline & 2010 & Canarias & 0,09 & $0,04-0,18$ & 1,1 & ns \\
\hline & 2010 & Gallego1 & 0,11 & $0,05-0,23$ & 1,4 & ns \\
\hline & 2010 & Almería & 0,14 & $0,10-0,19$ & 1,8 & ns \\
\hline & 2010 & Tudela & 0,17 & $0,11-0,24$ & 2,1 & ns \\
\hline & 2011 & Águilas & 0,10 & $0,06-0,14$ & 1,3 & ns \\
\hline \multirow{2}{*}{ Italia } & 2010 & Biancavilla & 0,09 & $0,05-0,16$ & 1,2 & ns \\
\hline & 2011 & Foggia & 0,20 & $0,11-0,29$ & 2,5 & ns \\
\hline \multirow{2}{*}{ Portugal } & 2010 & Charneca & 0,13 & $0,06-0,19$ & 1,6 & ns \\
\hline & 2010 & Boavista & 0,17 & $0,06-0,31$ & 2,1 & ns \\
\hline \multicolumn{3}{|c|}{ Línea Base de Susceptibilidad } & 0,12 & $0,11-0,14$ & - & \\
\hline
\end{tabular}

CL50: Concentración letal 50 en $\mathrm{mg} \mathrm{L}^{-1}$; LF (95\%): Límites fiduciales al 95\% en $\mathrm{mg} \mathrm{L}^{-1}$;

FR: Factor de Resistencia; ns: sin diferencias significativas; *: diferencias significativas

En 2013, Roditakis et al. (2013a) presentaron resultados de susceptibilidad a flubendiamida de poblaciones griegas de $T$. absoluta, con CL50 entre 0,31 y $1,31 \mathrm{mg} \mathrm{L}^{-1}$, valores ligeramente superiores a los presentados en este trabajo (Tabla 4.7). Por otro lado, en el año 2014, Campos et al. (2014b) mostraron los resultados de poblaciones brasileñas muy susceptibles a flubendiamida, con valores de CL50 entre 0,09 y $0,23 \mathrm{mg} \mathrm{L}^{-1}$. Estos valores fueron similares a los obtenidos en este trabajo entre los años 2010 y 2011 (Tabla 4.7).

En los años 2013 y 2014 se realizaron bioensayos de susceptibilidad para estudiar la evolución en el tiempo de la resistencia de T. absoluta al insecticida flubendiamida (Tabla 4.8). Los valores de CL50 de estos años se compararon con la línea base de susceptibilidad calculada con los bioensayos realizados entre los años 2010-2011. 
Tabla 4.8: Evolución de la toxicidad a flubendiamida de diferentes poblaciones de $T$. absoluta en los años 2013 y 2014.

\begin{tabular}{c|c|ccccc}
\hline \multicolumn{2}{c|}{ Año } & País & Población & CL50 & LF (95\%) & \multicolumn{1}{c}{ FR } \\
& & Línea Base & $\mathbf{0 , 1 2}$ & $\mathbf{0 , 1 1 - 0 , 1 4}$ & $\mathbf{1}$ & \\
\hline \multirow{2}{*}{$\mathbf{2 0 1 3}$} & Mezcla & Mixta & 0,14 & $0,12-0,16$ & 1,2 & ns \\
\hline \multirow{3}{*}{2014} & \multirow{2}{*}{ España } & Calnegre & 0,38 & $0,04-1,22$ & 3,2 & ns \\
\cline { 2 - 7 } & & Mojonera & 0,22 & $0,08-0,54$ & 1,8 & ns \\
\cline { 2 - 7 } & Italia & Sicilia & 449,8 & $115,32-875,19$ & 3748 & $*$ \\
\hline
\end{tabular}

CL50: Concentración letal 50 en $\mathrm{mg} \mathrm{L}^{-1}$; LF (95\%): Límites fiduciales al 95\% en $\mathrm{mg} \mathrm{L}^{-1}$;

FR: Factor de Resistencia; ns: sin diferencias significativas; * : diferencias significativas

En el año 2013 solamente se pudo bioensayar una población, Mixta, con un valor de CL50 de $0,14 \mathrm{mg} \mathrm{L}^{-1}$. Este valor fue similar a la línea base de susceptibilidad de flubendiamida para $T$. absoluta $\left(0,12 \mathrm{mg} \mathrm{L}^{-1}\right)$ calculada en años anteriores. En el caso de las poblaciones bioensayadas en el año 2014, no hubo diferencias significativas con respecto a la línea base de susceptibilidad para las dos poblaciones españolas Calnegre y Mojonera, que mostraron valores de CL50 de 0,38 y 0,22 $\mathrm{mg} \mathrm{L}^{-1}$ respectivamente. Sin embargo, para la población italiana Sicilia, se obtuvieron valores de CL50 de $449,8 \mathrm{mg} \mathrm{L}^{-1}$ y un FR con respecto a la línea base de susceptibilidad de 3748 , siendo esta población muy resistente comparada con las poblaciones de $T$. absoluta bioensayadas a flubendiamida en años anteriores. Asimismo, Roditakis et al. (2015) también mostraron los resultados de poblaciones italianas de T. absoluta muy resistentes a flubendiamida, con CL50 entre 993 y $1376 \mathrm{mg} \mathrm{L}^{-1}$, y poblaciones griegas moderadamente resistentes con CL50 de $8,4 \mathrm{mg} \mathrm{L}^{-1}$. En 2016, se encontraron poblaciones brasileñas muy resistentes a flubendiamida, con CL50 que variaban entre 0,038 y $3018 \mathrm{mg} \mathrm{L}^{-1}$ (Silva et al., 2016).

La población Sicilia, al igual que ocurre para las otras dos diamidas, clorantraniliprol y ciantraniliprol, fue la que mostró una menor susceptibilidad a flubendiamida (Tabla 4.8), superando la dosis de campo recomendada para este insecticida $\left(60 \mathrm{mg} \mathrm{L}^{-1}\right)$. Este hecho parece confirmar la sospecha de la posible resistencia cruzada entre las tres diamidas, conferida probablemente por un mecanismo de resistencia en el punto de acción.

En la actualidad, se pueden encontrar diferentes trabajos sobre la susceptibilidad a flubendiamida en P. xylostella. Liu et al. (2015) mostraron resultados de poblaciones chinas que presentaron baja susceptibilidad a flubendiamida, con CL50 entre 0,16 y $3,25 \mathrm{mg} \mathrm{L}^{-1}$, y una variabilidad de 20,3 (FR). Esta variabilidad es superior a la encontrada para $T$. absoluta en los años 2010 y 2011 (Tabla 4.7). Por otro lado, se han encontrado poblaciones de $P$. xylostella muy resistentes a flubendiamida (Troczka et al., 2012), con CL50 superiores a $200 \mathrm{mg} \mathrm{L}^{-1}, \mathrm{y}$ CL50 superiores a $1000 \mathrm{mg} \mathrm{L}^{-1}$ (Steinbach et al., 2015). 
Tabla 4.9: Toxicidad a flubendiamida de dos poblaciones de $T$. absoluta en estado larvario L2 y L4.

\begin{tabular}{ccccc}
\hline Población & CL50 & LF (95\%) & FR & \\
\hline Mixta (L2) & 0,14 & $0,12-0,16$ & 1 & \\
Mixta (L4) & 0,82 & $0,35-3,41$ & 5,9 & $*$ \\
\hline Calnegre (L2) & 0,38 & $0,04-1,22$ & 1 & \\
Calnegre (L4) & 5,57 & $2,53-21,74$ & 14,7 & $*$ \\
\hline
\end{tabular}

CL50: Concentración letal 50 en $\mathrm{mg} \mathrm{L}^{-1}$; LF (95\%): Límites fiduciales al 95\% en $\mathrm{mg} \mathrm{L}^{-1}$;

FR: Factor de Resistencia; *: diferencias significativas

En la tabla 4.9 se muestran los resultados de los bioensayos realizados con larvas en los estados de desarrollo L2 y L4, de dos poblaciones de $T$. absoluta. Para la población Mixta, sí hubo diferencias significativas entre los bioensayos, con CL50 de 0,14 y 0,82 $\mathrm{mg} \mathrm{L}^{-1}$ para los bioensayos con L2 y L4 respectivamente, obteniendo un FR de 5,9 al comparar la CL50 del bioensayo en L4 con el realizado en L2. Asimismo, en la población Calnegre también se observaron diferencias significativas, con $\mathrm{CL} 50$ de 0,38 y $5,57 \mathrm{mg} \mathrm{L}^{-1}$ para los bioensayos con $\mathrm{L} 2$ y $L 4$ respectivamente, resultando un FR de 14,7. A diferencia de lo que ocurre en las otras dos diamidas, sí existen diferencias significativas en la susceptibilidad a flubendiamida dependiendo del estado larvario en el que se encuentre la población, siendo menos susceptible al insecticida cuando las larvas se encuentran en estadio L4. Por lo tanto, parece aconsejable realizar los tratamientos con flubendiamida en estadio larvario L2 o estadios primarios de $T$. absoluta. Además, la diferencia se acrecienta según es menos susceptible la población, por lo que el tratamiento sobre los primeros estados larvarios es muy importante para prevenir el desarrollo de resistencias.

\subsection{Conclusiones}

En este capítulo se pone de manifiesto la alta susceptibilidad a las tres diamidas, clorantraniliprol, ciantraniliprol y flubendiamida, entre las poblaciones de $T$. absoluta bioensayadas en los años 2010 y 2012. Asimismo, son muy similares las líneas bases de susceptibilidad calculadas para los tres insecticidas y se encuentran muy por debajo de sus respectivas dosis de campo recomendadas para su uso en $T$. absoluta.

Además, al realizar un seguimiento de poblaciones de $T$. absoluta para comprobar la evolución de la susceptibilidad a las tres diamidas, se encontró en el año 2014 una población italiana, Sicilia, que mostró resistencia a clorantraniliprol, ciantraniliprol y flubendiamida, superando la dosis de campo recomendada en el caso de clorantraniliprol y flubendiamida. Este hecho parece confirmar la sospecha de la posible resistencia cruzada entre las tres diamidas, conferida probablemente por un mecanismo de resistencia en el punto de acción. 
En los últimos años y hasta la fecha de este trabajo, han aparecido en España poblaciones de $T$. absoluta que presentaban ligeros cambios en la susceptibilidad a las tres diamidas, siendo este hecho significativo y a tener en cuenta para realizar un seguimiento de estas poblaciones y así prevenir un posible desarrollo de resistencias a las diamidas en estas zonas.

Por otro lado, no se han encontrado diferencias en la susceptibilidad a clorantraniliprol y ciantraniliprol dependiendo del estadio larvario en el que se encuentran las poblaciones de $T$. absoluta. Sin embargo, sí existen diferencias significativas en la susceptibilidad a flubendiamida en función del estadio larvario, siendo menos susceptible a flubendiamida cuando las larvas se encuentran en estadio L4.

\subsection{Referencias bibliográficas}

Bielza, P., Guillén, J. (2015). Cyantraniliprole: a valuable tool for Frankliniella occidentalis (Pergande) management. Pest Manag Sci 71: 1068-1074.

Bird, L.J. (2015). Baseline Susceptibility of Helicoverpa armigera (Lepidoptera: Noctuidae) to Indoxacarb, Emamectin Benzoate, and Chlorantraniliprole in Australia. J Econ Entomol 108 (1): 294-300.

Caballero, R., Cyman, S., Schuster, D.J., Portillo, H.E., Slater, R. (2013). Baseline susceptibility of Bemisia tabaci (Genn.) biotype B in southern Florida to cyantraniliprole. Crop Prot 44: 104-108.

Campos, M.R., Rodrigues, A.R.S., Silva, W.M., Silva, T.B.M., Silva, V.R.F., Guedes, R.N.C., Siqueira, H.A.A. (2014a). Spinosad and the Tomato Borer Tuta absoluta: A Bioinsecticide, an Invasive Pest Threat, and High Insecticide Resistance. PLoS One 9: e103235.

Campos, M.R., Silva, T.B.M., Silva, W.M., Silva, J.E., Siqueira, H.A.A. (2014b). Susceptibility of Tuta absoluta (Lepidoptera: Gelechiidae) Brazilian populations to ryanodine receptor modulators. Pest Manag Sci 71 (4): 537-544.

Che, W., Shi, T., Wu, Y., Yang, Y. (2013). Insecticide resistance status of field populations of Spodoptera exigua (Lepidoptera: Noctuidae) from China. J Econ Entomol 106 (4): 1855-1862.

Foster, S.P., Denholm, I., Rison, J-L., Portillo, H.E., Margaritopoulis, J., Slater, R. (2012). Susceptibility of standard clones and European field populations of the green peach aphid, Aphis gossypii (Hemiptera: Aphididae), to the novel anthranilic diamide insecticide cyantraniliprole. Pest Manag Sci 68: 629-633.

García-Vidal, L., Martínez-Aguirre, M.R., Bielza, P. (2015). Evolution of Tuta absoluta (Meyrick) (Lepidoptera: Gelechiidae) resistance to diamide insecticides over the last 5 years. En: ArtésHernández, F., Egea Gutiérrez-Cortines, M., Fernández-Hernández, J.A., Baille, A., Calatrava, J. (Eds.). Proceedings of the 4th WORKSHOP ON AGRI-FOOD RESEARCH. Ed. TAIDA-UPCT, Cartagena, España, pp. 112-115. 
Gong, W., Yan, H.H., Gao, L., Guo, Y.Y., Xue, C.B. (2014). Chlorantraniliprole resistance in the diamondback moth (Lepidoptera Plutellidae). J Econ Entomol 107 (2): 806-814.

González-Cabrera, J., Mollá, O., Montón, H., Urbaneja, A. (2011). Efficacy of Bacillus thuringiensis (Berliner) in controlling the tomato borer, Tuta absoluta (Meyrick) (Lepidoptera: Gelechiidae). BioControl 56: 71-80.

Grávalos, C., Fernández, E., Belando, A., Moreno, I., Ros, C., Bielza, P. (2014). Cross-resistance and baseline susceptibility of Mediterranean strains of Bemisia tabaci to cyantraniliprole. Pest Manag Sci doi: 10.1002/ps.3885.

Herron, G.A., Marshall, K.L., Cornwell, G.W. (2014). Australian baseline data for western flower thrips (Frankliniella occidentalis) susceptibility to cyantraniliprole (DPX-HGW86) and the establishment of a discriminating dose for resistance detection. Gen Appl Ent 42: 1-5.

Karaağaç, S.U. (2015). Enzyme Activities and Analysis of Susceptibility Levels in Turkish Tuta absoluta Populations to Chlorantraniliprole and Metaflumizone Insecticides. Phytoparasitica 43: 693-700.

Lai, T., Li, J., Su, J. (2011). Monitoring of beet armyworm Spodoptera exigua (Lepidoptera: Noctuidae) resistance to chlorantraniliprole in China. Pestic Biochem Physiol 101: 198-205.

LeOra-Software. (2005). POLO-Plus, POLO for Windows Petaluma, CA, LeOra Software.

Liu, X., Ning, Y., Wang, H., Wang, K. (2015). Cross-resistance, mode of inheritance, synergism, and fitness effects of cyantraniliprole resistance in Plutella xylostella. Entomol Exp Appl 157: 271-278.

Ribeiro, L.M.S., Wanderley-Teixeira, V., Ferreira, H.N., Teixeira, Á.A.C., Siqueira, H.A.A. (2014). Fitness costs associated with field-evolved resistance to chlorantraniliprole in Plutella xylostella (Lepidoptera: Plutellidae). B Entomol Res 104: 88-96.

Roditakis, E., Mavridis, K., Riga, M., Vasakis, E., Morou, E., Rison, J.L., Vontas, J. (2017a). Identification and detection of indoxacarb resistance mutations in the para sodium channel of the tomato leafminer, Tuta absoluta. Pest Manag Sci doi: 10.1002/ps.4513.

Roditakis, E., Skarmoutsou, C., Staurakaki, M. (2013a). Toxicity of insecticides to populations of tomato borer Tuta absoluta (Meyrick) from Greece. Pest Manag Sci 69: 834-840.

Roditakis, E., Skarmoutsou, C., Staurakaki, M., Martínez-Aguirre, M.R., García-Vidal, L., Bielza, P., Haddi, K., Rapisarda, C., Rison, J-L., Bassi, A., Teixeira, L.A. (2013b). Determination of baseline susceptibility of European populations of Tuta absoluta (Meyrick) to indoxacarb and cholorantraniliprole using a novel dip bioassay method. Pest Manag Sci 69: 217-227. 
Roditakis, E., Steinbach, D., Moritz, G., Vasakis, E., Stavrakaki, M., Ilias, A., García-Vidal, L., Martínez-Aguirre, M.R., Bielza, P., Morou, E., Silva, J.E., Silva, W.M., Siqueira, H.A.A., Iqbal, S., Troczka, B.J., Williamson, M.S., Bass, C., Tsagkarakou, A., Vontas, J., Nauen, R. (2017b). Ryanodine receptor point mutations confer diamide insecticide resistance in tomato leafminer, Tuta absoluta (Lepidoptera: Gelechiidae). Insect Biochem Mol Biol 80: 11-20.

Roditakis, E., Vasakis, E., García-Vidal, L., Martínez-Aguirre, M.R., Rison, J.L., Haxaire-Lutun, M.O., Nauen, R., Tsagkarakou, A., Bielza, P. (2017c). A four-year survey on insecticide resistance and likelihood of chemical control failure for tomato leaf miner Tuta absoluta in the European/Asian región. J Pest Sci doi: 10.1007/s10340-017-0900-x.

Roditakis, E., Vasakis, E., Grispou, M., Stavrakaki, M., Nauen, R., Gravouil, M., Bassi, A. (2015). First report of Tuta absoluta resistance to diamide insecticides. J Pest Sci 88: 9-16.

Sang, S., Shu, B., Yi, X., Liu, J., Hu, M., Zhong, G. (2016). Cross-resistance and baseline susceptibility of Spodoptera litura (Fabricius) (Lepidoptera: Noctuidae) to cyantraniliprole in the south of China. Pest Manag Sci 72: 922-928.

Silva, J.E, Assis, C.P.O., Ribeiro, L.M.S., Siqueira, H.A.A. (2016). Field-Evolved Resistance and Cross-Resistance of Brazilian Tuta absoluta (Lepidoptera: Gelechiidae) Populations to Diamide Insecticides. J Econ Entomol 109 (5): 2190-2195.

Steinbach, D., Gutbrod, O., Lümmen, P., Matthiesen, S., Schorn, C., Nauen, R. (2015). Geographic spread, genetics and functional characteristics of ryanodine receptor based targetsite resistance to diamide insecticides in diamondback moth, Plutella xylostella. Insect Biochem Mol Biol 63: 14-22.

Su, J., Lai, T., Li, J. (2012). Susceptibility of field populations of Spodoptera litura (Fabricius) (Lepidoptera: Noctuidae) in China to chlorantraniliprole and the activities of detoxification enzymes. Crop Prot 42: 217-222.

Teixeira, L.A., Andaloro, J.T. (2013). Diamide insecticides: Global efforts to address insect resistance stewardship challenges. Pestic Biochem Phys 106: 76-78.

Troczka, B., Zimmer, C.T., Elias, J., Schorn, C., Bass, C., Davies, T.G.E., Field, L.M., Williamson, M.S., Slater, R., Nauen, R. (2012). Resistance to diamide insecticides in diamondback moth, Plutella xylostella (Lepidoptera: Plutellidae) is associated with a mutation in the membranespanning domain of the ryanodine receptor. Insect Biochem Mol Biol 42: 873-880.

Wang, X., Khakame, S.K., Ye, C., Yang, Y., Wu, Y. (2013). Characterisation of field-evolved resistance to chlorantraniliprole in the diamondback moth, Plutella xylostella, from China. Pest Manag Sci 69: 661-665.

Wang, X., Wu, Y. (2012). High levels of resistance to chlorantraniliprole evolved in field populations of Plutella xylostella. J Econ Entomol 105 (3): 1019-1023. 
Yalçin, M., Mermer, S., Kozaci, L.D., Turgut, C. (2015). Insecticide resistance in two populations of Tuta absoluta (Meyrick, 1917) (Lepidoptera: Gelechiidae) from Turkey. Türk Entomol Derg 39 (2): 137-145.

Zhang, S., Zhang, X., Shen, J., Mao, K., You, H., Li, J. (2016). Susceptibility of field populations of the diamondback moth, Plutella xylostella, to a selection of insecticides in Central China. Pestic Biochem Phys 132: 38-46. 


\section{CAPÍTULO 2}

SUSCEPTIBILIDAD DE POBLACIONES EUROPEAS DE

Tuta absoluta (MEYRICK) (LEPIDOPTERA:

GELECHIIDAE) A LOS INSECTICIDAS SPINOSAD E

INDOXACARB 



\subsection{Introducción}

Tuta absoluta (Meyrick) es considerada una de las principales plagas en tomate, tanto en cultivo al aire libre como bajo invernadero, pudiendo causar pérdidas del $90-100 \%$ de la producción de tomate si no se realiza un adecuado control en campo (Akiyoshi et al., 1999; Leite et al., 1999; Estay, 2000; Torres et al., 2001; Flores et al., 2003; Akiyoshi et al., 2004; EPPO, 2005; Pereyra et al., 2006).

Desde la propagación de $T$. absoluta por diferentes países de Sudamérica, de donde es originaria, el uso de insecticidas tales como cartap, abamectina, organofosforados y piretroides, suponían el principal método de control de esta plaga (Salazar et al., 1997; Siqueira et al., 2000b; Salazar et al., 2001; Lietti et al., 2005). Sin embargo, posteriormente aparecieron los primeros casos de resistencia a estos insecticidas en poblaciones de $T$. absoluta (Salazar et al., 1997; Siqueira et al., 2000a, 2000b; Salazar et al., 2001; Siqueira et al., 2001; Lietti et al., 2005).

Este problema de aparición de resistencias a los insecticidas que hasta ese momento se estaban empleando para el control de $T$. absoluta, hizo necesario el registro y uso de nuevas sustancias activas, como spinosad e indoxacarb, los cuales ya se estaban empleando en ese momento en el control químico de otras plagas de lepidópteros (Guedes et al., 2012).

Spinosad fue introducido por vez primera en 1997 para el control de lepidópteros en el cultivo de algodón. Este insecticida es una materia activa de origen natural formada por la mezcla de dos componentes activos, spinosyn A y spinosyn D, producidos por el actinomiceto Saccharopolyspora spinosa Mertz \& Yao (Actinomycetales: Pseudonocardiaceae) (Kirst et al., 1992; Salgado, 1998).

La materia activa indoxacarb pertenece a la familia de las oxadiacinas (Von Stein et al., 2013), y es eficaz en el control de varias plagas agrícolas. Es respetuoso con el medioambiente ya que se trata de un pro-insecticida, es decir, necesita estar en el interior del insecto para su activación metabólica y así poder realizar su acción tóxica (Wing et al., 2010).

En el año 2016 se encontraron poblaciones de campo de T. absoluta procedentes de Grecia, Italia, Portugal, España, Reino Unido y Brasil, con una menor susceptibilidad a indoxacarb y spinosad. A partir de esas poblaciones, se obtuvieron poblaciones resistentes a estos dos insecticidas realizando una presión de selección al insecticida en laboratorio (Berger et al., 2016; Silva et al., 2016b; Roditakis et al., 2017a, 2017b).

En este capítulo se ha estudiado la evolución de la resistencia de diferentes poblaciones europeas de $T$. absoluta a los insecticidas spinosad e indoxacarb, y cómo afecta el estado de desarrollo larvario de $T$. absoluta en la susceptibilidad a estos insecticidas. 


\subsection{Material y Métodos}

\subsubsection{Poblaciones de T. absoluta}

En la tabla 3.1 dentro del apartado 3.2. del capítulo 3 de Material y Métodos Generales, se detallan las poblaciones de $T$. absoluta estudiadas en este apartado. Todas las poblaciones fueron recolectadas (ver apartado 3.2. en el capítulo 3 de Material y Métodos Generales) en invernaderos de tomate de distintos países de Europa, en un intervalo de tiempo de 7 años (2010-2016).

\subsubsection{Insecticidas}

Las formulaciones comerciales de los insecticidas utilizados en los bioensayos fueron: spinosad 48\% SC (Spintor 480 SC, Dow AgroScience) e indoxacarb 30\% WG (Steward, DuPont).

\subsubsection{Bioensayos de susceptibilidad}

En este trabajo se realizaron bioensayos de susceptibilidad con larvas en estadio 2 (L2) de $T$. absoluta para todas las poblaciones estudiadas en este trabajo, así como bioensayos con larvas en estadio 4 (L4) de una población de T. absoluta para cada insecticida.

Ver apartado 3.4.1. Bioensayos de susceptibilidad, en el capítulo 3 de Material y Métodos Generales.

\subsubsection{Análisis de datos}

Los datos de los bioensayos se analizaron usando el programa estadístico POLO-Plus para el análisis probit de los datos (LeOra-Software, 2005). Los parámetros calculados para este estudio fueron: la concentración letal $50(C L 50)$ y sus límites fiduciales al 95\% para cada población e insecticida, expresados en $\mathrm{mg} \mathrm{L}^{-1}$, y los factores de resistencia (FR) de cada población, comparando la CL50 de cada población con la CL50 de la población más susceptible.

\subsection{Resultados y Discusión}

A continuación, se muestran los resultados de los análisis probit de los bioensayos realizados para los insecticidas spinosad e indoxacarb. Estos resultados nos permiten observar la evolución de la susceptibilidad de las poblaciones de $T$. absoluta a estos insecticidas en los últimos 7 años. Además, en los primeros años de investigación (2010-2012) se calculó la línea base de susceptibilidad de $T$. absoluta para spinosad e indoxacarb. Por otro lado, se evaluó 
para cada uno de los insecticidas cómo afecta a la susceptibilidad de una población el estado de desarrollo larvario en la cual se encuentre el insecto.

\subsection{1. $\underline{\text { Spinosad }}$}

Los resultados obtenidos de los bioensayos realizados en los años 2010, 2011 y 2012 para el insecticida spinosad se muestran en la tabla 5.1. Comparando las CL50 de todas las poblaciones, Foggia resultó ser la población más susceptible a spinosad, con una CL50 de 0,06 $\mathrm{mg} \mathrm{L}^{-1}$, considerándose como la población susceptible de referencia con respecto a las otras poblaciones. Por otro lado, la población española Abarán fue la que presentó una mayor CL50 $\left(0,63 \mathrm{mg} \mathrm{L}^{-1}\right)$, siendo la menos susceptible de todas las poblaciones bioensayadas. Entre la población más susceptible y la menos susceptible se observó una variabilidad de 10,5 (FR), y se encontraron diferencias significativas en otras poblaciones con respecto a la población más susceptible (Foggia). Sin embargo, todas estas diferencias se encuentran dentro de la variabilidad natural esperable. La línea base de susceptibilidad calculada fue de $0,25 \mathrm{mg} \mathrm{L}^{-1}$, siendo este valor, junto a los datos de CL50 obtenidos en todas las poblaciones bioensayadas, muy inferiores a la dosis de campo de este insecticida $\left(120 \mathrm{mg} \mathrm{L}^{-1}\right)$. Con estos resultados podemos concluir que entre los años 2010 y 2012, no había sospechas de resistencia a spinosad en poblaciones mediterráneas de $T$. absoluta.

Tabla 5.1: Toxicidad a spinosad de diferentes poblaciones de $T$. absoluta y línea base de susceptibilidad.

\begin{tabular}{|c|c|c|c|c|c|c|}
\hline País & Año & Población & CL50 & LF $(95 \%)$ & $F R$ & \\
\hline \multirow{8}{*}{ España } & 2010 & Abarán & 0,63 & $0,33-1,11$ & 10,5 & $*$ \\
\hline & 2010 & Níjar & 0,11 & $0,01-0,22$ & 1,8 & ns \\
\hline & 2010 & Canarias & 0,43 & $0,32-0,63$ & 7,2 & $*$ \\
\hline & 2010 & Gallego1 & 0,24 & $0,09-0,44$ & 4,0 & ns \\
\hline & 2010 & Almería & 0,16 & $0,10-0,22$ & 2,7 & $*$ \\
\hline & 2010 & Tudela & 0,18 & $0,07-0,31$ & 3,0 & ns \\
\hline & 2011 & Águilas & 0,29 & $0,14-0,50$ & 4,8 & $*$ \\
\hline & 2012 & Mazarrón & 0,16 & $0,09-0,33$ & 2,7 & ns \\
\hline \multirow{2}{*}{ Italia } & 2010 & Biancavilla & 0,24 & $0,08-0,64$ & 4,0 & $\overline{n s}$ \\
\hline & 2011 & Foggia & 0,06 & $0,03-0,09$ & 1 & - \\
\hline \multirow{2}{*}{ Portugal } & 2010 & Charneca & 0,53 & $0,31-0,96$ & 8,8 & $*$ \\
\hline & 2010 & Boavista & 0,27 & $0,19-0,37$ & 4,5 & $*$ \\
\hline \multicolumn{3}{|c|}{ Línea Base de Susceptibilidad } & 0,25 & $0,21-0,31$ & - & \\
\hline
\end{tabular}

CL50: Concentración letal 50 en $\mathrm{mg} \mathrm{L}^{-1}$; LF (95\%): Límites fiduciales al 95\% en $\mathrm{mg} \mathrm{L}^{-1}$;

FR: Factor de Resistencia; ns: sin diferencias significativas; * : diferencias significativas 
Los resultados obtenidos entre los años 2010 y 2012 difieren ligeramente de los aportados por otros autores. Silva et al. (2011) publicaron datos sobre poblaciones brasileñas que presentaban CL50 entre 0,46 y $2,26 \mathrm{mg} \mathrm{L}^{-1}$, valores superiores a nuestra línea base de susceptibilidad $\left(C L 50=0,25 \mathrm{mg} \mathrm{L}^{-1}\right)$. Además, la variabilidad a spinosad observada entre las poblaciones brasileñas fue de 4,9 (FR), estando este valor por debajo de la variabilidad observada en este trabajo ( $F R=10,5$ ). Además, se han encontrado diferencias significativas entre la población brasileña menos susceptible $\left(C L 50=2,26 \mathrm{mg} \mathrm{L}^{-1}\right)$ y Abarán, nuestra población menos susceptible $\left(C L 50=0,63 \mathrm{mg} \mathrm{L}^{-1}\right)$. Los autores Dağli et al. (2012) también presentaron resultados sobre poblaciones turcas de $T$. absoluta con valores de CL50 entre 0,3 y $1,6 \mathrm{mg} \mathrm{L}^{-1}$, siendo estos valores superiores a nuestra línea base de susceptibilidad (CL50 = $\left.0,25 \mathrm{mg} \mathrm{L}^{-1}\right)$. Además, se encontraron diferencias significativas entre la población turca menos susceptible $\left(C L 50=1,6 \mathrm{mg} \mathrm{L}^{-1}\right.$ ) y nuestra población menos susceptible Abarán. Por otro lado, en 2013 se publicaron resultados de poblaciones griegas de T. absoluta que presentaban elevada susceptibilidad a spinosad (Roditakis et al., 2013a), con CL50 entre 0,08 y 0,26 mg L-1, y una variabilidad de 3,3 (FR). Comparando con los resultados mostrados en la tabla 5.1, no existen diferencias significativas entre los valores de CL50 obtenidos en las poblaciones griegas de $T$. absoluta y las CL50 obtenidas en este trabajo. Además, la variabilidad obtenida entre las poblaciones griegas es inferior a la encontrada entre las poblaciones de $T$. absoluta bioensayadas entre los años 2010 y 2012 (FR = 10,5). Al igual que sucede con otros insecticidas, las pequeñas diferencias entre los valores de susceptibilidad de los trabajos citados y los obtenidos en este trabajo, pueden deberse a las diferencias en la metodología de los bioensayos y la valoración de la mortalidad en la lectura de los bioensayos.

En los años 2013, 2014 y 2016 se llevaron a cabo bioensayos con varias poblaciones europeas de $T$. absoluta para estudiar la evolución en el tiempo de la resistencia de $T$. absoluta a spinosad (Tabla 5.2). Las CL50 obtenidas para cada población se compararon con la línea base de susceptibilidad de spinosad calculada a partir de los bioensayos realizados entre los años 2010-2012. 
Tabla 5.2: Evolución de la toxicidad a spinosad de diferentes poblaciones de $T$. absoluta entre los años 2013 y 2016.

\begin{tabular}{|c|c|c|c|c|c|c|}
\hline Año & País & Población & CL50 & LF $(95 \%)$ & FR & \\
\hline & & Línea Base & 0,25 & $0,21-0,31$ & 1 & \\
\hline 2013 & Italia & Pomodoro & 0,07 & $0,03-0,13$ & 0,3 & $*$ \\
\hline \multirow{3}{*}{2014} & \multirow{2}{*}{ España } & Calnegre & 0,04 & $0,02-0,07$ & 0,2 & $*$ \\
\hline & & Mojonera & 0,01 & $0,003-0,03$ & 0,1 & $*$ \\
\hline & Italia & Sicilia & 0,05 & $0,03-0,08$ & 0,2 & $*$ \\
\hline \multirow{4}{*}{2016} & España & Totana & 0,22 & $0,14-0,48$ & 0,9 & ns \\
\hline & \multirow{2}{*}{ Italia } & Sannito & 0,05 & $0,03-0,08$ & 0,2 & $*$ \\
\hline & & Frasanito & 0,07 & $0,04-0,11$ & 0,3 & $*$ \\
\hline & Portugal & Portugal2 & 0,04 & $0,02-0,06$ & 0,2 & $*$ \\
\hline
\end{tabular}

CL50: Concentración letal 50 en $\mathrm{mg} \mathrm{L}^{-1}$; LF (95\%): Límites fiduciales al $95 \%$ en $\mathrm{mg} \mathrm{L}^{-1}$;

FR: Factor de Resistencia; ns: sin diferencias significativas; *: diferencias significativas

Como se observa en la tabla 5.2 casi todas las poblaciones de $T$. absoluta bioensayadas en los años 2013, 2014 y 2016 presentaron diferencias significativas con respecto a la línea base de susceptibilidad calculada en años previos, obteniendo CL50 muy inferiores a la línea base, y siendo Mojonera la población más susceptible, con un factor de resistencia de 0,1 con respecto a la línea base de susceptibilidad. La población española Totana, bioensayada en el año 2016, fue la única que no presentó diferencias significativas con respecto a la línea base de susceptibilidad, con una CL50 de 0,22 $\mathrm{mg} \mathrm{L}^{-1}$ y un factor de resistencia de 0,9. Estos datos sugieren que en los últimos años no se ha detectado resistencia a spinosad en $T$. absoluta en Europa.

En el año 2014, Campos et al. (2014) publicaron resultados sobre la susceptibilidad a spinosad de poblaciones brasileñas, con CL50 entre 0,01 y $0,41 \mathrm{mg} \mathrm{L}^{-1}$ y una variabilidad de 41 (FR), no habiendo diferencias significativas entre la población brasileña menos susceptible ( $C L 50=0,41$ $\mathrm{mg} \mathrm{L}^{-1}$ ) y la línea base de susceptibilidad mostrada en la tabla 5.2. Sin embargo, la variabilidad encontrada entre las poblaciones brasileñas $(F R=41)$ es superior a la variabilidad observada entre las poblaciones de T. absoluta bioensayadas entre los años 2010 y 2012 (FR = 10,5). Asimismo, Campos et al. (2015) mostraron resultados de poblaciones brasileñas susceptibles a spinosad con CL50 entre 0,007 y 0,63 $\mathrm{mg} \mathrm{L}^{-1}$ y una variabilidad de 90 (FR), siendo esta variabilidad muy superior a la observada en nuestro trabajo (Tabla 5.1). Por otro lado, en 2015 se publicaron resultados de poblaciones turcas de T. absoluta susceptibles a spinosad (Yalçin et al., 2015) con CL50 entre 0,11 y 0,70 $\mathrm{mg} \mathrm{L}^{-1}$ y una variabilidad de 6,4 (FR). Estos valores de CL50 no difieren significativamente de la línea base de susceptibilidad calculada para spinosad en este trabajo $\left(C L 50=0,25 \mathrm{mg} \mathrm{L}^{-1}\right)$. 
Por otra parte, en el año 2016 se publicaron los primeros casos de poblaciones brasileñas de $T$. absoluta que presentaban cambios en la susceptibilidad a spinosad (Silva et al., 2016b), con CL50 entre 0,02 y $5,87 \mathrm{mg} \mathrm{L}^{-1}$, y una variabilidad de 294 (FR). Esta variabilidad es muy superior a la observada en este trabajo entre los años 2010 y 2012 ( $F R=10,5)$, y se encontraron diferencias significativas entre la población brasileña menos susceptible ( $\left.C L 50=5,87 \mathrm{mg} \mathrm{L}^{-1}\right)$ y la línea base de susceptibilidad calculada entre los años 2010 y $2012\left(0,25 \mathrm{mg} \mathrm{L}^{-1}\right)$. Asimismo, en el año 2016, Berger et al. (2016) encontraron poblaciones de campo procedentes de España, Brasil, Italia y Portugal con baja susceptibilidad a spinosad (CL50 entre 1,8 y 6,1 mg L' $\left.{ }^{1}\right)$. Aunque estos autores consideran estas poblaciones como susceptibles a la hora de comparar con otras poblaciones menos susceptibles, existen diferencias significativas entre estas poblaciones y la línea base de susceptibilidad calculada en este trabajo para spinosad $\left(C L 50=0,25 \mathrm{mg} \mathrm{L}^{-1}\right)$. Además, estos autores también encontraron una población portuguesa de campo que presentaba una ligera resistencia a spinosad, con una CL50 de 14,9 $\mathrm{mg} \mathrm{L}^{-1}$. Si bien los datos publicados en 2016 por otros autores sugieren que en la actualidad existen poblaciones de $T$. absoluta ligeramente resistentes a spinosad, estos resultados son aún muy inferiores a las dosis de campo de este insecticida (120 $\mathrm{mg} \mathrm{L}^{-1}$ ). Sin embargo, es necesario realizar un seguimiento de estas poblaciones con el fin de evitar una elevada resistencia a spinosad, y como consecuencia una resistencia cruzada con otros insecticidas.

En el año 2017, Roditakis et al. (2017a) publicaron resultados de poblaciones griegas que presentaban una elevada susceptibilidad a spinosad, con CL50 entre 0,27 y 0,32 $\mathrm{mg} \mathrm{L}^{-1}$, no encontrando diferencias significativas entre estos valores y la línea base de susceptibilidad calculada para spinosad entre los años 2010 y $2012\left(0,25 \mathrm{mg} \mathrm{L}^{-1}\right)$. Por otro lado, Roditakis et al. (2017b) mostraron resultados sobre la susceptibilidad a spinosad de poblaciones de campo de T. absoluta procedentes de Italia, Grecia, Israel y Reino Unido. Para las poblaciones italianas, griegas e israelitas, las variabilidades encontradas entre poblaciones fueron de 4, 6,5 y 1,2 (FR) respectivamente. Estas variabilidades son inferiores a las encontradas en este trabajo entre los años 2010 y 2016 (Tabla 5.1; Tabla 5.2). En el caso de la población procedente de Reino Unido, esta presentó una ligera resistencia a spinosad ( $C 550$ de $9,02 \mathrm{mg} \mathrm{L}^{-1}$ ), encontrándose diferencias significativas entre esta población y la línea base de susceptibilidad calculada para spinosad en este trabajo $\left(C L 50=0,25 \mathrm{mg} \mathrm{L}^{-1}\right)$.

En los últimos años se ha estudiado la susceptibilidad a spinosad en otros lepidópteros. Ahmad et al. (2015) encontraron poblaciones de Spodoptera litura (Fabricius) (Lepidoptera: Noctuidae) procedentes de Pakistán con baja susceptibilidad a spinosad (CL50 entre 5,55 y $40,9 \mathrm{mg} \mathrm{L}^{-1}$ ) y una variabilidad de 7,4 (FR). Esta variabilidad es similar a la observada en este trabajo para $T$. absoluta $(\mathrm{FR}=10,5)$. 
También hay varias publicaciones sobre la susceptibilidad a spinosad en Plutella xylostella Linnaeus (Lepidoptera: Plutellidae). Liu et al. (2015) publicaron resultados sobre la susceptibilidad de poblaciones chinas de $P$. xylostella a spinosad, con CL50 que variaban entre 0,24 y $3,66 \mathrm{mg} \mathrm{L}^{-1}$ y una variabilidad de 15,3 (FR). Asimismo, en 2016 se encontraron poblaciones brasileñas de $P$. xylostella que presentaban CL50 entre 0,017 y 3,64 $\mathrm{mg} \mathrm{L}^{-1}$ a spinosad, y una variabilidad de 214 (FR) (Neto et al., 2016). Estos rangos de variabilidad son superiores a los encontrados para T. absoluta en este trabajo (Tabla 5.1). Por otro lado, Zhang et al. (2016) también estudiaron la susceptibilidad de poblaciones chinas de $P$. xylostella a spinosad, con CL50 que variaban entre 0,71 y $2,57 \mathrm{mg} \mathrm{L}^{-1}$ y una variabilidad de 3,6 (FR). Esta variabilidad se encuentra dentro del rango observado para T. absoluta (Tabla 5.1).

Spinosad es un insecticida de amplio espectro, siendo bastante eficaz en otras plagas agrícolas. Existen varios trabajos sobre el estudio de la susceptibilidad y la resistencia a spinosad en Frankliniella occidentalis (Pergande) (Thysanoptera: Thripidae). Bielza et al. (2007) publicaron resultados de poblaciones de campo españolas de $F$. occidentalis muy resistentes a spinosad, con una variabilidad de más de 2 millones de veces entre la población de campo más resistente y la población susceptible de referencia. Por otro lado, Li et al. (2016) estudiaron la susceptibilidad a spinosad de poblaciones de campo chinas de $F$. occidentalis. Estos autores encontraron una variabilidad de 81 veces $(F R)$ entre su población de campo más resistente y su población susceptible de referencia.

La tabla 5.3 muestra los resultados de los bioensayos realizados con larvas en diferentes estados de desarrollo, L2 y L4, de una población de T. absoluta. No se encontraron diferencias significativas entre los estados de desarrollo, con CL50 de 0,29 y $0,42 \mathrm{mg} \mathrm{L}^{-1}$ para los bioensayos con L2 y $L 4$ respectivamente. Estos resultados sugieren que no existen diferencias en la susceptibilidad a spinosad en función del estado de desarrollo larvario de T. absoluta.

Tabla 5.3: Toxicidad a spinosad de una población de T. absoluta en estado larvario L2 y L4.

\begin{tabular}{c|cccc}
\hline Población & CL50 & LF (95\%) & FR & \\
\hline Águilas (L2) & 0,29 & $0,14-0,50$ & 1 & \\
Águilas (L4) & 0,42 & $0,26-0,82$ & 1,4 & ns \\
\hline
\end{tabular}

CL50: Concentración letal 50 en $\mathrm{mg} \mathrm{L}^{-1}$; LF (95\%): Límites fiduciales al 95\% en $\mathrm{mg} \mathrm{L}^{-1} ; \mathbf{F R}$ : Factor de Resistencia; $\mathbf{n s :}$ sin diferencias significativas 


\subsubsection{Indoxacarb}

En la tabla 5.4 se muestran los resultados obtenidos de los bioensayos realizados en los años 2010, 2011 y 2012 para indoxacarb. La población española Gallego1 fue la que presentó un menor valor de $\operatorname{CL50}\left(0,27 \mathrm{mg} \mathrm{L}^{-1}\right)$, siendo la población más susceptible con respecto al resto de poblaciones. Por otro lado, fue la población española Mazarrón la menos susceptible, ya que presentó el valor de CL50 más elevado $\left(0,80 \mathrm{mg} \mathrm{L}^{-1}\right)$. Se observó una variabilidad de 3 veces entre la población más susceptible y la menos susceptible (FR). Además, se encontraron diferencias significativas en tres poblaciones, Mazarrón, Almería y Águilas con respecto a la población más susceptible Gallego1, aunque estas diferencias se encuentran dentro de la variabilidad natural esperable. La línea base de susceptibilidad calculada fue de $0,43 \mathrm{mg} \mathrm{L}^{-1}$. Este valor de línea base de susceptibilidad, y todos los valores de CL50 de las poblaciones bioensayadas entre 2010 y 2012, están muy por debajo de la dosis de campo de este insecticida ( $60 \mathrm{mg} \mathrm{L}^{-1}$ ). Por lo tanto, estos resultados muestran la elevada susceptibilidad de estas poblaciones a indoxacarb, no habiendo indicios de resistencia a este insecticida en poblaciones europeas de T. absoluta entre los años 2010 y 2012.

Tabla 5.4: Toxicidad a indoxacarb de diferentes poblaciones de $T$. absoluta y línea base de susceptibilidad.

\begin{tabular}{|c|c|c|c|c|c|c|}
\hline País & Año & Población & CL50 & LF (95\%) & FR & \\
\hline \multirow{8}{*}{ España } & 2010 & Abarán & 0,44 & $0,33-0,53$ & 1,6 & ns \\
\hline & 2010 & Níjar & 0,44 & $0,26-0,97$ & 1,6 & ns \\
\hline & 2010 & Canarias & 0,43 & $0,29-0,55$ & 1,6 & ns \\
\hline & 2010 & Gallego1 & 0,27 & $0,13-0,36$ & 1 & - \\
\hline & 2010 & Almería & 0,64 & $0,43-0,87$ & 2,4 & $*$ \\
\hline & 2010 & Tudela & 0,31 & $0,18-0,48$ & 1,1 & ns \\
\hline & 2011 & Águilas & 0,66 & $0,39-1,13$ & 2,4 & $*$ \\
\hline & 2012 & Mazarrón & 0,80 & $0,44-1,24$ & 3,0 & $*$ \\
\hline \multirow{3}{*}{ Italia } & 2010 & Biancavilla & 0,54 & $0,23-0,85$ & 2,0 & ns \\
\hline & 2011 & Foggia & 0,30 & $0,19-0,43$ & 1,1 & ns \\
\hline & 2012 & Fossano & 0,44 & $0,28-0,69$ & 1,6 & ns \\
\hline \multirow{2}{*}{ Portugal } & 2010 & Charneca & 0,29 & $0,21-0,38$ & 1,1 & ns \\
\hline & 2010 & Boavista & 0,38 & $0,28-0,51$ & 1,4 & ns \\
\hline Francia & 2012 & Francia & 0,43 & $0,15-0,84$ & 1,6 & ns \\
\hline Grecia & 2012 & Grecia & 0,55 & $0,33-1,13$ & 2,0 & ns \\
\hline \multicolumn{3}{|c|}{ Línea Base de Susceptibilidad } & 0,43 & $0,38-0,48$ & - & \\
\hline
\end{tabular}

CL50: Concentración letal 50 en $\mathrm{mg} \mathrm{L}^{-1}$; LF (95\%): Límites fiduciales al 95\% en $\mathrm{mg} \mathrm{L}^{-1}$;

FR: Factor de Resistencia; ns: sin diferencias significativas; *: diferencias significativas 
En el año 2011 se publicaron resultados sobre la susceptibilidad de poblaciones brasileñas de T. absoluta a indoxacarb (Silva et al., 2011), con CL50 entre 0,86 y 10,82 $\mathrm{mg} \mathrm{L}^{-1}$, y una variabilidad de 27,7 (FR). Comparados con los resultados obtenidos en este trabajo entre los años 2010 y 2012 para indoxacarb (Tabla 5.4), existen diferencias significativas entre la CL50 de la población brasileña menos susceptible $\left(10,82 \mathrm{mg} \mathrm{L}^{-1}\right)$ y la línea base de susceptibilidad calculada para indoxacarb $\left(0,43 \mathrm{mg} \mathrm{L}^{-1}\right)$. Dağli et al. (2012) presentaron resultados de poblaciones turcas susceptibles a indoxacarb, con CL50 entre 0,2 y $4 \mathrm{mg} \mathrm{L}^{-1}$ y una variabilidad de 20 (FR), encontrando diferencias significativas entre la población turca menos susceptible (4 $\left.\mathrm{mg} \mathrm{L}^{-1}\right)$ y Mazarrón $\left(0,80 \mathrm{mg} \mathrm{L}^{-1}\right)$, nuestra población menos susceptible. Además, la variabilidad observada entre las poblaciones turcas es muy superior a la observada en este trabajo (Tabla 5.4). Por otro lado, Roditakis et al. (2013a) publicaron resultados de poblaciones griegas ligeramente resistentes a indoxacarb, con CL50 entre 1,73 y $17,50 \mathrm{mg} \mathrm{L}^{-1}$, y una variabilidad de 10,1 (FR), encontrando diferencias significativas entre estos valores de CL50 y nuestra línea base de susceptibilidad $\left(0,43 \mathrm{mg} \mathrm{L}^{-1}\right)$. También, en el año 2013 se mostraron datos sobre la susceptibilidad de poblaciones italianas de T. absoluta a indoxacarb (Roditakis et al., 2013b), con CL50 entre 0,93 y 10,76 mg L ${ }^{-1}$ y una variabilidad de 11,6 (FR). Esta variabilidad es superior a la encontrada en nuestro trabajo ( $F R=3$; Tabla 5.4). Sin embargo, los resultados mostrados por los autores anteriormente citados son inferiores a la dosis de campo de indoxacarb $(60 \mathrm{mg}$ $\left.L^{-1}\right)$.

En la tabla 5.5 se presentan los resultados de la evolución de la resistencia de $T$. absoluta a indoxacarb entre los años 2013 y 2015, comparando las CL50 obtenidas de los bioensayos realizados en ese periodo de tiempo, con la línea base de susceptibilidad calculada entre los años 2010-2012.

Tabla 5.5: Evolución de la toxicidad a indoxacarb de diferentes poblaciones de $T$. absoluta entre los años 2013 y 2015.

\begin{tabular}{|c|c|c|c|c|c|c|}
\hline Año & País & Población & CL50 & LF $(95 \%)$ & FR & \\
\hline & & Línea Base & 0,43 & $0,38-0,48$ & 1 & \\
\hline \multirow{2}{*}{2013} & Italia & Pomodoro & 0,53 & $0,31-0,81$ & 1,2 & ns \\
\hline & Grecia & Peloponeso & 0,39 & $0,24-0,60$ & 0,9 & ns \\
\hline \multirow{5}{*}{2014} & \multirow{4}{*}{ España } & Gallego2 & 0,22 & $0,11-0,39$ & 0,5 & ns \\
\hline & & Villaverde & 0,32 & $0,19-0,55$ & 0,7 & ns \\
\hline & & Calnegre & 0,42 & $0,06-1,60$ & 1,0 & ns \\
\hline & & Mojonera & 0,67 & $0,36-1,18$ & 1,6 & ns \\
\hline & Italia & Sicilia & 0,47 & $0,14-1,16$ & 1,1 & ns \\
\hline \multirow{2}{*}{2015} & \multirow{2}{*}{ España } & Almería15 & 0,90 & $0,49-1,45$ & 2,1 & $*$ \\
\hline & & La Palma & 0,29 & $0,17-0,49$ & 0,7 & ns \\
\hline
\end{tabular}

CL50: Concentración letal 50 en $\mathrm{mg} \mathrm{L}^{-1}$; LF (95\%): Límites fiduciales al $95 \%$ en $\mathrm{mg} \mathrm{L}^{-1}$;

FR: Factor de Resistencia; ns: sin diferencias significativas; *: diferencias significativas 
En los años 2013, 2014 y 2015 no se encontraron diferencias significativas entre las distintas poblaciones bioensayadas y la línea base de susceptibilidad, salvo para la población española Almería15, que presentó una CL50 de $0,90 \mathrm{mg} \mathrm{L}^{-1}$, y una variabilidad con respecto a la línea base de susceptibilidad de 2,1 (FR). Sin embargo, esta variabilidad está dentro de la variabilidad natural esperable, y la CL50 calculada para Almería15 está muy por debajo de la dosis de campo de indoxacarb $\left(60 \mathrm{mg} \mathrm{L}^{-1}\right)$.

Entre los años 2014 y 2017, varios autores publicaron resultados de la susceptibilidad a indoxacarb en T. absoluta. Campos et al. (2014) estudiaron la susceptibilidad a indoxacarb en una población brasileña de $T$. absoluta, que presentaba una CL50 de $0,86 \mathrm{mg} \mathrm{L}^{-1}$, valor superior a la línea base de susceptibilidad a indoxacarb calculada en este trabajo (Tabla 5.4). Yalçin et al. (2015) encontraron poblaciones de campo de $T$. absoluta procedentes de Turquía moderadamente resistentes a indoxacarb. Estas poblaciones presentaban CL50 entre 26,81 y $215,26 \mathrm{mg} \mathrm{L}^{-1}$ y una variabilidad de 8 (FR), siendo esta variabilidad superior a la encontrada en este trabajo ( $F R=3)$. En 2016, Silva et al. (2016a) mostraron resultados de poblaciones brasileñas de $T$. absoluta que presentaban CL50 entre 0,86 y $2,89 \mathrm{mg} \mathrm{L}^{-1}$ y una variabilidad de 3,4 (FR). Estos valores de CL50 son superiores a la línea base de susceptibilidad calculada para indoxacarb $\left(0,43 \mathrm{mg} \mathrm{L}^{-1}\right)$, pero la variabilidad encontrada entre las poblaciones brasileñas es similar a la calculada entre las poblaciones bioensayadas entre los a los 2010 y 2012 (Tabla 5.4).

Por otro lado, Roditakis et al. (2017a) publicaron resultados de poblaciones griegas ligeramente resistentes a indoxacarb, con CL50 entre 0,97 y 21,9 $\mathrm{mg} \mathrm{L}^{-1}$, y una población italiana con baja susceptibilidad a indoxacarb $\left(C L 50=10,4 \mathrm{mg} \mathrm{L}^{-1}\right)$. A pesar de que todos estos valores de CL50 son superiores a la línea base de susceptibilidad de indoxacarb (Tabla 5.4), siguen estando por debajo de la dosis de campo de este insecticida $\left(60 \mathrm{mg} \mathrm{L}^{-1}\right)$. Además, estos autores obtuvieron una población griega resistente a indoxacarb, al realizar una presión de selección al insecticida en el laboratorio. La CL50 que alcanzaron con la selección fue de 1740 $\mathrm{mg} \mathrm{L}^{-1}$, y a partir de esta población resistente identificaron dos mutaciones, F1845Y y V1848I, las cuales demostraron que intervienen en la resistencia a indoxacarb en $T$. absoluta. Por lo tanto, en este trabajo se llegó a la conclusión que en el mecanismo de resistencia a indoxacarb en $T$. absoluta intervienen tanto las enzimas de detoxificación, P-450 monooxigenasas y esterasas, y las dos mutaciones encontradas en el trabajo de estos autores, siendo una combinación de mecanismo de resistencia metabólica y en el punto de acción.

También en el año 2017, Roditakis et al. (2017b) publicaron resultados sobre la susceptibilidad a indoxacarb de poblaciones de campo de $T$. absoluta procedentes de Grecia, Italia, Israel y Reino Unido. Con respecto a la población procedente de Reino Unido, esta mostró una elevada susceptibilidad a indoxacarb, con una CL50 de $0,26 \mathrm{mg} \mathrm{L}^{-1}$. Este valor está por debajo de la línea base de susceptibilidad calculada para indoxacarb en este trabajo ( $C L 50=0,43 \mathrm{mg} \mathrm{L}^{-1}$ ). En las poblaciones griegas, italianas e israelitas bioensayadas, la variabilidad encontrada entre ellas fue de $135,14,7$ y 45,8 (FR) respectivamente. Estas variabilidades están muy por encima de las encontradas en este trabajo (Tabla 5.4; Tabla 5.5). 
A diferencia de los trabajos citados, en nuestro trabajo no se detectaron indicios de poblaciones de $T$. absoluta resistentes a este insecticida en los primeros años de uso de indoxacarb. Sin embargo, sería conveniente realizar un control sobre las poblaciones que han presentado baja susceptibilidad a indoxacarb en estos últimos años, y así poder prevenir el desarrollo de resistencia a este insecticida.

En la actualidad, existen numerosos trabajos en donde se ha estudiado la susceptibilidad a indoxacarb en otros lepidópteros plaga, observándose en la mayoría de los casos rangos de variabilidad superiores a los encontrados en este trabajo para T. absoluta. En el año 2015 se encontraron poblaciones de $S$. litura procedentes de Pakistán moderadamente resistentes a indoxacarb (Ahmad et al., 2015), con valores de CL50 entre 6,65 y $484 \mathrm{mg} \mathrm{L}^{-1}$, y una variabilidad de 72,8 (FR). Esta variabilidad es muy elevada comparada con la observada en este trabajo para T. absoluta ( $F R=3$; Tabla 5.4). En 2016, Sang et al. (2016) encontraron poblaciones chinas de $S$. litura con CL50 que variaban entre 3,52 y $88,89 \mathrm{mg} \mathrm{L}^{-1}$, y una variabilidad de 25,2 (FR). Estos valores de CL50 son superiores a los observados en este trabajo para T. absoluta (Tabla 5.4; Tabla 5.5). Por otro lado, en 2015 se encontraron poblaciones australianas de Helicoverpa armigera (Hübner) (Lepidoptera: Noctuidae) muy susceptibles a indoxacarb (Bird, 2015), con valores de CL50 entre 0,147 y $0,518 \mathrm{mg} \mathrm{L}^{-1}$, y una variabilidad de 3,5 (FR). Esta variabilidad es muy similar a la encontrada para T. absoluta $(F R=3)$.

Zhang et al. (2016) también estudiaron la susceptibilidad de poblaciones chinas de $P$. xylostella a indoxacarb. Estos autores encontraron poblaciones con CL50 entre 2,08 y 17,92 mg L-1, valores superiores a la línea base de susceptibilidad de $T$. absoluta a indoxacarb $\left(0,43 \mathrm{mg} \mathrm{L}^{-1}\right)$.

En la tabla 5.6 se muestran los resultados de los bioensayos realizados con larvas en estado de desarrollo L2 y L4, de una población griega de $T$. absoluta. Como se puede observar en la tabla, no hubo diferencias significativas entre los dos estados de desarrollo, con CL50 de 0,39 y 0,68 $\mathrm{mg} \mathrm{L}^{-1}$ para los bioensayos con L2 y $\mathrm{L} 4$ respectivamente. De la misma forma que sucede con spinosad, no existen diferencias en la susceptibilidad a indoxacarb al emplear el insecticida sobre larvas en estadio L2 o L4.

Tabla 5.6: Toxicidad a indoxacarb de una población de $T$. absoluta en estado larvario L2 y L4.

\begin{tabular}{l|cccc}
\hline \multicolumn{2}{c}{ Población } & CL50 & LF (95\%) & FR \\
\hline Peloponeso (L2) & 0,39 & $0,24-0,60$ & 1 & \\
\hline Peloponeso (L4) & 0,68 & $0,49-1,13$ & 1,8 & ns \\
\hline
\end{tabular}

CL50: Concentración letal 50 en $\mathrm{mg} \mathrm{L}^{-1}$; LF (95\%): Límites fiduciales al 95\% en $\mathrm{mg} \mathrm{L}^{-1}$; FR: Factor de Resistencia; ns: sin diferencias significativas 


\subsection{Conclusiones}

Los resultados expuestos en este capítulo muestran la elevada susceptibilidad a los insecticidas spinosad e indoxacarb entre las poblaciones de T. absoluta bioensayadas entre los años 2010 y 2012, y las bioensayadas en el monitoreo realizado en años posteriores. Además, las líneas bases de susceptibilidad calculadas para estos dos insecticidas se encuentran muy por debajo de sus respectivas dosis de campo recomendadas para su uso en $T$. absoluta.

Sin embargo, en los años 2015 y 2017 se han citado poblaciones brasileñas, griegas, italianas, portuguesas, turcas, israelitas, inglesas y españolas de $T$. absoluta con ligeros a moderados cambios en la susceptibilidad a spinosad e indoxacarb, lo cual hace necesario un control de la evolución de la susceptibilidad a estos insecticidas, con el fin de realizar una buena estrategia de prevención de desarrollo de la resistencia de estos dos insecticidas.

Por último, no se han encontrado diferencias en la susceptibilidad a spinosad e indoxacarb en función del estadio larvario del insecto, siendo igual de eficaz el tratamiento insecticida en larvas en estadio L2 como en L4.

\subsection{Referencias bibliográficas}

Ahmad, M., Mehmood, R. (2015). Monitoring of Resistance to New Chemistry Insecticides in Spodoptera litura (Lepidoptera: Noctuidae) in Pakistan. J Econ Entomol 108 (3): 1279-1288.

Akiyoshi, F., Picanço, M., Jham, G.N., Brommonschenkel, S.H. (1999). Causas químicas de resistencia de Lycopersicum peruvianum (L.) a Tuta absoluta (Meyrick) (Lepidoptera: Gelechiidae). An Soc Entomol 28: 313-321.

Akiyoshi, F., Wagner, V., Picanço, M., Foster, J. (2004). Genetic divergence among tomato leaf miner populations based on AFLP analysis. Pesq Agropec Bras 39: 645-651.

Berger, M., Puinean, A.M., Randall, E., Zimmer, C., Silva, W.M., Bielza, P., Field, L.M., Hughes, D., Mellor, I., Hassani-Pak, K., Siqueira, H.A.A., Williamson, M.S., Bass, C. (2016). Insecticide resistance mediated by an exon skipping event. Mol Ecol 25: 5692-5704.

Bielza, P., Quinto, V., Contreras, J., Torne, M., Martin, A., Espinosa, P.J. (2007). Resistance to spinosad in the western flower thrips, Frankliniella occidentalis (Pergrande), in greenhouses of south-eastern Spain. Pest Manag Sci 63: 682-687.

Bird, L.J. (2015). Baseline Susceptibility of Helicoverpa armigera (Lepidoptera: Noctuidae) to Indoxacarb, Emamectin Benzoate, and Chlorantraniliprole in Australia. J Econ Entomol 108 (1): 294-300.

Campos, M.R., Rodrigues, A.R.S., Silva, W.M., Silva, T.B.M., Silva, V.R.F., Guedes, R.N.C., Siqueira, H.A.A. (2014). Spinosad and the Tomato Borer Tuta absoluta: A Bioinsecticide, an Invasive Pest Threat, and High Insecticide Resistance. PLoS One 9: e103235. 
Campos, M.R., Silva, T.B.M., Silva, W.M., Silva, J.E., Siqueira, H.A.A. (2015). Spinosyn resistance in the tomato borer Tuta absoluta (Meyrick) (Lepidoptera: Gelechiidae). J Pest Sci 88: 405-412.

Dağli, F., Ikten, C., Sert, E., Bölücek, E. (2012). Susceptibility of tomato borer, Tuta absoluta (Meyrick) (Lepidoptera: Gelechiidae) populations from Turkey to 7 different insecticides in laboratory bioassay. Bulletin OEPP/EPPO Bulletin 42 (2): 305-311.

EPPO. (2005). European and Mediterranean Plant Protection Organization. Tuta absoluta. Data sheets on quarantine pests. EPPO Bull 35: 434-435.

Estay, P. (2000). Polilla del tomate Tuta absoluta (Meyrick). Informativo La Platina 9: 1-4.

Flores, L.V., Gilardón, E., Gardenal, C.N. (2003). Genetic structure of populations of Tuta absoluta Meyrick (Lepidoptera: Gelechiidae). J Basic Appl Genet 15: 29-32.

Guedes, R.N.C., Picanço, M.C. (2012). The tomato borer Tuta absoluta in South America: pest status, management and insecticide resistance. Bulletin OEPP/EPPO Bulletin 42 (2): 211-216.

Kirst, H.A., Michel, K.H., Mynderse, J.S., Chao, E.H., Yao, R.C., Nakatsukasa, W.M., Boeck, L.D., Occlowitz, J., Paschel, J.W., Deeter, J.B., Thompson, G.D. (1992). Discovery, isolation and structure elucidation of a family of structurally unique fermentation-derived tetracyclic macrolides. En: Baker, D.R., Fenyes, J.G., Steffens, J.J. (Eds.). Synthesis and Chemistry of Agrochemicals III. Ed. American Chemical Society, Washington DC. Vol. 504, pp. 214-225.

Leite, G.L.D., Picanço, M., Zanuncio, J.C., Jham, G.N., Moura, M.F. (1999). Efecto de los niveles de fertilización en la intensidad de ataque de Tuta absoluta en Lycopersicum hirsutum y $L$. esculentum. Manejo Integrado de Plagas 53: 72-76.

LeOra-Software. (2005). POLO-Plus, POLO for Windows Petaluma, CA, LeOra Software.

Li, D.G., Shang, X.Y., Stuart, R., Nauen, R., Lei, Z.R., Si, H.L., Gao, Y.L. (2016). Field resistance to spinosad in western flower thrips Frankliniella occidentalis (Thysanoptera: Thripidae). J Integr Agr 15 (12): 2803-2808.

Lietti, M.M.M., Botto, E., Alzogaray, R.A. (2005). Insecticide resistance in Argentine populations of Tuta absoluta (Meyrick) (Lepidoptera: Gelechiidae). Neotrop Entomol 34: 113-119.

Liu, X., Ning, Y., Wang, H., Wang, K. (2015). Cross-resistance, mode of inheritance, synergism, and fitness effects of cyantraniliprole resistance in Plutella xylostella. Entoml Experim App 157: 271-278.

Neto, J.E.L., Amaral, M.H.P., Siqueira, H.A.A., Barros, R., Silva, P.A.F. (2016). Resistance monitoring of Plutella xylostella (L.) (Lepidoptera: Plutellidae) to risk-reduced insecticides and cross resistanceto spinetoram. Phytoparasitica 44: 631-640.

Pereyra, P.C., Sánchez, N.E. (2006). Effect of two solanaceous plants on developmental and population parameters of the tomato leaf miner, Tuta absoluta (Meyrick) (Lepidoptera: Gelechiidae). Neotrop Entomol 35: 671-676. 
Roditakis, E., Mavridis, K., Riga, M., Vasakis, E., Morou, E., Rison, J.L., Vontas, J. (2017a). Identification and detection of indoxacarb resistance mutations in the para sodium channel of the tomato leafminer, Tuta absoluta. Pest Manag Sci doi: 10.1002/ps.4513.

Roditakis, E., Skarmoutsou, C., Staurakaki, M. (2013a). Toxicity of insecticides to populations of tomato borer Tuta absoluta (Meyrick) from Greece. Pest Manag Sci 69: 834-840.

Roditakis, E., Skarmoutsou, C., Staurakaki, M., Martínez-Aguirre, M.R., García-Vidal, L., Bielza, P., Haddi, K., Rapisarda, C., Rison, J-L., Bassi, A., Teixeira, L.A. (2013b). Determination of baseline susceptibility of European populations of Tuta absoluta (Meyrick) to indoxacarb and cholorantraniliprole using a novel dip bioassay method. Pest Manag Sci 69: 217-227.

Roditakis, E., Vasakis, E., García-Vidal, L., Martínez-Aguirre, M.R., Rison, J.L., Haxaire-Lutun, M.O., Nauen, R., Tsagkarakou, A., Bielza, P. (2017b). A four-year survey on insecticide resistance and likelihood of chemical control failure for tomato leaf miner Tuta absoluta in the European/Asian región. J Pest Sci doi: 10.1007/s10340-017-0900-x.

Salazar, E.R., Araya, J.E. (1997). Detection of insecticide resistance in the tomato moth. Simiente 67: 8-22.

Salazar, E.R., Araya, J.E. (2001). Response of the tomato moth, Tuta absoluta (Meyrick), to insecticides in Arica, Chile. Agricultura Técnica 61: 429-435.

Salgado, V.L. (1998). Studies on the Mode of Action of Spinosad: Insect Symptoms and Physiological Correlates. Pestic Biochem Phys 60: 91-102.

Sang, S., Shu, B., Yi, X., Liu, J., Hu, M., Zhong, G. (2016). Cross-resistance and baseline susceptibility of Spodoptera litura (Fabricius) (Lepidoptera: Noctuidae) to cyantraniliprole in the south of China. Pest Manag Sci 72: 922-928.

Silva, G.A., Picanço, M.C., Bacci, L., Crespo, A.L.B., Rosado, J.F., Guedes, R.N.C. (2011). Control failure likelihood and spatial dependence of insecticide resistance in the tomato pinworm, Tuta absoluta. Pest Manag Sci 67: 913-920.

Silva, T.B.M., Silva, W.M., Campos, M.R., Silva, J.E., Ribeiro, L.M.S., Siqueira, H.A.A. (2016a). Susceptibility levels of Tuta absoluta (Meyrick) (Lepidoptera: Gelechiidae) to minor classes of insecticides in Brazil. Crop Prot 79: 80-86.

Silva, W.M., Berger, M., Bass, C., Williamson, M., Moura, D.M.N., Ribeiro, L.M.S., Siqueira, H.A.A. (2016b). Mutation (G275E) of the nicotinic acetylcholine receptor $\alpha 6$ subunit is associated with high levels of resistance to spinosyns in Tuta absoluta (Meyrick) (Lepidoptera: Gelechiidae). Pestic Biochem Phys 131: 1-8.

Siqueira, H.A.A., Guedes, R.N.C., Fragoso, D.B., Magalhães, L.C. (2001). Abamectin resistance and synergism in Brazilian populations of Tuta absoluta (Meyrick) (Lepidoptera: Gelechiidae). Int J Pest Manage 47: 247-251. 
Siqueira, H.A.A., Guedes, R.N.C., Picanço, M.C. (2000a). Cartap resistance and synergism in populations of Tuta absoluta (Lep., Gelechiidae). J Appl Entomol 124: 233-238.

Siqueira, H.A.A., Guedes, R.N.C., Picanço, M.C. (2000b). Insecticide resistance in populations of Tuta absoluta (Lepidoptera: Gelechiidae). Agric For Entomol 2: 147-153.

Torres, J.B., Faria, C.A., Evangelista, W.S., Pratissoli, D. (2001). Within-plant distribution of the leafminer Tuta Absoluta (Meyrick) immatures in processing tomatoes, with notes on plant phenology. Int J Pest Manage 47 (3): 173-178.

Von Stein, R.T., Silver, K.S., Soderlund, D.M. (2013). Indoxacarb, metaflumizone, and other sodium channel inhibitor insecticides: Mechanism and site of action on mammalian voltagegated sodium channels. Pestic Biochem Phys 106: 101-112.

Wing, K.D., Andaloro, J.T., McCann, S.F. (2010). Indoxacarb and the Sodium Channel Blocker Insecticides: Chemistry, Physiology and Biology in Insects. En: Gilbert, L.I., Gill, S.S. (Eds.). Insect Control Biological and Synthetic Agents. Ed. Elsevier, Oxford, UK, pp. 35-57.

Yalçin, M., Mermer, S., Kozaci, L.D., Turgut, C. (2015). Insecticide resistance in two populations of Tuta absoluta (Meyrick, 1917) (Lepidoptera: Gelechiidae) from Turkey. Türk Entomol Derg 39 (2): 137-145.

Zhang, S., Zhang, X., Shen, J., Mao, K., You, H., Li, J. (2016). Susceptibility of field populations of the diamondback moth, Plutella xylostella, to a selection of insecticides in Central China. Pestic Biochem Phys 132: 38-46. 



\section{CAPÍtulo 3}

MECANISMOS DE RESISTENCIA A DIAMIDAS Y RESISTENCIAS CRUZADAS EN Tuta absoluta (MEYRICK) (LEPIDOPTERA: GELECHIIDAE) 



\subsection{Introducción}

La polilla del tomate o gusano minador del tomate, Tuta absoluta (Meyrick), es nativa de Sudamérica y fue detectada por primera vez en España en el año 2006, concretamente en Castellón (Urbaneja et al., 2012) desde donde se extendió a todas las áreas de cultivo de tomate en España, y posteriormente a otros países de Europa. En la actualidad, T. absoluta es considerada una de las plagas más devastadoras del cultivo del tomate (Desneux et al., 2011).

El uso de fitosanitarios es fundamental para el control en campo de T. absoluta, siendo esencial su integración en un programa global de Gestión Integrada de Plagas (GIP). Debido al creciente riesgo de desarrollo de resistencias a insecticidas en $T$. absoluta, es necesario llevar a cabo un estudio sobre la evolución de la resistencia a los insecticidas autorizados para su control, con el fin de poder prevenir el desarrollo de resistencias cruzadas y estudiar los mecanismos de resistencia implicados.

Clorantraniliprol y ciantraniliprol son dos diamidas del ácido antranílico (Lahm et al., 2005, $2007,2009)$. Las diamidas son un nuevo grupo de insecticidas que han sido clasificados como moduladores del receptor de la rianodina (IRAC, 2016). A diferencia de los insecticidas neurotóxicos, las diamidas son muy tóxicas frente a las plagas agrícolas, pero al mismo tiempo respetuosas con los enemigos naturales, convirtiéndose en herramientas adecuadas dentro de un programa de GIP (Mills et al., 2016).

Recientemente se han encontrado poblaciones de $T$. absoluta bastantes resistentes a las diamidas (Roditakis et al., 2015; Silva et al., 2016; Roditakis et al., 2017a, 2017b, 2017c). Este hecho pone de manifiesto la importancia del estudio de la resistencia a diamidas en $T$. absoluta, los mecanismos implicados en esta resistencia y la posible resistencia cruzada que pueda haber entre las propias diamidas, y entre las diamidas y otros insecticidas autorizados para el control de T. absoluta.

En este trabajo se obtuvieron dos poblaciones de $T$. absoluta resistentes a dos diamidas, a partir de una población de campo que ya mostraba cierta resistencia. Por un lado, se seleccionó en el laboratorio una población resistente a clorantraniliprol, Sicilia Rclorantraniliprol, y por otro lado se seleccionó una población resistente a ciantraniliprol, Sicilia $\mathrm{R}$-ciantraniliprol. Con estas dos poblaciones se estudiaron las resistencias cruzadas entre ellas y con los insecticidas flubendiamida, spinosad, indoxacarb y emamectina benzoato. También se realizaron bioensayos con los sinergistas PBO, DEF y DEM para determinar si la resistencia a clorantraniliprol y a ciantraniliprol en $T$. absoluta se debe a un mecanismo de resistencia metabólico. 


\subsection{Material y Métodos}

\subsubsection{Población de T. absoluta}

La población de T. absoluta elegida en este trabajo, con el fin de obtener dos poblaciones resistentes a los insecticidas clorantraniliprol y ciantraniliprol, fue Sicilia. Esta población se recolectó en diciembre del año 2014 en un invernadero de tomate situado en la región de Sicilia (Italia). Previamente se había informado de fallos de control en campo de T. absoluta al emplear el insecticida clorantraniliprol en la zona de recolección y alrededores de esta población. En el laboratorio, esta población resultó resistente, con factores de resistencia de 367 (FR) para clorantraniliprol y de 77,1 (FR) para ciantraniliprol (Tabla 4.2 y Tabla 4.5, Capítulo 4). Para eliminar los posibles individuos sensibles de la población y aumentar su resistencia a cada diamida, se seleccionó más en el laboratorio. Por lo tanto, nos resultó útil partir de una población que presentara una menor susceptibilidad a clorantraniliprol y ciantraniliprol, y así obtener poblaciones con una mayor resistencia de forma más rápida.

\subsubsection{Insecticidas}

Las formulaciones comerciales de los insecticidas utilizados en los bioensayos fueron: clorantraniliprol 35\% WG (Altacor (rynaxypyr), DuPont), ciantraniliprol 10,26\% OD (Benevia (cyazypyr), DuPont), flubendiamida 24\% WG (Fenos, Bayer CropScience), spinosad 48\% SC (Spintor 480 SC, Dow AgroScience), indoxacarb 30\% WG (Steward, DuPont) y emamectina benzoato $0,855 \%$ SG (Affirm, Syngenta Agro).

\subsubsection{Bioensayos de susceptibilidad}

Se realizaron bioensayos de susceptibilidad con larvas en estadio 2 (L2) de T. absoluta para cada una de las poblaciones resistentes, con el fin de determinar si hay resistencias cruzadas con otros insecticidas estudiados en este trabajo.

Ver apartado 3.4.1. Bioensayos de susceptibilidad, en el capítulo 3 de Material y Métodos Generales.

\subsubsection{Bioensayos de selección de resistencias}

Los bioensayos de selección se realizaron para obtener una población resistente a clorantraniliprol y otra a ciantraniliprol. Se partió de la población Sicilia para obtener ambas selecciones.

Ver apartado 3.4.2. Bioensayos de selección de resistencias, en el capítulo 3 de Material y Métodos Generales. 


\subsubsection{Bioensayos con sinergistas}

Se realizaron bioensayos con los sinergistas butóxido de piperonilo (PBO) a una concentración de $1000 \mathrm{mg} \mathrm{L}^{-1}, \mathrm{~S}, \mathrm{~S}, \mathrm{~S}$ tributil fosforotritioato (DEF) a una concentración de $300 \mathrm{mg} \mathrm{L}^{-1}$, y dietil maleato (DEM) también a una concentración de $300 \mathrm{mg} \mathrm{L}^{-1}$. Estos bioensayos se llevaron a cabo tanto con la población seleccionada a clorantraniliprol como con la seleccionada a ciantraniliprol, para determinar si la resistencia a estos insecticidas se debe a un mecanismo de resistencia metabólica o no.

Ver apartado 3.4.3. Bioensayos con sinergistas, en el capítulo 3 de Material y Métodos Generales.

\subsubsection{Análisis de datos}

Los datos de los bioensayos se analizaron usando el programa estadístico POLO-Plus para el análisis probit de los datos (LeOra-Software, 2005). Los parámetros calculados para este estudio fueron: la concentración letal 50 (CL50), que es la concentración que causa una mortalidad del 50\%, y sus límites fiduciales al $95 \%$ para cada población e insecticida, expresados en $\mathrm{mg} \mathrm{L}^{-1}$; los factores de resistencia (FR) de cada población, comparando la CL50 de cada población con la CL50 de la línea base de susceptibilidad (Tabla 4.1, Tabla 4.4 y Tabla 4.7, Capítulo 4; Tabla 5.1 y Tabla 5.4, Capítulo 5); el factor de sinergismo (FS), comparando la CL50 del bioensayo con el sinergista y la CL50 de la población resistente.

\subsection{Resultados y Discusión}

En este apartado se presentan los resultados obtenidos de la selección de resistencia de la población Sicilia a los insecticidas clorantraniliprol y ciantraniliprol. Una vez obtenidas las dos poblaciones resistentes, estas se bioensayaron a los distintos insecticidas estudiados en este trabajo para determinar la existencia o no de resistencias cruzadas. Por otro lado, en este apartado también se muestran los resultados obtenidos al bioensayar las poblaciones resistentes con los tres sinergistas, PBO, DEM y DEF. Estos bioensayos se realizan para determinar si el mecanismo implicado en la resistencia a estos dos insecticidas se debe a un mecanismo de resistencia metabólica. 


\subsubsection{Selección a clorantraniliprol, resistencias cruzadas y mecanismos de resistencia}

En la tabla 6.1 se muestran los resultados obtenidos de la selección a clorantraniliprol de la población de T. absoluta Sicilia. Como se puede observar en la tabla, al inicio de la selección (SO) se aumentó la concentración insecticida de 100 a $300 \mathrm{mg} \mathrm{L}^{-1}$, obteniendo una media de mortalidad de 58,7\%. Se decidió comenzar la selección con un tratamiento de $100 \mathrm{mg} \mathrm{L}^{-1}$ debido a que la CL50 a clorantraniliprol de la población Sicilia fue de 47,65 $\mathrm{mg} \mathrm{L}^{-1}$ (Tabla 4.2, Capítulo 4), y buscábamos una concentración a la cual se muriera alrededor del $80 \%$ de la población. Con esto queríamos conseguir que los individuos supervivientes fueran realmente resistentes a clorantraniliprol. Conforme aumenta la selección también aumenta la concentración de insecticida, pero los porcentajes de mortalidad varían, aumentando o disminuyendo a medida que se avanza en la selección. Sin embargo, a partir de la selección 3 (S3), donde se realizaron tratamientos de selección con una concentración de insecticida de $300 \mathrm{mg} \mathrm{L}^{-1}$, se observó una tendencia descendente de la mortalidad hasta la selección 6 (S6). En esta selección se realizó primero un tratamiento con una concentración insecticida de 1000 $\mathrm{mg} \mathrm{L}^{-1}$, pero al obtener muy baja mortalidad se descartó y por este motivo no aparece en la tabla 6.1. Se decidió entonces aumentar la concentración insecticida a $3000 \mathrm{mg} \mathrm{L}^{-1}$. Finalmente, llegamos a una selección 7 (S7), donde el tratamiento insecticida fue de $3000 \mathrm{mg}$ $\mathrm{L}^{-1}$, obteniéndose una mortalidad de 22,9\%. Decidimos detener el tratamiento de selección en este punto, ya que consideramos que habíamos conseguido una población bastante resistente en comparación con la población original de partida. A esta población seleccionada y resistente al insecticida clorantraniliprol se le llamó Sicilia R-clorantraniliprol.

Tabla 6.1: Selección de la resistencia a clorantraniliprol en la población Sicilia.

\begin{tabular}{c|ccc}
\hline Selección & Tratamiento $\left(\mathrm{mg} \mathrm{L}^{-1}\right)$ & Total larvas & \% Mortalidad \\
\hline S0 & $100-300$ & 2080 & 58,7 \\
S1 & $250-300$ & 962 & 31,6 \\
S2 & $300-500$ & 1598 & 81,1 \\
S3 & 300 & 769 & 72,8 \\
S4 & 300 & 1624 & 63,1 \\
S5 & 300 & 1222 & 48,6 \\
S6 & 3000 & 860 & 56,1 \\
S7 & 3000 & 976 & 22,9 \\
\hline
\end{tabular}

Una vez obtenida la población resistente a clorantraniliprol, se determinó su CL50 para comprobar el nivel de resistencia adquirido en el proceso de selección. Al mismo tiempo, esta población resistente se bioensayó a diferentes insecticidas (ciantraniliprol, flubendiamida, spinosad, indoxacarb y emamectina benzoato) para determinar si existe resistencia cruzada con otros insecticidas empleados en $T$. absoluta. 
En la tabla 6.2 se muestran los resultados de estos bioensayos, comparando las CL50 de la población resistente a clorantraniliprol con la línea base de susceptibilidad de cada uno de los insecticidas. También se observa en la tabla 6.2 las CL50 de la población Sicilia a todos los insecticidas estudiados. Estos valores nos sirven para ver la variación de la susceptibilidad a cada uno de los insecticidas, al comparar la población original Sicilia con la población resistente Sicilia R-clorantraniliprol.

La CL50 a clorantraniliprol de la población resistente Sicilia R-clorantraniliprol fue de $7453 \mathrm{mg}$ $\mathrm{L}^{-1}$, con un factor de resistencia con respecto a la línea base de susceptibilidad de 57333. Además, la población Sicilia R-clorantraniliprol fue 156 veces más resistente a clorantraniliprol que la población Sicilia. Este hecho nos indica que la selección de la resistencia a clorantraniliprol se llevó a cabo de forma exitosa, obteniendo una población muy resistente a este insecticida.

Tabla 6.2: Toxicidad a clorantraniliprol y a diferentes insecticidas de la población Sicilia y la población resistente Sicilia R-clorantraniliprol.

\begin{tabular}{|c|c|c|c|c|c|}
\hline Insecticida & Población & CL50 & LF $(95 \%)$ & FR & \\
\hline \multirow{3}{*}{ Clorantraniliprol } & Línea Base de Susceptibilidad & 0,13 & $0,11-0,17$ & 1 & \\
\hline & Sicilia & 47,65 & $24,54-183,09$ & 367 & \\
\hline & Sicilia R-clorantraniliprol & 7453 & $2705-26004$ & 57333 & $*$ \\
\hline \multirow{3}{*}{ Ciantraniliprol } & Línea Base de Susceptibilidad & 0,09 & $0,08-0,11$ & 1 & \\
\hline & Sicilia & 6,94 & $2,34-13,59$ & 77 & \\
\hline & Sicilia R-clorantraniliprol & 751,71 & $289,15-1347$ & 8352 & $*$ \\
\hline \multirow{3}{*}{ Flubendiamida } & Línea Base de Susceptibilidad & 0,12 & $0,11-0,14$ & 1 & \\
\hline & Sicilia & 449,80 & $115,32-875,19$ & 3748 & \\
\hline & Sicilia R-clorantraniliprol & 21216 & $6518-32350$ & 176800 & $*$ \\
\hline \multirow{3}{*}{ Indoxacarb } & Línea Base de Susceptibilidad & 0,43 & $0,38-0,48$ & 1 & \\
\hline & Sicilia & 0,47 & $0,14-1,16$ & 1,1 & \\
\hline & Sicilia R-clorantraniliprol & 0,74 & $0,44-1,29$ & 1,7 & ns \\
\hline \multirow{3}{*}{ Spinosad } & Línea Base de Susceptibilidad & 0,25 & $0,21-0,31$ & 1 & \\
\hline & Sicilia & 0,05 & $0,03-0,08$ & 0,2 & \\
\hline & Sicilia R-clorantraniliprol & 0,03 & $0,02-0,05$ & 0,1 & $*$ \\
\hline \multirow{3}{*}{$\begin{array}{c}\text { Emamectina } \\
\text { benzoato }\end{array}$} & Línea Base de Susceptibilidad $^{a}$ & 0,014 & $0,012-0,016$ & 1 & \\
\hline & Sicilia & 0,034 & $0,013-0,067$ & 2,4 & \\
\hline & Sicilia R-clorantraniliprol & 0,015 & $0,007-0,032$ & 1,1 & ns \\
\hline
\end{tabular}

CL50: Concentración letal 50 en $\mathrm{mg} \mathrm{L}^{-1}$; LF (95\%): Límites fiduciales al 95\% en $\mathrm{mg} \mathrm{L}^{-1}$; FR: Factor de Resistencia; ns: sin diferencias significativas; *: diferencias significativas;

a: Martínez-Aguirre (2017). 
Al mismo tiempo, en la tabla 6.2 se puede observar que la población resistente a clorantraniliprol Sicilia R-clorantraniliprol, cuando se bioensayó al resto de insecticidas, mostró diferencias significativas con respecto a la línea base de susceptibilidad de ciantraniliprol, flubendiamida y spinosad, pero no para indoxacarb y emamectina benzoato. Por lo tanto, en vista de los resultados obtenidos para estos dos insecticidas, no hay resistencia cruzada entre clorantraniliprol e indoxacarb ni entre clorantraniliprol y emamectina benzoato. En el caso de spinosad, la CL50 de la población resistente a clorantraniliprol fue de $0,03 \mathrm{mg} \mathrm{L}^{-1}$, inferior a la CL50 de la población Sicilia $\left(0,05 \mathrm{mg} \mathrm{L}^{-1}\right)$. El factor de resistencia al compararlo con la línea base de susceptibilidad de spinosad fue de 0,1. Estos resultados podrían indicar una posible resistencia cruzada negativa, es decir, cuanto más resistente es la población a clorantraniliprol, esta parece ser más susceptible a spinosad. Sin embargo, la diferencia de factor de resistencia de casi 60000 (FR) para clorantraniliprol y de apenas 10 (FR) para spinosad, sugiere que más que una resistencia cruzada negativa sea un ligero cambio en la población sin relación con la selección a clorantraniliprol, debido quizás a un coste en la aptitud de los individuos.

Para ciantraniliprol, la CL50 de la población Sicilia R-clorantraniliprol fue de $751,71 \mathrm{mg} \mathrm{L}^{-1}$, con una variabilidad en comparación con la línea base de susceptibilidad de 8352, y 108 veces más resistente a ciantraniliprol que la población Sicilia. En el caso de flubendiamida, la CL50 de la población resistente a clorantraniliprol fue de $21216 \mathrm{mg} \mathrm{L}^{-1}$, con un factor de resistencia con respecto a la línea base de susceptibilidad de 176800 , y siendo 47 veces más resistente a flubendiamida que la población Sicilia. Estos resultados nos indican que existe una fuerte resistencia cruzada entre clorantraniliprol y ciantraniliprol, y entre clorantraniliprol y flubendiamida, confirmando las sospechas que nos habían surgido en los resultados obtenidos en el capítulo 4 de esta Tesis. Además, se observa que la resistencia cruzada con flubendiamida es 21 veces mayor que la resistencia cruzada con ciantraniliprol. Por lo tanto, cuando se selecciona a clorantraniliprol, aumenta más la resistencia a flubendiamida que a ciantraniliprol. Esta resistencia cruzada entre las tres diamidas en poblaciones de $T$. absoluta ya ha sido observada por otros autores. Roditakis et al. (2017b) mostraron resultados sobre la resistencia cruzada entre clorantraniliprol y flubendiamida (con un factor de resistencia superior a 2500) en una población italiana de $T$. absoluta seleccionada en el laboratorio a clorantraniliprol, siendo 1356 veces más resistente a clorantraniliprol que su población sensible. Silva et al. (2016) encontraron poblaciones brasileñas muy resistentes a clorantraniliprol, ciantraniliprol y flubendiamida, observando una fuerte resistencia cruzada entre las tres diamidas.

En Plutella xylostella Linnaeus (Lepidoptera: Plutellidae) también se ha observado resistencia cruzada entre las tres diamidas. Liu et al. (2015b) observaron resistencia cruzada entre clorantraniliprol y flubendiamida y entre clorantraniliprol y ciantraniliprol al bioensayar una población de $P$. xylostella seleccionada a clorantraniliprol $(F R=48,2)$ a las otras dos diamidas. En este trabajo se obtuvieron factores de resistencia con respecto a su población susceptible de referencia de 7,3 (FR) para flubendiamida y 3,3 (FR) para ciantraniliprol. 
Por otra parte, esta resistencia cruzada entre los tres insecticidas diamidas sugiere la existencia de un mecanismo de resistencia que afecta a estos tres insecticidas. Por lo tanto, es interesante comprobar si este mecanismo de resistencia se debe a una resistencia metabólica, es decir, si la resistencia se debe a la acción de enzimas de detoxificación presentes en el insecto, o si por el contrario se debe a una modificación en el punto donde actúa la molécula insecticida en el interior del insecto. En la tabla 6.3 se muestran los resultados de los bioensayos realizados con los tres sinergistas junto al insecticida clorantraniliprol en la población resistente Sicilia R-clorantraniliprol.

Tabla 6.3: Toxicidad a clorantraniliprol y clorantraniliprol más PBO, DEF y DEM de la población resistente Sicilia R-clorantraniliprol.

\begin{tabular}{|c|c|c|c|c|c|c|c|}
\hline Insecticida & Población & CL50 & LF $(95 \%)$ & $\mathbf{F R}$ & & FS & \\
\hline \multirow[t]{2}{*}{ Clorantraniliprol } & $\begin{array}{l}\text { Línea Base de } \\
\text { Susceptibilidad }\end{array}$ & 0,13 & $0,11-0,17$ & 1 & & & \\
\hline & Sicilia R-clorantraniliprol & 7453 & $2705-26004$ & 57333 & $*$ & 1 & \\
\hline $\begin{array}{c}\text { Clorantraniliprol } \\
+ \text { PBO }\end{array}$ & Sicilia R-clorantraniliprol & 482,46 & $121,06-1178$ & 3711 & $*$ & 15,4 & $*$ \\
\hline $\begin{array}{c}\text { Clorantraniliprol } \\
+ \text { DEF }\end{array}$ & Sicilia R-clorantraniliprol & 4271 & $1660-11053$ & 32860 & $*$ & 1,7 & ns \\
\hline $\begin{array}{c}\text { Clorantraniliprol } \\
\text { + DEM }\end{array}$ & Sicilia R-clorantraniliprol & 4608 & $1244-11450$ & 35448 & $*$ & 1,6 & ns \\
\hline
\end{tabular}

CL50: Concentración letal 50 en $\mathrm{mg} \mathrm{L}^{-1}$; LF (95\%): Límites fiduciales al 95\% en $\mathrm{mg} \mathrm{L}^{-1}$; FR: Factor de Resistencia; FS: Factor de Sinergismo; ns: sin diferencias significativas; * : diferencias significativas

Como se observa en la tabla 6.3, en los bioensayos donde se emplearon los sinergistas DEF o DEM junto al insecticida clorantraniliprol, no disminuyó de forma significativa la CL50 con respecto a la CL50 obtenida cuando se bioensayó el insecticida solo. Se obtuvo un factor de sinergismo de 1,7 (FS) para el bioensayo con DEF y de 1,6 (FS) para el realizado con DEM. Sin embargo, al bioensayar la población resistente al insecticida junto al sinergista PBO, se observó una disminución significativa de la resistencia con un factor de sinergismo de 15,4 (FS). Esta disminución de la resistencia a clorantraniliprol al emplear el sinergista PBO junto al insecticida, parece indicar que las enzimas P450 monooxigenasas tienen un papel en la resistencia a clorantraniliprol en $T$. absoluta. Otros autores difieren con estos resultados. Roditakis et al. (2017b) observaron una disminución (no estadísticamente significativa) de la resistencia a clorantraniliprol en su población resistente a este insecticida cuando se bioensayó esta población con clorantraniliprol junto al sinergista DEF (FS =11), pero no con los sinergistas PBO y DEM. 
Con respecto a otros lepidópteros, Liu et al. (2015b) observaron una disminución de la resistencia a clorantraniliprol en una población de $P$. xylostella seleccionada a este insecticida, cuando se bioensayó el insecticida junto al sinergista PBO, obteniendo un factor de sinergismo de 6,1 (FS). Por otro lado, no observaron disminución de la resistencia al insecticida cuando lo emplearon junto con los sinergistas DEF y DEM.

Aunque el uso combinado de clorantraniliprol y el sinergista PBO da lugar a una disminución significativa de la resistencia en la población Sicilia R-clorantraniliprol, esta sigue siendo muy resistente con respecto a Sicilia (10 veces más resistente). Este hecho parece indicar que existen mecanismos de resistencia adicionales implicados en la resistencia a clorantraniliprol en $T$. absoluta, como el mecanismo de resistencia en el punto de acción.

\subsubsection{Selección a ciantraniliprol, resistencias cruzadas y mecanismos de resistencia}

Los resultados obtenidos de la selección a ciantraniliprol de la población Sicilia se muestran en la tabla 6.4. Se realizaron tratamientos de selección a concentraciones del insecticida de 5 y 10 $\mathrm{mg} \mathrm{L}^{-1}$ al inicio de la selección (S0), obteniendo una mortalidad media de $78,8 \%$. Se mantuvo una concentración de $5 \mathrm{mg} \mathrm{L}^{-1}$ durante dos selecciones más (S1 y S2) y a medida que la mortalidad media fue disminuyendo mientras avanzaba la selección, se aumentó la concentración insecticida. En la selección 6 (S6) se realizaron tratamientos a concentraciones de 100 y $1000 \mathrm{mg} \mathrm{L}^{-1}$, y se obtuvo una mortalidad media de 16,8\%. Esta mortalidad nos indicó que en realidad no estábamos seleccionando, ya que la mortalidad obtenida fue similar a la que pudiese tener un control en un bioensayo similar. Por lo tanto, en la siguiente selección, selección 7 (S7), se aumentó la concentración de ciantraniliprol a $3000 \mathrm{mg} \mathrm{L}^{-1}$. En este caso, la mortalidad media fue de $73,4 \%$. Aunque el porcentaje fue elevado, se tomó la decisión de interrumpir el proceso de selección a ciantraniliprol en la selección 7 (S7), ya que parecía que habíamos conseguido una población bastante resistente a ciantraniliprol, si la comparábamos con la población original Sicilia (CL50 a ciantraniliprol =6,94 $\mathrm{mg} \mathrm{L}^{-1}$; Tabla 4.5, Capítulo 4). A la población seleccionada y resistente a ciantraniliprol se le llamó Sicilia R-ciantraniliprol.

Tabla 6.4: Selección de la resistencia a ciantraniliprol en la población Sicilia.

\begin{tabular}{|c|ccc|}
\hline Selección & Tratamiento $\left(\mathrm{mg} \mathrm{L}^{-1}\right)$ & Total larvas & \% Mortalidad \\
\hline S0 & $5-10$ & 2102 & 78,8 \\
S1 & 5 & 2306 & 70,9 \\
S2 & 5 & 778 & 58,1 \\
S3 & $5-8$ & 899 & 57,5 \\
S4 & $8-10$ & 992 & 64,9 \\
S5 & $10-60$ & 914 & 19,8 \\
S6 & $100-1000$ & 1081 & 16,8 \\
S7 & 3000 & 1043 & 73,4 \\
\hline
\end{tabular}


En la tabla 6.5 se muestran los resultados de los bioensayos realizados con la población resistente a ciantraniliprol Sicilia R-ciantraniliprol. Se determinó su CL50 a ciantraniliprol y a los otros insecticidas estudiados en este trabajo (clorantraniliprol, flubendiamida, spinosad, indoxacarb y emamectina benzoato) con el fin de, por un lado, comprobar el nivel de resistencia a ciantraniliprol alcanzado en el proceso de selección, y al mismo tiempo comprobar si existía resistencia cruzada con los otros insecticidas estudiados. Los valores de CL50 obtenidos de los bioensayos realizados con la población resistente a ciantraniliprol se compararon con la línea base de susceptibilidad de cada uno de los insecticidas. Para poder comparar la variación de la susceptibilidad a estos insecticidas entre la población de partida Sicilia y la población resistente a ciantraniliprol, se muestran las CL50 de la población Sicilia a todos los insecticidas estudiados.

Se observa en la tabla 6.5, que la CL50 a ciantraniliprol de la población resistente Sicilia Rciantraniliprol fue de $1910 \mathrm{mg} \mathrm{L}^{-1}$, presentando un factor de resistencia con respecto a la línea base de susceptibilidad de 21223, y siendo la población resistente a ciantraniliprol 275 veces más resistente que Sicilia. Por lo tanto, podemos confirmar que se obtuvo con éxito una población resistente al insecticida ciantraniliprol.

Tabla 6.5: Toxicidad a ciantraniliprol y a diferentes insecticidas de la población Sicilia y la población resistente Sicilia R-ciantraniliprol.

\begin{tabular}{|c|c|c|c|c|c|}
\hline Insecticida & Población & CL50 & LF $(95 \%)$ & FR & \\
\hline \multirow{3}{*}{ Ciantraniliprol } & Línea Base de Susceptibilidad & 0,09 & $0,08-0,11$ & 1 & \\
\hline & Sicilia & 6,94 & $2,34-13,59$ & 77 & \\
\hline & Sicilia R-ciantraniliprol & 1910 & $1280-2574$ & 21223 & $*$ \\
\hline \multirow{3}{*}{ Clorantraniliprol } & Línea Base de Susceptibilidad & 0,13 & $0,11-0,17$ & 1 & \\
\hline & Sicilia & 47,65 & $24,54-183,09$ & 367 & \\
\hline & Sicilia R-ciantraniliprol & 1418 & $432,47-2417$ & 10914 & $*$ \\
\hline \multirow{3}{*}{ Flubendiamida } & Línea Base de Susceptibilidad & 0,12 & $0,11-0,14$ & 1 & \\
\hline & Sicilia & 449,80 & $115,32-875,19$ & 3748 & \\
\hline & Sicilia R-ciantraniliprol & 4139 & $1030-10178$ & 34496 & $*$ \\
\hline \multirow{3}{*}{ Indoxacarb } & Línea Base de Susceptibilidad & 0,43 & $0,38-0,48$ & 1 & \\
\hline & Sicilia & 0,47 & $0,14-1,16$ & 1,1 & \\
\hline & Sicilia R-ciantraniliprol & 0,29 & $0,18-0,44$ & 0,7 & ns \\
\hline \multirow{3}{*}{ Spinosad } & Línea Base de Susceptibilidad & 0,25 & $0,21-0,31$ & 1 & \\
\hline & Sicilia & 0,05 & $0,03-0,08$ & 0,2 & \\
\hline & Sicilia R-ciantraniliprol & 0,02 & $0,01-0,04$ & 0,1 & $*$ \\
\hline \multirow{3}{*}{$\begin{array}{l}\text { Emamectina } \\
\text { benzoato }\end{array}$} & Línea Base de Susceptibilidad $^{\text {a }}$ & 0,014 & $0,012-0,016$ & 1 & \\
\hline & Sicilia & 0,034 & $0,013-0,067$ & 2,4 & \\
\hline & Sicilia R-ciantraniliprol & 0,006 & $0,003-0,009$ & 0,4 & $*$ \\
\hline
\end{tabular}

CL50: Concentración letal 50 en $\mathrm{mg} \mathrm{L}^{-1}$; LF (95\%): Límites fiduciales al 95\% en $\mathrm{mg} \mathrm{L}^{-1}$; FR: Factor de Resistencia; ns: sin diferencias significativas; *: diferencias significativas;

a: Martínez-Aguirre (2017). 
Como se puede observar en la tabla 6.5, no hay diferencias significativas entre la CL50 a indoxacarb de la población Sicilia R-ciantraniliprol y la línea base de susceptibilidad de indoxacarb $(F R=0,7)$. Por lo tanto, no existe resistencia cruzada entre ciantraniliprol e indoxacarb. Sin embargo, sí existen diferencias significativas con el resto de insecticidas. Para spinosad y emamectina benzoato, las CL50 de la población resistente a ciantraniliprol fueron inferiores tanto a la línea base de susceptibilidad de ambos insecticidas como a las CL50 de la población Sicilia. En el caso de spinosad, el factor de resistencia al compararlo con su línea base de susceptibilidad fue de 0,1 (FR). Este valor parece indicar, al igual que en el caso de la población resistente a clorantraniliprol (Tabla 6.2), una posible resistencia cruzada negativa entre ciantraniliprol y spinosad. El factor de resistencia obtenido para emamectina benzoato en la población resistente a ciantraniliprol, al compararla con la línea base de susceptibilidad de emamectina benzoato, fue de 0,4 (FR). El aumento de la susceptibilidad a spinosad y emamectina benzoato en la población resistente a ciantraniliprol, siendo 12,5 y 2,3 más susceptible a spinosad y emamectina benzoato respectivamente, sugiere que se ha producido un coste en el vigor de la población resistente asociado al proceso de selección de resistencia.

A diferencia de lo que ocurre con spinosad, emamectina benzoato e indoxacarb, sí se observa resistencia cruzada entre ciantraniliprol y las otras diamidas, clorantraniliprol y flubendiamida. Para clorantraniliprol, la CL50 de la población resistente a ciantraniliprol fue de $1418 \mathrm{mg} \mathrm{L}^{-1}$, con un factor de resistencia al compararla con la línea base de susceptibilidad de 10914 (FR). En el caso de flubendiamida, la CL50 de la población resistente Sicilia R-ciantraniliprol a flubendiamida fue de $4139 \mathrm{mg} \mathrm{L}^{-1}$, con un factor de resistencia con respecto a la línea base de susceptibilidad de 34496 (FR). Además, la población Sicilia R-ciantraniliprol fue 29,8 y 9,2 veces más resistente a clorantraniliprol y flubendiamida respectivamente, que la población Sicilia. Al igual que sucede para la población resistente a clorantraniliprol, estos resultados nos vuelven a confirmar la fuerte resistencia cruzada que existe entre las tres diamidas en $T$. absoluta, siendo esta resistencia cruzada mayor con flubendiamida que con ciantraniliprol.

Por otro lado, se observó una mayor resistencia cruzada entre clorantraniliprol y flubendiamida que entre ciantraniliprol y las otras diamidas. La selección de la población Sicilia a clorantraniliprol resulta en una elevada resistencia a clorantraniliprol y flubendiamida, pero menor a ciantraniliprol. En cambio, cuando la selección es a ciantraniliprol, se obtiene una menor resistencia a clorantraniliprol y flubendiamida.

Con respecto a otros lepidópteros, en $P$. xylostella también se ha observado resistencia cruzada entre las tres diamidas. Liu et al. (2015a) observaron resistencia cruzada entre ciantraniliprol y clorantraniliprol, y entre ciantraniliprol y flubendiamida en una población de $P$. xylostella seleccionada a ciantraniliprol $(F R=326)$. En este trabajo se obtuvieron factores de resistencia con respecto a la población susceptible de referencia de 209 y 105 para clorantraniliprol y flubendiamida respectivamente. 
A raíz de los resultados obtenidos en este trabajo (Tabla 6.5), que confirman la resistencia cruzada entre ciantraniliprol, clorantraniliprol y flubendiamida, se realizaron bioensayos con los sinergistas PBO, DEF y DEM para determinar la existencia o no de un mecanismo de resistencia metabólico que pueda estar implicado en la resistencia a ciantraniliprol en $T$. absoluta, y por tanto también en la resistencia a las otras dos diamidas. En la tabla 6.6 se pueden observar los resultados de los bioensayos realizados con los tres sinergistas y el insecticida ciantraniliprol en la población resistente Sicilia R-ciantraniliprol.

Tabla 6.6: Toxicidad a ciantraniliprol y ciantraniliprol más PBO, DEF y DEM de la población resistente Sicilia R-ciantraniliprol.

\begin{tabular}{c|c|r|r|r|r|r|r}
\hline \multicolumn{1}{c}{ Insecticida } & \multicolumn{1}{c}{ Población } & \multicolumn{1}{c}{ CL50 } & LF (95\%) & FR & 1 & & \\
\hline Ciantraniliprol & $\begin{array}{c}\text { Línea Base de Susceptibilidad } \\
\text { Sicilia R-ciantraniliprol }\end{array}$ & 1910,06 & $1280-2574$ & 21223 & $*$ & 1 & $0,08-0,11$ \\
\hline $\begin{array}{c}\text { Ciantraniliprol } \\
\text { + PBO }\end{array}$ & Sicilia R-ciantraniliprol & 2607,63 & $1395-3826$ & 28974 & $*$ & 0,7 & ns \\
\hline $\begin{array}{c}\text { Ciantraniliprol } \\
\text { + DEF }\end{array}$ & Sicilia R-ciantraniliprol & 4365,33 & $3416-5526$ & 48504 & $*$ & 0,4 & $*$ \\
\hline $\begin{array}{c}\text { Ciantraniliprol } \\
\text { + DEM }\end{array}$ & Sicilia R-ciantraniliprol & 2571,79 & $1303-4555$ & 28575 & $*$ & 0,7 & ns \\
\hline
\end{tabular}

CL50: Concentración letal 50 en $\mathrm{mg} \mathrm{L}^{-1}$; LF (95\%): Límites fiduciales al 95\% en mg L ${ }^{-1} ; \mathbf{F R}$ : Factor de Resistencia; FS: Factor de Sinergismo; ns: sin diferencias significativas; ${ }^{*}$ : diferencias significativas

Los resultados obtenidos muestran que en los casos donde se empleó de forma conjunta los sinergistas PBO, DEF o DEM junto al insecticida ciantraniliprol, aumentó la CL50 de forma significativa en el caso de DEF, y no significativa para PBO y DEM, si la comparamos con la CL50 sin el sinergista. En el caso del bioensayo con DEF, se obtuvo un factor de sinergismo de 0,4 (FS), y para PBO y DEM el factor de sinergismo fue de 0,7 (FS) para cada uno de ellos. Estos resultados difieren de los obtenidos en este trabajo para la población resistente Sicilia Rclorantraniliprol (Tabla 6.3), donde se observó una disminución significativa de la resistencia a clorantraniliprol al emplear el insecticida y PBO juntos, por lo que el posible mecanismo metabólico afectado por PBO con clorantraniliprol no afecta a ciantraniliprol.

En P. xylostella también se ha estudiado el efecto de los sinergistas PBO, DEF y DEM en la resistencia de una población resistente a ciantraniliprol (Liu et al., 2015a). En este trabajo se observó una disminución significativa de la resistencia a ciantraniliprol cuando se combinó este insecticida junto con PBO o DEM, obteniendo factores de sinergismo de 2,8 y 3,2 (FS) para PBO y DEM respectivamente. 
Teniendo en cuenta los resultados obtenidos de los bioensayos con las poblaciones resistentes a clorantraniliprol y ciantraniliprol y los sinergistas PBO, DEF y DEM, así como la fuerte resistencia cruzada hallada entre las tres diamidas, parece que la resistencia en $T$. absoluta a las diamidas se debe a un mecanismo de resistencia en el punto de acción. Este mecanismo de resistencia se produce por una modificación en el punto de acción donde actúan estos insecticidas en el interior del insecto. Un trabajo publicado recientemente (Roditakis et al., 2017b) en el que hemos participado, confirma las conclusiones halladas en esta Tesis. Se encontraron dos mutaciones que parecen ser las responsables de la resistencia a las diamidas en $T$. absoluta, G4903E y G4903V. Ambas mutaciones alteran la unión de la molécula insecticida diamida en el receptor de la rianodina en el insecto. La mutación G4903E ya había sido previamente identificada y descrita en una población de $P$. xylostella resistente a diamidas, mientras que la mutación G4903V se identificó por vez primera en este trabajo.

\subsection{Conclusiones}

En vista de los resultados obtenidos en este trabajo, podemos concluir que se han obtenido con éxito en el laboratorio dos poblaciones de $T$. absoluta resistentes a clorantraniliprol y ciantraniliprol. Estas poblaciones presentan unos niveles de resistencia muy superiores a los de la población original que se empleó para los procesos de selección de resistencias.

Los resultados también indican que no se han encontrado resistencias cruzadas entre clorantraniliprol y ninguno de los otros insecticidas (spinosad, indoxacarb y emamectina benzoato). De igual manera, no se han encontrado resistencias cruzadas entre ciantraniliprol y el resto de insecticidas (spinosad, indoxacarb y emamectina benzoato).

Por el contrario, sí existe una fuerte resistencia cruzada entre las tres diamidas, clorantraniliprol, ciantraniliprol y flubendiamida, confirmando las sospechas que nos habían surgido en los resultados obtenidos en el capítulo 4 de esta Tesis.

Con respecto a los mecanismos implicados en la resistencia a clorantraniliprol y ciantraniliprol, el uso conjunto de clorantraniliprol con el sinergista PBO dio lugar a una disminución significativa de la resistencia en la población resistente Sicilia R-clorantraniliprol. Sin embargo, esta población sigue siendo bastante resistente con respecto tanto a la población de origen como con la dosis de campo (35 $\left.\mathrm{mg} \mathrm{L}^{-1}\right)$. Por lo tanto, parece que la resistencia a diamidas en $T$. absoluta se debe principalmente a un mecanismo de resistencia en el punto de acción. 


\subsection{Referencias bibliográficas}

Desneux, N., Luna, M.G., Guillemaud, T., Urbaneja, A. (2011). The invasive South American tomato pinworm, Tuta absoluta, continues to spread in Afro-Eurasia and beyond: the new threat to tomato world production. J Pest Sci 84: 403-408.

IRAC. (2016). Mode of Action Classification Scheme (Version 8.1) (2016). En línea: http://www.irac-online.org.

Lahm, G.P., Cordova, D., Barry, J.D. (2009). New and selective ryanodine receptor activators for insect control. Bioorg Med Chem 17: 4127-4133.

Lahm, G.P., Selby, T.P., Freudenberger, J.H., Stevenson, T.M., Myers, B.J., Seburyamo, G., Smith, B.K., Flexner, L., Clark, C.E., Cordova, D. (2005). Insecticidal anthranilic diamides: a new class of potent ryanodine receptor activators. Bioorg Med Chem Lett 15: 4898-4906.

Lahm, G.P., Stevenson, T.M., Selby, T.P., Freudenberger, J.H., Cordova, D., Flexner, L., Bellin, C.A., Dubas, C.M., Smith, B.K., Hughes, K.A., Hollingshaus, J.G., Clark, C.E., Benner, E.A. (2007). Rynaxypyr: a new insecticidal anthranilic diamide that acts as a potent and selective ryanodine receptor activator. Bioorg Med Chem Lett 17: 6274-6279.

LeOra-Software. (2005). POLO-Plus, POLO for Windows Petaluma, CA, LeOra Software.

Liu, X., Ning, Y., Wang, H., Wang, K. (2015a). Cross-resistance, mode of inheritance, synergism, and fitness effects of cyantraniliprole resistance in Plutella xylostella. Entoml Experim App 157: 271-278.

Liu, X., Wang, H., Ning, Y., Qiao, K., Wang, K. (2015b). Resistance Selection and Characterization of Chlorantraniliprole Resistance in Plutella xylostella (Lepidoptera: Plutellidae). J Econ Entomol 108 (4): 1978-1985.

Martínez-Aguirre, M.R. (2017). Resistencia a emamectina benzoato en Tuta absoluta (Meyrick) (Lepidoptera: Gelechiidae). Tesis doctoral, Universidad Politécnica de Cartagena, pp. 139.

Mills, N.J., Beers, E.H., Shearer, P.W., Unruh, T.R., Amarasekare, K.G. (2016). Comparative analysis of pesticide effects on natural enemies in western orchards: A synthesis of laboratory bioassay data. Biol Control 102: 17-25.

Roditakis, E., Mavridis, K., Riga, M., Vasakis, E., Morou, E., Rison, J.L., Vontas, J. (2017a). Identification and detection of indoxacarb resistance mutations in the para sodium channel of the tomato leafminer, Tuta absoluta. Pest Manag Sci doi: 10.1002/ps.4513.

Roditakis, E., Steinbach, D., Moritz, G., Vasakis, E., Stavrakaki, M., Ilias, A., García-Vidal, L., Martínez-Aguirre, M.R., Bielza, P., Morou, E., Silva, J.E., Silva, W.M., Siqueira, H.A.A., Iqbal, S., Troczka, B.J., Williamson, M.S., Bass, C., Tsagkarakou, A., Vontas, J., Nauen, R. (2017b). Ryanodine receptor point mutations confer diamide insecticide resistance in tomato leafminer, Tuta absoluta (Lepidoptera: Gelechiidae). Insect Biochem Mol Biol 80: 11-20. 
Roditakis, E., Vasakis, E., García-Vidal, L., Martínez-Aguirre, M.R., Rison, J.L., Haxaire-Lutun, M.O., Nauen, R., Tsagkarakou, A., Bielza, P. (2017c). A four-year survey on insecticide resistance and likelihood of chemical control failure for tomato leaf miner Tuta absoluta in the European/Asian región. J Pest Sci doi: 10.1007/s10340-017-0900-x.

Roditakis, E., Vasakis, E., Grispou, M., Stavrakaki, M., Nauen, R., Gravouil, M., Bassi, A. (2015). First report of Tuta absoluta resistance to diamide insecticides. J Pest Sci 88: 9-16.

Silva, J.E, Assis, C.P.O., Ribeiro, L.M.S., Siqueira, H.A.A. (2016). Field-Evolved Resistance and Cross-Resistance of Brazilian Tuta absoluta (Lepidoptera: Gelechiidae) Populations to Diamide Insecticides. J Econ Entomol 109 (5): 2190-2195.

Urbaneja, A., González-Cabrera, J., Arnó, J., Gabarra, R. (2012). Prospects for the biological control of Tuta absoluta in tomatoes of the Mediterranean basin. Pest Manag Sci 68: 12151222. 


\section{CAPÍTULO 4}

MECANISMOS DE RESISTENCIA A SPINOSAD Y RESISTENCIAS CRUZADAS EN Tuta absoluta (MEYRICK) (LEPIDOPTERA: GELECHIIDAE) 



\subsection{Introducción}

Tuta absoluta (Meyrick) es una plaga invasiva originaria de Sudamérica. Recientes estudios han demostrado que proviene de la zona central de Chile (Guillemaud et al., 2015). Desde el año 2006 se ha extendido a Europa, África y Oriente Medio, afectando tanto la producción de tomate al aire libre como en invernadero (Desneux et al., 2010).

En la actualidad, son escasos los insecticidas empleados para el control de $T$. absoluta, entre los que destacan las diamidas clorantraniliprol, ciantraniliprol y flubendiamida, la avermectina emamectina benzoato, la oxadiacina indoxacarb y la spinosina spinosad. Debido a la escasez de productos químicos autorizados para el control de $T$. absoluta y la necesidad de que estos sean compatibles con los enemigos naturales, es imprescindible evitar que $T$. absoluta desarrolle resistencia a estos insecticidas. Para ello es necesario estudiar los mecanismos implicados en la resistencia en $T$. absoluta y las posibles resistencias cruzadas que puedan existir entre los distintos insecticidas.

Spinosad es apto para la producción ecológica de tomate debido a su origen y forma de obtención, procedente de la fermentación del actinomiceto Saccharopolyspora spinosa Mertz \& Yao (Actinomycetales: Pseudonocardiaceae) (Racke, 2006; Biondi et al., 2013; Puinean et al., 2013). Spinosad actúa sobre los receptores acetilcolina-nicotínicos de las células nerviosas post-sinápticas (Torné et al., 2010), provocando la hiperexcitación del sistema nervioso (IRAC, 2016).

La aparición recientemente de poblaciones de campo de $T$. absoluta menos susceptibles a spinosad y su posterior selección a este insecticida en laboratorio (Campos et al., 2014; Berger et al., 2016; Silva et al., 2016), sugiere que se ha producido una rápida evolución de la resistencia a spinosad en $T$. absoluta en los últimos años. Por lo tanto, es necesario estudiar los mecanismos implicados en la resistencia a spinosad y su resistencia cruzada con otros insecticidas.

Los objetivos de este trabajo son, por un lado estudiar las resistencias cruzadas entre spinosad y el resto de insecticidas estudiados en esta Tesis (clorantraniliprol, ciantraniliprol, flubendiamida, indoxacarb y emamectina benzoato), a partir de una población resistente a spinosad; y por otro lado averiguar si la resistencia a spinosad en $T$. absoluta se debe a un mecanismo de resistencia metabólico. Para esto, se realizaron bioensayos con los sinergistas PBO, DEF, DEM y la población resistente a spinosad. 


\subsection{Material y Métodos}

\subsubsection{Población de T. absoluta}

La población de $T$. absoluta empleada en este trabajo fue la población resistente a spinosad Spin Sel, procedente de un laboratorio de Reino Unido. En este laboratorio se sometió a una población de campo de T. absoluta recolectada en 2012 en Alcochete (Portugal) a un proceso de selección al insecticida spinosad durante 11 generaciones, con el fin de obtener una población resistente a spinosad. Esta población había tenido fallos de control en campo al emplear spinosad como método químico de control. Tras el proceso de selección, obtuvieron una población resistente a spinosad llamada Spin Sel, con una CL50 de 498,6 $\mathrm{mg} \mathrm{L}^{-1}$ (Berger et al., 2016). Esta población llegó a nuestro laboratorio en agosto de 2016, en donde se bioensayó a spinosad para comprobar que el nivel de resistencia a spinosad que presentaba antes de su llegada a nuestro laboratorio fuera el mismo. Además, decidimos partir de esta población para estudiar las resistencias cruzadas y los mecanismos de resistencia a spinosad en T. absoluta.

\subsubsection{Insecticidas}

Las formulaciones comerciales de los insecticidas utilizados en los bioensayos fueron: spinosad 48\% SC (Spintor 480 SC, Dow AgroScience), clorantraniliprol 35\% WG (Altacor (rynaxypyr), DuPont), ciantraniliprol 10,26\% OD (Benevia (cyazypyr), DuPont), flubendiamida 24\% WG (Fenos, Bayer CropScience), indoxacarb 30\% WG (Steward, DuPont) y emamectina benzoato 0,855\% SG (Affirm, Syngenta Agro).

\subsubsection{Bioensayos de susceptibilidad}

Se realizaron bioensayos de susceptibilidad con larvas en estadio 2 (L2) de T. absoluta para la población resistente a spinosad con el fin de estudiar las resistencias cruzadas con otros insecticidas.

Ver apartado 3.4.1. Bioensayos de susceptibilidad, en el capítulo 3 de Material y Métodos Generales. 


\subsubsection{Bioensayos con sinergistas}

La población resistente a spinosad se bioensayó por separado con los sinergistas butóxido de piperonilo (PBO) a una concentración de $1000 \mathrm{mg} \mathrm{L}^{-1}, \mathrm{~S}, \mathrm{~S}, \mathrm{~S}$ tributil fosforotritioato (DEF) a una concentración de $300 \mathrm{mg} \mathrm{L}^{-1} \mathrm{y}$ dietil maleato (DEM) también a $300 \mathrm{mg} \mathrm{L}^{-1}$, para determinar si la resistencia a spinosad se debe a un mecanismo de resistencia metabólica.

Ver apartado 3.4.3. Bioensayos con sinergistas, en el capítulo 3 de Material y Métodos Generales.

\subsubsection{Análisis de datos}

Los datos de los bioensayos se analizaron usando el programa estadístico POLO-Plus para el análisis probit de los datos (LeOra-Software, 2005). Los parámetros calculados fueron: la concentración letal 50 (CL50), que es la concentración que causa una mortalidad del $50 \%$, y sus límites fiduciales al 95\% para cada población e insecticida, expresados en $\mathrm{mg} \mathrm{L}^{-1}$; los factores de resistencia (FR) de cada población, comparando la CL50 de cada población con la CL50 de la línea base de susceptibilidad (Tabla 4.1, Tabla 4.4 y Tabla 4.7, Capítulo 4; Tabla 5.1 y Tabla 5.4, Capítulo 5); el factor de sinergismo (FS), comparando la CL50 del bioensayo con el sinergista y la CL50 de la población resistente.

\subsection{Resultados y Discusión}

En este apartado se muestran los resultados obtenidos de los bioensayos realizados con la población resistente a spinosad Spin Sel, y el resto de insecticidas (clorantraniliprol, ciantraniliprol, flubendiamida, indoxacarb y emamectina benzoato), con el fin de determinar la existencia o no de resistencias cruzadas. Al mismo tiempo, se presentan los resultados obtenidos al bioensayar la población resistente Spin Sel con los tres sinergistas, PBO, DEM y $\mathrm{DEF}$, para comprobar si el mecanismo implicado en la resistencia a spinosad se debe a un mecanismo de resistencia metabólica.

\subsubsection{Resistencias cruzadas y mecanismos de resistencia a spinosad}

La población resistente a spinosad, Spin Sel, se bioensayó a spinosad para obtener su CL50 una vez que se estableció su cría en nuestro laboratorio. Al mismo tiempo, esta población también se bioensayó al resto de insecticidas estudiados en este trabajo (clorantraniliprol, ciantraniliprol, flubendiamida, indoxacarb y emamectina benzoato) para determinar si existe resistencia cruzada con alguno de estos insecticidas.

En la tabla 7.1 se muestran los resultados de los bioensayos realizados con la población resistente a spinosad Spin Sel, comparando las CL50 a los diferentes insecticidas con la línea 
base de susceptibilidad de cada uno de ellos. La CL50 a spinosad de la población resistente Spin Sel fue de 159,16 $\mathrm{mg} \mathrm{L}^{-1}$, con un factor de resistencia con respecto a la línea base de susceptibilidad de 636 (FR). Si comparamos esta CL50 con la que se calculó en el laboratorio de Reino Unido donde se seleccionó esta población $\left(498,6 \mathrm{mg} \mathrm{L}^{-1}\right)$, se puede observar una disminución de la resistencia a spinosad de 3 veces, debido probablemente a la interrupción de la presión insecticida. Esto indica que la resistencia a spinosad no es estable en esta población. Campos et al. (2014) comprobaron este suceso en una población brasileña de $T$. absoluta seleccionada en el laboratorio a spinosad. Obtuvieron una población 100000 veces más resistente a spinosad que su población susceptible de laboratorio. Sin embargo, una vez que se interrumpió el proceso de selección, esta población redujo su resistencia a spinosad hasta alcanzar valores de CL50 similares a los de la población de partida, observando un coste en el vigor de la población asociado a la resistencia a spinosad.

Tabla 7.1: Toxicidad a spinosad y a diferentes insecticidas de la población resistente Spin Sel.

\begin{tabular}{|c|c|c|c|c|c|}
\hline Insecticida & Población & CL50 & LF (95\%) & FR & \\
\hline \multirow{2}{*}{ Spinosad } & Línea Base de Susceptibilidad & 0,25 & $0,21-0,31$ & 1 & \\
\hline & Spin Sel & 159,16 & $65,80-550,09$ & 636 & $*$ \\
\hline \multirow{2}{*}{ Ciantraniliprol } & Línea Base de Susceptibilidad & 0,09 & $0,08-0,11$ & 1 & \\
\hline & Spin Sel & 0,11 & $0,04-0,24$ & 1,2 & ns \\
\hline \multirow{2}{*}{ Clorantraniliprol } & Línea Base de Susceptibilidad & 0,13 & $0,11-0,17$ & 1 & \\
\hline & Spin Sel & 0,33 & $0,14-0,79$ & 2,5 & ns \\
\hline \multirow{2}{*}{ Flubendiamida } & Línea Base de Susceptibilidad & 0,12 & $0,11-0,14$ & 1 & \\
\hline & Spin Sel & 0,10 & $0,05-0,18$ & 0,8 & ns \\
\hline \multirow{2}{*}{ Indoxacarb } & Línea Base de Susceptibilidad & 0,43 & $0,38-0,48$ & 1 & \\
\hline & Spin Sel & 0,61 & $0,33-1,32$ & 1,4 & ns \\
\hline \multirow{2}{*}{$\begin{array}{c}\text { Emamectina } \\
\text { benzoato }\end{array}$} & Línea Base de Susceptibilidad $^{\text {a }}$ & 0,014 & $0,012-0,016$ & 1 & \\
\hline & Spin Sel & 0,013 & $0,007-0,024$ & 0,9 & ns \\
\hline
\end{tabular}

CL50: Concentración letal 50 en $\mathrm{mg} \mathrm{L}^{-1}$; LF (95\%): Límites fiduciales al $95 \%$ en $\mathrm{mg} \mathrm{L}^{-1}$; FR: Factor de Resistencia; ns: sin diferencias significativas; *: diferencias significativas; a: Martínez-Aguirre (2017).

Como se observa en la tabla 7.1, la población resistente a spinosad Spin Sel no mostró diferencias significativas con respecto a la línea base de susceptibilidad de ciantraniliprol, clorantraniliprol, flubendiamida, indoxacarb y emamectina benzoato, cuando Spin Sel fue bioensayada a estos insecticidas. Por lo tanto, observando los resultados obtenidos para estos insecticidas, no hay resistencia cruzada entre spinosad y el resto de insecticidas estudiados. Sin embargo, Campos et al. (2014) observaron una posible resistencia cruzada negativa entre spinosad y clorantraniliprol en una población resistente a spinosad seleccionada en el laboratorio. Esta población fue casi 30 veces más susceptible a clorantraniliprol que la población original empleada para la selección a spinosad, debido tal vez a un coste en la 
aptitud de los individuos más que a una resistencia cruzada negativa. Por el contrario, en el capítulo 6 de esta Tesis (Tabla 6.2) se observó una posible resistencia cruzada negativa entre clorantraniliprol y spinosad en una población resistente a clorantraniliprol. Igualmente, este hecho puede deberse más a un ligero cambio en la aptitud de los individuos de la población sin relación con la selección a clorantraniliprol, que a una resistencia cruzada negativa.

En Spodoptera litura (Fabricius) (Lepidoptera: Noctuidae) se ha estudiado la resistencia cruzada entre spinosad y otros insecticidas. Rehan et al. (2014) estudiaron las resistencias cruzadas entre spinosad y otros insecticidas, en una población procedente de Pakistán de $S$. litura seleccionada en el laboratorio a spinosad durante 11 generaciones. Esta población presentó un factor de resistencia a spinosad con respecto a la población de partida de 35,6. Asimismo, observaron diferencias significativas con respecto a su población susceptible de referencia, al bioensayar a indoxacarb $(F R=455)$ y emamectina benzoato $(F R=18)$ la población resistente a spinosad.

En resumen, en vista de los resultados obtenidos en la tabla 7.1, no se observan resistencias cruzadas entre spinosad y el resto de insecticidas estudiados. Además, parece existir una disminución de la resistencia a spinosad en la población resistente a este insecticida al detener el proceso de selección y dejar de ejercer presión insecticida sobre la población, coincidiendo así con otros trabajos publicados con anterioridad a esta Tesis.

Para determinar si el mecanismo de resistencia implicado en la resistencia a spinosad en $T$. absoluta es metabólico, se realizaron bioensayos con los tres sinergistas por separado y el insecticida spinosad en la población resistente Spin Sel. Los resultados se muestran en la tabla 7.2 .

Tabla 7.2: Toxicidad a spinosad y spinosad más PBO, DEF y DEM de la población resistente Spin Sel.

\begin{tabular}{|c|c|c|c|c|c|c|c|c|c|}
\hline Insecticida & Población & CL50 & LF $(95 \%)$ & FR & & $\begin{array}{c}\text { FS } \\
(2016)\end{array}$ & & $\begin{array}{c}\text { FS } \\
(2017)\end{array}$ & \\
\hline \multirow{3}{*}{ Spinosad } & Línea Base de Susceptibilidad & 0,25 & $0,21-0,31$ & 1 & & & & & \\
\hline & SpinSel (noviembre 2016) & 159,16 & $65,80-550,09$ & 637 & $*$ & 1 & & - & \\
\hline & SpinSel (febrero 2017) & 2,86 & $1,02-5,92$ & 11,4 & $*$ & - & & 1 & \\
\hline Spinosad + PBO & SpinSel (febrero 2017) & 0,98 & $0,16-2,08$ & 3,9 & ns & 162 & $*$ & 2,9 & ns \\
\hline Spinosad + DEF & SpinSel (febrero 2017) & 1,02 & $0,08-2,46$ & 4,1 & ns & 156 & $*$ & 2,8 & ns \\
\hline Spinosad + DEM & SpinSel (febrero 2017) & 0,82 & $0,03-2,15$ & 3,3 & ns & 194 & $*$ & 3,5 & ns \\
\hline
\end{tabular}

CL50: Concentración letal 50 en $\mathrm{mg} \mathrm{L}^{-1}$; LF (95\%): Límites fiduciales al 95\% en $\mathrm{mg} \mathrm{L}^{-1}$; FR: Factor de Resistencia; FS: Factor de Sinergismo; ns: sin diferencias significativas; ${ }^{*}$ : diferencias significativas 
En la tabla 7.2 se observa que al bioensayar la población resistente a spinosad Spin Sel con los sinergistas, PBO, DEF o DEM más spinosad y comparar estos resultados con la CL50 a spinosad de Spin Sel de noviembre de 2016, disminuyó de forma significativa la resistencia a spinosad en la población resistente a este insecticida. Se obtuvieron factores de sinergismo de 162 para el bioensayo con PBO, de 156 con DEF y de 194 con DEM. Estos resultados no concordaban con otros trabajos publicados en 2014 y 2016. Campos et al. (2014) obtuvieron factores de sinergismo de 2,3 y 1,4 para los bioensayos realizados con PBO y DEF respectivamente, en una población seleccionada en el laboratorio a spinosad. Estos autores observaron que las enzimas P450 monooxigenasas y las esterasas representan un mínimo papel en la resistencia a spinosad en T. absoluta. Berger et al. (2016) estudiaron el efecto del sinergista PBO junto a spinosad en una población resistente a este insecticida, no observando diferencias significativas entre el bioensayo con PBO y spinosad y el bioensayo con spinosad solo (FS = 1,2). Asimismo, Silva et al. (2016) estudiaron cómo afectaba el uso por separado de los sinergistas PBO, DEF y DEM junto al insecticida spinosad en una población de campo resistente a spinosad de $T$. absoluta. No observaron una disminución de la resistencia a spinosad al usar cualquiera de los tres sinergistas, con factores de sinergismo de 0,5 para PBO y 0,6 para DEF y DEM. Estos trabajos indicaban que el mecanismo metabólico no estaba implicado en la resistencia a spinosad en $T$. absoluta, o tenía un papel poco significativo. Además, encontraron alteraciones moleculares en el punto de unión de la molécula insecticida en el interior del insecto en las poblaciones resistentes a spinosad, sugiriendo que la resistencia a spinosad en $T$. absoluta se debe a un mecanismo de resistencia en el punto de acción, producido por una mutación en el punto de unión. A raíz de los resultados observados en los trabajos anteriormente mencionados, los cuales distan de nuestros resultados con los sinergistas PBO, DEF y DEM, decidimos volver a bioensayar con el insecticida spinosad nuestra población resistente Spin Sel, ya que intuíamos que podría haberle bajado otra vez la resistencia a spinosad, al no estar sometida a ninguna presión de selección en el momento que se realizaron los bioensayos con los sinergistas.

En la tabla 7.2 se observan los resultados obtenidos al comparar los bioensayos con PBO, DEF o DEM más spinosad, con el resultado del bioensayo a spinosad de Spin Sel de febrero de 2017. La CL50 de la población resistente Spin Sel al bioensayarla, en febrero de 2017, fue de 2,86 mg $\mathrm{L}^{-1}$, con un factor de resistencia de 11,4 (FR) con respecto a la línea base de susceptibilidad de spinosad. Esta CL50 es muy inferior a la calculada en noviembre de 2016, siendo 55,7 veces menos resistente a spinosad. Con este nuevo resultado de $\mathrm{CL} 50$, se compararon los bioensayos con los sinergistas y el insecticida spinosad. Como se observa en la tabla 7.2, no hay diferencias significativas entre las CL50 cuando se bioensayó la población Spin Sel con los sinergistas PBO, DEF o DEM y spinosad, con respecto a la CL50 obtenida cuando se bioensayó Spin Sel a spinosad en febrero de 2017. Los factores de sinergismo en este caso fueron de 2,9 para el bioensayo con PBO, 2,8 para DEF y 3,5 para el sinergista DEM. Estos nuevos resultados nos indican que el mecanismo metabólico no está claramente implicado en la resistencia a spinosad en $T$. absoluta, coincidiendo con trabajos ya publicados y mencionados con anterioridad en este capítulo (Campos et al., 2014; Berger et al., 2016; Silva et al., 2016). 
En otros lepidópteros también se ha estudiado el mecanismo implicado en la resistencia a spinosad. Rehan et al. (2014) observaron una disminución significativa de la resistencia a spinosad en una población de S. litura seleccionada a este insecticida. Al bioensayar la población resistente a spinosad con PBO y spinosad, obtuvieron un factor de sinergismo de 2,3 (FS). Sin embargo, no observaron disminución de la resistencia a spinosad cuando bioensayaron la población con DEF y spinosad.

Al analizar los resultados obtenidos en este trabajo, se deduce que el mecanismo metabólico no parece estar implicado en la resistencia a spinosad en $T$. absoluta, siendo quizás una mutación en el punto de acción el mecanismo causante de la resistencia a spinosad.

\subsection{Conclusiones}

En este trabajo no se han encontrado resistencias cruzadas entre spinosad y los insecticidas clorantraniliprol, ciantraniliprol, flubendiamida, indoxacarb y emamectina benzoato.

Al mismo tiempo, se ha observado una disminución drástica de la resistencia a spinosad en la población resistente Spin Sel, cuando se dejó de ejercer presión insecticida sobre esta población resistente durante 3 generaciones.

Por otro lado, los resultados nos indican que el mecanismo metabólico no está implicado en la resistencia a spinosad en $T$. absoluta, pudiendo deberse esta resistencia a una mutación en el punto de acción.

\subsection{Referencias bibliográficas}

Berger, M., Puinean, A.M., Randall, E., Zimmer, C., Silva, W.M., Bielza, P., Field, L.M., Hughes, D., Mellor, I., Hassani-Pak, K., Siqueira, H.A.A., Williamson, M.S., Bass, C. (2016). Insecticide resistance mediated by an exon skipping event. Mol Ecol 25: 5692-5704.

Biondi, A., Zappalà, L., Stark, J.D., Desneux, N. (2013). Do biopesticides affect the demographic traits of a parasitoid wasp and its biocontrol services through sublethal effects? PLOS ONE 8 (9): e76548.

Campos, M.R., Rodrigues, A.R.S., Silva, W.M., Silva, T.B.M., Silva, V.R.F., Guedes, R.N.C., Siqueira, H.A.A. (2014). Spinosad and the Tomato Borer Tuta absoluta: A Bioinsecticide, an Invasive Pest Threat, and High Insecticide Resistance. PLoS One 9: e103235.

Desneux, N., Wajnberg, E., Wyckhuys, K.A.G., Burgio, G., Arpaia, S., Narváez-Vasquez, C.A., González-Cabrera, J., Catalán Ruescas, D., Tabone, E., Frandon, J., Pizzol, J., Poncet, C., Cabello, T., Urbaneja, A. (2010). Biological invasion of European tomato crops by Tuta absoluta: ecology, geographic expansion and prospects for biological control. J Pest Sci 83: 197-215. 
Guillemaud, T., Blin, A., Le Goff, I., Desneux, N., Reyes, M., Tabone, E., Tsagkarakou, A., Niño, L., Lombaert, E. (2015). The tomato borer, Tuta absoluta, invading the Mediterranean Basin, originates from a single introduction from Central Chile. Sci Rep 5: 8371.

IRAC. (2016). Mode of Action Classification Scheme (Version 8.1) (2016). En línea: http://www.irac-online.org.

LeOra-Software. (2005). POLO-Plus, POLO for Windows Petaluma, CA, LeOra Software.

Martínez-Aguirre, M.R. (2017). Resistencia a emamectina benzoato en Tuta absoluta (Meyrick) (Lepidoptera: Gelechiidae). Tesis doctoral, Universidad Politécnica de Cartagena, pp.139.

Puinean, A.M., Lansdell, S.J., Collins, T., Bielza, P., Millar, N.S. (2013). A nicotinic acetylcholine receptor transmembrane point mutation (G275E) associated with resistance to spinosad in Frankliniella occidentalis. J Neurochem 124: 590-601.

Racke, K.D. (2006). A reduced risk insecticide for organic agriculture: spinosad case study. En: Felsot, A.S., Racke, K.D. (Eds.). Crop protection products for organic agriculture: environmental, health and efficacy assessment. Ed. American Chemical Society, Washington DC. Vol. 947, pp. 92-108.

Rehan, A., Freed, S. (2014). Selection, mechanism, cross resistance and stability of spinosad resistance in Spodoptera litura (Fabricius) (Lepidoptera: Noctuidae). Crop Prot 56: 10-15.

Silva, W.M., Berger, M., Bass, C., Williamson, M., Moura, D.M.N., Ribeiro, L.M.S., Siqueira, H.A.A. (2016). Mutation (G275E) of the nicotinic acetylcholine receptor $\alpha 6$ subunit is associated with high levels of resistance to spinosyns in Tuta absoluta (Meyrick) (Lepidoptera: Gelechiidae). Pestic Biochem Phys 131: 1-8.

Torné, M., Martín, A., Fernández, J. (2010). Spintor 480SC: eficacia natural. PHYTOMA España 217: 27-31. 


\section{CONCLUSIONES GENERALES}





\subsection{Conclusiones}

1. Las poblaciones de Tuta absoluta (Meyrick) bioensayadas entre los años 2010 y 2012 presentaron una elevada susceptibilidad a los insecticidas clorantraniliprol, ciantraniliprol, flubendiamida, spinosad e indoxacarb. Además, las líneas base de susceptibilidad calculadas para estos insecticidas estaban muy por debajo de sus respectivas dosis de campo recomendadas para su uso en $T$. absoluta.

2. Al estudiar la evolución en el tiempo de la susceptibilidad de poblaciones europeas de T. absoluta a las diamidas clorantraniliprol, ciantraniliprol y flubendiamida, aparecieron poblaciones españolas que presentaban ligeros cambios en la susceptibilidad a diamidas, y se encontraron poblaciones italianas con resistencia a estos tres insecticidas.

3. En el seguimiento de la evolución de la susceptibilidad de poblaciones de T. absoluta a spinosad e indoxacarb, se observó una alta susceptibilidad en las poblaciones bioensayadas entre los años 2013 y 2016.

4. No se han encontrado diferencias en la susceptibilidad a clorantraniliprol, ciantraniliprol, spinosad e indoxacarb en función del estadio larvario, L2 o L4, en el que se encuentren las poblaciones de T. absoluta.

5. Sí se han observado diferencias significativas en la susceptibilidad a flubendiamida dependiendo del estadio larvario en el que se realicen los bioensayos, siendo menos susceptible a flubendiamida cuando las larvas se encuentran en L4.

6. Se han obtenido con éxito dos poblaciones de $T$. absoluta resistentes a los insecticidas clorantraniliprol y ciantraniliprol, presentando unos niveles de resistencia muy superiores a los de la población original empleada para la selección de resistencias, y a las dosis de campo recomendadas para cada insecticida en $T$. absoluta.

7. Existe una fuerte resistencia cruzada entre clorantraniliprol, ciantraniliprol y flubendiamida, atribuida posiblemente por un mecanismo de resistencia en el punto de acción.

8. No se han encontrado resistencias cruzadas entre clorantraniliprol y spinosad, ni con indoxacarb ni emamectina benzoato.

9. Tampoco se han encontrado resistencias cruzadas entre ciantraniliprol y spinosad, ni con indoxacarb ni emamectina benzoato. 
10. Respecto a los mecanismos implicados en la resistencia a clorantraniliprol y ciantraniliprol, a pesar de que las enzimas P450 monooxigenasas parecen tener un papel menor en la resistencia a clorantraniliprol en $T$. absoluta, los resultados obtenidos en este trabajo parecen indicar que la resistencia en $T$. absoluta a las diamidas se debe más bien a un mecanismo de resistencia en el punto de acción.

11. Se ha observado una fuerte disminución de la resistencia a spinosad en la población resistente a este insecticida cuando se dejó de ejercer presión insecticida, debida quizás a un coste en el vigor de la población asociado a la resistencia a spinosad.

12. No existen resistencias cruzadas entre spinosad y los insecticidas clorantraniliprol, ciantraniliprol, flubendiamida, indoxacarb y emamectina benzoato.

13. Los resultados obtenidos en el presente trabajo indican que el mecanismo metabólico no está implicado en la resistencia a spinosad en $T$. absoluta, pudiendo deberse esta resistencia a un mecanismo de resistencia en el punto de acción. 